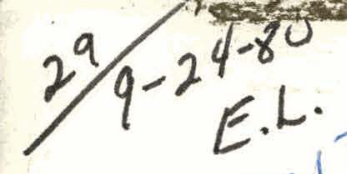

\title{
Overview Paper on Nuclear Power
}

\author{
Irving Spiewak
}

David F. Cope

UNION CARBIDE

\section{OPERATED BY}

UNION CARBIDE CORPORATION FOR THE UNITED STATES DEPARTMENT OF ENERGY
An overview paper prepared for the Oak Ridge National Laboratory national energy perspective 


\section{DISCLAIMER}

This report was prepared as an account of work sponsored by an agency of the United States Government. Neither the United States Government nor any agency Thereof, nor any of their employees, makes any warranty, express or implied, or assumes any legal liability or responsibility for the accuracy, completeness, or usefulness of any information, apparatus, product, or process disclosed, or represents that its use would not infringe privately owned rights. Reference herein to any specific commercial product, process, or service by trade name, trademark, manufacturer, or otherwise does not necessarily constitute or imply its endorsement, recommendation, or favoring by the United States Government or any agency thereof. The views and opinions of authors expressed herein do not necessarily state or reflect those of the United States Government or any agency thereof. 


\section{DISCLAIMER}

Portions of this document may be illegible in electronic image products. Images are produced from the best available original document. 


\section{Printed in the United States of America. Available from National Technical Information Service U.S. Department of Commerce 5285 Port Royal Road, Springfield, Virginia 22161 NTIS price codes-Printed Copy: A11 Microfiche A01}

This report was prepared as an account of work sponsored by an agency of the United States Government. Neither the United States Government nor any agency thereof, nor any of their employees, makes any warranty, express or implied, or assumes any legal liability or responsibılity for the accuracy, completeness, or usefulness of any information, apparatus, product, or process disclosed, or represents that its use would not infringe privately owned rights. Reference herein to any specific commercial product, process, or service by trade name, trademark, manufacturer, or otherwise, does not necessarily constitute or imply its endorsement, recommendation, or favoring by the United States Government or any agency thereof. The views and opinions of authors expressed herein do not necessarily state or reflect those of the United States Government or any agency thereof. 


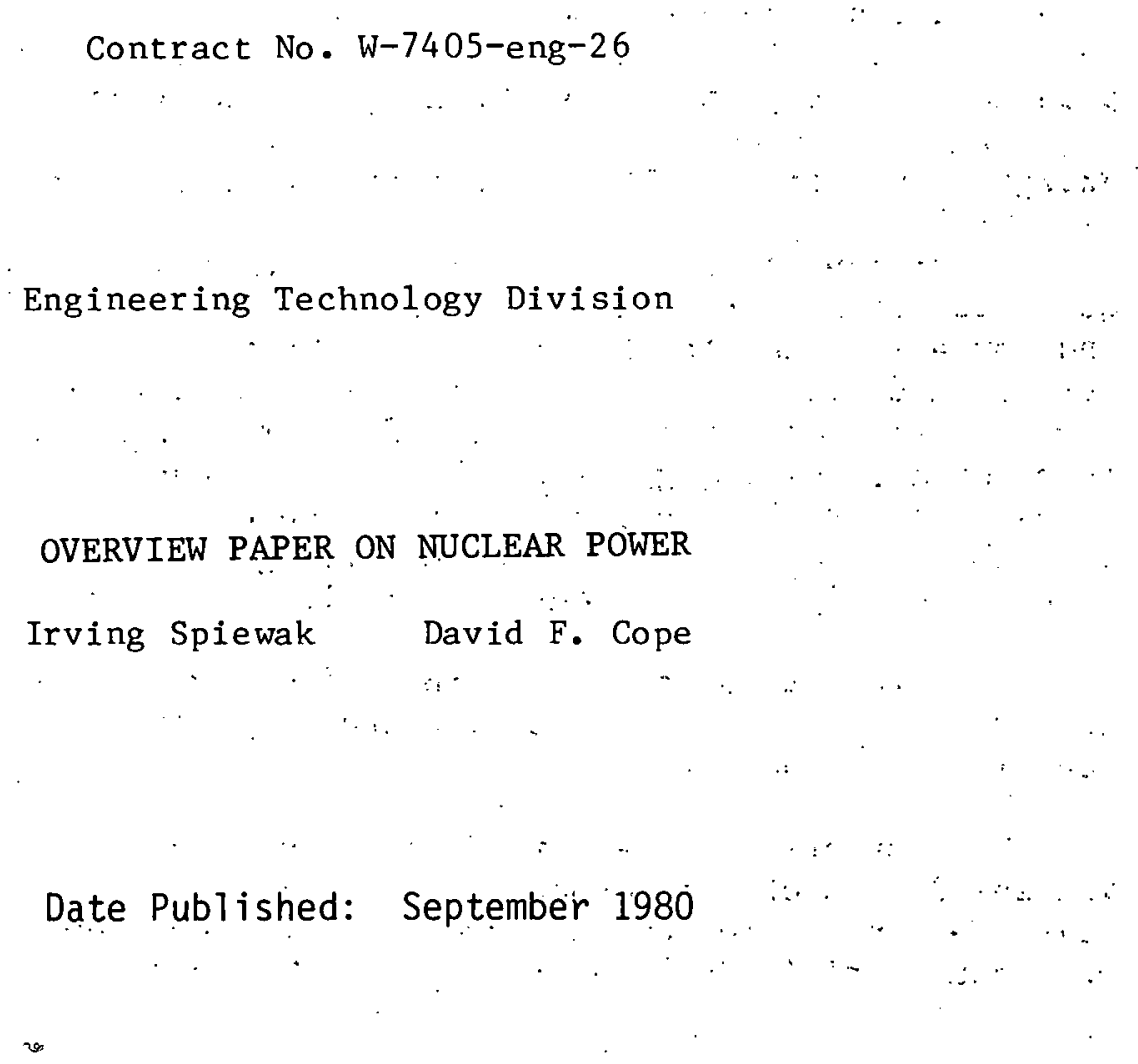

Not1ce: Th1s document contains information of a preliminary nature. It is subject to revision or correction and therefore does not répresent a final report.

Prepared by

OAK RIDGE NATIONAL LABORATORY

Oak Ridge, Tennessee 37830

operated by

UNION CARBIDE CORPORATION

for the

DEPARTMENT OF ENERCY 
FOREWORD

As an essential part of the continuing long range planning process (begun in 1974) at ORNL, the Laboratory feels that it is important to develop and articulate a set of conclusions about the technical nature and priorities of national energy problems to guide future institutional planning. This planning is now an essential ingredient in the DOELaboratory management process. Thus work on preparing the ORNL National Energy Perspective (ONEP) was started in the summer of 1979.

By articulating a perspective on the nation's energy future, ORNL seeks to clarify its own views about priorities for seeking DOE funding and for allocating the Laboratory's resources during the 1980s. The perspective will serve as a reference point for Laboratory and Research Division strategic planning, as a foundation for Laboratory initiatives to stimulate new energy research, and as a catalyst for policy-related assessments by the research staff. Developing an ORNL energy perspective aids the Laboratory and DOE in fulfilling mutual responsibilities for judging technical and scientific problems needing priority attention.

This report is one of a number of Overview Papers prepared to assist the ONEP Working Group to develop their conclusions on the basis of technically sound data.

The authors have benefited from comments received from reviewers of initial drafts of this report and have made appropriate changes to the text. However, the report represents our own views and is in no way a consensus position or the position of ORNL management. 
CONTENTS

$\underline{\text { Page }}$

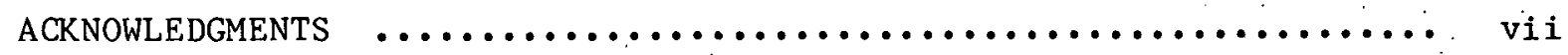

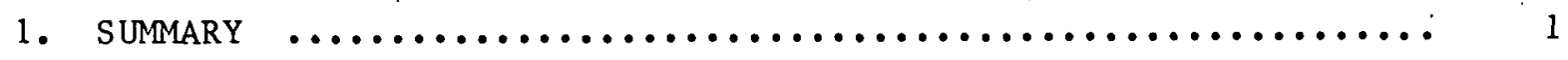

1.1 Origins and Current Status of Nuclear Power $\ldots \ldots \ldots \ldots \ldots \ldots 1$

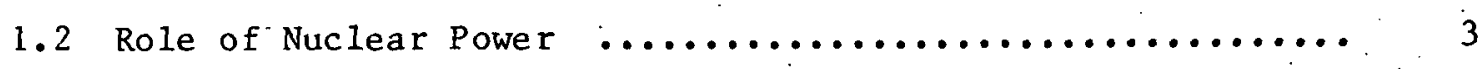

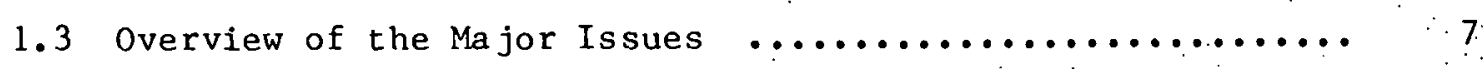

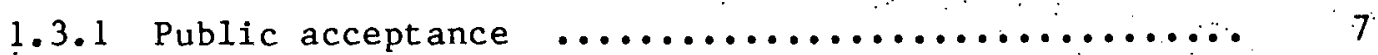

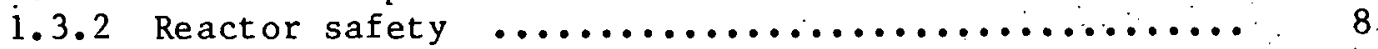

1.3.3 Licensing and regulation of nuclear power

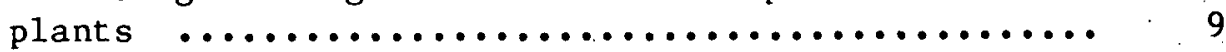

1.3.4 Trends in nuclear plower plant construction

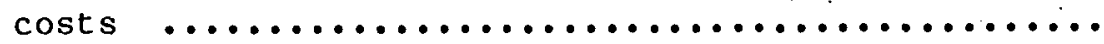

1.3.5 Constraints, uncertainties and financial

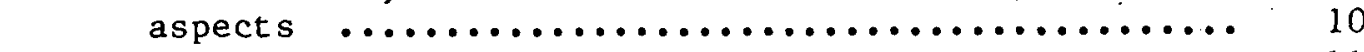

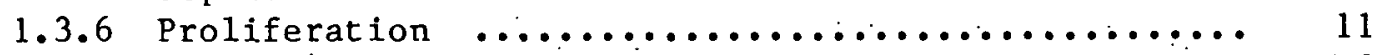

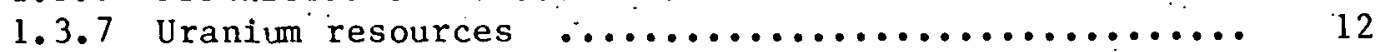

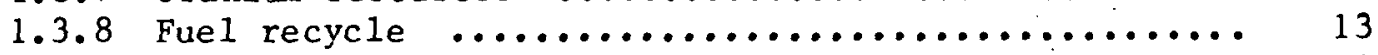

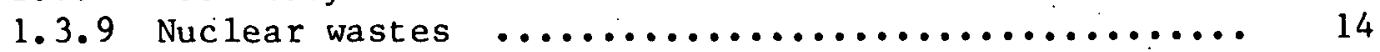

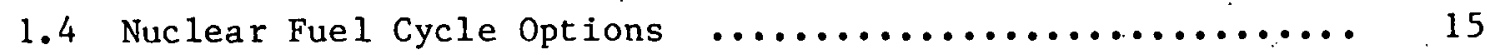

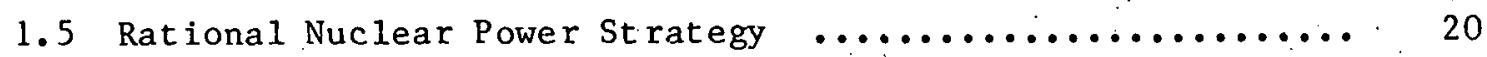

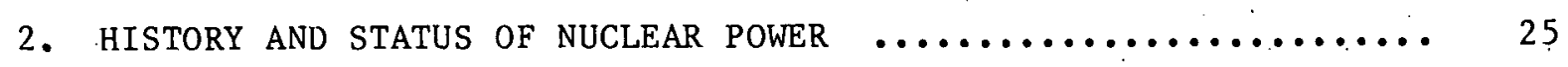

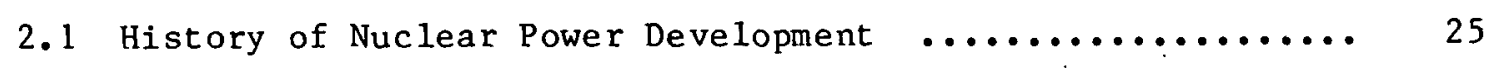

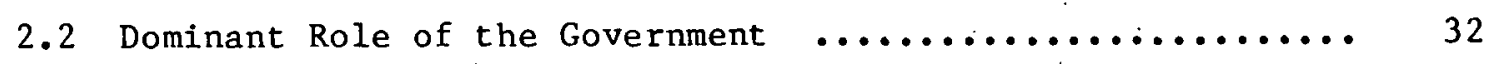

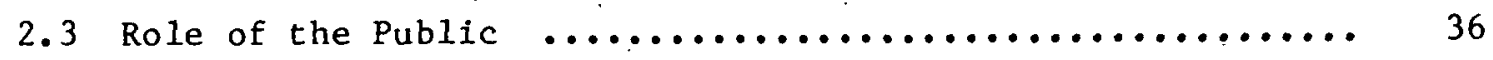

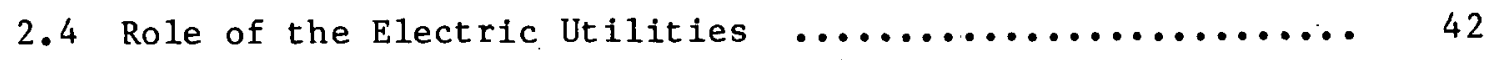

2.5 Role of the Industrial Manufacturers ................ 44

2.6 Role of the Participants Influencing Nuclear R\&D Policy ..................................... 46

2.7 Advanced Technology in Nuclear Power Development........ 49

2.8 Transfer of Nuclear Power Technology $\ldots \ldots \ldots \ldots \ldots \ldots \ldots \ldots \ldots 1$

2.9 Circumstances Favoring Nuclear Power Development in the United States $\ldots \ldots \ldots \ldots \ldots \ldots \ldots \ldots \ldots \ldots \ldots \ldots \ldots . . \ldots \ldots$ 
3. ROLE OF NUCLEAR POWER IN THE U.S. ENERGY FUTURE $\ldots \ldots \ldots \ldots \ldots \ldots . . . .57$

3.1 Generation of Electricity - The Primary Mission ........ 57

3.2 Near-Term Role of Nuclear Power ..................... 59

3.2 .1 Potential role of various fuels for generat-

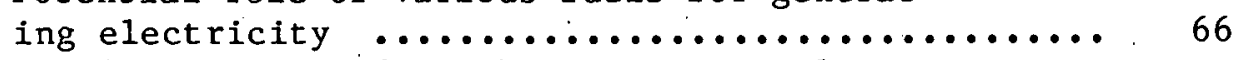

3.2 .2 Conclusions regarding the near-term role
of nuclear power $\ldots \ldots \ldots \ldots \ldots \ldots \ldots \ldots \ldots \ldots \ldots \ldots \ldots \ldots$

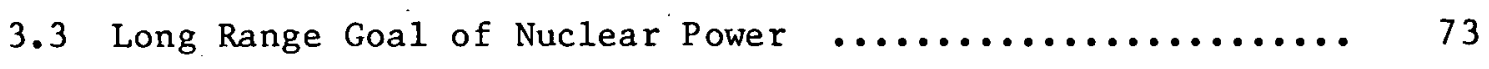

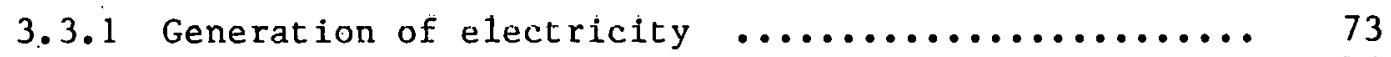

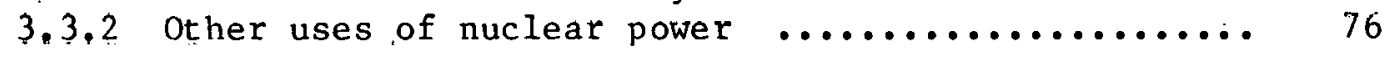

3.4 Role of Nuclear Power in the world Context $\ldots \ldots \ldots \ldots \ldots . .67$

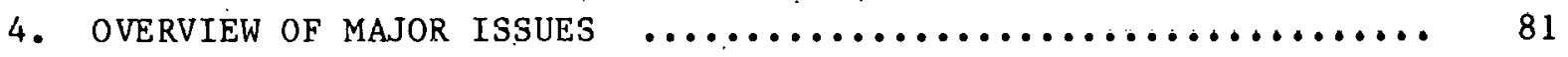

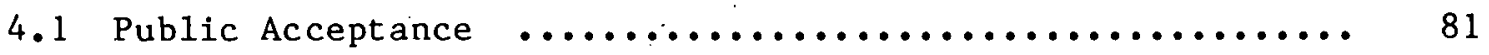

4.1 .1 Introduction $\ldots \ldots \ldots \ldots \ldots \ldots \ldots \ldots \ldots \ldots \ldots \ldots . \ldots \ldots . \ldots \ldots$

4.1 .2 History and nature of putlic concerns $\ldots \ldots \ldots \ldots \ldots . . .63$

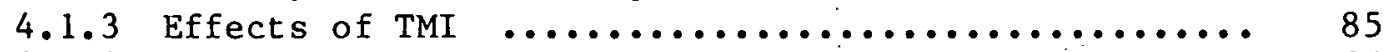

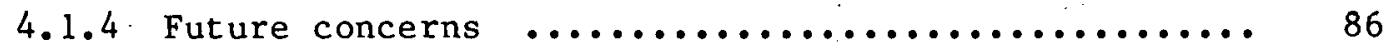

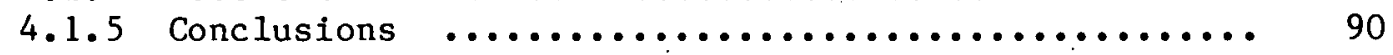

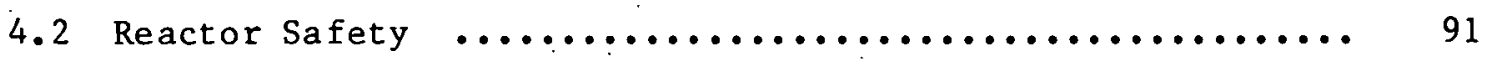

4.3 Licensing and Regulation of Nuclear Power Plants ....... 95

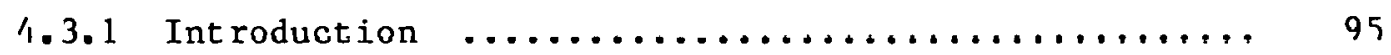

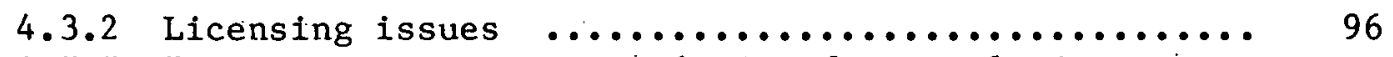

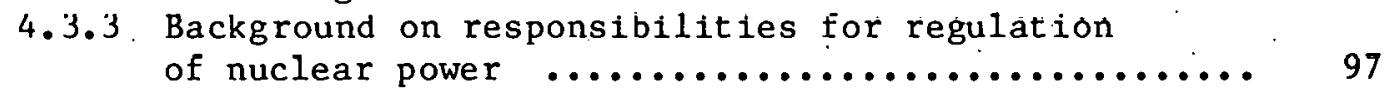

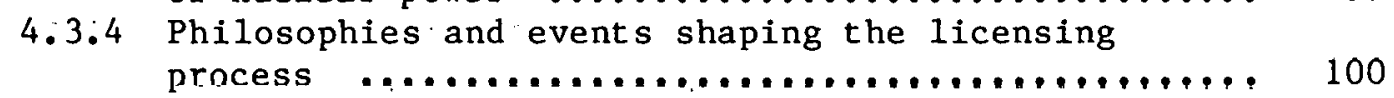

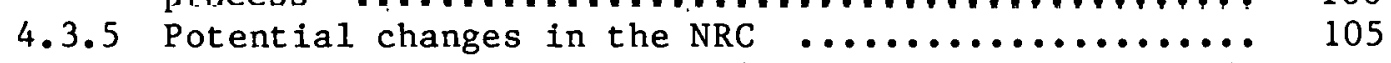

4.3.6 Potential role of research into licensing and

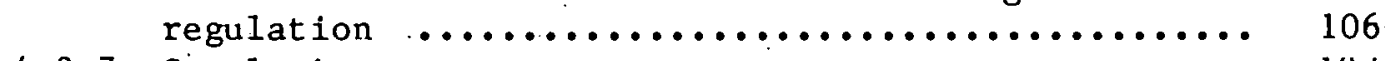

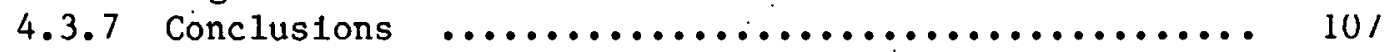

4.4 Trends in Nuclear Power Plant Construction Costs ........ 108

4.5 Constraints, Uncertainties and Financial Needs of

Nuclear Power ................................ 111

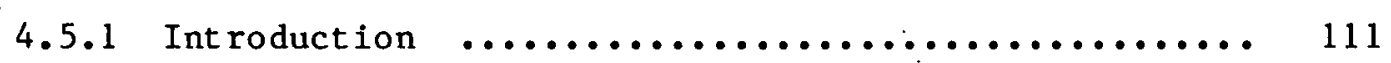

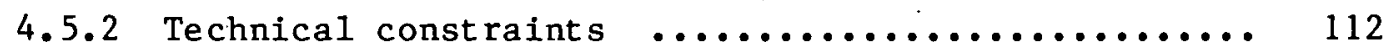

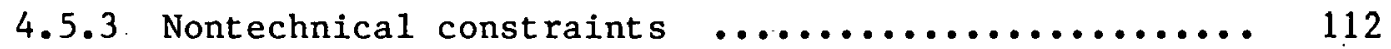

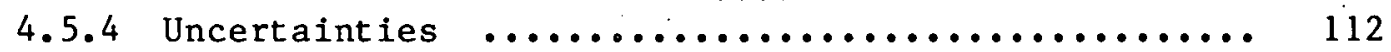

4.5.5 Manufacturing and construce ion viability ......... 114

4.5.6 Capital needs and financial risks ............. 116 


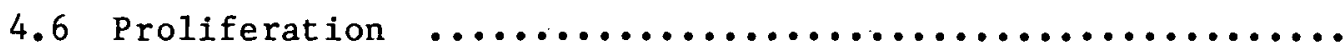

4.6 .1 Int roduction $\ldots \ldots \ldots \ldots \ldots \ldots \ldots \ldots \ldots \ldots \ldots \ldots \ldots . \ldots \ldots$

4.6.2 Problem of nuclear weapons proliferation ........ 119

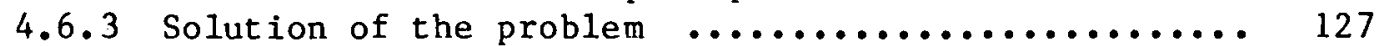

4.6.4 Conclusions and recommendations ............... 134

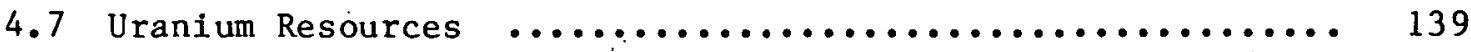

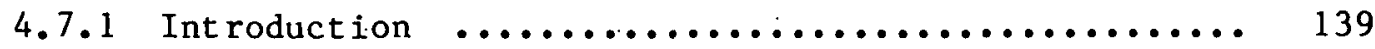

4.7.2 Current estimates of high-grade uranium

resources in the United States $\ldots \ldots \ldots \ldots \ldots \ldots \ldots \ldots$

4.7.3 Interpretation of resource data $\ldots \ldots \ldots \ldots \ldots \ldots \ldots$

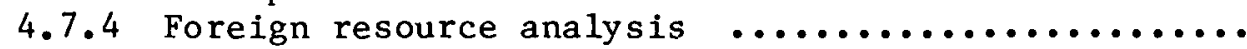

4.7.5 Conclusions and recommendations $\ldots \ldots \ldots \ldots \ldots \ldots \ldots$

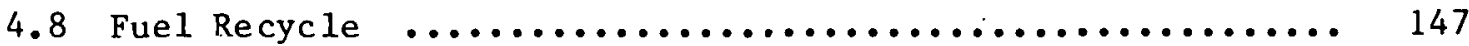

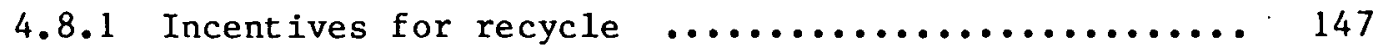

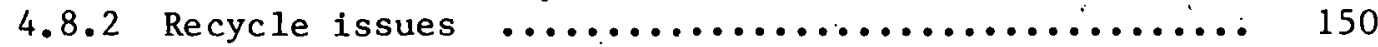

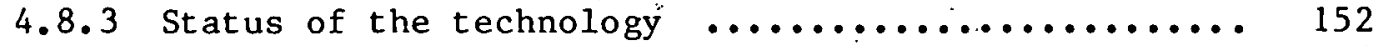

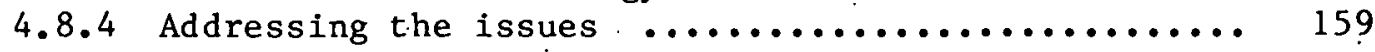

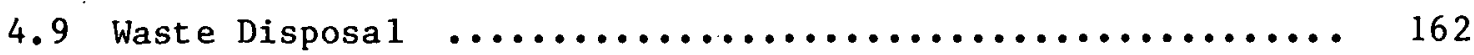

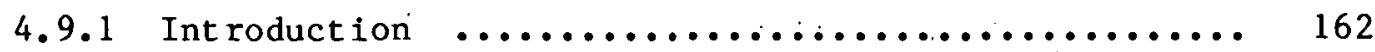

4.9.2 Source and nature of radioactive wastes ......... 162

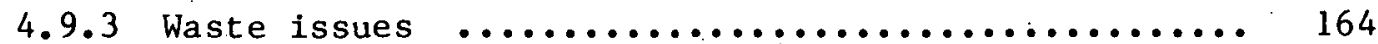

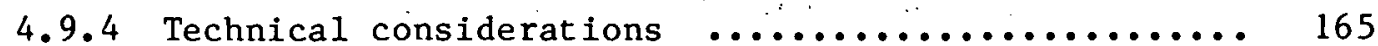

4.9.5 Considerations of public concern .................. 169

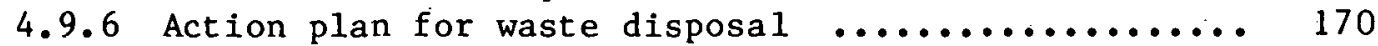

4.9.7 Decommissioning and decontamination ............ 171

5. NUCLEAR FUEL CYCLE OPTIONS $\ldots \ldots \ldots \ldots \ldots \ldots \ldots \ldots \ldots \ldots \ldots \ldots \ldots \ldots$

5.1 Introduction - General Choices Which Are Available. ..... 173

5.2 Criteria for Ranking Nuclear Options ............... 173

5.3 Capabilities of the Various Reactor Options .......... 175

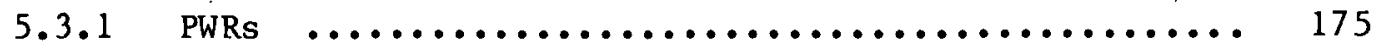

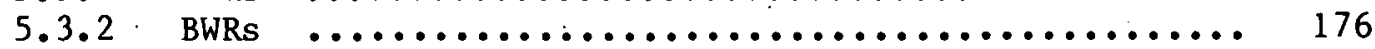

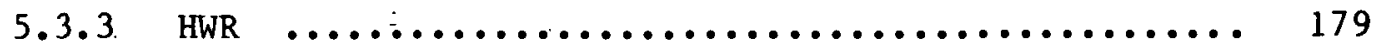

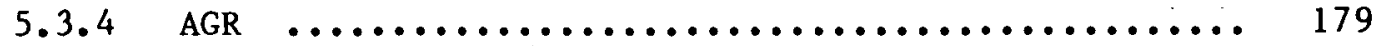

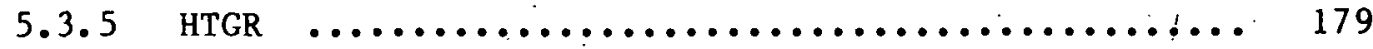

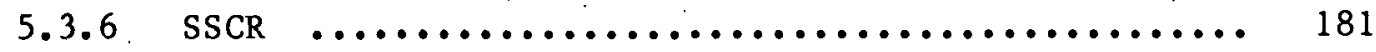

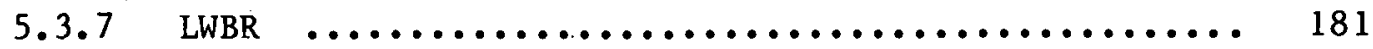

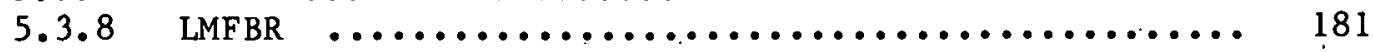

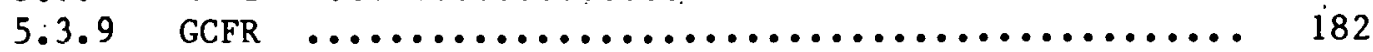

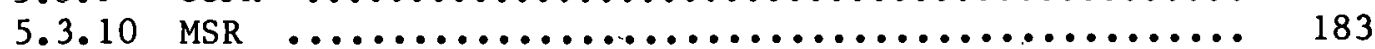

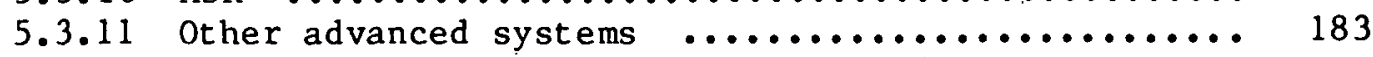


$\underline{\text { Page }}$

5.4 Genera1 Choices for an ULtimate Nuclear cycle .......... 184

5.4.1 Transition from the present cycle .............. 184

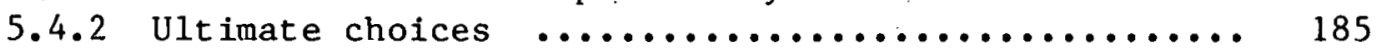

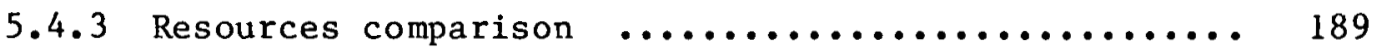

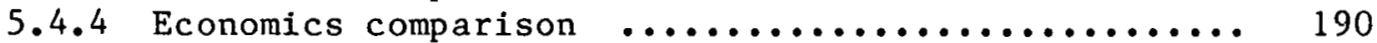

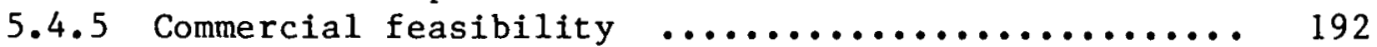

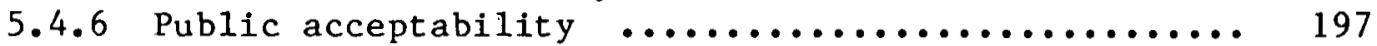

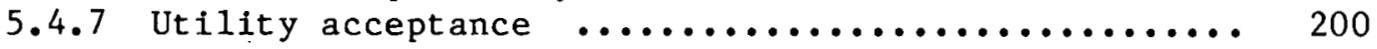

5.4 .8 Political acceptance $\ldots \ldots \ldots \ldots \ldots \ldots \ldots \ldots \ldots \ldots . \ldots . \ldots 201$

5.5 Implications for Nuclear strategy ................. 203

5.6 Implications for Nuclear K\&D Pollcy ............... 203

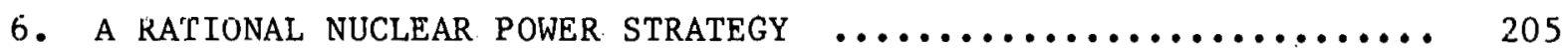

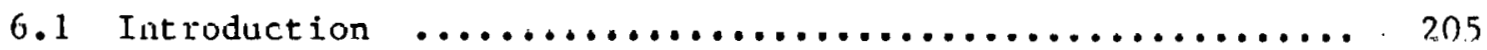

6.2 Development of a Basis for Acceptance of Nuclear

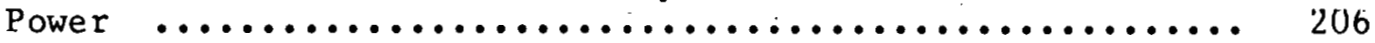

6.3 Government's Key Role $. . \ldots \ldots \ldots \ldots \ldots \ldots \ldots \ldots \ldots \ldots \ldots . \ldots \ldots$

6.4 Considerations in a Rational Nuclear Power St rategy ..... 218

6.5 Steps in the Development of a Rational Nuclear

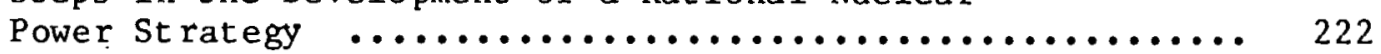

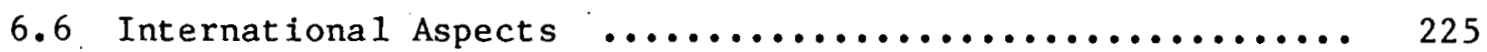

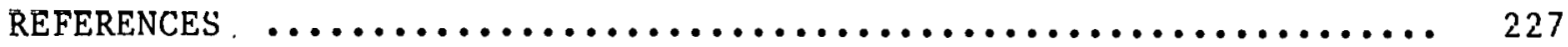




\section{ACKNOWLEDGMENTS}

The authors wish to express their appreciation to William D. Burch, John C. Cleveland, Paul R. Kasten, Mitchell Olszewski, and William E. Unger who reviewed this report and provided many helpful comments and suggestions. We thank Howard I. Bowers for his contribution of the issue paper on nuclear plant capital costs. We particularly appreciate the efforts of Jamie Copeland and of Judy Kibbe's Engineering Technology Division Word Processing Center, who struggled through numerous drafts of the report with patience and skill. 
THIS PAGE

WAS INTENTIONALLY

LEFT BLANK 
OVERVIEW PAPER ON NUCLEAR POWER

\author{
I. Spiewak. \\ Engineering Technology Division \\ and \\ D. F. Cope \\ Consultant
}

\begin{abstract}
This paper was prepared as an input to ORNL's Strategic Planning Activity, ORNL National Energy Perspective (ONEP). It is intended to provide historical background on nuclear power, an analysis of the mission of nuclear power, a discussion of the issues, the technology choices, and the suggestion of a strategy for encouraging further growth of nuclear power. Nuclear power prospered in this country as the result of industrial application of technology supplied by the Government. Favorable Government policies created a climate where rapid growth occurred. This climate was gradually eroded in the 1970s by legislative and executive actions which made nuclear plants less attractive to the utility industry. Some of the issues which led to a reversal in nuclear prospects were the nonacceptance of nuclear power by an influential minority of the public; public concerns about reactor safety, nuclear waste disposal and nuclear proliferation; growth of a complex regulatory structure; increased plant costs; and growing un-. certainty in all the above.

The role of nuclear power is divided into near-term and long-term aspects. The near-term role is to share, with coal, the base-load generation of electricity. To the extent that nuclear power is unable to deliver its share of the energy, increasing pressure is placed on coal, up to a fourfold increase in mining by the year 2000 in the event of a nuclear moratorium. The long-term role of nuclear energy is to supply an "inexhaustible" energy option.

Assuming nuclear power capacity of 255 to 395 GWe by 2000, there appears to be sufficient uranium in the United States to support the light water reactor (LWR) once-through cycle into the twenty-first century. It would be necessary, then, to deploy more efficient cycles both in the once-through mode and later to include fuel recycle in improved LWRs or advanced converters, or breeders, or an advanced once-through cycle (mo1ten salt reactor) or a combination of thermal reactors and breeders. Development of reprocessing/recycle technology is believed to be the most effective near-term response to insufficient uranium supply; breeders are the best long-term response.
\end{abstract}


The strategy to revitalize the nuclear option requires positive federal intervention to rationalize the regulation of nuclear power and to reduce the almost unmanageable uncertainties current ly perceived by utilities. 


\section{SUMMARY}

\subsection{Origins and Current Status of Nuclear. Power}

In all of the early developments related to nuclear power, the government's role was pervasive and dominant. The early civilian power concepts came from the government-owned contractor laboratories; and the dominant one, the LWR, came directly out of the Naval Reactor Program, whose success was undoubtedly determined by the success of the nuclear submarine program. With the passage of the Atomic Energy Act of 1954, the AEC was not only encouraged, but also mandated, to develop and promote atomic energy for peaceful purposes. As a result, the AEC initiated a well planned and organized program to develop civilian nuclear power as the main effort in promoting peaceful atomic energy. At the same time, the 1954 Act ended the government's monopoly on nuclear energy and enabled the AEC to bring in industry and utilities as partners in the developing nuclear program.

The government still retained a strong and dominant role; but, bringing industry in at the time and in the way it was, led to the establishment of a broad industrial capability which became the basis for the rapid growth in nuclear power taking place from the mid-1960s through the mid1970s. Industry also began its own R\&D programs which, although intended to increase commercial competitiveness, greatly broadened the technological support base for all reactor systems. However, private industry efforts were mainly aimed at developing and strengthening reactor concepts which appeared ready for commercialization, thus leaving the invention and development of new concepts and unproven technologies to the government. This is the situation which generally prevails today.

One aspect of the government's past role in the development of nuclear power that merits special attention was the teamwork and coherence of purpose that the government participants elicited among themselves and private industry during the early phases of nuclear power development. On the governmental side there were two powerful forces: the AEC, the dominant Executive Branch Agency, vested with responsibility for both the promotional and regulatory aspects of nuclear power; and the Joint Committee 
of Atomic Energy ( $\mathrm{JCAE}$ ), which represented both houses of Congress and had, in a practical sense, the final arbitration of all congressional actions on atomic energy. These two governmental bodies closely coordinated their plans and actions in an aggressive effort with the objective of attaining a world leadership position in the development of peaceful nuclear energy. Furthermore, due to their preeminent positions in the Executive Branch and Congress, their concurrence on a program virtually assured its acceptance and implementation as national policy.

However, over the years the AEC was subjected to increased criticism on two issues: (1) combining in one agency the functions of promoting the development of nuclear and regulating that development; and (2) the refusal of the AEC to concern itself with nonradiological impacts on the environment resulting from the construction and operation of nuclear power facilities. These issues came to a climax in two unrelated events. The first event was the enactment of the National knvironmental Policy Act (NEPA) in 1969. This act required that the AEC in conjunction with the Environmental Protection Agency (EPA) consider the effect upon the environment of nonradiological impacts from nuclear power plants. This provided the environmentalists and antinuclearites an opportunity to oppose and delay the licensing of nuclear power plants.

The second event, which was the more important of the two, was the Energy Reorganization Act of 1974. This act split the AEC's jurisdiction between the Energy Research and Development Agency (ERDA) for the research, development, and promotional phase, and the Nuclear Regulatory Commission (NRC) for the regulatory phase, of nuclear power. This act also stimulated changes in Congress which resulted in the demise of the JCAE and distribution of its tunctions among a number of congressional committees, none of which possessed the power and prestige of the ICAF. The effect of thccc two actions was to fragment the governmental team members into its several components, each pursuing a limited mission, and the grand strategy for developing nuclear power lost its proponents and leadership.

The public's role in nuclear power development has grown from a passive and indirect role in the early phases to an aggressive and critical 
one in recent years. Regulatory hearings have been drawn out over extended periods and costs of plants increased significantly because of interventionists' actions. At the same time the regulatory bodies have become more sensitive to public and political pressure, and utilities have complained that the regulatory actions were becoming oppressive and punitive. This pervasiveness of regulatory actions, the reduced demand for electricity, and their strained financial situation caused the electric utilities to reappraise their commitment to nuclear power with the result that for the past three years net cancellations of nuclear plants have exceeded new orders. The Three Mile Island accident has accelerated these trends. At the same time, the chaos and uncertainty existing among governmental bodies has changed private industry's mood of confidence and enthusiastic participation to one of lack of confidence and reluctant participation.

A few general conclusions can be drawn. History has shown that the rate of progress in the nuclear program was related to the consistency of government policies, clearness of purpose, degree of cooperation among the participants, and confidence in the leadership. This, for the time at least, has been replaced with a pervasive atmosphere of opposition and negativism toward nuclear power. To change this and again put nuclear power on a positive course, the President and Congress need to agree that we need nuclear power and follow up with actions which will foster its development. Both the public's and industry's confidence need to be restored. In the final analysis. this means that the people must be convinced of the need for nuclear power so that they, working through the political process, will elect people to office who favor this position and take actions to support it.

\subsection{Role of Nuclear Power}

The mission of nuclear power may be subdivided into a near-term and a long-term phase. Since the near-term.mission is to generate electricity, one must assess the role of nuclear power relative to demands for electricity and to fuel options for meeting these demands. Table 1 summarizes 
Table 1. Projection of fuel for electricity production in the United States

(yuads)

\begin{tabular}{lrrccc}
\hline & 1978 & 1985 & 1990 & 2000 & 2010 \\
\hline Oil & 4 & 5 & 5 & 4 & 2 \\
Gas & 3 & 2 & 1 & 0 & 0 \\
Hydro & 3 & 3 & 3 & 3 & 3 \\
Solar/geotherma1 & 0 & 0 & 1 & 2 & 6 \\
Coal and nuclear & 14 & 24 & 29 & 44 & 52 \\
$\quad$ Subtotal, nuclear & 3 & 8 & $11-13$ & $12-25^{a}$ & $12-40$ \\
$\quad$ Subtotal, coal & 11 & 16 & $16-18$ & $19-32$ & $12-40$ \\
Totals & 24 & 34 & 39 & 53 & 63 \\
\hline
\end{tabular}

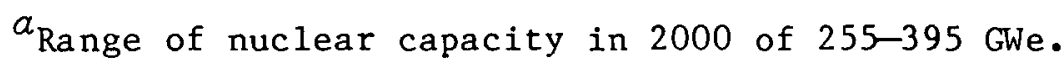


near-term (to 2010) prospects for electricity production based on a scenario of $4.3 \%$ annual growth in the early 1980 s to below $2 \%$ after 2000 . Although this is a low projection of growth compared to the past 30 to 35 years, actual growth conceivably could be less, particularly if oil and gas should become unavailable for the generation of electricity. Should there be no growth in electricity generation between 1980 and 2010, and should the use of oil and gas for this use be phased out, there would need to be about 21 quads of primary energy inputs from coal, nuclear, geothermal and solar. There are serious questions on whether coal can be depended upon to contribute this amount of energy to the generation of electricity, since coal will be needed as an industrial fuel and as a feed-stock for synfuels. The role of geothermal and solar is speculative and uncertain. The situation. for coal coupled with the uncertainty of future oil supplies and the speculative nature of alternative energy sources, clearly points to nuclear as a badly needed major backup energy source.

The longer range outlook for nuclear power appears to be more positive than the near-term outlook primarily because of a narrower range of options likely to be available. Beyond 2010 oil and gas will be in even shorter supply than they are today, the burning of coal may be approaching a practical limit, natural hydro power will be approaching the limit of its potential capacity, and geothermal and solar energy for the generation of electricity face technological and economic issues which render their future outlook highly speculative and uncertain. This leaves nuclear as the main, dependable energy source for the generation of electricity. Eventually, nuclear power should be envisioned as a long-term "inexhaustible" energy supply which can be used for the generation of electricity (which in turn can be substituted for other fuels), for the manufacture of fuel substitutes such as hydrogen, and as a source of process heat. In this sense it is a competitor to solar and geothermal energy as a longterm source of energy supply. Only a breeder reactor can meet the longterm "sustainability" requirement, hence the development and demonstration of a breeder reactor is an essential element in the long-term future of nuclear power. 
The role of nuclear power in other countries will be significantly different from what it is in the United States because of variations in the nuclear resource bases, the availability of alternative fuels, the technological capabilities, and the size of the electricity generating systems. The United States, though short of oil and gas for its own needs, still has domestic coal, oil, and gas resources which are much more abundant than those of most countries of the world. The U.S.S.R.; Canada, and China also have large fossil fuel resources and can delay large commitments to nuclear. This is not true for most other countries of the world. Those with the fewest resources and therefore most likely to be dependent upon nuclear are Western Europe, Japan, South Korea, and Brazil. The developed nations, most of whom are short of energy, are engaged in an intensive nuclear program which includes construction of LWRs or their national equivalent, development of the liquid metal breeder reactor, and development and implementation of fuel recycle so as to lessen dependence upon imported uranium.

The underdeveloped countries have a much lower demand for energy than the developed countries, but their rate of growth in energy consumption is generally higher than in the developed countries; and their aspirations are growing in spite of energy resource limitations. From a world point of. view, the rate of energy supply expansion is critically dependent on the availability of nuclear technology and fuel. This is true because of constraints on alternatives, especially limitations in supply of fossil fuels. Thus, desires to limit transfer of nuclear technology because of concern about nuclear weapons proliferation are in direct conflict with desires to avoid international warfare over diminishing quantities of fossil fuel.

Another aspect of nuclear power from a world point of view is that nuclear power is an important element of a geopolitical stratcgy for national security and energy self-sufficiency. Proponents of energy selfsufficiency as a geopolitical goal claim that a major power cannot retain its security if secondary powers can cut off food, energy, strategic materials, etc. In fact a long time political goal of the U.S.S.R. is believed to be a cut off of the capitalistic countries from their sources of supply which would reduce them to impotence as world powers. 
Energy self-sufficiency would not only enhance our national security but would also stop one of the main driving forces for rapid inflation, remove a major cause for erosion in the value of American currency, and stop arbitrary oil prices to the benefit of all non-oil producing countries of the world. The achievement of these goals would immeasurably strengthen the country both internally and in the world. There are other nonnuclear elements to an energy self-sufficiency strategy such as: replacement of oil usage with coal, synfuels from coal and shale, gas production from unconventional sources, and strong incentives for conservation. Examples of countries trying to pursue such a strategy are the U.S.S.R. and France. Energy non-self-sufficiency has external costes such as susceptibility to supply interruptions, political pressures: and higher defense budgets. In some ways, these external costs are analogous to the external costs associated with environmental impacts. Society can therefore anticipate external costs associated with both abundant energy supply and with inadequate energy supply. Great skill is required to integrate these considerations and arrive at optimal energy growth, including nuclear power growth.

\subsection{Overview of the Major Issues}

\subsubsection{Public acceptance}

In the final analysis it is the general public who wields the power to make the decision to have or not have nuclear energy. However, in the face of an indifferent or divided public, an aggressive and well organized opposition can seriously impede the development of nuclear power without bringing the general public into the issue. They can do this by adopting harassment tactics which put the utilities on the defensive, by creating an atmosphere of distrust and lack of confidence in the utilities and the government, and by making the uncertainties so pervasive and the risks so high that the utilities will look for easier alternatives. Such tactics leave the utilities little room for defense. Also in today ${ }^{\circ}$ situation they have no one to turn to for support except the government or the 
general public. The government can decide what actions are in the best interests of the country and try to lead the public into support of such actions, or it can let events take their course and do what the vocal public indicates that it wants or what the government perceives this public as wanting. Unfortunately the latter seems to be the more representative of today's situation. In either case the utilities cannot ignore the issue of public acceptability because even though the government assumes a positive leadership role, and one which supports the utilities' position, a dissatisfied general public could force a reversal of this position. The conclusion is that the future of nuclear power rests upon its use by utilities to generate electricity, which in turn ultimately depends upon its acceptability to the public.

\subsubsection{Reactor safety}

Assessment of risk to the general public and to the labor torce by technologists has generally given nuclear power an excellent rating relative to other sources of electricity. No deaths have been reported thus far directly relatable to a nuclear accident in the nuclear power industry. On the other hand, it is evident that many members of the public consider nuclear power very hazardous. The Three Mile Is land accident has convinced many decision makers that reactor safety must be strengthened. Steps which are suggested to bring these divergent points of view closer together include strengthening both the nuclear utilities and the Nuclear Regulatory Commission (NRC), improving operator training and instruments, improving emergency planning, educating the public about nuclear safety, and siting reactors in remote areas.

Part of the effort to improve safety is research. We believe high priority in research should be given to operation safety (including the human element), to risk analysis (to help resolve the difference between the technician's perception of risk and the public's perception), and to sociological questions (How safe is safe enough?). Consideration should be given to the public's desire to reduce the potential number of casualties following a disaster to something of the order of the worst airplane accident, through some "technical fix." 


\subsubsection{Licensing and regulation of nuclear power plants}

The licensing and regulation of nuclear power plants has been conducted in a more thoroughly planned and organized manner than for any other electricity generating systems, and from the infancy of the nuclear. industry has been subjected to closer scrutiny, more open reviews, more public inputs and with a broader informational base than any other technology in history. The licensing process has been controversial and subject to strong criticism from its very inception and has been accompanied by confusion, uncertainity, and increasing redundancy. Much of this can be traced to the nature of the problem and particularly how the public perceives the risks associated with nuclear power, and how the politicans and the regulators react to these perceptions of the public.

In general the nature of the licensing process as emphasized by recent events, has put the NRC on the defensive. They are an open target for criticism for many reasons but particularly on the issue of making $1 i-$ censing decisions, which may affect public safety, on a probability analysis. No matter how low the probability of an event, it is never zero, and one can't explain away this non-zero probability event when it happens such as TMI. Therefore, the NRC can never guarantee zero risk short of closing down all nuclear plants. If the public is unwilling to accept the very small risk of serious accidents posed by nuclear power plants, no system of regulation will suffice.

Meanwhile, however, a system does exist; but the system is under great stress and fundamental changes in the system are almost certain to occur. The (somewhat conflicting) objectives in revising the NRC include reducing the likelihood of serious accidents, improving emergency response, reducing the time required for licensing, improving the quality of public participation, and above all, increasing public trust in the NRC.

\subsubsection{Trends in nuclear power plant construction costs}

Commercial nuclear power plant construction costs have increased dramatically in the past ten years from about $\$ 200 / \mathrm{k}$ We for plants completed in the late 1960s and early 1970 s to about $\$ 500$ to $1000 / \mathrm{kWe}$ for plants being completed in 1979 and 1980 with current utility company projections 
of $\$ 1000$ to $2000 / \mathrm{kWe}$ for plants being completed in the late 1980s. Concurrently, project schedules measured from the award of the nuclear steam supply system (NSSS) contract to fuel loading have increased from seven years in the late 1960s and early 1970s to 11 to 12 years for plants being completed today with projections of 12 to 15 years for plants to be completed in the late 1980s. The increasing costs and lengthening construction schedules are attributed to (1) increased scope of plant because of additional safety and environmental regulations and (2) high inflation in costs of equipment, materials, and labor for plant construction and yields on utility bonds for financing construction.

An analysie of the quantitative impacts of these factors yields the following results:

$\begin{array}{ll}\text { Plant costs in } 1970 & 1.0 \\ \text { Multiplier for increased scope, 1970-80 } & 1.75 \\ \text { Multiplier for increased schedule, 1970-80 } & 1.15 \\ \text { Multiplier for inflation, 1970-80 } & 2.1 \\ \text { Plant costs in } 1980 & 4.0 \\ \text { Multiplier for increased scope, 1980-90 } & 1.0-1.4 \\ \text { Multiplicr for incrcaocd schcdulc, } 198090 & 0.95-1.1 \\ \text { Multiplier for inflation, 1980-90 } & 2.1-2.5 \\ \text { Plant costs in } 1990 & 8-15\end{array}$

While these increases are very discouraging, many of the same problems are being felt in competing systems such as coal plants. Nuclear power many continue to be competitive, but it cannot be expected to be cheap.

\subsubsection{Constraints, uncertainties and financial aspects}

There are a number of constraints and uncertainties facing nuclcar power. Some are technical, some political, and some public relations issues; in composite they are of such overriding importance that they can potentially dictate the viability of nuclear power and the direction it will take. Uncertainties impose a severe burden on the nuclear industry, particularly the utility sector. The utilities' ability to finance construction (reflected in the stock and bond markets) is greatly impaired by 
conflicting requirements among various federal and state agencies, vacillation in regulatory bodies, retroactive changes to design, inadequacies in rate adjustment, inflation; and harassment by intervenors. While the Federal Government has not caused all of these problems, it is the only potential source of relief through positive policies and actions.

The result of these uncertainties has been to postpone decisions, delay construction, and increase the costs of nuclear power plants to the point where the utilities are not willing to assume the high risks of going through the process. Consequently, they are forced to go nonnuclear where the time and costs are more predictable, even though the long-term costs may be greater.

The curtailment of nuclear power plant construction also has potentially severe consequences for reactor manufacturers and constructors. If the utilities do not build nuclear plants, then the manufacturers cannot sell them. Further, there is a minimum level below which the industry cannot maintain its viability. A precise number is not available on how many new orders per year a reactor manufacturer must obtain to sustain a viable but economic manufacturing operation, but the consensus seems to be that it should be about four to six 1000 MWe units per manufacturer per year. As a minimum, there must be at least two reactor manufacturers in order to maintain competition.

The analysis indicates that projected nuclear programs in the United States can readily be financed in a stable political environment. And nuclear power may be needed in substantial quantities, both in the United States and globally, to maintain economic growth. The financing process will require a reduction in the current levels of constraint and uncertainty.

\subsubsection{Proliferation}

The problem of nuclear weapons proliferation concerns management of the global nuclear power enterprise so as to be acceptable from the standpoint of weapons proliferation while, at the same time, making available widespread economic benefits in both the short and the long term. The classical methods for dealing with proliferation are, on the one hand, 
technology denial, and on the other international cooperation under safeguards. Recent tension between these approaches has not been resolved, possibly contributing to the growth of undesirable national programs.

Analysis of the problem indicates that proliferation cannot be prevented through any technical and/or political fix. However, proliferation risks can be significantly reduced through optimal technology choices combined with international cooperation under evolving safeguards. The U.S. position favors continued use of the once-through fuel cycle in water reactors until resource constraints dictate the adoption of cycles involving greater access to weapons-usable material. The safeguards technology and institutions should be strengthened during this period to be equal to the challenges imposed by cycles such as the plutonium-fueled fast breeder. A vigorous U.S. nuclear technology and fuel cycle services program within the context of international agreements is a vital element of the ability of the United States to stimulate nonproliferation in other countries.

The U.S. position on nonproliferation has been challenged in the International Nuclear Fuel Cycle Evaluation by a number of countries which regard reprocessing and plutonium recycle as vital to their interests. These are generally importers of uranium, who see a much more immediate need for breeder reactors and who believe that the safeguards system is adequate to deal with proliferation risks.

The general slowdown of nuclear programs in most countries delays substantially the world-wide need to deploy breeders and "the plutonium economy". The Carter nonproliferation policy may have been more effective than opponents will admit. The long-term price may be high, however, if the result is an insufficient supply of energy.

\subsubsection{Uranium resources}

Our analyoic of uranium recourcec ic baced on DOE projectione of 255 to 395. GWe of nuclear power in the United States in 2000 and 320 to 910 GWe in 2025 and on DOE estimates of 2.4 million tons of $\mathrm{U}_{3} \mathrm{O}_{8}$ in the reserves and probable category plus 1.8 million tons in the possible-plus speciulative category.

In the event of high demand the standard light water reactor-oncethrough cycle with $0.2 \%$ enrichment plant tails will commit the 2.4 million 
ton $\mathrm{U}_{3} \mathrm{O}_{8}$ endowment by shortly after 2000 and will use the 4.2 million ton endowment by 2025. A total of 6.8 million tons would have been committed by 2025 . The resource picture can be substantially improved by either (a) a 15\%-improved LWR on the once-through cycle combined with enrichment plant tails-stripping, or (b) recycle (preferably combined with tailsstripping). All of these options would be economic if uranium prices rise as expected. The combination of recycle and tails-stripping would reduce $2025 \mathrm{U}_{3} \mathrm{O}_{8}$ consumption below 2.4 million tons and commitment below 4 million tons. If demand for nuclear power is "low", then once-through LWR options are adequate through 2025.

World uranium supply-demand relationships approximate those of the United States; both Communist and non-Communist regions are adequately endowed with uranium. If anything, the world may be better endowed than the United States because it has not been as well explored. The only major regional shortage of uranium applies to Western Europe and Japan, which must import major quantities. Fuel production in breeders has obvious strategic impact for these regions.

A long as demand for nuclear power is within the range covered by recent DOE projections, orderly development of conventional resources should suffice to supply both world and U.S. needs. This is construed to require the following developmental activities:

- Resource assessment programs such as NURE.

- Research on low-grade and by-product sources of uranium.

- Moderately-improved LWRs.

- Advanced isotope separation technology. Improves tails-stripping economics.

- Retain the reprocessing/recycle option.

\section{-1.3 .8 Fuel recycle}

The spent fuel discharged from light water reactors contains substantial amounts of slightly enriched $U-23$ b (between $0.7 \%$ and $1.0 \%$ ) and plutonium. If recycled into LWRs, the system energy output would be 
increased by about $80 \%$ (according to NASAP mass flow data). The $\mathrm{U}_{3} \mathrm{O}_{8}$ requirements for 30 years at 1 GWe ( $70 \%$ capacity factor, $0.2 \% \mathrm{U}-235$ tails) are as follows:

$\begin{array}{ll}\text { Once-through } & 5680 \text { tons } \mathrm{U}_{3} \mathrm{O}_{8} \\ \text { U-only recycle } & 4340 \text { tons } \mathrm{U}_{3} \mathrm{O}_{8} \\ \mathrm{U}+\mathrm{Pu} \text { recycle } & 3120 \text { tons } \mathrm{U}_{3} \mathrm{O}_{8} \text { * }\end{array}$

Assuming that nuclear power is permitted to expand on the oncethrough cycle with spent fuel in interim storage, the recycle option will continue to be open. It will be relatively easy (from a cechnical and financial point of view) to adopt recycle at any time. Recycling material from the spent fuel stockpile will be economically attractive when $\mathrm{U}_{3} \mathrm{O}_{8}$ prices reach $\$ 100 / 1 b$ (in 1979 dollars) which might be expected by 2000 to 2010 .

Fuel reprocessing and recycle not only provides a resource safety valve for light water reactors, but it also provides for much more efficient fuel cycles for both converter and breeder reactors. Finally, reprocessing would be a decisive preliminary to permanent waste disposal.

Given the current slowdown in the nuclear business, there is truly little to be gained by immediate thrusts into large-scale fuel recycle. However, good arguments can be made for resumption of the AGNS program as an early demonstration commercial-scale recycle fuel plant. The purpose of these activities would be to prove the recycle option, its regulation, its costs and environmental impacts. The facilities could also be used to demonstrate safeguards, U.S.-style.

\subsubsection{Nuclear wastes}

Perceived progress toward a solution to the waste problem is a necessary step toward a viable nuclear power program. This is so because the

*The data reported here are more favorable to recycle than those usually reported, the main difference being that we are taking credit for plutonium recovered from batches discharged at and near the end of core iffe. NASAP reports 3420 tons $\mathrm{U}_{3} \mathrm{O}_{8}$ for "self-generated recycle" of $\mathrm{U}+\mathrm{Pu}$, over 30 year life. Sufficient $P u$ was available in fuel discharged in years 28,29 and 30 to get about $10 \%$ more energy in a Pu-burner LWR. 
public and government decision makers no longer have faith in technologists' claims that the waste problem can readily be solved. Construction of nuclear power plants is increasingly being challenged on the basis that the wastes are unmanageable. At the same time it should be noted that regardless of what course nuclear power might take, the nation and the world has a radioactive waste disposal problem which will not vanish but be with us indefinitely.

Although a great deal of effort has been expended to develop methods of nuclear waste treatment and disposal, the lack of agreement on waste disposal forms and of standards for licensability constitute a major deficiency of the nuclear fuel cycle. It has been assumed that wastes from any of the major fuel cycle options can be disposed of in an acceptable way. However, major decisions must be made to resolve the outstanding issues. Major economic impacts may result from mandated standards for waste management.

Solving the nuclear waste problem requires a coordinated set of federal actions to work toward regional sites for low-level and high-level wastes, the adequate compensation of state and local governments undergoing risks in the waste disposal operations, demonstrations of "permanent" geologic emplacement of wastes of both military and civilian origin, concurrent research into optimal waste forms and geologic media, and a program to give the public realistic information. Utilities should be encouraged to develop on-site storage facilities for spent fuel and lowlevel wastes.

A program concentrating on research and development will not do the job. The public will regard such a program as proof the problems have not been solved; the central problems are social and political, not technical.

\subsection{Nuclear Fuel Cycle Options}

The world-wide nuclear industry is currently based on the oncethrough fuel cycle based on natural uranium or low-enriched uranium (LEU). This cycle is currently the lowest-cost possibility. However, it is limited in two respects, i.e., it will become uneconomic as we run out of low-cost uranlum and it cannot support a long-term nuclear option. 
The general choices to follow the once-through cycle are the following:

- thermal reactor fuel recycle,

- recycle system dominated by fast breeders (the plutonium economy),

- recycle system dominated by thermal reactors but making use of fast breeders,

- advanced once-through cycle, and

- de-emphasis of nuclear power.

The resource analysis of Sect. 1.3.7 indicates that the present oncethrough LWR fuel cycle policy could be sustained within the United States for another 30 years or more, depending on the balance between uranium supply and demand. It could be much longer than 30 years if nuclear power growth is limited to the low end of the supply projection. Resource constraints are not the only criteria to be considered in possible future reassessments of the present policy. Future considerations may include:

- The desire to stimulate nuclear capacity growth.

- The economics of reprocessing and Pu recycle may appear attractive.

- There may be international agreements on fuel recycle safeguards that may favor establishment of fuel recycle centers in the United States (instead of in less secure countries).

- Since the world does not appear to be following the U.S. lead in deferring reprocessing, the policy may be reconsidered.

- It may be desirable to undertake reprocessing to supply fuel for breeder reactor deployment.

To justify supplementation or eventual replacement of the oncethrough cycle by a nuclear alternative implies superiority of the replacement system in one or more respects. The criteria for ranking systems include considerations of resource etticiency, economics, commercial feasibility, safety and public acceptance. Some of the advantages and disadvantages of future options are summarized below.

Thermal reactor recycle

The transition to reprocessing and plutonium recycle is technically easy at any time that political acceptance is gained. Closing of the fuel 
cycle substantially increases the resource base (at least temporarily) and provides time for the ultimate cycle configuration to develop. If the growth of demand for nuclear power is no greater than projected in the resource discussion (the 1978 DOE forecasts), then introduction of a new commercial technology (other than possibly reprocessing-recycle) is unnecessary prior to 2010 and can probably be delayed well beyond then.

of long-term significance are the possibilities of improving the neutron economy of recycle LWRs by increasing the metal/water ratio. Whereas the present lattice has a conversion ratio of 0.6 , the conversion ratio of $\mathrm{Pu} / \mathrm{U}$ or $\mathrm{U} 233$ fuels can be increased to 0.8 by removing half the water from the lattice. Additional gains are possible by removing more water and adding blankets or movable fuel control. On the other hand, these advanced LWR concepts would require $R \& D$ to address potential safety and licensing problems. The fissile loadings of tight-pitch cores must be high; savings in fuel burnup costs are compensated with higher fuel inventory costs.

Adoption of a long-term thermal recycle policy may stimulate use of an advanced converter such as the HTGR or the HWR. Advanced recycle LWRs or advanced converters could probably be economic as long as uranium supplies were available from domestic shales and phosphates, but the thermal recycle option is likely to be ultimately limited by resources.

Thermal recycle supported by fast breeders

The fast breeder is by far the best system for Pu fuels. U233 is generally the best fuel for thermal reactors, although Pu239 is also an excellent fuel for LWRs.

One can envision an ultimate nuclear system dominated by thermal reactors in a recycle mode but where fast breeders are used as fuel producers and to burn the garbage efficiently - the transuranium isotopes including Pu240 and Pu242. Approximately 15 to $30 \%$ of the reactor mix would be breeders. Uranium is obtained at a modest rate from low-grade and by-product sources.

The fuel produced by breeders for LWRs may consist of Pu239/U, U233/ Th (possibly denatured) or U233/U. If HTGRs were deployed, U233/Th would bc the preferred thermal reactor fuel. 
Fast-breeder-dominated system

I'he fast breeder-dominated scenario emphasizes deployment of $\mathrm{Pu} / \mathrm{U}$ cycle breeders during the expansion of nuclear power. Pu is recovered initially from spent LWR fuel but later is generated by the breeders. Surplus fuel may be exported, either as $\mathrm{Pu}$ or as U233 (including denatured U233).

The ultimate configuration may be assumed to be LMFBRs supporting an equal number of Pu-burner LWRs and process-heat HTGRs. Many of the thermal reactors may be outside the United States.

This scenario has the most favorable uranium resource characteristics. However, there may be public and political acceptance problems and it may not be economically optimal. In any case, rapid deployment of a new systen will entail high commercial risks.

Advanced once-through cycles

The molten salt reactor appears to be the best choice for an advanced once-through cycle if fuel reprocessing were permanently ruled out. The resource consumption would be comparable to that of the thermal recycle mode, although subject to improvement to a probably less proliferationresistant breeder cycle. Such an approach would have difficulty gaining commercial support and utility acceptance.

De-emphasis of nuclear power

This may be assumed for the long-term if suitable fusion or solar sources of electricity are developed. We believe it premature to adopt this approach until an alternative is commercialized.

\section{Comparative resource utilization and economics}

Relative resource and economic parameters for the general fuel cycle options are given in Table 2. What is striking about the table is that the resource utilization can vary nearly two orders of magnitude while the

economic differences between the options are less than the economic error band. Choice of cycles, therefore, is likely to be made on the basis of 
Table 2. Comparative resource utilization and economics of nuclear options

\begin{tabular}{|c|c|c|c|c|c|}
\hline & \multirow{2}{*}{$\begin{array}{l}\text { Relative } \\
\text { uranium } \\
\text { consumption }\end{array}$} & \multicolumn{3}{|c|}{ Relative power costs } & \multirow{2}{*}{$\begin{array}{l}\text { Relative } \\
\text { facility } \\
\text { capital } \\
\text { costs }\end{array}$} \\
\hline & & $\begin{array}{c}\mathrm{U}_{3} \mathrm{O}_{8} \\
\$ 40 / 1 \mathrm{~b}\end{array}$ & $\begin{array}{l}\mathrm{U}_{3} \mathrm{O}_{8} \\
\$ 100 / 1 \mathrm{~b}\end{array}$ & $\begin{array}{c}\mathrm{U}_{3} \mathrm{O}_{8} \\
\$ 160 / 1 \mathrm{~b}\end{array}$ & \\
\hline \multicolumn{6}{|l|}{ Continuation of present } \\
\hline Once-through cycle & 1.0 & 1.0 & $1.2-1.25$ & $1.4-1.5$ & 1.0 \\
\hline Thermal recycle & $0.3-0.4$ & 1.0 & $1.15-1.25$ & $1.3-1.5$ & $0.9-0.95$ \\
\hline Therma $1+$ breeders & $0.1-0.2$ & - & $1.15-1.3$ & $1.3-1.5$ & $0.9-1.0$ \\
\hline Breeder-dominated & 0.02 & - & $1.2-1.35$ & $1.3-1.45$ & $0.98-1.08$ \\
\hline Aćvanced once-through & 0.3 & - & $1.05-1.35$ & $1.15-1.45$ & $1.05-1.15$ \\
\hline
\end{tabular}


other than economic criteria, i.e. resource utilization and political acceptability, as long as $\mathrm{U}_{3} \mathrm{O}_{8}$ were available for less than $\$ 200 / 1 \mathrm{~b}$. Resource consumption impacts economics strongly in an indirect way, since uranium price will be a function of demand and economics are strongly related to uranium price. The unavailability of breeders (fuel producers) could result in significantly higher power costs than if breeders were available in the asymptotic situation.

\subsection{Rational Nuclear Power Strategy}

Achieving the strategic goals discussed in the previous section depends upon maintaining the nuclear option in its present form as a shortterm contributor to our electrical energy needs but eventually expanding and shaping the short-term developments into a form compatible with the long-term goal. The following are some of the major steps which need to be taken in the development of such a strategy:

1. Since the public, acting through government, will ultimately decide how much nuclear power will be used, they must be convinced of the need. Actions which can be taken that will promote accomplishment of this goal are:

- Take steps to demythologize nuclear radiation and put it in perspective with other real and potential hazards.

- Establish trade-offs between the needs for energy to support society and the risks of generating this energy.

- Enhance the public's confidence in nuclear power by

- Assuring a government/industry structure that pláces saféty above profits, while keeping the two in a balanced perspective.

- Take steps to develop confidence and trust in the regulatory inatitutions.

- Demonstrate the safe management of nuclear wastes.

- Provide evidence of the true economic status of nuclear power.

- Accept that some of the nuclear opposition will never be convinced.

2. Conduct research and development as a means for strengthening the nuclear option to include: 
- Developing safer reactors/improving design margins

- Demonstrating nuclear waste disposal

- Military wastes

- (Pilot-scale) wastes from nuclear power

- Improving LWR reliability/economics.

For the last 15 years, AEC/ERDA/DOE has concentrated on advanced nuclear technology and put little effective effort into the above.

3. Prepare for mitigation of resource constraints (nuclear power in the United States may hit uranium resource constraints sometime between 2000 and 2025) to include:

- Development of more resource-efficient LWRs on the once-through cycle.

- Increased uranium exploration.

- Improved processes for recovery of uranium from low-grade ores.

- Advanced isotope separation processes which can more economically strip U235 from enrichment tails.

- Demonstration of reprocessing and recycle technology.

- Development of technology for optimal recycle in LWRs (higher conversion ratios provided safety margins can be maintained).

- Demonstration of fast breeder reactor and its fuel cycle.

According to the NASAP analysis, the first four of these improvements should be sufficient to support growth to 600 GWe through 2025 . Considering 5 and 6 as well, we conclude that LWRs might do the nuclear job through 2050, if nuclcar capacity were limited to 600 GWe. The breeder is required as a hedge against rising uranium prices and in the event more nuclear power is required.

4. Develop and demonstrate the reprocessing/recycle technology as the key to greatly expanding the potential of nuclear power.

- A great deal of energy stored in the spent fuel from LWRs, can be made rapidly available.

- Recycle in LWRs increases energy production per unit of $\mathrm{U}_{3} \mathrm{O}_{8}$ produced by up to $80 \%$ in present systems. Fuels optimized for once-through cycles would yield somewhat less. 
- From a resource point of view, fast breeders are much preferred to thermal reactors for utilizing $P u$ in spent LWR fuels. Fast breeders increase energy production per $\mathrm{U}_{3} \mathrm{O}_{8}$ by orders of magnitude.

- Reprocessing/recycle technology requires much greater attention to nonproliferation institutions and safeguards than the present oncethrough cycle.

- Implementation of reprocessing will tend toward a buyer's market in uranium, at least temporarily.

5. Develop as a long-term etrategy for the U.S. fission technology mix to consist of one or more of the following:

- A high-gain thermal recycle system with sustained mining of low-grade ures.

- 25,000 tons $\mathrm{U}_{3} \mathrm{O}_{8} /$ year might support about 500 GWe.

- The high gain converters can be supported in part by fuel production in breeders or electric hybrids. One LMFBR can support about four times as many high-gain converters.

- A fast-breeder dominated system (The Plutonium Economy)

- Little mining of uranium

- Allows export of (denatured?) fuel

- The choice of ultimate technology will be based on economic/political criteria.

6. Move rapidly to a long-term fission RD\&D program to cover the following major options:

- Demonstrate reprocessing/recycle on a large enough scale to develop meaningful licensing criteria, safeguards, cost experience. There is no doubt that other nations will also do the same.

- Develop high-gain LWR technology to be implemented when recycle is commercialized.

- Develop the HTGR

- Long-term use for process heat

- Likely to be competitive with LWKs in the long-term

- Intermediate-term possibility for commercialization in the event of an LWR construction moratorium. 
- Demonstrate the fast breeder on a meaningful scale so that the option would be available when needed (probably not needed for a long time).

- Requires significant reduction in capital cost

- Needs better image relative to catastrophic accidents.

- Introducing a new fission system will be very expensive and time consuming (\$billions and decades). Foreign developments may help reduce the time and the costs.

7. Take governmental actions to strengthen the nation's electric utilities including the following:

- Encourage state utility commissions to give rate increases commensurate with the need.

- Provide tax incentives for raising capital funds.

- Consider government-backed loans to reduce interest rates.

- Provide "fast-track" licensing for generating plants.

8. Above all, the government (particularly Congress and the Executive Branch) must adopt and demonstrate a receptive attitude toward nuclear power; exert strong leadership in gaining its acceptance; and develop and follow-through on plans and actions necessary to assure its rightful role in our nation's and the world's energy strategy.

It should be noted that the above steps constitute the elements of a strategy which will: educate the public of the need for nuclear power, provide a climate in which utilities can continue to make a vigorous contribution to the nation's energy supply, retain and enhance the nuclear option in its present form, provide for fuel recycle as a hedge against uranium resource inadequacy, and eventually provide for development of a breeder reactor system as the ultimate in the achievement of an inexhaustible nuclear power fuel supply which will meet a large portion of the country's energy needs for an indefinite period.

The special needs of industrialized and of developing countries should be recognized. Some of the industrialized countries perceive a very large need for nuclear power relative to the uranium available to them. The only system perceived to have the resource potential to satisfy these constraints is the $\mathrm{Pu}$ cycle breeder. It is quite possible for the 
breeder to be the optimum choice of reactor in some countries while converters are the optimum choice (for the majority of reactors) in resourcerich countries such as the United States.

The developing countries have a different (not always clear) set of priorities. These may include:

1. Desire to minimize foreign exchange component of reactor cost. Some countries perceive HWRs to have advantages here.

2. Need for small units. If the United States wishes to make an impact here, completing development of a small integral reactor such as B\&W's Consolidated Nuclear Steam System would be we1comed by several countries, assuming the price would be competitive. (Such a system would be attractive to U.S. utilities, as wel1, in the current low-growth situation.)

3. Assurances that they will not be discriminated against for access to the most economic technology. The key is to insure that the most economic technology is designed in a nonproliferating way, and that economic fuel cycle services are readily available in the international market.

The history of nuclear power development thus far has been characterized by technology transfer, mainly of LWRs and HWRs from North America. Future reactor technology may well be transferred from the country of initial commercialization to the United States. Advanced reactor programs in the United States should be conducted accordingly. 
2. HISTORY AND STATUS OF NUCLEAR POWER

\subsection{History of Nuclear Power Development 1.}

In early 1933, Sir Ernest Rutherford declared that anyone who expected a source of power from breaking down of the atom was talking moonshine. Twenty-five years later, Lewis Strauss, then Chairman of the Atomic Energy Commission, asserted that nuclear power would generate such cheap electricity that it wouldn't be worth metering. As might be expected, the true answer lies between these two extremes.

Although there are a great variety of practical applications for nuclear energy, its use for the generation of electricity dominates its contribution to the nation's energy needs, and currently nuclear power generates $12 \%$ of the electricity used in the United States.

Concepts for the use of nuclear fission reactors to produce useful power go back to the early days of atomic energy. Some of the earlier projects consisted of Farrington Daniels' high-temperature, helium-cooled power pile; Zinn's highly-enriched U-235, liquid metal cooled fast breeder pile; Morrison's fast-neutron pile using plutonium fuel; Weinberg's aqueous homogeneous thermal breeder reactor; and the Naval Research Laboratory's use of a sodium potassium alloy, liquid at room-temperature, as the reactor coolant. This latter concept was initially envisioned as being a source of nuclear propulsion power for submarines. However, it was after World War II before significant work was performed on any of the concepts.

The first formal power reactor project was the Daniel's pile set up by the Manhattan Engineering District (MED) at the Clinton Laboratories [later Oak Ridge National Laboratory (ORNL)]. However, a Navy team under Admiral Rickover, assigned to Oak Ridge in 1946, were unimpressed with the Daniel's pile and persuaded the Navy to develop and build a land-based prototype and a sea-going version of two promising reactor concepts: the high-pressure, water-cooled, water-moderated, uranium-fueled reactor; and the liquid metal-cooled type. The high-pressure water project was established at Argonne National Laboratory (ANL) in April 1948, with Westinghouse Electric Corporation as the prime industrial contractor. Meanwhile, General Electric Company (GE) worked to develop the liquid metal-cooled 
reactor as an alternative to the water reactor. Initially, GE was more interested in developing a nonmilitary liquid metal-cooled power breeder reactor, but when the AEC refused to authorize construction of a prototype, GE established the liquid metal-cooled submarine land-based prototype at Milton, New York, in 1950.

In 1949, the AEC authorized construction of Zinn's experimental breeder reactor (EBR) at the National Reactor Testing Station in Idaho. Construction started in 1949, the small liquid metal-cooled, fast-neutron breeder (LMFBR) was completed in 1951 and before the end of 1951 became the world's first reactor to produce net electric power in significant amounts.

In early 1950, the AEC authorized ORNL to build the aqueous homogeneous reactor experiment (HRE), this having been preceded by a small demonstration reactor of the same type at Los Alamos Scientific Laboratory. 'I'he HKE was completed and started up in 1952.

Although the United States was the leader in early nuclear energy developments, other nations, through cooperation with us and from their own efforts, had made rapid progress in developing nuclear reactor technology.

By March 1952, 33 nuclear reactors had been operated, were in operation, or were under construction in Canada, England, France, Norway, the Soviet Union, and the United States. In addition, there were plans for construction of reactors in Argentina, Belgium, Brazil, Canada, France, Holland, India, Mexico, and Sweden. However, most of these were designed for plutonium production for weapons, scientific research, or civilian isotope production, and only a third or fewer for the development of central station power reactors.

Since most of the world's uranium-enriching capability was in the United States, there was a great incentive in Europe and Canada to use natural (unenriched) uranium as fuel, which inherently favored larger reactor types. This led toward a graphite moderated, gas-cooled reactor (the choice of Britain and France), or a heavy water moderated and cooled unit (the choice of Canada). In the United States, the availability of enriched uranium made compact light water reactor types readily feasible, and the submarine application placed a premium on compactness. 
Although EBR and HRE operated successfully, Rickover obtained top priority for the submarine projects, and they received most of the attention and available manpower during the early 1950s.

Rickover's ambitious target date of January 1, 1955, for the first nuclear submarine to put to sea required solutions to some formidable technological problems, such as: finding the appropriate metal, to house the uranium fuel; solving the problem of shielding; developing a reactor control material and a control rod drive system; developing canned motor, high-pressure pumps having rigorous performance specifications; and many other equally difficult problems. Nevertheless, these difficulties were resolved, and on January 17, 1955, the USS Nautilus sent her famous message, "Under way on nuclear power."

Meanwhile the land-based prototype twin of the USS Nautilus reactor, the submarine thermal reactor (STR) Mark I, located in Idaho, went critical on March 30, 1953, and soon after developed several thousand kilowatts of thermal energy. Thus, the Mark I became the world's first reactor capable of producing practical amounts of energy on a sustained and reliable basis.

In July 1952, Rickover contracted with Westinghouse to develop a nuclear power plant capable of driving large surface ships. The large ship reactor was not approved but its pressurized light water reactor (PWR) design, scaled up from submarine size, held sufficient promise for central station power that the AEC decided to continue R\&D on the concept.

The Atomic Energy Act of 1954 ended the federal monopoly over the peaceful atomic energy program and enabled the AEC to enter into a series of cooperative ventures with private industry for the development of central nuclear power stations. Congress appropriated the necessary government funding in 1954, and soon afterwards the AEC entered into cooperative projects with the utilities and the manufacturing industry to demonstrate the potential of various reactor concepts for serving as nuclear electrical power plants. The first five reactor types involved were the:

1. PWR - a pressurized water reactor;

2. SRE - a graphite moderated, liquid sodium-cooled reactor;

3. HRE-2 - a scale-up of ORNL's HRE; 
4. $E B R-2$ - a scale-up of ANL's first EBR; and

5. EBWR - an experimental boiling water reactor.

Each of these had its proponents who claimed unique advantages for their chosen concept, but only the water reactors survived to the commercial stage, although the EBR-2 is still operating today as a test facility. Meanwhile, in 1955, GE's land-based prototype of the sodium-cooled submarine reactor started up; and in 1956, the USS Seawolf, powered with the sea-going sister reactor, operated successfully. Although the Seawolf had problems with leaks in the heat exchanger, it performed remarkably well, traveling 72,000 miles on the first reactor core with no need to enter the reactor compartment during the entire eighteen months involved. However, because of the sodium leakage problems and in view of their success with the water reactors, the Navy closed out the sodium-cooled reactor program.

The Navy pioneered also in the utility application of its pressurized water technology, starting up its historic proof-of-principle Shippingport plant in 1957. While Shippingport did not demonstrate economic nuclear power generation, it was an unqualified technological success.

While these proof-of-principle projects were under way and before detinitive results were obtained, the AEC in 1955 entered into the first Power Reactor Demonstration Program in which they provided financial assistance to utilities willing to build a nuclear power plant. This program produced the Yarkee Rowe (1960) uranium cycle and the Indian Point (1962) thorium cycle PWRs, the Dresden-1 BWR (1959), the Hallam sodiumgraphite reactor, and the Fermi fast breeder reactor.

Thus, by the the late 1950s, the l1ght water reactors (PWRs and BWRs) were the dominant reactor types in use in the United States. A few more reactor concepts appeared but faded out for one reason or another. These included, among others, an organic couled and moderated reactor; the mo1ten salt reactor; and the high-temperature, gas-cooled reactor (HTGR). While the country was still debating the economic feasibility of various reactor concepts, economic nuclear power suddenly apjeared to become a reality with the Oyster Creek BWR, announced in December 1963. Jersey Central Power and Light Company published an economic analysis explaining 
their choice of nuclear power over coal for their next large generating station. This analysis demonstrated convincingly that competitive nuclear power had been achieved. General Electric Company and, shortly thereafter, Westinghouse provided commercial warranties for turnkey plants, including the fuel loadings.

The ultimate factor in making nuclear power economic at that time was the scale factor. It had been recognized early that nuclear plants, because of their higher capital cost, would be favored by large units. What had not been expected was the rapidity of scaling up in size from Yankee Rowe at 170 MWe in 1955 to Oyster Creek at 650 MWe in 1963, and to TVA's 1000 MWe stations in 1966 and 1300 MWe stations in 1972.

The effect of Oyster Creek was catalytic. In 1963, three other nuclear plants were ordered; in 1965, seven; in 1966, twenty; in 1967, thirty; in 1968, fourteen; etc., with orders peaking in 1973 at 39,000 MWe. Orders then began to fall off, and the 1978 market of 2300 MWe was lower than the 2500 MWe of 1963, the first real year for reactor orders. In addition to falling orders, postponements and cancellations during the period 1974 to 1978 reduced the originally ordered capacity from 215,000 to 199,000 MWe, of which only about 182,000 MWe can. be considered reasonably firm as of $12 / 31 / 79$. Thus, a definite downward trend in nuclear reactor orders is apparent, and up to now the 1979 orders have not been sufficient to indicate a reversal of this situation.

Although the LWR is the dominant reactor concept throughout the world, several countries have developed and followed different approaches to nuclear power. The Inited Kingdom (UK) enjoyed early success with gascooled graphite-moderated uranium-metal magnox-clad reactors. This lead was initially followed by France, with minor interest in Italy, Japan and the United States. However, both the Magnox reactors and the more advanced AGRs (clad $\mathrm{UO}_{2} \mathrm{fuel}$ ) have had a disappointing performance record and are being deployed only by the UK at present.

The United Kingdom decided in the early 1950s to use the gas-cooled reactor as the basic concept on which to build their nuclear power electricity generation system. In 1956 they started up their Calder Hall dual-purpose nuclear station for the production of plutonium for military use and for the generation of commercial electrical power. The reactor 
was graphite moderated and $\mathrm{CO}_{2}$ cooled, with a magnesium alloy fuel. The UK built eleven Magnox fueled plants before going to an advanced version of the GCR, called the Advanced Gas-Cooled Reactor (AGR). This reactor has a uranium-oxide fuel in a stainless steel cladding and operates at higher temperatures and thus higher efficiencies than the Magnox reactors. The UK commercial nuclear power program is firmly committed to the AGR, and the UK is the center of R.\&D technology for this type of reactor. Most of this technology was initially developed in government-owned institutions but industry is now making a significant contribution. The UK follow-up program is based on the LMFBR.

France also built a graphite-moderated, air-cooled reactor. (Marcoule GI) which evolved into their graphite-moderated, carbon dioxide $\left(\mathrm{CO}_{2}\right)$ cooled reactors and became the basis for five commercial scale power reactors built to provide electricity to the Electricite de France (EdF) grid. However, France abandoned this concept in favor of the LWR which now dominates their nuclear power system.

Prodded by the UK's experience, the United States entered late in GCR development by supporting two projects: the government-owned Experimental Ga's-Cooled Reactor (EGCR) and a cooperative government-industry-utility project for the construction of the 40 MWe Peach Bottom 1 prototype. The EGCR was a modified version of the UK's AGR, and though its construction was almost completed, it was never started up. Peach Bottom was a different type of GCR and was the forerunner of the high-temperature, gas-cooled reactors (HTGRs), so named because much higher operating temperatures could be obtained than with the AGR types. The reactor was built by General Atomic (GA), operated successfully by Philadelphia Electric Company for eight years, and was followed by the 330 MWe Fort st. Vrain commerclal prototype. General Atomic instigated an aggressive worldwide R\&D and marketing program and developed cooperative $R \& D$ and licensing programs with several foreign countries. They obtained up to six orders for large commercial units, but these were eventually cancelled, and GA's role in the reactor business is dependent upon a revival of the HTGR or development of a gas-cooled fast breeder reactor (GCFR). The R\&D programs related to the HTGRs were joint government-GA projects with GA concentrating on the commercialization of the reactors, the major components, and commercialization of the fuel recycle. Government support was primarily directed to 
basic and small-scale demonstration fuel development and recycle work. Canada has followed the path of heavy water-moderated reactors because of not wanting to be dependent upon enriched uranium. Their program is a vigorous one and has been successful in meeting their national needs. Thus, they are unlikely to change direction. This approach appears to be competitive with LWRs in some countries and has been adopted by India, Argentina and Romania.

France, the Federal Republic of Germany, the U.S.S.R., Japan, South Korea, and Spain have adopted the PWR; the first three of those countries are supplying PWRs for export. Sweden has adopted the BWR.

The only other reactor type under worldwide serious consideration is the LMFBR. Although the need for the LMFBRs, and particularly the timing of its need, has come under critical reevaluation in this country, many of the major industrialized countries of the world have selected it as an essential means of supplementing future energy needs: A number of experimental demonstration and prototype LMFBRs have been operated, and commercial types are under design and construction.

In 1974 the French LMFBR made history with the startup of the 250. MWe Phenix fast breeder. Proceeding in series with Phénix, the French developed plans for a 1200 MWe commercial LMFBR power station, the Super Phénix. This station is now under construction by an international company at Creys-Malville in southwest France and is scheduled for commissioning in 1983.

Meanwhile, Britain, France, and the U.S.S.R. have LMFBRs generating electricity on line; Japan and West Germany have plants in design and construction; and all the major industrial countries with the exception of the United States have aggressive programs leading to developing the LMFBR to supplement the LWRs in meeting their nuclear energy needs. The United States, on the other hand, has a very large LMFBR program but one which is either unfocused or focused on technology development, depending on one's point of view. Thus, the United States, once the leader in LMFBR development, is rapidly falling behind other countries in this field in spite of gencrous R\&D budgets. 


\subsection{Dominant Role of the Government}

In all of the early developments related to nuclear power, the government's role was pervasive and dominant. The early civilian power concepts came from the government-owned contractor laboratories; and the dominant one, the LWR, came directly out of the Naval Reactor Program, whose success was undoubtedly determined by the success of the nuclear submarine program. Other concepts which received their main impetus from the military programs were the liquid metal-cooled fast breeder and the molten salt reactor. With the passage of the Atomic Energy Act of 1954, the AEC was not only encouraged, but mandated, to develop and promote atomic energy for peaceful purposes. As a result, the AEC initiated a well planned and organized prograin to develop civilian nuclear power as the main effort in promoting peaceful atomic energy. At the same time, the 1954 Act ended the government's monopoly on nuclear energy and enabled the AEC to bring in industry and utilities as partners in the developing nuclear program.

The government still retained a strong and dominant role; but, bringing industry in at the time and in the way it was, led to the establishment of a broad industrial capability which became the basis for the rapid growth in nuclear power taking place from the mid-1960s through the mid1970s. Industry also began its own R\&D programs which, although intended to increase commercial competitiveness, greatly broadened the technological support base for ali reactor systems. However, private industry efforts were mainly aimed at developing and strengthening reactor concepts which appeared ready for commercialization, thus leaving the invention and development of new concepts and unproven technologies to the government. This is the situation which generally prevails today.

The government has also maintained a dominant role in the nuclear fuel cycle. Initially the government retained title to enriched uranium, leasing it to civilian users. Currently, enriched uranium is owned by the utility users; however enrichment technology, once considered for transfer to the private sector, is firmly in the federal domain. Reprocessing, currently unlicensable, was in the private sector for two decades but its future is in doubt. The political sensitivity of plutonium is great 
enough that a future plutonium recycle industry may have significant government participation. The ultimate disposal of nuclear wastes is considered a government responsibility.

The role of private industry has varied greatly from country to country. However, regardless of the pattern followed, the technological capability existing within a particular country is based upon strong participation by both government and private industry.

A history of nuclear fuel cycle milestones throughout the world is presented below:

- 1943 - Diffusion, centrifuge, electromagnetic, thermal diffusion pilot plants or production plants built.

- 1943-1944 - Construction of radiochemical pilot plant at X-10 and separation of first plutonium on a large scale. Training of operators for the Hanford processing plant.

- 1954 - Atomic Energy Act permitted private use of leased special nuclear material (SNM).

- 1954 - Startup of fuel reprocessing plant at Savannah River:

- 1955 - Construction of Hanford Purex Plant completed.

- 1956 - First announced schedule of charges for enrichment service.

- 1956-1957-U.S. gaseous diffusion plants (GDP's) consumed over $\$ 2 \times$ $10^{8}$ /year of electric power; in 1956 this represented more. than $10 \%$ of the total U.S. power consumption.

- 1957 - AEC policy of reprocessing spent power reactor fuel on an interim basis announced.

- 1957 - WASH-743, "Summary Report: AEC Reference Fuel Reprocessing Plant," issued.

- 1957 - National Academy of Sciences National Research Council proposed storage of high level wastes (HLW) in natural salt formations.

- 1958 - Startup of Marcoule, France Central Electric Authority (CEA), early military plant at 900-1200 tonne/year of uranium metal.

- 1962 - AEC requested ORNL to consider possibility of testing or demonstrating disposal of HLW in a salt mine. 
- 1964 - Private Ownership of Special Nuclear Materials Act to allow private ownership of enriched uranium and plutonium.

- 1964 - Startup/operation of Windscale, British Nuclear Fuel Laboratory (BNFL), at 1500 tonne/year of natural uranium metal.

- 1965 - Startup of Trombay, India IAEC, pilot scale plant at 60 tonne/year of natural uranium oxide.

- 1966 - Startup of Nuclear Fuel Services (NFS) operations at 300 tonne/year.

- 1966 - GE applied for license to construct Midwest Fuel Recovery Plant (MFRP).

- 1965-1967 - Project Salt Vault demonstration with 14 irradiated Engineering Test Reactor (ETR) fuel elements contained in seven cans (Lyons, Kansas).

- 1966 - Hanford Redox reprocessing plant shutdown.

- 1966 - Startup of LaHague, France CEA, plant at 800 tonne/year of natural uranium metal.

- 1967 - A 10-stage Becker nozzle uranium isotope separation pilot plant was in operation.

- 1969 - Start of enriching of privately-owned uranium in governmentowncd planto.

- 1969 - AEC contemplated installing Cascade Improvement Program (CIP) in FY 1973-1978 and Cascade Upgrading Program (CUP) in FY 1977-1978. (1-year slip in 1969 due to funding.)

- 1969 - E. W. Becker published comparison of GDP/GCP/Nozzle processes in Nuclear News.

- 1969 - Preliminary Safety Analysis Keport (PSAK) issued for Barnwell reprocessing plant.

- 1969 - Saluggia Eurex 1, France CNEN, pilot plant startup at 10 tonne/year Un,

- 1970 - AEC publishes HLW disposal requirements (solidification and maximum of 10 year retention time).

- 1970 - Startup of Karlsruhe, Germany KEWA, pilot plant at 40 tonne/year $\mathrm{UO}_{2}$.

- 1970 - End of LWR fuel leases and Pu purchases by AEC announced. 
- 1970 - AEC announced tentative selection of Lyons, Kansas for demonstration high-level radioactive waste repository.

- 1970-1971 - Atlantic Richfield, Gulf General Atomic, Jersey Nuclear (Exxon), National Lead-Anaconda indicate interest in building privately owned reprocessing plants.

- 1971 - AEC policy of accepting spent LWR fuel for reprocessing expires.

- 1971 - AEC announces plans to provide access to classified enrichment technology to encourage future investments in private facilities.

- 1971 - AEC allowed interested companies to conduct feasibility studies of converting Hanford Purex plant to commercial processing.

- 1971 - Last shipment of recovered uranium from NFS.

- 1972 - AEC withdrew from proposed Lyons, Kansas repository.

- 1973 - Private ownership of reactor fuel became mandatory.

- 1973 - AEC resumes long-term enrichment contracting after halting contracting on December 8, 1972.

- 1974 - First announced atomic laser isotope separation of uranium (U).

- 1974 - Issue of draft GESMO Report on plutonium mixed oxide fuel.

- 1974 - GE MFRP declared "inoperable in its present form."

- 1975 - Draft Environmental Impact Statement (EIS) for Barnwel1 Fuel Reprocessing Plant issued by NRC.

- 1975 - AEC offers to modify delivery schedules for enrichment customers - on a one time basis.

- 1975 - International Conference on Uranium Isotope Separation, London, with 200 delegates from 22 nations outside England; 29 papers covering nozzle, lasers, plasmas, ion exchange Gaseous Diffusion Process (GDP) and Gaseous Centrifuge Process (GCP).

- 1975 - Centrifuge Component Test Facilitiy at K-25 operational with $50,000 \mathrm{SWU} /$ year capacity.

- 1975 - Conceptual design study for a Gas Centrifuge Plant.

- 1976 - Nuclear Fuel Assurance Act an attempt to help private industry to get into the enrichment business. (Believe this bill died in the Senate.) 
- 1976 - Drastically increased seismic requirements imposed on NFS by Nuclear Regulatory Commission (NRC). Needed capital to expand operations went from $\$ 15$ million in 1973 to $\$ 600$ million.

- 1976 - First run with oxide fuel completed at LaHague plant.

- 1976 - BNFL stockpiling plutonium as mixed oxide.

- 1976 - Energy Research and Development Agency (ERDA) announced greatly expanded waste management program that led to formation of Office of Waste Isolation (OWI) by UCCND.

- 1977 - President declares indefinite postponement of Pu recycle and reprocessing.

- 1977 - Announcement that Portsmouth enrichment add-on plant would be changed from GDP to GCP.

- 1977 - Capenhurst, England centrifuge.plant of the Tripartite inaugurated.

- 1977 - Almelo centrifuge p1lor plant Inauguraled. Operating at 68,000 SWU/year, design capacity of $200,000 \mathrm{SWU} /$ year to be reached in early 1979.

- 1978 - Draft Interagency Review Group (IRG) report issued on alternative waste technology strategies.

\subsection{Role of the Public}

The public's role in nuclear power development has grown from a rather passive and indirect role in the early phases to an aggressive and critical one at the present. From the earliest days there was concern about the military aspects of nuclear energy, but this was mainly on the professional scientist and political levels and the general public never really became involved. The 1954 Atomic Energy Act opened the peaceful uses of atomic energy for public participation and the 1955 Geneva Atoms for Peace Conference placed into the public domain large quantities of information that had hitherto been classified. However, participation by the general public in the domain of nuclear power development was slow and the sources of information and control of the programs remained vested in the government and special segments of the public such as certain industries, utilities, the universities, and the professional societies. Also 
nuclear power did not emerge as a significant factor in the electricity generation picture until the late 1960s. About this same time there was growing public concern about environmental degradation, and various organized groups began to question the effect of nuclear power and the effectiveness of the AEC on this issue. The Air Quality Control Act was passed in 1967 and initially air pollution played a big role in the shift to nuclear power. However, by late 1968 segments of the public began to voice. concern about increased water pollution from nuclear plants; the Vermont Yankee and Turkey Point plants encountered well organized opposition from public environmental groups. The year 1969 became the water-shed year on the environmental issues. During this year there was significantly increased opposition to nuclear power plants from environmental groups; agitation developed in both houses of Congress for environmental control legislation; states began to challenge the AEC's authority as the sole arbitrator of environmental standards for nuclear plants; the AEC held its first public meeting at the University of Vermont on the safety and environmental effects from nuclear power plants; the JCAE staged a Washington version of the national environmental debate; and in late 1969 the National Environmental Protection Act (NEPA) was enacted by Congress.

The AEC had long contended that nonradiological effects from nuclear plants upon the environment were beyond its jurisdiction and had refused to concern itself with this issue. However, NEPA forced the AEC to consider in the licensing of nuclear plants the effects upon the environment of nonradiological effluents, particularly the discharge of warm coolant water into streams or other natural bodies of water. This decision encouraged an increasing number of public groups to challenge the AEC on this environmental issue in relation to the licensing of nuclear plants. In 1971 the courts were called upon to interpret NEPA in the context of AEC regulatory actions in the precedent-setting case of the Calvert Cliffs Coordinating Committee, Inc., et al versus the U.S. Atomic Energy Commission. The decision rendered by the U.S. Court of Appeals for the District of Columbia on July 23, 1971, faulted the AEC on several counts and ruled that they must consider environmental issues in connection with all nuclear power licensing actions that took place after January 1, 1970, the effective date of NEPA. This ruling became a landmark in the licensing of 
nuclear plants and presented the environmental, antinuclear, and other interventionists groups with almost an unlimited opportunity to challenge the AEC on every aspect of the nuclear plant licensing process. The AEC estimated at the time that the Court's decision would affect 61 license applications involving 88 nuclear plants, and delays in licensing of nuclear plants at between six months and one year. (The actual delays turned out to be some three or four times longer than this.) Thus, the public in the form of small but numerous activists groups was interjected into the nuclear power issue in a major way.

It is not practicable in this report to trace in detail the many actions which took place in the intervening years between the late 1960s and now that demonstrated the growing public role in the nuclear power issue. However, in retrospect it appears that this was an important transition period with respect to public participation. It should be noted that the public participation was by special interest groups who were not necessarily representative of the public at large. These groups were primarily antinuclear and through their aggressiveness and vociferousness they created the illusion that most of the general public was against nuclear power when in fact public opinion surveys indicated that a substantial majority of the general public supported nuclear power. Sume of the major events which were indicative of this trend are listed below:

- 1970 - Eugene, Oregon, voted a 4-year moratorium on nuclear plant construclión.

- 1970 - Earth Day environmental movement initiated.

- 1970 - AEC's "As low as practicable radiation release from nuclear plants," attacked by critics as being unresponsive.

- 1971-1972 - Moratoria on nuclear plant construction pushed in several states; initiative proposition placed on primary ballot in California.

- 1971 - Scientific Institute for Public Information (SIPI) filed a successful suit to force the AEC to write an environmental impact statement on the LMFBR.

- 1971-1972 - The Union of Concerned Scientists (UCS) and other public interest groups pressured the AEC into holding hearings on the 
reliability of the nuclear power reactor's Emergency Core Coolant System (ECCS).

- 1972 - NRC holds public hearing to get views on As-Low-As-Practicable standards and ECCS.

- 1972 - Environmental groups file a lawsuit to force separation of AEC promotional and regulatory functions.

- 1972 - Environmental Action group urges national moratorium on LMFBR.

- 1972 - BPI allowed to intervene in three nuclear plant hearings.

- 1972 - JCAE holds public hearings on reactor'safety.

- 1973 - Nader and UCS pressure ACRS to make available to the public information on reactor safety.

- 1973 - AEC widens public role in licensing of nuclear plants.

- 1973 - Nader and Friends of the Earth sue to shut down 20 nuclear plants.

- 1974 - The Audubon Society sues to block the Offshore Power Systems (OPS) project.

- 1974 - Madison, Wisconsin, opposes the. Koshkonong nuclear plant.

- 1974 - The Sierra Club decides to oppose nuclear power.

- 1974 - EPA holds public hearings to assess the environmental impacts from plutonium releases.

- 1974-1975 - Nader's Critical Mass Meetings organize to oppose nuclear power.

- 1975 - Two public referendums show acceptance of nuclear power; California places nuclear moratorium initiative on the ballot for 1976; nuclear initiatives organized in a number of other states.

- 1975 - Harris survey finds public majority for nuclear power.

- 1975 - Professional and technical groups oppose moratoria actions.

- 197.5 - AFL-CIO convention endorses nuclear power; National Council of Churches opposes plutonium reactors.

- 1975 - The World Council of Churches commends to its member denominations a study of nuclear power from a religious and ethical point of view.

- 1976 - National Intervenors sponsor over 200 antinuclear day fetes.

- 1976 - Nuclear moratorfum initiatives initiated in more than 15 states. 
- 1976 - Over 50 eastern antinuclear groups form an action federation.

- 1976 - Activists protest the Seabook Nuclear plant.

- 1976 - Carter election raises question of future of nuclear power.

- 1977 - 31 Vermont towns vote to ban the construction of nuclear plants.

- 1977 - Common Cause advocates the abolishment of JCAE.

- 1977 - Congress strips JCAE of its powers.

- 1977 - NRC proposes to amend its regulations to broaden the potential role of state and local governments and members of the public.

- 1977 - Speth, a President Carter appointee to the Council on Environmental Quality, advocates no new construction of nuclear plants.

- 1978 - Role of environmentalists in White House energy policy questioned.

- 1978 - The ACRS invites the public to submit nominations for ACRS vacancies.

- 1978 - The National Association for the Advancement of Colored People backs nuclear power.

- 1978 - The League of Women Voters opposes growth of nuclear power.

- 1978 - Montana passes a nuclear moratorium initiative.

- 1979 - The Three Mile Island nuclear accident and all the attendent public participation.

The foregoing examples illustrate the growing role of public special interest groups in influencing nuclear power issues. Initially there were only a small number of these activist groups, and generally they were not representative of the public at large but of special interest, some of which were not directly related to nuclear power. Also, the initial activist groups had limited objectives, such as increased safety or environmental protection from nuclear power plants. However, as ditterent groups met with varying degrees of success, they worked to enlarge their constituencies, expand their activities, and established more ambitious goals. Their first confrontations were with the AEC on regulatory issues, but later they carried their protests to the courts, to the halls of Congress and state legislatures, to the Presidency, and through the President 
to the Executive Branch agencies and regulatory bodies. From the very first these groups had a dramatic appeal for the communciations media and through them they sought to influence and control larger and larger segments of the general public. It appears that their strategy has been to influence the "influencers of public opinion," such as the communications media, religious and homogeneous social groups, educational institutions, and the holders of public offices. Their objections to nuclear power, which originally were based on environmental and safety questions, were enlarged to questioning the projected energy needs, advocating a ban on nuclear power, and attacking the structure of the country's political system. Some groups have presented nuclear energy as being a moral and social issue and in this context have persuaded both the National Council of Churches and the World Council of Churches to adopt resolutions opposing nuclear energy. Through the press, radio and television, the general.public has been barraged with a constant stream of criticisms and alleged health, safety and social dangers from nuclear power. Many of these are false, or speculative extrapolations of known information; but there is a sufficient factual basis to provide creditability to the uninformed and the technique has proved to be an extremely effective means of swaying the public to a point of view.

Although the title of this section is "The Public's Role in Nuclear Power Development," the above examples and related discussions have emphasized the growing of the opponents to nuclear power. The reason is that this is the way that the public's role has actually developed. Furthermore, it is not unusual for the public to become involved in a situation such as this through being on one side or the other of a cause. Causes stimulate involvement and public participation is involvement. Up until recently, the involvement and hence public participation has been on the antinuclear power side and some of the general public has been converted to this point of view. This may be changing and we may see more participation on the other side of the issue which is desirable since it will give the general public a more balanced picture of the issues.

In either case the public's opinions are the ultimate determinant of political decisions. The public influences and even controls the decision makers and the decision makers respond to what they perceive the public 
as wanting. However, public judgements are of ten based on inadequate information or information which they are unable to evaluate; and, thus, what the public wants is not always sound or in its best interests. To the extent that the general public is swayed by special groups, they reflect the interests of these groups and these are not necessarily synonymous with the public interest. Thus, during times of controversy and change, such as those through which the country is now going, the role of the public is critical in determining the actions that will finally be taken. In the case of nuclear power, the public will ultimately determine whether we have nuclear power in limited amounts, unlimited amounts, or at all.

\subsection{Role of the Electric Utilities}

Nuclear energy' $\varepsilon$ development in the past and at present has been premised upon its utilization for the generation of electricity. This may change in the future but for a long time other uses will be small in relation to its primary use for generating electricity. Thus, it was logical that the AEC in its efforts to promote the peaceful uses of nuclear energy should turn to the utilities as one of its natural partners in this endeavor. As discussed in Sect 2.1, the AEC as early as 1954 entered into cooperative projects with the utilities and the manufacturing industry to demonstrate various reactor concepts as potential nuclear electrical power plants. Starting in 1955 and continuing into the early 1960 s the AEC initiated a series of Power Reactor Demonstration Projects in which they provided financial assistance to utilities who were willing to build and operate such plants. In the mid-1960s nuclear power became a commercial item and utilities proceeded on their own to purchase nuclear power plants in competition with fossil fueled plants as part of their normal electric generating system. However, they continued to have an important part in the development of advanced concepts.

During the late 1960s the AEC called upon the electric utilities and the reactor manufacturers to participate in organizing, financing, and implementing a program to develop and demonstrate the liquid metal fast breeder reactor (LMFBR) technology。 This program included detailed plans 
for R\&D, design studies for demonstration and commercial pilot plants, and the construction and operation of test facilities. The utilities and the reactor manufacturers played key roles in all these efforts. In 1971 Congress passed the authorizing legislation for an LMFBR demonstration plant and the AEC convened two utility advisory groups to assist in establishing a program for carrying out the demonstration and establishing program and design objectives for the project. In early 1972 the AEC accepted a joint proposal by Commonwealth Edison Company (CECO) and the Tennessee Valley Authority (TVA) to build a partnership plant on the TVA system. Shortly afterwards the partnership established the Project Management Corporation to manage and carry out the demonstration project, which was to become the Clinch River Breeder Reactor (CRBR) project.

In March 1972 the utility industry established the Breeder Reactor Corporation ( $B R C$ ) to represent its interests in the demonstration plant and to solicit utility support for the project. This solicitation resulted in agreements representing 753 electric systems to pledge over $\$ 250$ million to the CRBR project, the largest contribution ever made by the utility industry to a single project. Although the CRBR project is in limbo, these agreements which were built on objectives continue to be supported by the utility industry. The historical record of government vacillation on the CRBR program and in other areas (such as enrichment) make it unlikely that much private capital will be invested in future demonstration programs.

In summary, the prospects for nuclear power are intimately tied in with the electric utilities who hold a strateglc position in determining the extent to which nuclear power will or will not be used on the nation's electrical grid system. In this context it should be noted that changes which have taken place within about the last ten years have significantly altered the financial incentives for utilities to build nuclear power plants. First the increases in nuclear (and coal) plant capital costs mean that the marginal costs of additions to a utility system are higher than the average system power costs. This is a reversal of conditions which prevailed previously and is a disincentive for utilities to add new plants to their system. Secondly, the rapid growth of inflation and high interest costs have made it difficult for the utilities to arrange the 
long-term financing needed for new power plants. Utility stock prices are generally below book value and hard to sell. Thirdly, state public utility commissions are failing to provide the rate increases needed to support new plant construction, forcing the utilities to defer potentially necessary construction projects in the future. And, finally, state utility commissions are more reluctant to approve as part of the rate base some of the costs related to nuclear power plants. In total, these conditions have imposed a serious financial burden upon the utilities and have greatly weakened their financial capabilities and incentives for building new nuclear power plants.

\subsection{Role of the Industrial Manufacturers}

The manufacturing industry, particularly the manufacturers of electrical generating equipment, also have had key roles in the development of nuclear power. The Westinghouse Electric Corporation was the prime industrial contractor in the Navy's light water reactor project established at Argonne Nationa1 Laboratory in 1948, and eventually they became the dominant industrial participant in the Navy's program. This naturally led to their working with the Navy and the Duquesne Light Company in the design, construction and operation of the 90 MWe Shippingport Atomic Power Station which started up in 1957 and became the prototype for pressurized 1ight water reactor (PWR.) commercial central station power plants. Westinghouse also participated in the AEC's nuclear power cooperative projects and Power Reactor Demonstration Programs and eventually became the dominant manufacturer of commercial pressurized water reactors.

The General Electric Company was also an early industrial participant in the nuclear power program. In the late 1940 s they started work on the development of the liquid metal-cooled power breeder reactor and under contract to the Navy established the liquid metal-cooled submarine landbased prototype in 1950. GE also had a prominent role in the Aircraft Nuclear Propulsion (ANP) project, the maritime propulsion project and the nuclear space. program. Their entry into the commercial nuclear power program was through the development of the boiling water reactor (BWR). In cooperation with Commonwealth Edison Company they designed, constructed, 
and operated the 200 MWe Dresden Nuclear Power Station which started up in 1959 as the first commercial BWR prototype central station nuclear power plant. GE also made nuclear power history by entering into a turnkey contract with Jersey Central Power and Light Company for construction of the 650 MWe Oyster Creek Nuclear Power Plant in 1963. This event was a turning point in establishing nuclear power as a competitor in the electricity generating field, and turnkey contracts were a gamble on the future of nuclear power in which private industry assumed the risks necessary to get the nuclear power market activated.

Other industrial manufacturers also played important roles in the development of nuclear power. Combustion Engineering Company was an early Navy contractor, and they and Babcock and Wilcox soon joined Westinghouse in the design and construction of commercial PWRs. The General Atomic Company, then a subsidiary of General Dynamics, designed, built prototypes of, and attempted to market the High Temperature Gas Cooled Reactor (HTGR). This was done with minimum government assistance. Other industrial companies played important roles in the development of key components, such as valves, pumps, pressure vessels, fuel materials, and many other critical items. Also the industrial contractors, particularly the reactor manufacturers, conducted many experiments, tests, and general R\&D necessary for the development of these critical materials and component it ems.

It is not feasible within the limitations of this report to adequately treat the role of the industrial manufacturers in the development of: nuclear power. However, it is no exaggeration to say that they were and are a critical element in the process and that safe, reliable, and economic nuclear power cannot be achieved without the full support and cooperation of a diversified, capable and resourceful manufacturing industry.

Commercially, all but one of the 70 power reactors licensed in the United States today are LWRs with the rest of the world generally following suit. As of December 31, 1978, there were about 405,000 MWe of commercial nuclear plants in operation, under construction, or on order worldwide. $^{2}$ of these, $91 \%$ are LWRs, $4.5 \%$ HWRs, $3.7 \%$ GCRs, and about $0.7 \%$ LMFBRs, Forty-seven percent of the total capacity is in the United 
States which represents a slow but steady decline of its share of world nuclear capacity. By the year 2000, the U.S. fraction of capacity is projected to decline to about $25 \%$ of the total world capacity. ${ }^{3}$ These figures demonstrate that the LWR nuclear plants are now a standard commercial item which the utilities can buy as they. would a conventional fossilfueled plant. The LWR supply capability is distributed among 13 worldwide reactor manufacturers, four of whom are American.

Whereas the nuclear world market was completely dominated by the U.S. manufacturers prior to 1970, their share had dropped to essentially zero by 1977, as shown by Fig. 1. (There has been some recovery since then.) The situation with respect to the LMFBR is even worse: the United States has lost its leadership position, perhaps irretrievably, and may end up. having to license the LMFBR from a foreign manufacturer.

A. substantial investment supports the LWR industry in this country. It is estimated that the United States (government and industry) has expended over $\$ 6$ billion on the development of the light water reactor system and an additional $\$ 2$ billion on associated nuclear equipment facilities. This.industrial infrastructure has been built up over the last three decades, and a comparable industry buildup would be needed to support any other category of reactors to the commercialization stage. The development and supply industries support an installation program for the nearly 200 GWe already committed and have the potential to supply up to 500 MWe of installed capacity by the year 2000. Some industrial capability has been developed in support of the LMFBR, but it needs to be expanded and strengthened to provide an adequate base for commercialization of the concept.

\subsection{Role of the Participants. Influencing Nuclear R\&D Policy}

We have discussed the role of the public, that of the electric utilities, and that of the manufacturing industries in the nuclear enterprise. The role of participants shaping nuclear $R \& D$ policy are perhaps even more 
ORNL-DWG 80-4935 ETD
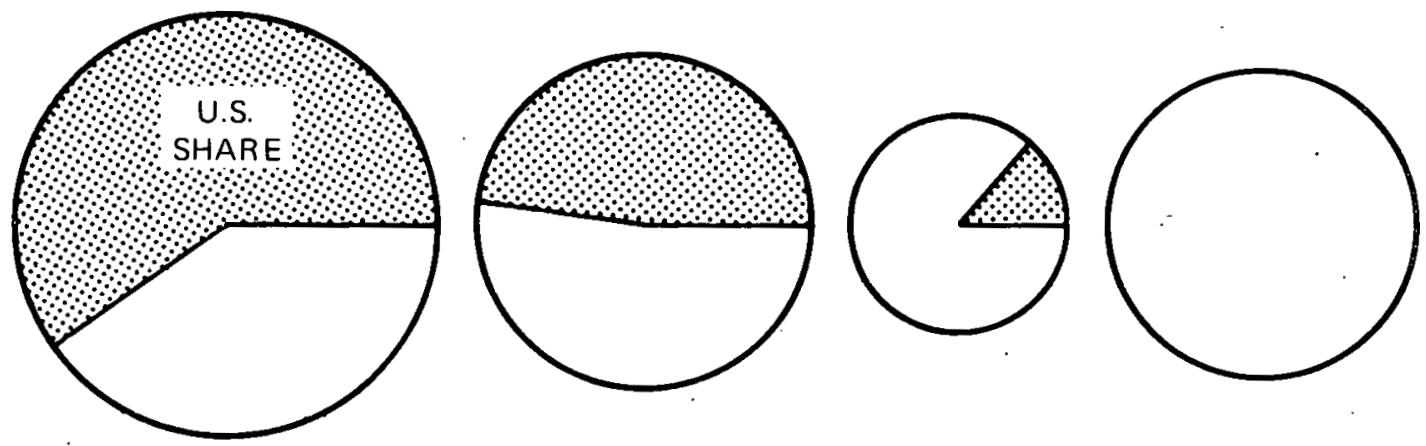

YEAR

1974

.1975

1976

1977

WORLD

EXPORTS

(GWe):

15.6

3.3

4.3

7.8

Figure 1. U.S. share of the world nuclear reactor export market Source: T. D. Anderson, "The Outlook for Nuclear Fission Energy," Dec. 1, 1978 
complex, and have been traced in a paper by D. F. Cope. ${ }^{4}$ The participants include the Federal Government ( $a$ maze of institutions of ten representing opposing views), the utilities (the ultimate customer), the nuclear power manufacturing industries (in part, a sponsor), the nuclear R\&D community (which contributes to shaping policy as well as doing the research), the public (especially the "attentive" public) and the international community.

The federal agency most directly concerned with nuclear power development is the Department of Energy, although safety research is supported by the Nuclear Regulatory Commission. The contractors carrying out government-sponsored $R \& D$ exert a strnng influence in developing programo. Policy is shaped to a major extent by the White House (the President, the office of Management and Budget) and by Congress. It should be noted that the Secretary of Energy is in a very weak position to exert leadership because he is obliged to support the President (OMB) on the one hand and Congress on the other; in other words a strong DOE leader must start by gaining followers in the White House and in Congress. The various Executive policymakers and the various committees of Congress seem to be continually at cross-purposes. As a result the nuclear R\&D program is only moderately responsive to public concerns and cannot be regarded as very effective, technically or cost-wise.

Privace Industry supports some R\&D, primarily through the utilitysupported Electric Power Research Institute. The resources required to commercialize new nuclear reactors are beyond what industry currently has available. However, government decision makers are strongly influenced by Inductrial preferences.

The attentive publics include not only the scientific and engineering communities, but also the opponents of nuclear power. Technical societies and national academies have increasingly become involved in accescments of nuclear power which have influenced government decisions. Nuclear opponents have challenged some of the $R \& D$ programs, especially the breeder program, and the radioactive waste management program; hut their criticisms have not been constructive.

Finally, foreign $R \& D$ programs are becoming increasingly important as the U.S. loses its technological lead in nuclear power. 


\subsection{Advanced Technology in Nuclear Power Development}

The evolution of light water reactor technology has been traced in earlier sections. The PWRs and BWRs were two out of a large number of competing concepts. Coupled with the commercial success of the light water reactors were assessments of advanced technology, believed to be required for second generation reactors. The advanced reactors were to be substantially more resource-efficient. The assessments indicated that the LMFBR was the most promising of the advanced reactors and that it needed to be deployed commercially during the final decades of the century.

In 1964 the AEC brought in Milton Shaw as Director of Reactor Development with the chief objective being to expedite the commercial development of the LMFBR. Shaw moved aggressively toward the achievement of this goal and in the process withheld support from competing programs, concentrating resources on the LMFBR to the detriment of other AEC responsibilities* (1965-1974). The HTGR survived this de-emphasis of alternative reactor concepts because of substantial private support.

The LMFBR program under Shaw was unusual in that it focused on technology development and the development of nuclear steam supply (NSSS) capabilities from several vendors. The emphasis differed from that of earlier programs and the LMFBR programs of the UK, France, and the U.S.S.R., all of which were focused on the development of prototypes. Also in the past, responsibility for the development of a given reactor experiment or demonstration had been clearly delegated to a single contractor, frequently one of the AEC national laboratories. In the case of the LMFBR, responsibility was divided among several contractors with the AEC exercising central and detailed control. This resulted in a cumbersome unwieldy organization and in practice proved to be unworkable.

In retrospect the Shaw program was a serious strategical mistake. While competitors have produced tangible operational hardware, the United

*Among the AEC responsibilities which were allowed to slide were LWR safety (the GAO thought that should be private industry's responsibility), waste treatment and disposal (the Commissioners yere never interested), and reprocessing (supposedly covered by privat. .adustry). 
States has produced a nuclear R\&D constituency which soaks up dollars while prevented by its sponsors from achieving significant accomplishments. These problems will be discussed later in Chapters 4, 5, and 6 . Had the Shaw program been allowed to mature, it would have culminated in one or more prototype power plants that would lead directly to commercial LMFBRs for central power stations. The first of these cooperative efforts was to be the Clinch River Breeder Reactor (CRBR) involving the Federal Government, reactor manufacturers, and utilities. Unfortunately, the CRBR has become a political issue and is in limbo at present. Meanwhile, the government's R\&D support program has lost much of its momentum, and though still sizable; is not as effective nor as productive as it needs to be. At least five other industrialized countries all have strong and broadly based LMFBR R\&D programs.

As indicated earlier, France has the 250 MWe Phenix demonstration LMFBR in operation and a 1200 MWe commercial size LMFBR under construction. The U.S.S.R. has a 350 MWe LMFBR in operation and a 600 MWe commercial prototype scheduled to start up in $1979 / 80$. The UK has a 250 MWe LMFBR demonstration plant operating and a 1300 MWe commercial sized prototype scheduled for construction. The Federal Republic of Germany has a 300 MWe demonstration plant scheduled to start up by 1984 and a 2000 MWe commercial size prototype scheduled for construction. Japan has a $300 \mathrm{MWe}$ demonstration plant under construction and commercial sized prototypes under design. The United States has the Experimental Breeder $20 \mathrm{MW}$ Reactor (EBR-2) operating, the 400 MWt Fast Flux Test Facility (FFTF) scheduled to start up in 1980, but the 350 MWe CRBR and all subsequent LMFBRS ale in 1 imbo.

In recent years it has become evident that the government may have withdrawn from LWR R\&D prematurely, particularly with respect to the safety features of these systems. Thus, for the past five years, the government has become increasingly involved in LWR safety R\&D; and this trend is likely to grow as a result of the Three Mile Island accident. The government has also undertaken limited efforts to improve the operability of LWRs and, most recently, their fuel utilization efficiency.

Presently, in the United States, GA and a utility consortium are doing a small amount of work on design and evaluation of advanced converter 
and fast gas cooled breeder reactor concepts, with the bulk of the R\&D work being government funded. The government's (DOE's) program has gradually de-emphasized the fuel recycle $R \& D$ and has announced that their main objective starting in 1980 will be to develop a gas turbine-high temperature, gas-cooled reactor (GT-HTGR). However, this program is not firm and, there are indications that the primary HTGR objective could change. This radically changes the emphasis of the HTGR program and will have a significant influence on the R\&D to be pursued.

Abroad, other than the UK which has already been discussed, the main center of gas-cooled reactor $R \& D$ and technology is in the Federal Republic of Germany (FRG). Germany has demonstrated a different type of HTGR (the pebble-bed reactor) and is concentrating on developing a reactor which will produce industrial heat, make steam for the generation of electricity, and produce high-temperature gas for a direct cycle gas turbine. At present, the FRG undoubtedly has the strongest gas-cooled R\&D program in the world.

Japan also has indicated an interest in HTGRs, particularly as a means of producing high-temperature industrial heat. However, their program is third to that of West Germany and the United States.

\subsection{Transfer of Nuclear Power Technology}

The development of nuclear power as evidenced by the brief history given earlier, was not confined to any one country but from the very beginning was shared by the United States, Great Britain, France, the U.S.S.R., and Canada, with the Federal Republic of Germany's and Japan's development coming later because of war treaty restrictions. Although the United States was the undisputed leader, Great Britain, France, and Canada independently developed their.own national reactor systems and became the leaders in the development of gas-cooled and heavy water reactors, respectively. France later switched to LWRs. Other countries also moved rapidly to develop their reactor technology proficiency. This was given great impetus by the 1955 Geneva Atoms Peace Conference, which was promoted and sponsored by the United States, and which helped to create worldwide interest in nuclear energy for power and other peaceful purposes, Also the 
1955 conference and the subsequent follow-up international conferences were exceedingly effective instruments for transferring nuclear technology from the limited number of know-how countries to the world at large. In the late 1950s, the International Atomic Energy Agency (IAEA), an arm of the United Nations, was organized to promote peaceful nuclear energy on an international basis, and at the same time to serve as a deterrent to the proliferation of nuclear military capabilities. The IAEA soon became a very effective force for the transfer of nuclear energy information and know-how to the smaller and less developed countries.

The general pattern to technological transfer has been for the various countries to first develop their own government supported national programs. Technology transfer among countries is then achieved through government promoted and approved information exchange programs and through the open scientific literature. The national programs are broadened internally by bringing in private industry which in turn develops its own technological bases, some of which is public information but much of which is proprietary. This proprietary information provides the basis for commercial exchange and licensing agreements with other companies (both national and foreign) and with foreign countries. This technology transfer which proceeds from government to government, government to private industry, and private industry to private industry has proved to be an effective way of building an increasingly stronger and broader base from which future technology is developed.

Technology transfer and nuclear weapons proliferation have shared a curious coupling from the early days of nuclear energy. The United States first offered nuclear technology to the United Nations in 1946 (the Baruch Plan) in an effort to eliminate competitive national nuclear weapons programs; the effort was unsuccessful. The Eisenhower Atoms-for-Peace program (19.53) was another attempt to channel nuclear research into a cooperative international mode in preference to competitive national programs. The Nuclear Non-Proliferation Treaty (NPT, 1969) coupled the promise of nonproliferation by nonnuclear weapons states with a promise of access to nuclear technology from advanced nuclear states. Recent actions by the U.S. Government (notably the Nonproliferation Act of 1978) to restrict 
export of nuclear materials and technology have been interpreted by some countries as in violation of the NPT. The result could be growth of national programs, if the advanced countries are viewed as unreliable suppliers.

Returning to the history of technology transfer, the transfer of LWR technology from the United States to Western Europe was the result of an unprecedented government-industry collaboration. The government made available loans and cheap enrichment services; the industry was flush with commercial success at home and exported both reactors and license agreements. U.S. manufacturers obtained $7,9 \%$ of the worldwide nuclear orders from 1953. through 1976, but in 1976 their share of the orders dropped to $17 \%$.

The export of heavy water reactor technology also enjoyed some success. HWRs have appealed to some countries which regard the natural uranium fuel cycle as less prone to supply interruption than an enriched fuel cycle.

The LMFBR has a broad base of interest, not only as the logical successor to converter reactors, but especially for its potential for eliminating vulnerability to uranium/enrichment supply interruptions. As evidenced by the INFCE discussions, the United States and some other advanced nuclear nations do not believe export of LMFBR technology to developing countries to be appropriate.

International agreements on nuclear technology transfer are obviously in a very unsettled state.

\subsection{Circumstances Favoring Nuclear Power Development in the United States}

One aspect of the government's past role in the development of nuclear power that merits special attention was the teamwork and coherence of purpose that the government participants elicited among themselves and private industry during the early phases of nuclear power development. On the governmental side there were two powerful forces: the AEC, the dominant Executive Branch Agency, vested with responsibility for both the promotional and regulatory aspects of nuclear power; and the Joint Committee 
of Atomic Energy (JCAE), which represented both houses of Congress and had, in a practical sense, the final arbitration of all congressional actions on atomic energy. These two governmental bodies closely coordinated their plans and actions in an aggressive effort with the objective of attaining a world leadership position in the development of peaceful nuclear energy. Furthermore, due to their preeminent positions in the Executive Branch and Congress, their concurrence on a program virtually assured its acceptance and implementation as national policy.

This clearness, coherence, and consistency of national purpose with respect to nuclear power was not lost on private industry - and they, perceiving nuclear power as the dominant energy form of the future, quickly became a strong and enthusiastic addition to the team. The result was a de facto triumvirate that became an exceedingly powerful and effective force in moving nuclear power to a viable commercial industry with the expectation that within 30 to 40 years it would become the primary energy source for meeting the country's electricity demands.

Under the Atomic Energy Act of 1954, private industry was admitted to nuclear energy development under a comprehensive statutory program of federal licensing and regulations. The AEC as both the regulator and promoter of nuclear power worked diligently to strike a balance between these conflicting roles. On the promotional side they encouraged private industry through a combination of favorable policies and incentives to become involved in, and push, the development of nuclear power. On the regulatory side they established an elaborate system of standards and controls to private industry's participation in the nuclear power program. Under this system no one could build a reactor, possess nuclear materials, or operate a nuclear reactor without a license from the AEC. This combination of promotion and regulation along with the cooperation of the JCAE worked eftectively and created an environment of strength, confidence, and harmony in which nuclear power flourished.

However, over the years the AEC was subjected to increased criticism on two issues: (1) combining in one agency the functions of promoting the development of nuclear and regulating that development, and (2) the refusal of the AEC to concern itself with nonradiological impacts on the environment resulting from the construction and operation of nuclear power 
facilities. These issues came to a climax in two unrelated events. The first event was the enactment of the National Environmental: Policy. Act (NEPA) in 1969. This act required that the AEC in conjunction with the Environmental Protection Agency (EPA) consider the effect upon the Environment of nonradiological impacts from nuclear power plants. This provided the environmentalists and antinuclearites an opportunity to oppose and delay the licensing of nuclear power plants.

The second event, which was the more important of. the two, was the Energy Reorganization Act of 1974. This act split the AEC's jurisdiction between the Energy Research and Development Agency (ERDA) for the $x \in-$ search, development, and promotional phase, and the Nuclear. Regulatory. Commission (NRC) for the regulatory phase, of nuclear power. This act also stimulated changes in Congress which resulted in the demise of the JCAE and distribution of its functions among a number of congressional committees, none of which possessed the knowledge, power, and prestige of the JCAE. The effect of these two actions was to fragment the governmental team members into its several components, each pursuing a limited mission, and the grand strategy for developing nuclear knowledge, power. lost its proponents and leadership. The net result of these events was. that the former coherence and consistency of government actions was replaced by vacillation, uncertainty, and chaos. Industry was no longer a respected member of a successful team, but became the scapegoat for the real and perceived ills of the nuclear power business. Regulatory hearings were drawn out over extended periods and costs of plants increased significantly because of interventionists' actions. At the same time the regulatory bodies became more sensitive to public and political pressure, and utilities complained that the regulatory actions were becoming oppressive and punitive. This pervasiveness of regulatory actions, the reduced demand for electricity, and their strained financial situation caused the electric utilities to reappraise their commitment to nuclear power with the result that for the past three years net cancellations of nuclear plants have exceeded new orders. At the same time, the chaos and uncertainty existing among the governmental bodies has changed private industry's mood of confidence and enthusiastic participation to one of lack of confidence and reluctant participation. Thus, the situation todey among 
the nuclear power proponents is one of loss of confidence, defensiveness and loss of purpose, with strong prospects that the nuclear power option may be forsaken.

This paper is not the appropriate place to discuss the detailed actions which need to be taken to correct this situtation. However, a few general conclusions can be drawn. History has shown that the rate of progress in the nuclear program was related to the consistency of government policies, clearness of purpose, degree of cooperation among the participants, and confidence in the leadership. This, for the time at least, has been replaced with a pervasive atmosphere of opposition and negativism toward nuclear power. To change this and again put nuclear power on a positive course, the President and Congress need to agree that we need nuclear power and follow up with actions which will foster its development. Private industry's confidence in goverment must be restored. They must be assured that they can make profits in spite of restraints, and the NRC must be reformulated to bring about a better balance between the need for power and the environmental restraints which impede achievement of this goal. In the final analysis this means that the people must be convinced of the need for nuclear power so that they, working through the political process, will elect people to office who favor this position and take actions to support it. 


\section{ROLE OF NUCLEAR POWER IN THE U.S. ENERGY FUTURE}

\subsection{Generation of Electricity - The Primary Mission}

The mission of nuclear power may be subdivided into a near-term and a long-term phase. At present and continuing for the next 10 to 20 years the primary application of nuclear energy is and will be to generate electricity. In the long-term its role in the generation of electricity will become even more important, but there is a modest potential for other uses such as process or space heat, and these will be briefly discussed. Thus, one cannot adequately assess the role of nuclear power without assessing the role of electricity in relation to total energy needs. Specifically one needs to examine the demands for electricity, now and in the future, and assess the fuel options which are likely to be available for meeting these expected electricity demands.

With respect to the first of these two issues, projecting energy demands including demands for electricity are highly uncertain and difficult. Furthermore, they become increasingly less reliable as one goes out in time. Hence time becomes a key variable in projecting energy demands and the future role of any specific energy option. In the case of electricity, the institutional and regulatory environment in which our electric utilities operate requires that projecting and planning future energy needs be done in an organized and coherent manner. This reduces the uncertainties to something less than those associated with projecting total energy demands, but the remaining uncertainties are still substantial. The planning time frame of our electric utility industry is about 10 to 12 years, and over this period they can develop plans with a reasonable degree of confidence that they will be compatible with the needs which develop. Beyond this time frame the uncertainties increase greatly and from 20 to 30 or more years ahead specific planning is of limited usefulness, and one must depend upon broad strategies which can encompass future trends and identify the various options that are most likely to be available for meeting future energy needs. Thus, rather than attempt precise projections of demand, a more useful technique is to develop a range of demands in the expectation that the range will bracket the actual demands 
which materialize and yet be sufficiently compressed to be compatible with strategic planning which will cover the most likely eventualities. Of particular importance at this time is the low demand estimate since there is mounting evidence of a trend to lower growth patterns than have prevailed for the past 40 to 50 years.

A major disadvantage of developing a range of projected energy needs is that such a range is necessarily so broad that the roles of the various fuel options overlap and become blurred to an extent that it becomes difficult to focus on the issues relating to any specific fuel option. Therefore, this report attempts to develop a projection of electricity requirements up to about 2010 which hopefully will lie within what would be projected as the low and high estimates and hopefully more likely to be realized than either of the extremes.

This approach involves examining historical developments, reviewing where we now are, and projecting future trends tempered with current information which indicates that there are constraints and pressures pushing toward lower electricity growth rates even though electricity may continue to grow faster than the total energy consumption. Having developed a projection of possible electricity demands, the various fuel options will be assessed for meeting these demands and the role of nuclear power assessed on the basis of a "last resort" choice. This is consonant with the present administration's position, gives recognition to the current attitudes toward nuclear power, and should represent a conservative position with respect to nuclear's role.

Historically, electricity generation in the United States increased from 150 to 2,210 billion $\mathrm{kWh} / \mathrm{yr}$ from 1940 to 1977 . This very rapid growth rate $(7.5 \% / y r)$ will be difficult to maintain even under a high growth philosophy and there are trends in evidence, such as consumer saturation, higher cost primary energy, higher consumer prices for electricity, and societal induced conservation, which portend a slowing in electricity demand. Opposing these trends is the possibility that electricity will be increasingly substituted for other energy forms. For the past five years the rate of growth of generated electricity ${ }^{6}$ ranged from $0 \%$ in 1974 to $6.3 \%$ in 1976 , or an average of $5.4 \%$ for the five years (1978 was $3.5 \%)$. The key question is whether this signals an era of slower growth 
relative to the historical past, and if so, what the future growth rate will be.

The 1978 total domestic energy consumption and the primary energy consumed in the generation of electricity is given by fuel types in Table 3. It is noted that more than $30 \%$ of our 1978 total domestic energy consumption was for the generation of electricity. This is expected to grow in the future. As for the fuels for the generation of electricity, coal provided $44 \%$ of the energy, petroleum nearly $17 \%$, and natural gas, nuclear and hydro about $13 \%$ each. Thus, this is where we are and the basic question is where do we go from here.

\subsection{Near-Term Role of Nuclear Power}

The near-term role of nuclear power will be analyzed by examining future electricity needs from several reliable sources, assessing the fuel alternatives which seem likely to be available for generating the electricity to meet these needs and examining nuclear power in the context of being "a last resort option". This approach seems appropriate in view of the current situation which finds nuclear power on shaky grounds because of unenthusiastic public and political acceptance, profound regulatory problems, and the financial constraints faced by the electric utilities in raising capital funds.

Table 4 gives the projections of electricity generation by fuels through 1988 as developed by the National Electric Reliability Council (NERC). The NERC projections are based on an annual survey of the utilities to determine fuel requirements for the projection of electricity in the United States for the next ten years. These fuel requirements are to a large extent determined for the next ten years by power plant construction decisions already made with approximately $80 \%$ of al1 new base load generating capacity to be added by 1988 now under construction. Therefore, they are based on what is perhaps the most reliable information available.

Table 5 represents an estimate of the primary energy input requirements into the generation of electricity up to the year 2010 and the fuel mix likely to be available for meeting these input requirements. Note 
Table 3: Domestic energy zonsumption by primary energy types ${ }^{a}$

(Total and electricity generation)

\begin{tabular}{|c|c|c|c|c|c|c|c|c|}
\hline & Ta:al & $\operatorname{Coal}^{b}$ & $\begin{array}{l}\text { Natural gas } \\
\text { (dry) }\end{array}$ & ?etrol & $\begin{array}{l}\text { Hydro } \\
\text { electric } \\
\text { power }\end{array}$ & $\begin{array}{l}\text { Nuclear } \\
\text { electric } \\
\text { Fcwer }\end{array}$ & $\begin{array}{l}\text { Net } \\
\text { coke } \\
\text { imports }\end{array}$ & other ${ }^{e}$. \\
\hline & & \multicolumn{7}{|c|}{ 1978. domestic energy colsumption by primary energy types } \\
\hline \multirow[t]{2}{*}{$\begin{array}{l}\text { Guads } \\
\stackrel{c}{i}\end{array}$} & $\begin{array}{l}78 .(10 \\
100.6\end{array}$ & $\begin{array}{l}14.07 \\
18.0\end{array}$ & $\begin{array}{l}19.81 \\
25.4\end{array}$ & $\begin{array}{l}37.81 \\
48.5\end{array}$ & $\begin{array}{l}3.15 \\
4.0\end{array}$ & $\begin{array}{l}2.98 \\
3.8\end{array}$ & $\begin{array}{l}0.13 \\
0.2\end{array}$ & $\begin{array}{l}0.07 \\
70.0\end{array}$ \\
\hline & \multicolumn{8}{|c|}{$\frac{\text { mary enersy by fuels to generate }}{\text { (incluling seneration losses) }}$} \\
\hline $\begin{array}{l}\text { Cuads } \\
\qquad \\
x\end{array}$ & 23.73 & $\begin{array}{l}10.37 \\
43.7\end{array}$ & $\begin{array}{l}3.29 \\
13.9\end{array}$ & $\begin{array}{l}3.91 \\
16.5\end{array}$ & $\begin{array}{l}3.11 \\
13.1\end{array}$ & $\begin{array}{l}2.98 \\
12.6\end{array}$ & & $\begin{array}{l}0.07 \\
0.3\end{array}$ \\
\hline
\end{tabular}

a Taken from DOE!'IEA Monthly Energy Review, April 1979, Fp. 10-12.

bIncludes bituminous coal, ligni=e, and anthracite coal.

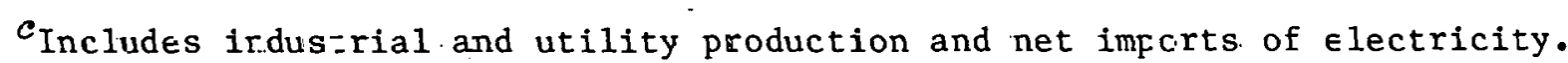

$d_{\text {Coke mede fror coal. }}$

Includes geothermal power and electricity produced from wood ard wastes. 
Table 4. Billions of $\mathrm{kWh}$ generated and projected $a$

(Contiguous U.S.)

\begin{tabular}{|c|c|c|c|c|c|c|}
\hline \multirow{2}{*}{ Fue 1} & \multicolumn{6}{|c|}{ Year } \\
\hline & 1978 & $\% b$ & 1980 & $\%$ & 1988 & $\% b$ \\
\hline Petroleum & 356 & 16 & 394 & 16 & 48 & 13 \\
\hline Natural gas & 295 & 13 & 240 & 10 & 120 & 3 \\
\hline Hyd ro & 278 & 13 & 236 & 10 & 243 & 7 \\
\hline Pumped storage & 11 & $<1$ & 12 & $<0.1$ & 22 & $<1$ \\
\hline Geotherma 1 & 3 & $<1$ & 6 & $<0.1$ & 15 & $<1$ \\
\hline Other & 1 & $<1$ & 9 & $<0.1$ & 10 & $<1$ \\
\hline Subtotal & 944 & 43 & 897 & 37 & 858 & 24 \\
\hline Coal 1 & 974 & 44 & 1177 & 48 & 1727 & 49 \\
\hline Nuclear & 278 & 13 & 365 & 15 & 959 & 27 \\
\hline Total & 2196 & 100 & 2439 & 100 & $3544^{c}$ & 100 \\
\hline
\end{tabular}

$a_{\text {National Electricity Reliability Council (NERC), }}$ 1979 Summary of Projected Peak Load, Generating Capability and Fossil Fuel Requirements - July 1979.

$b$ Derived.

${ }^{c}$ Annual growth of about 5\% between 1978 and 1988 . 
Table 5. Primary energy by fuels for generation of electricity (Quads)

\begin{tabular}{|c|c|c|c|c|c|c|c|c|}
\hline \multirow{2}{*}{ Fuel. } & \multicolumn{8}{|c|}{ Year } \\
\hline & $1978 a$ & $1980 b$ & $1985 b$ & 1990 & 1995 & 2000 & 2005 & 2010 \\
\hline $\begin{array}{l}\text { Projected tota } 1 \\
\text { requirement } c\end{array}$ & 23.7 & 26.0 & .32 .1 & 38.6 & 46.5 & 53.7 & 59.6 & 64.6 \\
\hline $\begin{array}{l}\text { Annual rate of } \\
\text { growth }(\%)\end{array}$ & & 4. & & 3.8 & 2.9 & 2.1 & 1.6 & \\
\hline NERC projections ${ }^{d}$ & & 26.6 & 33.5 & & & & & \\
\hline & & & el $\mathrm{Mix}^{b}$ & & & & & \\
\hline $\sin _{1}^{e}$ & 3.9 & 4.6 & 5.1 & 5.3 & 4.3 & 3.5 & 2.8 & 2.2 \\
\hline Natural gas $f^{f}$ & 3.3 & 2.6 & 1.7 & 0.9 & 0.5 & 0.3 & 0.1 & 0.1 \\
\hline Hyd ro. & 3.0 & 2.6 & 2.6 & 2.9 & 3.0 & 3.1 & 3.2 & 3.3 \\
\hline $\begin{array}{l}\text { Pumped storage } \\
\text { (PS). }\end{array}$ & & 0.2 & 0.3 & 0.3 & 0.4 & 0.5 & 0.6 & 0.7 \\
\hline Geotherm ${ }^{i}$ & $<0^{\circ} .1$ & $<0.1$ & 0.2 & 0.3 & 0.5 & $0 . \dot{8}$ & 1.4 & 2.2 \\
\hline Solar ${ }^{j}$ & 0.0 & $\leq 0.2$ & 0.2 & 0.3 & 0.4 & 1.0 & 2.0 & 4.0 \\
\hline Subtotal & 10.3 & 10.3 & 10.1 & 10.0 & 9.1 & 9.2 & 10.1 & 12.5 \\
\hline $\operatorname{Coa} 1^{k}$ & 10.4 & 12.5 & 15.5 & 17.6 & 25.4 & 32.2 & 37.2 & 39.8 \\
\hline $\begin{array}{l}\text { Nuclear }{ }^{2} \\
\text { (de facto moratorium) }\end{array}$ & 3.0 & 3.9 & 8.3 & 11.0 & 12.3 & $12.3^{p}$ & 12.3 & $\underline{12.3}$ \\
\hline Total & 23.7 & 26.7 & 33.9 & 38.6 & 46.5 & 53.7 & 59.6 & $64.6^{9}$ \\
\hline $\begin{array}{l}\text { Nus lear }{ }^{m} \\
\text { DOE } 1978 \text { projections } \\
\text { high, Quads }\end{array}$ & & & 7.9 & 12.4 & 17.8 & 25.6 & 31.1 & 38.2 \\
\hline $\begin{array}{l}\text { Coa } 1,{ }^{n} \text { rnmbined with high } \\
\text { nuclear, quads }\end{array}$ & & & 15.9 & lҺ.? & 19.9 & 18.9 & 18.4 & 13.9 \\
\hline $\begin{array}{l}\text { DOE } 1978 \text { projections } \\
\text { high, GWe }\end{array}$ & & & 122 & 192 & 275 & 395 & 480 & .590 \\
\hline $\begin{array}{l}\text { DOE } 1978 \text { projections } \\
\text { low, GWe }\end{array}$ & & & 100 & 157 & 200 & 255 & 275 & 295 \\
\hline
\end{tabular}

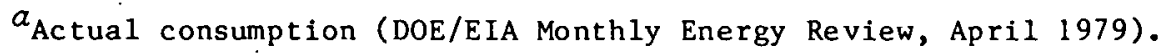

$b_{\text {Fuel mix }}$ based on NERC projections through 1985 using conversion ratios 11sted in body of report. Beyond 1985 fuel $\mathrm{mlx}$ projections adjusted as explained in body of report and in footnotes below.

CDerived from 29th Annual Electrical Industry Forecast, Electrical World (p. 67), September 1978 through 1995; beyond 1995 rate of growth reduced $25 \%$ each five-year period. 
$\mathrm{Bt} \mathrm{u} / \mathrm{kWh}$.

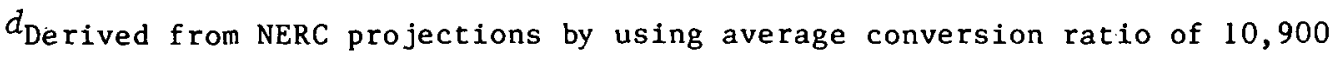

$e_{\text {Reduced }} 20 \%$ per each five-year period after 1990.

$f_{\text {After }} 1985$ reduced by the ratio of $1988 / 1985$ projected consumption.

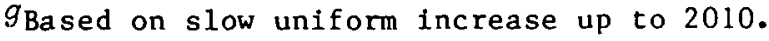

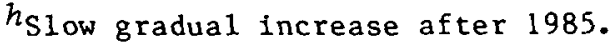

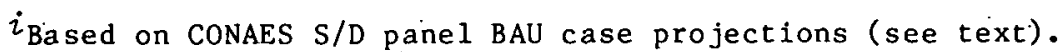

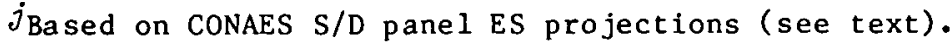

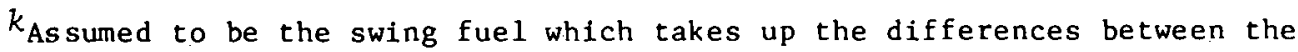
projected requirements and what will be provided by the other fuels including a constrained nuclear contribution.

$Z_{\text {Beyond }} 1978$ estimates based on capacities in Electrical World $1 / 15 / 79$ (p. 81) and a capactty factor of $68.5 \%$. Levels off after 1995 assuming no new plant commitments. The "de facto" moratorium is a methodology to illustrate that this is an improbable option (see text).

$m_{\mathrm{DOE}}$ projections indicate the primary input energy based on the high range of DOE projected.nuclear capacity operating at an average C.F. of $68.5 \%$.

$n_{\text {Represents }}$ the difference between projected input energy requirements and what will be provided by all the other fuels including a nonconstrained nuclear contribution.

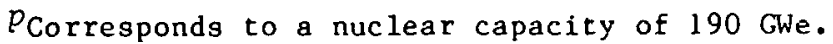

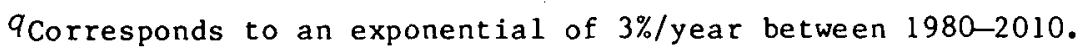


that although developed independently, these estimates fall near the middle of the DOE range of projections as shown in Fig. 2. The table was derived as follows:

Primary energy inputs for the generation of electricity

The primary energy input estimates up to the year 1995 were derived from the Edison Electric Institute's forecasts for electric utility sales as published in the September 15, 1978, issue of Electrical World (EW). The Electrical World forecasts were used instead of the NERC projections because they cover a longer time period (up to 1995), are in convenient 5 -year increments, and for the periods of overlap do not differ from the NERC projections by more than 2\%. (Note: The EW 1979 Forecast, now available, is from $1 \%$ to $2.5 \%$ lower than the 1978 estimates.) For the past eight years the ratio of net electric production to sales averaged about $110 \%$, thus the EW sales forecasts were adjusted accordingly to obtain approximate production estimates. Conversion from kWh to quads was based on the same ratio that prevailed for $1978(10,900 \mathrm{Btu} / \mathrm{kWh})$. The average growth in electricity generation during this period was $4.0 \% / y e a r$ which is significantly less than the historical growth rate which prevailed prior to 1974. In order to arrive at electricity production figures for the period 1995-2010, the annual growth rate was arbitrarily reduced $25 \%$ for each succeeding 5-year period on the assumption that there will be a steady decline in the growth rate of electricity consumption for the reasons listed earlier. The conclusions of the report are not strongly influenced by the growth rate chosen unless it should be significantly less than the values chosen. Should the growth rates be higher than what is assumed, nuclear must be implemented at a faster rate to avoid serious social economic disruptions.

$\underline{\text { Fuel } 1 \text { mix }}$

The fuel mix shown in the table was based on NERC estimates up to 1988 extrapolated to 1990. Beyond 1990 arbitrary adjustments were applied as explained in the footnotes to the table and based upon the following general assumptions. 
ORNL-DWG 80-4936 ETD

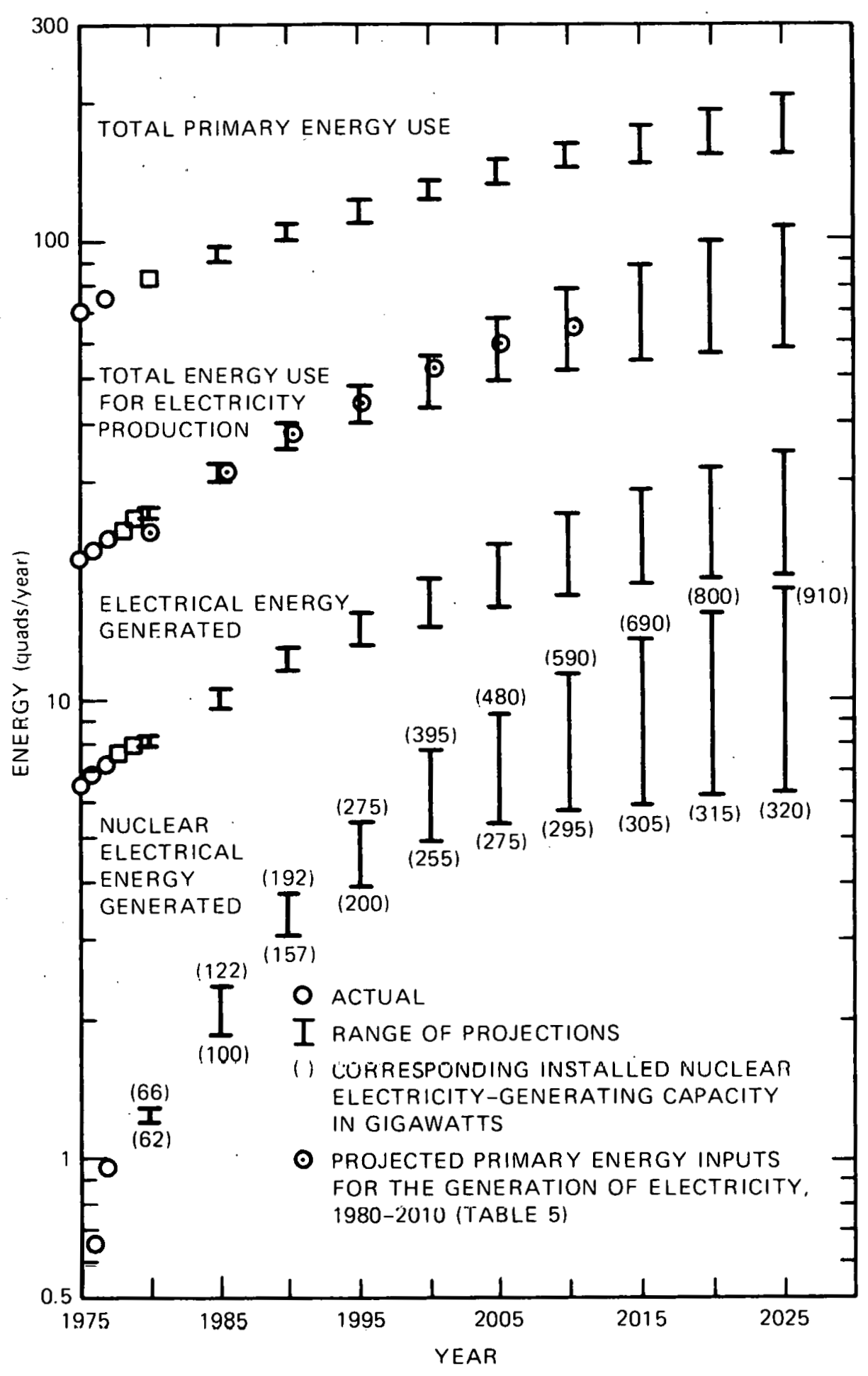

Figure 2. Projections for total energy, electrical energy, and nuclear energy generation, 1980-2025 (with corresponding nuclear generating capac1ty) 
Conversion from kWh to Btu's of primary energy inputs

The 1978 column represents the primary input energy equivalents to achieve the actual electricity generation for 1978 as given in Table 4. Equivalent Btus of input energy were derived from the energy consumptions for the various fuels and the kilowatt hours generated with each of the fuels as given in the DOE/EIA Monthly Energy Review, April 1979. These conversion ratios (listed below) for the various fuels are larger than the ones usually used but incorporate the lower efficiencies associated with the various modes of electricity generation in the base load and peaking cycles, and the energy contents of different types of a particular fuel sucli ds cual.

Btus of input energy per kWh for various fuels: Coal 10,630; petroleum 11,600; natural gas 10,800; nuclear 10,800; hydro 11,000; pumped storage 14,000; geotherma1 13,650; solar 19,400.

\subsubsection{Potential role of various fuels for generating electricity}

0i1. The amount of oil to be used for the generation of electricity will continue to increase up to about 1988 based on current utility power plant construction plans. However, beyond 1988, and perhaps sooner, the pressures to reduce the country's dependence on oil will bring about a reduction in its consumption for the generation of electricity. How rapidly this will take place is highly uncertain. The National Energy Plan II (Chapter IV) states, "...in the electricity sector, oil and gas use should be negligible by 2010." This may be more difficult to achieve for oil than for gas because oil-burning power plants operating in 1988 will be phased out gradually. To take this into account it has been assumed that oil consumption for the generation of electricity will be reduced $20 \%$ for each five-year period after 1990. This seems more likely to be an optimistic assumption with respect to oil than a pessimistic one and to the extent that it is optimistic the role of nuclear energy will be enhanced accordingly. The importance of oil for the generation of electricity is emphasized by noting that the equivalent of $22 \%$ of total oil imports goes for this purpose. 
Natural gas. Considerable confusion exists with respect to the status of natural gas for the generation of electricity. The National Energy Plan states that its use for this purpose should be negligible by the year 2000. The Fuel Use Act prohibits use of natural gas in new utility and large industrial boilers unless exemptions are granted by DOE. Due to the present surplus of natural gas, DOE has announced that it will grant temporary exemptions from the Fuel Use Act for up to five years to allow gas use in industrial boilers. Nevertheless, the use of gas for the generation of electricity has been declining since 1972; NERC projects this trend as continuing through 1988, and it is believed that the trend will continue until the use of gas is essentially phased out. .

Hydro. Although favorable sites for large capacity hydroelectric stations have been mostly developed, there still is a potential for further hydro development. Much of this potential is in the form of small capacity sites which though important will not add significantly to the existing hydro capacity. Some undeveloped large capacity sites exist but their development is constrained by environmental considerations. Taking all of these factors into account, it appears that hydro capacity might be increased by about $25 \%$ over the next 30 years, and the estimates in Table 5 are based on this assumption.

Pumped Storage. Pumped storage is treated separately from hydro and is assumed to increase at 0.1 quad per each five-year period after 1985 . This is roughly consistent with increases which occur up to 1987 . Note that pumped storage makes more efficient use of generating plants but resulls in slightly higher fuel consumpelon.

Geothermal and solar. Geothermal and solar energy for the generation of electricity are treated together since the estimates used in Table 5 for each of these energy sources are based on the CONAES Supply/Delivery Panel draft report. This group carefully assessed the future role of these energy sources under low (BAU), medium (ES), and high (NC) energy supply scenarios. The high national commitment scenario was realiy an upper limit to energy supply.options under the most optimistic assumptions and was not considered a likely possibility. The low business-as-usual scenario assumes a continuation of current conditions and trends, and the 
medium enhanced supply scenario was somewhere between these two extremes. Actually the low scenario may be optimistic if a strong trend develops to reduce energy growth, and the enhanced supply scenario may represent unreasonably high energy supply expectations. However, in view of current emphasis on solar, the enhanced supply case was used for this supply option; and for the converse reasons, geothermal estimates were based on the S/D Panel BAU case.

Coal and nuclear. Coal and nuclear are discussed together since jointly they must take up the slack in the fuel mix for electricity generation. The nuclear figures in Table 5 assume a constrained nuclear capacity limited to that which is now under contract. This is done to emr phasize the disbalances brought about from a de facto moratorium on nuclear power. Thus, the coal estimates represent the coal needed to make up the difference of primary input energy needed to meet the total projected electricity demands and what is proivded by the other fuels under the assumptions described above.

Table 5 illustrates the relative roles of nuclear power and coal if nuclear power growth is in accordance with the high DOE projections. Under this scenario, coal usage for the generation of electricity peaks at about 20 quads/yr near 1995 . This is a more realistic role for coal and one which is more achievable than the estimates prevailing under the constrained nuclear case which go up to nearly 40 quads/yr.

The following analysis illustrates the crucial role which coal has in the country's future energy supply picture, and its direct effect on the role of nuclear power.

By 1985 coal requirements for the generation of electricity and other needs will be more than 1 bilition ton per year assuming no growth in other coal requirements. To supply this amount of coal requires a $6 \%$ annual increase in coal production and transportation. While this is not an unreasonable expectation, experience indicates that such an achievement is not free of major problems and constraints. Also should oil not be available in the amount indicated, then the annual coal production increase would have to be greater than $6 \% /$ year in order to replace the oil shortfall. If 
oil is available for the generation of electricity in the amounts estimated, the 1985 electricity requirements can be met without too much difficulty provided nuclear meets its projected share of the needs since its role though sma11 is crucial and if it is not available something else will have to give.

By 1990 oil will still be used in large amounts, but the projected coal need has not increased greatly and five additional years will have been available in which to increase production. However, at this point in future time the country must give serious attention to having alternative sources to natural oil for liquid fuels, and at present synfuels from coal seem to be the preferred way to go. About 150 million tons of coal will produce about 2 quads of synfuels which indicates that the coal requirements to replace only a small portion of our 1 iquid fuel needs will be very large relative to present coal production rates.

By the year 2000, nearly 2 million bbls/day of oil are projected for the generation of electricity, and coal requirements based on a constrained nuclear power case will be in the range of at least 2 to 2.5 billion tons/year, depending on the size of the coal synfuels industry.

By 2010 about 1 million bbls/day (nearly 2 quads/yr) of oil and hopefully about 6 quads/year of solar and geothermal are projected as being available for the generation of electricty. Assuming that 4 quads/year of input energy are available from hydro and 12 quads/year from nuclear, this leaves 40 quads/year to be made up by coal, representing a production rate of about 2 billion tons/year, three times the present annual production. Providing additional coal for the manufacture of synfuels could increase the coal supply needs to the neighborhood of $21 / 2$ to 3 billion tons/year. This estimate includes only a relatively small amount of coal for export. However, the WAES study ${ }^{7}$ estimates a U.S. potential for coal export of 250 to 650 million tons of coal per year by the year 2000. Thus, the needs for coal might well exceed 3 billion tons/year by 2010 short of a significant incrcased contribution from nuclear.

However, should nuclear power be developed as depicted in Table 5, the demand for coal for the generation of electricity will peak at about 1 billion tons/year, and a total coal production of 2 billion tons/year would provide for about 6 t.n 10 quads of synfuels. 
Conclusions on fuel options for the generation of electricity. In line with the above observations, some general conclusions on the projected fuel mix for the generation of electricity for the next 30 to 35 years are:

a. Despite its high cost and the country's extreme vulnerability to imported oil, there continues to be strong dependence on oil for the generation of electricity. This is an unstable situation which could change suddenly and violently; prudent planning would dictate that a fall-back position be provided.

b. Natural gas is slowly being phased out as a fuel for the generation of electricity. There may be a short-term reversal of this trend, but by 2010 the use of natural gas. for this purpose should be practically phased out. In the event of an oil crisis, natural gas would be called upon to replace oil, but it is unlikely to become available in the large amounts needed for the generation of large amounts of eleccriclcy.

c. Hydro has an important but limited role in the generation of electricity, but it cannot be expanded to compensate for an unexpected oil shortage or to compensate for the lack of other fuels.

d. Geothermal and solar energy for electricity generation seem certain to grow in importance; but both of these options are faced with difficult problems and great uncertainties. Thus, it is extremely difficult to project their role with any degree of precision or confidence. This report's projections of 6 quads of primary input energy (less than 1.5 quads of output electrical energy) are highly speculative, and it is difficult to make a convincing case that these two options will be developed any more rapidly than indicated.

e. Coal will replace oil as the swing fuel in the intermediate future. Coal can be substituted for the generation of electricity, for oil and gas in certain industrial and restdenlial uses, and as a sourcc of liquid and gaseous synthetic fuels to replace natural oil and gas. Thus, it has great flexibility. However, this flexibility puts great demands upon cos?, and to meet the projected demands implies production and consumption levels by 2010 which are four to six times prevailing rates. This not only poses very difficult production and transportation problems but also may be unacceptable environmentally. Thus, there is serious 
doubt as to whether coal can be used to meet all of its projected needs, and it would be very unwise to depend primarily upon coal to meet the future energy needs of the country. This situation for coal coupled with the uncertainty of future oil supplies and the unavailability of alternative energy sources, clearly points to nuclear as a badly needed major backup energy source.

f. The growth in electricity generation projected in Table 5 corresponds to an average compound growth of $3 \%$ per year between 1980 and 2010 . Although this is a low rate of growth compared to the past 30 to 35 years, it conceivably could be less particularly if oil and gas should become un available for the generation of electricity. Should there be no growth in electricity generation between 1980 and 2010, and should the use of oil and gas for this use be phased out, there would need to be about 21 quads of primary energy inputs from coal, nuclear, geothermal and solar. As explained previously, there are serious questions on whether coal can be depended upon to contribute this amount of energy to the generation of electricity. The role of geothermal and solar is speculative and uncertain. Therefore, it appears that nuclear must be depended upon to generate some amount of electricity during this period. The 12 quads of nuclear primary energy inputs under the "de facto moratorium" case would be sufficient under this no electricity growth assumption, but whether a viable industry could be maintained in such a situation is questionable.

g. An alternative not discussed explicitly is to drastically reduce the country's total energy consumption. The estimates summarized in Table 5 assume a significant reduction in the growth of electrical energy, and it may be that conservation could force even faster reductions in energy growth. However, pushed too fast, reductions in energy consumption could conceivably have a revolutionary impact upon the country's political and socioeconomic structures. The results of these impacts are unpredictable, but potentially they are sufficiently drastic to pose a political risk which the country would be unwilling to take voluntarily. Reductions in growth rates of energy consumption which are not significantly less than the projections of this report would not change the basic conclusions but would affect the time and degree to which the various options would be implemented. 


\subsubsection{Conclusions regarding the near-term role of nuclear power}

In summary, the near-term role of nuclear power is to share with coal in the base load generation of electricity and in so doing reduce our dependence and vulnerability to imported oil. However, at present nuclear power is constrained and little can be done to increase its role between now and until about 1990. At the same time even in its limited role nuclear power is a critical element in the electric supply picture and a reduction in this role for any reason will accentuate the nation's vulnerability to imported oil and possible inadequate supplies of electricity.

Even though the utilities find nuclear power unattractive at present because of financial strains and the many uncertainties surrounding the building of nuclear power plants, nuclear power probably will survive because:

- oil and gas are being phased out,

- coal faces equally difficult problems,

- solar is not competitive, and

- geothermal faces uncertain economic and technical issues.

This means that plans should be laid now to increase and strengthen nuclear power's role in the generation of electricity as rapidly as possible which practically means after about 1990. 'The period between 1990 and 2010 will be a critical one for the reasons listed above, and it is during this period that the role of nuclear power is most apparent. Dus luy Llıis period the projections of Table 5 indicate that unless nuclear assumes a much greater role than it now has, the demands upon coal may be unsustainable. In addition, the country will still be heavily dependent upon an unstable oil supply for other uses in addition to use for the generation of electricity. In the year 2000, for example, oil is projected as having nearly as strong a role in the generation of electricity as it had in 1978, a role which for many reasons must be reduced. Hence it seems clear that sound national policy dictates an expanding role for nuclear power during the next 10 to 30 years. 
Considering the stalemate in which we now find ourselves with respect to nuclear power, the highest priority near-term goal may be to.find ways to enhance the nuclear option. The critical element in this regard is the general public since the public, acting through the government, will uicimately determine how much nuclear power will be used. There are certain key steps which can be taken to make nuclear power more attractive to the public. These include:

- development of safer reactors/improving design margins,

- demonstration of nuclear waste disposal,

- development of acceptable methods for handling the tailing wastes from uranium mining and processing, and

- improvement of LWR reliability and economics.

In the past AEC/ERDA/DOE has concentrated on advanced nuclear technology and essentially ignored the above items. This must be corrected in the near-term future.

\subsection{Long Range Goal of Nuclear Power}

\subsubsection{Generation of electricity}

The longer range prospects for nuclear power are more sanguine than the immediate future. As pointed out earlier in this report, beyond 20 to 30 years ahead one must depend upon broad strategies which can encompass future trends and identify the various options that are most likely to be available for meeting needs emerging from these trends. From this viewpoint the longer range outlook for nuclear power appears to be more positive primarily because of a narrower range of options likely to be available. Beyond 2010 oil and gas will be in even shorter supply than they are today, the burning of coal may be approaching a practical limit, natural hydro power will be approaching the limit of its potential capacity, and geothermal and solar energy for the generation of electricity face technological and economic issues which render their future out look highly speculative and uncertain. This leaves nuclear as the main, dependable energy source for the generation of electricity. 
In view of the current political and technical restraints, it is likely that most of the new nuclear capacity over the next 10 to 30 years will be once-through LWRs. This places increased emphasis on resource exploration and development to assure adequate supplies of uranium to support the needed capacity. According to the NASAP analysis nuclear power in the form of once-through LWRs may hit uranium resource constraints sometime between 2000 and 2025. The NASAP analysis further indicates that certain specific steps* can be taken which will extend the present resource base and use it more effectively. These steps if successful would provide sufficient resources to support nuclear growth to 600 GWe through 2025. Fucl recycle would extend this period or the capacity supported. However, there are others 8,9 who are less optimistic and conclude that only about half of this capacity ( $300 \mathrm{GWe})$ can be supported with the uranium resources which realistically can be expected to be found and produced by the time needed. Fuel recycle would permit about $50 \%$ more capacity to be supported.

This wide range of uncertainty in the fuel resource situation argues for not only taking the steps described above but also for developing other reactor options to supplement and eventually replace the LWRs. There has been much discussion and many analyses over what fuel cycle options should be developed - whether the nation should develop advanced converters, breeders, or both, and which of the advanced converters or breeders should be developed. Although the arguments pro and con for the -various options could be summarized and the crux of the analyses repeated, it is believed that the purposes of this paper can best be served by arriving at some conclusions, which, though debatable, are supportable. Considering the vulnerability of this nation to critical energy supplies over which it lacks control, and the uncertainities which beset the development of various energy supply options, prudent planning dictates moving in the direction of providing redundancy through maintaining the options for both an advanced converter system and a breeder system. Our

*The steps are more uranium-efficient LWRs, increased uranium exploration, improved processes for exploiting low-grade ores, and enrichment plant tails-stripping via advanced isotope separation processes. 
choice of the advanced converter system is the HTGR for the following reasons:

- It provides an approach to nuclear power which is different and independent of the LWR and might eventually be publicly acceptable should the LWR be rejected for safety reasons.

- It can be designed to make very effective use of resources.

- The technology is at a stage where it offers an intermediate-term possibility of commercialization in the event of an LWR construction moratorium.

- It has a long-term potential as a process heat source.

- It can operate more effectively than other options on a dry, or wet-dry, cooling cycle.

- Some of the technology can be used by a GCFR if developed.

- The potential economics seem favorable.

The development of a breeder reactor option is considered essential in order to provide a long-term supply alternative which is sustainable for thousands of years. Here we are defining breeder as a fissile fuel producer. The most obvious possibilities are fast breeders, LMFBR, or possibly GCFR. We opt for the LMFBR because of the large supporting technological base and because since many of the industrialized countries of the world are developing the LMFBR there will be large and diversified sources of experience to draw from. Since there is some uncertainty as to when a breeder will be needed, the mission should be to demonstrate the LMFBR on a meaningful scale so that a positive decision to deploy the breeder can be made when needed (which may be soon after the year 2000). Other breeders than LMFBRs and GCFRs might potentially be developed (MSRs or fission-fusion hybrids), but they will take at least 20 years longer than the LMFBR.

Since recycle fuel is essential to having advanced converters and/or breeders, an essential item in the long range is to develop and demonstrate fuel reprocessing and recycle for LWR type fuels, LMFBR fuels, and HTGR fuels. This aspect of the nuclear power program cannot be overemphasized. 
In summary, the primary mission of nuclear power beyond 2010 is to develop and retain sufficient flexibility in the various nuclear options that the country can move rapidly and confidently in whatever directions the events of the next 20 years indicate to be desirable in order to meet the country's future energy needs and decrease our dependence and vulnerability to import supplies. Even with the amounts of nuclear power which can with reasonable assurance be developed by 2000 , the country remains vulnerable unless effective measures are taken to slow the rate of energy growth and assure that coal can be mined and consumed in much larger amounts than at present. Eventually, nuclear power should be envisioned as a long-term "inexhaustible" energy supply which can be used for the generation of electricity (which in turn can be substituted for other fuels), for the manufacture of fuel substitutes such as hydrogen, and as a source of process heat. In this sense it is a competitor to solar and geothermal energy as a long-term source of energy supply. Only a breeder reactor can meet the long-term "sustainability" requirement, hence the development and demonstration of a breeder reactor is an essential element in the long-term future of nuclear power.

\subsubsection{Other uses of nuclear power}

Process heat. Thus far in this report nuclear energy has been viewed as an energy source for the generation of electrical power. However, as natural oil and gas become increasingly scarce, there is a potential mission for nuclear energy as a supplier of industrial process heat. In 1978 the industrial sector used about $36 \%$ of the total primary energy, including electricity, consumed in the United States and $24 \%$ of the total primary energy exclusive of the electricity consumed by industry. of this $24 \%$ nonelectrical primary energy, nearly $81 \%$ came from natural gas and petroleum. As thesc form of fucl become mure cubly dud less available, they must be replaced by coal, nuclear energy, or electricity. An ORNL 1975 report ${ }^{10}$ assessed the relative uses of coal and nuclear in this regard and concluded that coal is expected to be the more important substitute industrial fuel up to 1990, but that in the longer term, nuclear fuels could assume a major role for supplying industrial steam. Significant changes have taken place since 1975 with respect to the economic 
postures of both coal and nuclear energy, but the general conclusions of this report seem to still be valid. Should providing industrial heat become a mission of nuclear energy, it will require consideration of different reactor designs and concepts, such as small LWRs or High Temperature Gas Cooled Reactors (HTGRs).

District heating. Occasionally central power stations or other central sources of heat provide space heat for homes, industries, or businesses in areas where the load demand is sufficiently high and the transportation distances not too long. With increased emphasis on conservation and the higher cost of fuels, such utilization could receive more attention in the future. Also from time to time studies have been made on the use of nuclear power for this purpose. However, the use of nuclear energy for this purpose has always been marginal because nuclear plants are sited long distances from population centers and the heat capacity of central station nuclear plants is so great that, if effectively used, it would have to be distributed over large, densely populated areas. This situation will become more adverse in the future since the post-TMI trend will be to locate nuclear power plants even further away from population centers. Some existing plants are located close enough to population centers that they are likely candidates for district heating. Bauman ${ }^{1}$ in an $11 / 2 / 79$ study listed all nuclear plants in the colder regions of the United States that lie within 50 miles of cities of at least 50,000 population. Some of these might have a potential for meeting a district heating utilization criterion but the total amount of energy involved will be small and the economics marginal. Therefore, at this time district heating does not seem to be a major potential role for nuclear power because of the likelihood of remote siting of reactors.

\subsection{Role of Nuclear Power in the World Context}

The role of nuclear power in other countries will be significantly different from what it is in the United States because of variations in the nuclear resource bases, the availability of alternative fuels, the technological capabilities, and the size of the electricity generating 
systems. The United States, though short of oil and gas for its own needs, still has domestic oil and gas resources which are much more abundant than those of most countries of the world. We also have more abundant supplies of coal (an estimated $1 / 3$ of the world's resources) and oil shales than other countries and as a result have more freedom and flexibility to substitute one form of energy for another. The USSR, Canada, and China also have large fossil fuel resources and can delay large commitments to nuclear. This is not true for most other countries of the world. Those with the fewest resources and therefore most likely to be dependent upon nuclear are Western Europe, Japan, South Korea, and Brazil. The developed nations, most of whom are short of energy, are engaged in an intensive nuclear program which includes construction of LWRs or their national equivalent, development of the liquid metal breeder reactor, and development and implementation of fuel recycle so as to lessen dependence upon imported uranium.

The underdeveloped countries have a much lower demand for energy than the developed countries, but their rate of growth in energy consumption is generally higher than in the developed countries, ${ }^{12}$ and their aspirations are growing in spite of energy resource limitations. To the extent that they can afford and obtain fossil energy supplies, this is the preferred direction for them to move. However, should fossil energy sources not be available because of inadequacy, costs, or other reasons, more and more of these countries will seek the nuclear route to energy adequacy. This indicates that in the future a larger and larger number of these countries will be trying to develop their own nuclear capability. This is particularly true since nuclear power can compete with coal in most countries even if there, were a fivefold increase in uranium prices. For them to go the nuclear route will require help from more technically advanced countrico. The United Etates is a traditional and logical suirce of such assistance, and to the extent we comply with this need it could enhance our international stance and our own nuclear program. However, if much help is not available from the United States, it will be sought from other countries.

From a world point of view, the rate of energy supply expansion is critically dependent on the availability of nuclear technology and fuel. 
This is true because of constraints on alternatives, especially limitations in supply of fossil fuels. Thus, desires to limit transfer of nuclear technology because of concern about nuclear weapons proliferation are in direct conflict with desires to avoid international warfare over diminishing quantities of fossil fuel.

The WAES Report-V3 estimates the most likely maximum and minimum estimates of the non-Communist world's nuclear capacities for the year 2000 . to be 1772 and 913 GWe respectively.* This represents 43 and $22 \%$ respectively of the primary energy input for these countries. The ranges of estimated U.S. nuclear capacities for 2000 are 395 and 255 GWe, which is between 22 and $28 \%$ of the expected world capacity. These figures indicate that the nuclear mission outside the U.S. is several times greater, and is growing faster than what is expected for the U.S. Many of these plants are expected to be built in countries which have no - or only a limited supply of - uranium. Hence, it is logical to anticipate that these countries will develop fuel recycle capabilities and will supplement their LWR reactor capability with more advanced types, with preference being for the LMFBR.

Another aspect of nuclear power from a world point of view is that nuclear power is an important element of a geopolitical strategy for national security and energy self-sufficiency. Proponents of energy selfsufficiency as a geopolitical goal claim that a major power cannot retain its security if secondary powers can cut off food, energy, strategic materials, etc. In fact a long time political goal of the U.S.S.R. is believed to be a cut off of the capitalistic countries from their sources of supply which would reduce them to impotence as world powers.

Energy self-sufficiency would not only enhance our national security but would also stop one of the main driving forces for rapid inflation, remove a major cause for erosion in the value of American currency, and

*The October 1978 INFCE projections were 850-1200 GWe. DOE-EIA currently projects even less world nuclear capacity for the year 2000 . However, the relative importance of nuclear power outside the United States remains greater than its importance to the United States, where projections have also been reduced. 
stop arbitrary oil prices to the benefit of all non-oil-producing countries of the world. The achievement of these goals would immeasurably strengthen the country both internally and in the world. There are other nonnuclear elements to an energy self-sufficiency strategy such as: replacement of oil usage with coal, synfuels from coal and shale, gas production from unconventional sources, and developing strong incentives for conservation. Examples of countries trying. to pursue such a strategy are the U.S.S.R. and France. Energy non-self-sufficiency has external costs such as susceptibility to supply interruptions, political pressures and higher defense budgets. In some ways, these external costs are analogous to the external costs associated with environmental impacts. Society can therefore anticipate external costs associated with both abundant energy supply and with inadequate energy supply. Great skill is required to integrate these considerations and arrive at optimal energy growth, including nuclear power growth. 


\section{OVERVIEW OF MAJOR ISSUES}

\subsection{Public Acceptance}

\subsubsection{Introduction}

In the past ten years an important new element has been introduced into the nuclear power issue which may dominate all other considerations - this is public acceptability of nuclear energy. Public acceptability implies adherence to safety and environmental standards beyond those that would be a part of the usual economic analysis and hence these are a part of this consideration. In discussing public acceptability, there must be an understanding of which of the many different types of publics are referred to. This paper will consider two publics: the general public, meaning all the people of the nation; and the special interests publics meaning those having common interests, goals, or characteristics. This latter group consists of many publics each having different interests or goals, but for the purpose of this analysis they can be treated as one category.

As recently as 15 to 20 years ago the utilities could confidently count on the public accepting their judgement on what form of power plant was best to provide a reliable and adequate source of electricity. In fact the public usually was so indifferent that the utilities, in conjunction with the public service commissions, made the decision unchallenged. However, this situation changed as the public became more environmentally conscious, with the result that organized groups began to challenge the utilities on certain aspects of their power plant construction and operations program. Historically, the earlier protests were not aimed at nuclear power but at hydro-generating plants such as the Storm King Mountain Hydro Storage Project in New York and coal-fired plants for their emission of gaseous pollutants. Nuclear plants first came under close scrutiny when certain environmental and fishery groups began to worry about the increased amounts of waste heat released to cooling waters by nuclear power plants. The Consolidated Edison Company's Indian Point 1 nuclear plant was an early target of these groups. This was soon followed by other similar cases. 
Chapter 2 on the History and Status of Nuclear Power traces the history of increased opposition to nuclear power plants hy special interest publics from the late 1960 s to the present. The increase of this opposition over the past ten years does not necessarily indicate that the percentage of the general public supporting nuclear power has decreased but rather that the relatively small organized special interest groups have increased in number and activity. A factor which stimulated this growth was favorable court decisions which opened for intervention all phases of the nuclear plant licensing and regulatory process. This permitted the opposition groups to obstruct and delay nuclear plants, resulting in great increases in costs and construction times. The tactic is to increase the cost of electricity from nuclear plants to where they are no longer compericlve with alternative tuels, or to where the general public rebels at the higher electricity costs. Overlapping these factors is the strategy of creating an atmosphere of confusion and uncertainty in which it is difficult for the utilities or the govermental regulatory bodies to work smoothly and assuredly, thus undermining public confidence in these institutions.

Some of the early special interest groups did not particularly oppose nuclear as a form of energy but were more interested in afferting the regulatory standards to improve the safety or to increase the envirnnmental protection features of a plant. However, with some early successes the group increased their demands and were at the same time joined by other groups who had more radical political or social goals involving nuclear power. Consequently the dominant goal of the special interest groups has changed from one of modification of nuclear power plants to one of stopping nuclear power completely. Since the total population of these special interest groups is a very small fraction of the total population, it became important for their cause for them to involve a large percentage of the general public in order to increase their political influence. To this end they professed to represent larger segments of the public than they actually did, and simultaneously they adopted tactics aimed at influencing the general public to their point of view. Indications are that they are having some success in this regard, primarily through converting former uncommitted members of the public to an antinuclear position. 
This report will include brief discussions on the history and nature of public concerns, the effect of the Three Mile Island (TMI) accident, future concerns, and conclusions on public acceptance of nuclear power.

\subsubsection{History and nature of public concerns}

Public concerns about nuclear energy have existed since 1946 when publicly released information on atomic weapons provided dramatic evidence that here was a new and revolutionary source of energy with potential benefits and problems unlike anything previously experienced. The public did not fully understand the implications of this new form of energy, but there were from the beginning, manifestations of concerns relating to the possibility of nuclear war, the proliferating development of nuclear weapons and the dangers of fallout from the nuclear testing. Although stemming from the military applications of nuclear energy, these concerns were inseparably linked to nuclear energy in whatever form and thus automatically transferable from the military program to its peaceful nuclear energy off-shoot. Thus, as peaceful nuclear energy grew, the public's interests and concerns about nuclear power grew proportionately.

Everyone has his own impressions and prejudices as to what the major public concerns about nuclear energy really are. The ones most frequently mentioned are the trilogy of safeguarding of plutonium, disposal of radioactive wastes, and the safety of reactors; but these are technical issues and the evidence indicates that the concerns of some segements of the public are much broader than these. In fact, even a cursory perusal of the communications media outputs will show that the concerns receiving the most attention are most often of a political nature with only enough technical overtones to tie them to nuclear energy in a sensational and misleading way.

A survey of a number of public information sources provided a representative sampling of the gamut of issues that disturb the various segments of the public. Such a survey produced a list of more than 200 concerns, each differing in some way from the others. This list of specific issues clearly illustrated the number and variety of nuclear energy questions that are being raised. However, this long list of concerns can be condensed to five broad categories: (1) technical, (2) environmental, 
(3) socioeconomic, (4) political, and (5) ethical. The five categories could have been chosen differently, and a different categorization is given in the section on future concerns. In both cases; however, the categorizations demonstrate that concerns held by different people are much broader and include less tangible items than just the technical issues, and it may be that the technical category is the simplest and easiest of all to deal with.

Also, over the past 30 to 35 years many statistical surveys have been conducted in attempts to identify the types of nuclear energy concerns perceived by the public and to assess public attitudes with respect to the acceptance or rejection of nuclear power. These surveys found that the specific technical concerns about nuclear energy were nuclear safety, radiation health and genetic effects, and the safe disposal of radioactive wastes. The advantages of nuclear power as perceived by the general public were its economic benefits, unlimlted supply of fuel, and being a clean source of energy. Interestingly, the political concerns of current interest, namely nuclear safeguards, terrorism, and proliferation of nuclear weapons, we re rarely mentioned. 13 Thus, even though public statements evidence a wide range of concerns as indicated by the earlier described media survey, when narrowed to specific issues, they become simpler and more direct.

This apparent discrepancy in the complexity of concerns as perceived by the public versus what the media reports may be due to the meaning of public. The general public has been less active in raising concerns about nuclear energy than organized segments of the special interests public, i.e., citizens' groups, self-appointed public interest groups, local residents affected by nuclear power plant construction, scientists, 1abor unions, environmentalists and others. Also the special interests groups, partly becausc of the scnsational nature of their claime, have been more successful in getting the attention of the various communications media and their concerns have been given wider public distribution. Under these circumstances, public opinion polls may not reflect the full range of the concerns which are being raised and publicized, but they do reflect those concerns which are uppermost in the minds of the general public. 
In addition, these public surveys provide a measure of the general public's acceptance of nuclear power. The pre-TMI surveys, for example, indicated that about $60 \%$ of the public favored nuclear power, approximately $23 \%$ were opposed to it, and the remaining approximately $17 \%$ were undecided. 14 It will be noted that this situation has changed somewhat since the Three Mile Island.

\subsubsection{Effects of TMI}

The March 28, 1979, TMI Nuclear Plant accident was unquestionably the worst nuclear plant accident to occur in the United States and perhaps the world. As such it emoted such strong public and political reactions that it almost certainly represents a watershed in the development of nuclear power, whether in a more positive or more negative direction remaining to be seen. It certainly increased the general public's sensitivity to the nuclear power issues with respect to both its benefits and risks. It also accentuated the general public's concern about nuclear power and for the time being shook the public's confidence in the safety and reliability of nuclear power plants and their credibility in the government and the electric utilities. The key uncertainity is the direction in which public attitudes will move nuclear power in the future.

TMI also stimulated a great increase in public opinion polls and the results of these polls succinctly summarize the status of public concerns at the present time.

Louis Harris and Associates' polls, past and present, showed that the percentage of the public favoring nuclear power versus those opposing it was 58-31 - 1ate 1978; 47-45 - Apri1 1979; 52-42 - May 1979; 51-41 - June 1979; and 56-37 - August 1979. These results indicate that public support for nuclear power descended to a historic low then rebounded to a large extent from the April lows. However, it is still below the October 1978 level of 58-31 and much lower than the 1975-76 survey results of 60-23. Also the margin of support for nuclear power does not reflect the intensity of the opposition whose cause has been fueled by TMI. The Harris polls show that the public remains concerned about reactor safety and radiation effects, but on the other side there is also a growing public concern nver a possible inadequacy of supplies. In net balance it appears 
that public attitudes toward nuclear power are probably more durable than had previously been thought because, if anything was going to shake the confidence in nuclear power, it was TMI; but we are still short of having a publicly perceived vote of confidence for nuclear power.

Another output of TMI is a possible regulatory concern over the siting of reactors too close to high population density areas. The outcome of this concern could be a policy favoring remote sites for nuclear power plants. Such a policy, along with a likely increase of emphasis on enhanced capability for responding to reactor accidents could eventually lead to the concentration of reactors in nuclear energy centers (NEC).

\subsubsection{Future concerns}

Assessing future concerns about nuclear power is difficult and uncertain. Nonetheless, it is an important element in analyzing the future directions of nuclear power. A George Washington University (GWU) conducted study for DOE's NASAP program dealt with the question of "Public Concerns and Alternative Nuclear Power Systems," analyzing the concerns related to the present light water reactors as a base of comparison with alternative fuel cycle options. Hence, the GWU study is relevant to the subject of this section.

The approach taken by GWU for assessing the public acceptability of a nuclear power system included two elements: (1) a set of concerns which covers the range of concerns likely to be expressed by the general and attentive (special interests) publics, and (2) a method for evaluating the significance of concerns for public acceptance. The range of concerns was developed using public opinion surveys, literature by segments of the public concerned about nuclear power, and discussions with experts on public att1tudes toward nuclear power. These surveys resulted in GWU identifying over 100 specific issues of public concern. They then grouped these issues under thirteen general concerns which will be identified later.

The significance of a concern was taken broadly by GWU to mean the level of difficulty in resolving a concern and the time and cost of proving acceptability to the public. By resolution, is meant developing widespread confidence in the abilities of institutions to control risks of nuclear power development. A lack of resolution is assumed to provide a 
continuing source of challenges to the institutions introducing nuclear systems. GWU then ranked the concerns according to their significance as measured by nine so-called dimensions of the concern... Using these criteria they found the most significant future public concerns to be:

foreign sạfeguards, integrity and competence of institutions, economic viability and international position, future generations, and the least significant to be: radiological and chemical health hazards; environmental pollution, distribution of costs and benefits, relative costs of nuclear power, and the middle five concerns to be: materials diversion, low level radiation, sabotage, catastrophic accident, and individual rights.

Several things are of interest with respect to the GWU analysis. For example, catastrophic accident which was the paramount concern stemming from TMI is not ranked as a highly significant concern but falls in the middle category. Also, waste disposal and weapons proliferation do not show up in the list of thirteen specific concerns although the former is a significant issue to the public and the latter is a critical political issue. GWU's explanation for this is that the waste disposal problem is made up of a variety of concerns, and proliferation was broken up into its two components, foreign safeguards and domestic materials diversion.

The GWU study was practically complete by the time of the TMI accident so their analysis does not reflect the situation that has developed since. There has been much written and spoken on this situation and how it has affected public concerns on nuclear power. . No attempt has been made to do a thorough analysis of future public concerns as influenced by the TMI accident, but a few samplings of comments and statements will be 
of interest even if providing only limited enlightenment. Pokerny of Cambridge Reports reported that their public sampling indicated that the major reasons of the public for favoring nuclear power were:

1. We need the power.

2. Nuclear is cheaper.

3. It's good if its safe.

4. There is no alternative.

The reasons against were:

1. It is too dangerous.

2. TMI convinced me it's not safc.

3. Solar power is better.

Pokorny also points out that energy has replaced inflation as the number one issue concerning the public and that TMI has impressed a lot of the public with the role that nuclear power must play in the energy picture.

Paul Turner, Vice President of Atomic Industrial Forum (AIF), sees radiation effects rather than safety being the principal issue for the nuclear industry. Comstock of Northern States Power Company thinks that we need to work to demythologize radiation and to separate nuclear power from nuclear weapons, since the two are entangled in the public's mind. Comstock also sees less public acceptance of science in general, a new questioning of the corporation's role, and increased public concern over johs and energy supplies.

Richard T. Kennedy, NRC Commissioner, thinks that for the past two or three years safety of nuclear plants has not been as much of an issup as safeguard matters, the dangers of plutonium, transportation of nuclear materials, and waste storage and economics; but it must be remembered that Commissioner Kennedy deals mostly with the special interest public. Chauncey Starr (EPRI) believes that basically the antinuclear position is that nuclear proponents are seeking to develop an energy future that is not soclally responsible. This comment is buttressed by the National Council of Churches and the World Council of Churches adopting resolutions condemning nuclear power because it fails to measure up to their criteria of a just, susta1nable, and participatory world. Finally, Governor Thornburg of Pennsylvania summarizes the situation nicely by his statement that 
he has reservations as to the future of nuclear power, that his sensitivities on the issue have been raised by TMI, and that the state and locaI authorities and the public at large will have a great deal to say on this matter.

One critically important future concern on nuclear power is on the financial risks involved which were brought to the fore so suddenly and dramatically by TMI. This concern is not one of the general pubiic, but of special interests groups such as the utilities, the utility stockholders, insurance companies, investment bankers, and Wall street stock brokers, in general. Financial analysts and economists foresee severe financial difficulties for nuclear plants resulting from: uncertainty about future operability of nuclear plants if the current regulatory trend continues, delays in licensing due to NRC confusion and uncertainty aggravated by NRC manpower storages, increasing political opposition to nuclear plants, the financial risks associated with a possible nuclear plant accident, and the increased cancellation of nuclear plants should a recession develop.

These various comments and other developments make it clear that the picture of what future public concerns will be is hazy due to the doubt and uncertainty as to what will finally emerge and in what direction it will take nuclear power. Some things stand out, however. One is that public sensitivities have been aroused and that the public is in the mood for and demanding more and better information on nuclear power. Dr. Starr doubts that making plentiful information available has any impact on public acceptance of nuclear power, but this could indicate a need for more discrimination in the type and amount of information passed on to the public. For example, there is a great lack of public understanding on radiation itself, which is inherent to nuclear power. Therefore, efforts to demythologize radiation and place it in perspective with respect to natural radiation might be extremely helpful to better public understanding. Senator Hart has commented on the difficulty which the public has in understanding nuclear energy, asserting that nuclear energy is "ordered and constructed by remote industry power and controlled by equally remote economic interests, and, in effect, is the product of distant nuclear laboratories, Wall street and Washington," and that "For all practical 
purposes, this energy source has developed with little or no grass roots citizens' support." In commenting, Commissioner Kennedy said, "The need is clear. Those concerned with the future of nuclear power must do a better job of educating the public to its benefits and its risks." It is only by such a program that future public concerns can be alleviated and public acceptance of nuclear power be attained.

\subsubsection{Conclusions}

In the final analysis, it is the general public who wields the power to make the decision to have or not have nuclear energy. However, in the face of an indifferent or divided public, an aggressive and well organized opposition can seriously impede the development of nuclear power without bringing the general public into the issue. They can do this by adopting harassment tactics which put the utilities on the defensive, by creating an atmosphere of distrust and lack of contidence in the utilities, and by making the uncertainties so pervasive and the risks so high that the utilities will look for easier alternatives. Such tactics leave the utilities little room for defense. Also in today's situation they have no one to turn to for support except the government or the general public. The government can decide what actions are in the best interests of the country and try to lead the public into support of such actions, or it can let events take their course and do what the vocal public indicates that it wants or what the government perceives this public as wanting. Unfortunately the latter seems to be the more representative of today's situation. In either case the utilities cannot ignore the issue of public acceptability because even though the government assumes a positive leadership role, and one which supports the utilities' position, a dissatisfied general public could force a reversal of this position. The conclusion is that the future of nuclear power rectc upon ito uoc by utilitica to generate electricity, which in turn ultimately depends upon its acceptability to the public. 


\subsection{Reactor Safety}

Reactor safety is probably the foremost of the public concerns relating to the use of nuclear power. The concern is engendered by the existence of about 15 billion curies of radionuclides in the core of each operating power reactor. The consequences of dispersal of this material would include many casualties among persons exposed to the plume. The probability of such a serious accident is vanishingly small, however.

Assessments of risk to the general public and to the labor force by technologists have generally given nuclear power an excellent rating relative to other sources of electricity. No deaths have been reported thus far directly relatable to a nuclear accident in the nuclear power industry. (Assessments would indicate many deaths related to the conservative deployment of concrete and steel designed to protect the public against radiation.) Why then is there so much concern? One can only present the following speculations as partial answers:

1. Fear of an invisible hazard, outside normal human sensory ex-. perience. The hazard leads to an especially feared human il1ness, cancer.

2. Association of the nuclear reactor with a nuclear bomb, an association promoted by opponents of nuclear power.

3. A deliberate campaign by the opponents of nuclear power (and possibly even by agents wishing to overthrow the government) to discredit nuclear power.

4. Disagreement among "Safety experts" featured by the media.

5. Lack of faith in the industry and in the government regulators. This element has been very clearly publicized during the Three Mile Island accident and its aftermath.

6. Anxiety about the occurrence of a disastrous accident, however remote the probability.

TMI has convinced many decision makers in the Executive Branch and the Congress that reactor safety must be strengthened. Many in the industry would agree. A de facto moratorium on reactor licensing is in effect 
pending resolution of changes to be made. Many studies have been conducted and many sets of recommendations are on the table. We believe that Alvin Weinberg's ideas come close to a workable strategy both to make the public more secure and to make the public feel more secure. His proposals are as follows: ${ }^{15}$

- Future siting to be concentrated at multiunit stations in remote areas.

- Creation of strong generating organizations to manage and operate nuclear power stations.

- Creation of a professional operating cadre, highly trained and well paid.

- Strengthened safeguards and security, which would be facilitated by the above.

- Safer designs.

- Public education about the hazards of radiation.

The Kemeny. Commission has concentrated on more short-term issues: 16

- Reorganize and strengthen the NRC. Focus more strongly on operating safety as opposed to other concerns.

- Strengthen utility organization and accountabilicy.

- Upgrade operator qualifications.

- Strengthen control-room instrumentation.

- Strengthen documentation and analysis of abnormal events.

- Expand radiation-effects research and improve coordination of standards.

- Improve emergency planning.

- Improve coordination of public information on an accident. A recent study by the Engineering Technology Division's LWR Safety (Planning) Subcommittee 17 attempts to prioritize LWR safety research with the following results:

- Urgent - Operational safety

-. Very important - Fuel integrity

- Primary system integrity 
- Important - System behavior during loss of coolant accidents

- Extreme external phenomena

- Relevant - Risk assessment

- Marginal - Shutdown system behavior

- Gaseous effluents and cleaning systems

- Improved safety (design changes).

We should like first to comment on these priorities and then to suggest a safety research agenda (largely borrowed from the above reference). The highest priority given to operational safety is an obvious inference from the Three Mile Island post-mortems. The high priority given to fuel integrity and primary system integrity is possibly a reflection of the defense-in-depth philosophy of reactor safety. (i.e.., ceramic fuel, cladding, primary system, containment vessel, optional remote siting). We would be inclined to view these priorities somewhat differently, since safety is as much a perceptual problem as a scientific problem. In the "very important" category should be risk assessment and sociological research. Consideration should also be given to improved designs.

Research on operational safety is important because human errors have been responsible for the most serious nuclear "close calls" to date. Work is needed on the following:

- human engineering

- computer assistance to operators

- operating procedures

- qualification-testing of critical components

- fire protection research

- noise diagnostics

- communications priorities for emergencies

- disciplined reaction during emergencles.

Research on risk analysis is important because it may help to resolve the difference between the technician's perception of risk and the public's perception of risk. 
- Improved methods of analysis should be sought.

- Statistics of failures should be explored.

- Nonprobabilistic assessments should be made.

- Interfaces between risk analysis and sociological research should be explored.

- Analysis of accidents with limited consequences as well as analysis of maximum design-basis accidents.

Sociological research would address topics such as

- How safe is safe enough? or "How much safety is too much?"

- Cost-benefit analysis of safety measures.

- Cost-benefit analysis of safety research.

- Methods of compensating the public for risks.

- Methods of communicating with the public.

Other research topics would improve knowledge of safety margins and in some cases contribute to more reliable (and therefore more economic) plant operation. More knowledgeable regulators and experts should lead to increased confidence that the system is working.

The topic of improved design needs consideration. Improved designs are surely marginal in a cost-benefit analysis, but they may be winners in a poker game. Since one of the games we may be playing is "nuclear moratorium," improved designs might play a useful role in a renewed mandate for nuclear power. Risk analysis may also support the need for safer designs as the total number of reactors increases (much as we "need" safer airplanes as air travel increases). Improved design concepts include alternate containment schemes, alternate emergency cooling schemes, core retention measures, etc., up to other reactor types (HTGRs, MSRs). Consideration should be given to the public's desire to reduce the potential number of casualties following a disaster to something of the order of the worst airplane accident, through some "technical fix."

Any measures to strengthen reactor safety will bring in added costs which could be substantial. The accumulation of these costs will make nuclear power less economical, and utilities may forego nuclear plants in favor of coal or may be unable to finance needed capacity. The NRC must 
be in a position to balance the costs of incremental safety requirements against the benefits received.

\subsection{Licensing and Regulation of Nuclear Power Plants}

\subsubsection{Introduction}

Electric systems of all types are facing continuously increasing difficulties in meeting the legal, regulatory, and administrative requirements being imposed upon them. Also, electric power plants and transmission lines have become a focal point for action in responding to national concerns for protecting the environment. At the same time, in contradiction to these concerns on environmental protection, the public is continuing to increase its consumption of, and demand for, electricity. Thus, the nation faces a major problem in trying to put these conflicting concerns in proper perspective and establish a better balance between them. These issues come to a head in the licensing and regulatory process... In other areas a description of the licensing and regulatory process might be included as part of the background for discussion, but government regulation of nuclear power is so pervasive that the licensing and regulatory process becomes an important element in the controversy in its own right.

The licensing and regulation of nuclear power plants has been conducted in a more thoroughly planned and organized manner than for any other electricity generating systems, and from the infancy of the nuclear industry has been subjected to closer scrutiny, more open reviews, more public inputs and with a broader informational base than any other technology in history. This has brought a degree of order to the proceedings but probably has resulted in an "overkill" to the point where nuclear power is likely to become choked on the excesses. Some of the problems have been identified in Sect. 4.5 on Constraints, Uncertainties and Financial Needs of Nuclear Power and will not be repeated, but they represent growing concerns which must be addressed. Also the issue is so broad, involving among other items, political, legal, institutional and public attitude considerations that the subject is much broader than can be covered in this report. 
Therefore, the report will attempt to identify the most important issues and list a brief, and by no means complete bibliography ${ }^{18-24}$ for additional information on the subject. Emphasis has been placed on the TMI accident since this may be the catalyst which will bring about fundamental changes in the nuclear power plant licensing process.

\subsubsection{Licensing issues}

A license may be granted for a reactor or a fuel cycle facility when the licensing applicant can demonstrate that the system is safe and that the environmental impacts are acceptable relative to the benefits to be gained.

The safety issues relate to protection of the operating staff and the general public from radiation exposures exceeding legal standards as the result of unplanned events or accidents (equipment failures, operator errors, or external forces such as earthquakes). The primary assurance of safety depends on a high degree of predictability and reliability obtained through application of rigorous standards and extensive quality control. In addition, in accordance with the "defense-in-depth" concept, safety features and engineered safeguards systems are provided to mitigate the consequences of accidents postulated to occur in spite of the above precautions.

The environmenta $\perp$ issues, as analyzed in an environmental impact statement, cover a broad spectrum of physical and social impacts. The benefits from the proposed facility must be shown to justify the impacts. The need for the energy must be demonstrated, and other alternatives must be cunsidered.

The impacts include commitment of land and water resources; heat disposal; radiation exposures, both occupational and to the general public; proliferation risks; and social as well as direct costs.

Underlying the licensing process are the public concerns relating to nuclear power. The licensing process formalizes the assessment of nuclear technology to ensure that public concerns are adequately addressed. The benefit versus risk assessment is necessarily qualitative; there is, therefore, continual controversy surrounding the standards. Examples of 
public concerns that create long-term uncertainties about the acceptability of all nuclear power alternatives follow.

- Possibility of catastrophic accidents. How improbable is a catastrophic accident? What degree of improbability is acceptable? Was Three-Mile Island an acceptable accident? Can acceptable emergency plans be set up to handle such an accident?

- Disposal of high-level wastes. What should be the standards for encapsulation and terminal storage of nuclear wastes?

- Low-level radiation exposure. What level of risk is acceptable? The experts do not agree about the probable consequences of exposure.

- Nuclear proliferation. What level of safeguards and proliferation countermeasures would be required for sensitive operations such as reprocessing?

- Trust in institutions. Is the NRC prepared to deal with an emergency? Can NRC and EPA be trusted to be unbiased and competent nuclear industry regulators?

Regulating agencies have developed standards for nuclear technologies in commercial use. The granting of a license for construction and operation of a new type of facilitiy requires in-depth analysis of the safety and the environmental impacts of the proposed facility. Standards may have to be developed to assess the new facility in the licensing process. The RD\&D program serves, on the one hand, to demonstrate safety and environmental acceptability and, on the other hand, to develop standards hy which the commercial facility may be judged.

\subsubsection{Background on responsibilities for regulation of nuclear power}

The Atomic Energy Act of 1954 ended the government monopoly over atomic energy and permitted the participation by private industry in the development of peaceful atomic energy. However, in order to maintain government control over this development, the act established an elaborate system of licenses and regulation with respect to all phases of peaceful atomic energy. With respect to nuclear power, no one could bulld a reactor, possess nuclear fuel, or operate a nuclear plant without a license 
from the AEC. Even after the licenses were secured, the operation was, and is, subject to the control of initially the AEC and now the Nuclear Regulatory Commission (NRC). From its very beginning the nuclear regulatory program has been the subject of bitter controversy, those subjected to the regulations claiming that it was oppressive; nuclear opponents that it was inadequate.

Initially the AEC was the sole arbiter of matters pertaining to the licensing of nuclear power plants, but they interpreted their responsibilities to not extend to nonradiological impacts on the environment. This issue had arisen particularly in connection with the discharge of heated waters into lakes, rivers and oceans. However, subsequent congressional legislation, and the interpretation of these congressional acts by the courts changed both of these limitations. The National Environmental Policy Act (NEPA) of 1969, as later interpreted by the courts, mandated that the AEC's responsibilities included the consideration of nonradiological impacts to the environment. In addition under the current provision of the Atomic Energy Act, the regulation of general radiation hazards is shared by NRC, several other federal agencies, and the state governments. However, nuclear power reactors still are regulated almost exclusively by the NRC, although that monopoly is being challenged on several fronts.

The NRC grew out of another criticism of the AEC, namely the combining in one agency of the roles of nuclear energy promotion and nuclear energy regulation. The AEC took organizational actions to separate these potentially conflicting roles; but, since both groups reported to the same AEC commissioners, this internal organizational separation never satisfied the critics that the separation in policy and functions was real. Consequently, the Energy Reorganization Act of 1974 split the AEC's jurisdiction between the Energy Research Development Agency (ERDA) and the Nuclear Regulatory Commission (NRC), ERDA was given responsibility for development programs, and NRC was given the regulatory function. Since then ERDA has been replaced by the Department of Energy which was intended to consolidate all of the Federal Government's energy development programe. NRC. remained as the chief regulatory agency for nuclear power and other aspects of nuclear energy. 
As previously mentioned, NRC's role for the regulation of nuclear power is under concentrated attack from several sources. For example, as of this time there is still a question on the allocation of authority between NRC and the Environmental Protection Agency (EPA) for setting standards for discharges from nuclear power plants. In addition many states have attempted through legislative actions or by referendum to stop the development of nuclear power. Several states have been successful in varying degrees in these attempts and new efforts are almost certainly to be mounted aimed at achieving this goal. States also affect the development of nuclear power through control of transportation of radioactive materials, disposal of radioactive materials, disposal of radioactive wastes, and general environmental control. They have and are challenging the Federal Government's monopoly in other areas.

NRC has the basic responsibility for regulating hazards from byproduct, source and special nuclear materials, but other federal agencies also have some regulatory responsibilities over these materials. With respect to the transportation and packaging of 1icensed material, the 1icensee must comply with the regulations. of the Department of Transportation (DOT) and the Postal Service as appropriate to the mode of transportation, but states are challenging these regulations. EPA has been given authority to establish standards for the protection of the environment from radioactive materials including the ocean disposal of wastes. Under the Federal Water Pollution Control Act Amendments of 1972 (FWPCA), EPA has regulatory authority over the discharge of certain pollutants (such as heated water) from nuclear plants into navigable waters. FWPCA also emphasizes the "primary responsibilities and rights of the states. to prevent, reduce and eliminate pollution." This poses a potential conflict with the federal agencies which is likely to be tested in court. EPA and NRC have an agreement which coordinates NRC's responsibility under NEPA with respect to the environmental impact of the same discharge pollutants. But again this may be challenged in court, and in some cases the courts have upset or created great uncertaintes on the respective roles of NRC and EPA adding confusion to an already confused and uncertain situation. The NRC is authorized to enter into agreements with states for state regulatory authority over by-product, source and special nuclear materials 
in quantities insufficient to form a critical mass. Several such agreements are now in effect, and though these do not directly affect the licensing of nuclear power plants, they can impact such actions. Also any state in which a nuclear power plant is being licensed can submit evidence and offer recommendations on the application.

Until recently most states accepted the preemption by NRC of control over the safety of nuclear power plants. However, nuclear power opponents have worked to enact state legislation which would challenge this situation. An attempt of several years ago by the Minnesota Pollution Control Board to impose more stringent requirements on discharges from nuclear plants than were imposed by the AEC led to a court decision which preempted the states in this regard. However, states have the authority to regulate nonradiation aspects of power production such as need, rates, and site approva1; and this directly influences the ability of the utility to obtain a nuclear power plant license. At the present time there are sume strong sentiments for giving the states a more responsible role in nuclear power plant licensing so additional changes could be forthcoming in the near future. Indications of such trends are recent actions by the states of Washington and South Carolina regarding the acceptance by those states of low level wastes from out of the state, a consideration by the Rhode Island legislature of making itself the final state nuclear licensing authority, and the actions by several states to control, and even ban, the transportation of radioactive materials within or across the state.

\subsubsection{Philosophies and events shaping the licensing process}

Logically the problems of safety and hence the licensing process for nuclear power plants should be no different from those applicable to other industrial facilities or electricity generating plants. The traditional approach has been to test components, combine them into a system into which a high degree of conservatism has been incorporated; and learn by experience where the deficiencies are and what parts of the system need to be strengthened in order to achieve the desired degree of safety and reliability. Conceptually the regulation and licensing of nuclear power has followed this same approach. The NRC's elaborate process for licensing 
nuclear power plants is based on the philosophy of assuring that the engineering safeguards designed, engineered and constructed into the plant insure a low risk of public exposure against the maximum credible accident. This requires engineered reliability and redundant backup systems. It also assumes that the consequence of any accident will be less than, and hence acceptable, within the boundary of this worst conceivable accident. Other safety philosophies could have been adopted such as that followed by the DOT in which one tries to quantify the criteria used in terms of the magnitude of the exposure and the probability of the event occurring. But this was not done by the NRC or its predecessor, and the philosophy of engineered safeguards in depth was adopted since it was understood and backed by successful precedents in other heavy industries. Unfortunately in the nuclear field this approach has been subject to criticism on primarily two aspects: (1) the technology is a new and rapidly developing one, and the experience is insufficient to provide a basis for reliable. statistical analyses; (2) the possible consequences of a serious accident constitutes a hitherto unknown type of risk and is not yet understood and accepted by the public. Underlying both of these issues is the question of "how safe does a nuclear power plant have to be in order to be safe enough?" This question has never before arisen with other industrial developments - certainly not to the same degree and intensity that it has for nuclear power. The licensing of nuclear plants would have been much simpler and more straightforward if an answer to this question could have been derived and adopted as a basic criterion for the licensing of nuclear power plants. However, an answer to this question borders on the impossible. It is not only conceptually difficult but involves subjective values on which it would be extremely difficult to obtain a public consensus and even when obtained would be vulnerable to constant attack by those who want increased safety or those who want to undermine nuclear power. Consequently, the NRC has vacillated in their opinions of what constitutes adequate measures for safety and has adopted what in essence is a moving licensing target. This gives rise to changes in regulation standards, retrofitting of already licensed reactors, and other requirements, which hopefully lead in the direction of safer and safer reactors, but generate great confusion and uncertainty which obscures and dilutes the real safety 
goals. The fact that the limited experience with operating reactors indicates that it is one of the safest of industries, including all other alternatives for generating electricity, is irrelevant since the probability for a serious accident does exist and the public still fears this hypothetical accident that has not yet happened.

Even with this ultraconservatism by the various regulatory bodies, the critics of nuclear power charge that the process does not produce safe reactors and that safety has been sacrificed for economics. Thus they are pushing for more and more safety measures which in the logical extreme can be achieved only by shutting down all reactors and at best would assure that nuclcar power can never be cconomic and hence not acceptablc to the utilities. On the other hand nuclear power proponents criticized the licensing process because of redundancy being carried too far; the uncertainties created by changes in standards; the retrofitting required for licensed reactors; the inordinate time required to license a plant; and the duplicating and often conflicting requirements of many federal, state, and local agencies. In some states more than 50 state and federal permits may be required to license a nuclear power plant. In California for example no fewer than 91 permits from 43 agencies are required for bringing on a single nuclear power plant. This stretches out the licensing time over a very long period. It also provides many opportunities for veto of the project. The time required from the start to bring a nuclear power plant on line is now 12 to 14 years of which 4 to 6 years is involved in the 1icensing process. There is general agreement that this time is much longer than it need be, and it poses serious problems for the utilities in that it results in enormous increases in the cost of the plant and reduces the utilities' flexibility for adjusting to sudden changes in their situation as has occurred during the past five years. Under these circumstances and with the high cost of money, the tremendous increase in capital costs, and excessively long time before the utility can obtain a positive cash flow from the plant, the utilities have a strong incentive to postpone, cancel or not build nuclear plants. Thus, this aspect of the licensing issue is critical to the future of nuclear power. 
President Carter soon after assuming office directed that the licensing process be improved and substantially shortened. A number of suggestions for changes have been advanced in accordance with this goal. Many of these proposed changes are controversial but several which seem to have general support are: reduce the number and length of hearings, use "generic" hearings to shorten and simplify the process, make greater use of standardization, prelicense the nuclear site, and provide for joint proceedings of state and federal licensing bodies. Much of this reform was under way when the Three Mile Island (TMI) Unit 1 accident occurred, and this event introduced a significant new set of dimensions to the whole. nuclear licensing and regulatory issue.

The effects of TMI accident are to some extent summarized by the Report of the President's Commission on the Accident at Three Mile Island and the title itself emphasizes "the need to change". 25 . One of the main features of this report was its severe criticism of the NRC. This is evidenced by their overall conclusion which reads: "To prevent nuclear accidents as serious as Three Mile Island, fundamental changes will be necessary in the organization, procedures, and practices and above ali in the attitudes of the Nuclear Regulatory Commission and, to the extent that the institutions we investigated are typical, of the nuclear induetry." This conclusion which is a very serious indictment of the NRC "speaks of necessary fundamental changes," and was reinforced by the Commission's 18 pages of reconmendations. The subsections of the recommendations were: (a) the Nuclear Regulatory Commission, (b) the Utility and its Suppliers, (c) Training of Operating Personne1, (d) Technical Assessment, (e) Worker and Public Health and Safety, (f) Emergency Planing and Response, and (g) the Public's Right to Information. Each of these bears on the licensing issue to varying degrees, but item $\mathrm{A}$, which constitutes one-third of the space given to the recommendations, deals with fundamental issues relating to the NRC structure, management, mandate, and procedures - and these recommendations if adopted in whole or in part could have far-reaching and lasting effects on the regulation and licensing of nuclear power.

Even prior to TMI the NRC was sensitive to need for licensing and regulatory reforms, and their concern was accentuated by the lessons learned 
from TMI. Chairman Hendrie briefly addressed this issue in a talk given at the American Embassy, London, England, on 0ct. 1, $1979 .{ }^{26}$ In this talk Chairman Hendrie summarized the philosophy of the commission by stating that they can and do consider costs and related factors, but that improvement in safety is the dominant element in their consideration.

In contrast, Commissioner Victor Gilinsky, ${ }^{27}$ in a talk before the New York Chapter of the American Jewish Committe on Oct. 22, 1979, gave more attention to the political issues and tended to belittle the role and importance of nuclear power to the American economy. He laid the blame for TMI on the basics of the nuclear industry and concluded his talk by stating that "we can live with nuclear power only if we are willing to pay the price of living with dangerous high technologies, the price of which is extraordinary care, discipline, and superior craftsmanship." This seems to avoid the basic issue of how safe nuclear power plants need to be.

Commissioner Bradford in addressing the NARUC Annual Regulatory Studies Program on Aug. 2, 1979,28 also give a talk heavy with political overtones. He linked nuclear energy's decline to "self-delusion" and attributed most of its problems to the industry itself. Bradford also was very critical of the regulators, particularly the NRC.

These talks, along with other statements made by the commissioners, 29,30 seem indicative of their individual attitudes and philosophies, and although one must be careful in drawing conclusions from such statements, they nevertheless reveal several important points: (1) there is a great divergency of philosophy among the commissioners on what the problems are in nuclear power and how they should be dealt with in the $1 i-$ censing process, (2) they emphasize that changes are the order of the day, but (3) they give no clue as to what direction these changes might take. Up to this point little has been sald about the rold of the guriual public in the nuclear power plant licensing process. There was a brief general discussion of this aspect of the problem in Sect. 4.1 - Public Acceptance of Nuclear Power. As noted in that section, the public generally did not become involved in the licensing of nuclear power plants unt11 after 1968. Since then, however, their involvement, particularly by 
the special interest groups, has grown at a tremendous rate. This has had its effect upon the attitudes and operating philosophies of the commission both as individuals and as a collective body. In fact, there is cumulating evidence as indicated by previous discussions that some members of the commission were appointed to office and act in accordance with their political philosophy with respect to nuclear power in contrast to the technical and safety issues. These different philosophies among the commissioners were accentuated by the TMI situation and whereas the Commission was formerly criticized for putting more emphasis on economics than on safety, it is presently receiving criticism for putting undue emphasis on the political aspects of nuclear power plant siting in lieu of either economics. or safety. The NRC's recent decision to delay indefinately any licensing actions on nuclear power plants was seen by some as a political decision, and Dr. Edmund Teller called for the resignations of all the commissioners on these grounds. Also it was recently reported that a special white House Task Force is considering suggesting to the President that he ask all five commissioners to resign. ${ }^{31}$

\subsubsection{Potential Changes in the NRC}

We are not in any position to suggest a complete program for restructuring the NRC. Such a restructuring appears to be necessary with at least the following objectives:

1. To reduce the likelihood of serious nuclear accidents.

2. To improve the response to an emergency, both inside and outside nuclear plants.

3. To reduce the time required to license a nuclear plant for construction and operation.

4. To improve the quality of public participation in the 11censing process.

5. To increase public trust in the NRC.

The restructuring may be initiated by executive action, but will probably require legislation in Congress. Some of the actions which should be taken include: 
1. Strengthened management and decision-making.

2. Increased focus on safety rather than in following an increased number of regulations.

3. Streamlined licensing process which assigns proper role to states as well.

4. Reduce NRC responsibility for matters unrelated to public health and safety (especially for political policymaking.)

5. Elimination of adversary proceedings where NRC staff "defends" the Iicensee.

These improvements to the NRC are a necessary step toward improving public contidence in nuclear power.

\subsubsection{Potential role of research into licensing and regulation}

There are so many complex issues to be resolved in the licensing area that it would be desirable to conduct research into alternative licensing approaches and into the relationships between electricity production and economic well-being. The following are issues which in our view should be explored, and the results of this research could be of considerable benefit to decioion makcrot

- The need for power. The methodology which is used by the various ctatc commicciono ic a jumble of conflicting approachco. $\Lambda$ much better approach to predicting the consequences of "not enough" capacity and "too much" capacity is needed.

- Substitutability of electricity for oil and gas. More research is required into the relative merits of conservation, "soft" technologies such as solar, and centralized electricity generation to deal with the energy crisis. This type of analysis should consider both near-term and long-term dynamics of the substitution.

- Internalization of indirect costs. Much of the intervention into nuclear facility licensing stems from an unequal distribution of benefits and burdens among the population. Research is required into means of compensating those unfairly being burdened and taxing those gaining the benefits. 
- Role of states in nuclear power regulation. Potential role of the States vis-a-vis the Federal Government should be investigated.

- Public participation. How can the public participate in a way which is constructive rather than obstructive?

- Risk assessment. How to bridge the gap between the public's assessment of risk and the experts' assessment.

- Communication. How to make the public and decision-makers aware of the licensing issues and the consequences of building or not building nuclear plants. Also how to communicate with the public on site selection.

The above is by no means a complete agenda; other topics will be generated in an on-going research program.

\subsubsection{Conclusions}

The licensing and regulation of nuclear power plants has been controversial and subject to strong criticism from its very inception. Also the licensing process has been accompanied by confusion, uncertainity, and redundancy. Much of this can be traced to the nature of the problem and particularly how the public perceives the risks associated with nuclear power, and how the politicans and the regulators react to these perceptions of the public.

In general the nature of the licensing process as it has existed, and as emphasized by recent events, has been to put the NRC on the defensive. They are an open target for criticism for many reasons but particularly on the issue of making licensing decisions, which may affect public safety, on a probability analysis. No matter how low the probability of an event, it is never zero, and one can't explain away this nonzero probability event when it happens - such as TMI. Therefore, the NRC can never guarantee zero riek short of closing down all nuclear plants. This raises a problem of public acceptability since psychologically the public may never be able to accept the probability of a serious accident, no matter how low the chance may be. The following quote from Arthur $W$. Murphy ${ }^{32}$ succinictly summarizes the situation: "In the last analysis the key question of 
regulation would seem to be that of public acceptability of the safety decision. If the public is unwilling to accept the very small risk of serious accidents posed by nuclear power plants, no system of regulation will suffice."

Meanwhile, however, a system does exist; but the system is under great stress and fundamental changes in the system are almost certain to occur. Presently the process is in a transition stage and it is difficult to predict what will emerge.

\subsection{Trends in Nuclear Power Plant Construction Costs*}

Commercial nuclear power plant construction costs have increased dramatically in the past ten years from about $\$ 200 / \mathrm{kWe}$ for plants completed in the late 1960s and early 1970 s to about $\$ 500$ to $1.000 / \mathrm{kWe}$ for plants heing completed in 1979 and 1980 with current utility company projections of $\$ 1000$ to $2000 / \mathrm{kWe}$ for plants being completed in the late $1980 \mathrm{~s} .33,34$ Concurrently, project schedules measured from the award of the nuclear steam supply system (NSSS) contract to fuel loading have increased from seven years in the late 1960s and early 1970 s to 11 to 12 years for plants being completed today with projections of 12 to 15 years for plants to be completed in the late 1980 s. $^{34}$ (There is some hope of legislation countering the trend to lengthened schedules.) The increasing costs and lengthening construction schedules are usually attributed to (1) increased scope of plant becausé of addicional safery and environmental regulatiuus dul (2) high inflation in costs of equipment, materials, and labor for plant construction and yfelds on utility bonds for financing construction.

The number of standards and regulations affecting nuclear power plant design issued by the American National Standards Institute, the Atomic Energy Commission, the Nuclear Regulatory Commission, the Environmental Protection Administration, the Occupational Safety and Health Administration, and other governmental agencies during the past ten years has increased to nearly 2000 ANSI Standards ${ }^{35}$ proposed or in effect and more

*Contributed by Howard I. Bowers. 
than 300 NRC Regulatory Guides and Revisions and Technical Branch Positions and Revisions that have been issued. ${ }^{36}$ The major impact of these criteria regarding reactor safety and environmental protection, e.g., quality assurance, emergency core cooling, missile protection, seismic protection, radioactive waste control, cable separation, in-service inspection, pipe break restraint, fire protection, plant security, operator training, waste water management, thermal releases, air quality, noise abatement, environmental reviews, antitrust reviews, etc., is reflected in more concrete, steel, piping, electrical cable, equipment, and design and construction labor and longer lead times for design, licensing, and construction of nuclear power plants. Typical increases are tabulated below. $34,37,38$

\begin{tabular}{lllc}
\hline & \multicolumn{1}{c}{ Early 1970s } & \multicolumn{1}{c}{$1979-1980$} & $\begin{array}{c}\text { Percent } \\
\text { increase }\end{array}$ \\
\hline Building volume & $11 \mathrm{ft}^{3} / \mathrm{kWe}$ & $13 \mathrm{ft}^{3} / \mathrm{kWe}$ & 18 \\
Structural steel & $14 \mathrm{lb} / \mathrm{kWe}$ & $201 \mathrm{~b} / \mathrm{kWe}$ & 43 \\
Reinforcing steel & $281 \mathrm{~b} / \mathrm{kWe}$ & $391 \mathrm{~b} / \mathrm{kWe}$ & 39 \\
Structural concrete & $0.11 \mathrm{yd}^{3} / \mathrm{kWe}$ & $0.14 \mathrm{yd}^{3} / \mathrm{kWe}$ & 27 \\
Formwork & $1.5 \mathrm{ft}^{2} / \mathrm{kWe}$ & $1.9 \mathrm{ft}^{2} / \mathrm{kWe}$ & 27 \\
Piping & 0.21 ineal ft/kWe & 0.31 ineal ft/kWe & 50 \\
Electrical cable & 2.71 ineal ft/kWe & 3.71 ineal ft/kWe & 37 \\
Manual labor & $8 \mathrm{~h} / \mathrm{kWe}$ & $12 \mathrm{~h} / \mathrm{kWe}$ & 50 \\
Nonmanual labor & $4 \mathrm{~h} / \mathrm{kWe}$ & $6 \mathrm{~h} / \mathrm{kWe}$ & 50 \\
\hline
\end{tabular}

The licensing lead time measured from award of contract for NSSS to issuance of construction permit has doubled from about two years in 1970 to over four years today. ${ }^{34}$ The actual construction time measured from issuance of construction permit to fuel loading has increased from about five years in 1970 to about eight years for plants being readied for fuel loading toady. ${ }^{34}$ The increases in manpower requirements and lengthening construction schedules are the direct results of the increased scope of equipment and materials. 
The second major factor bringing about higher costs is inflation. The costs of equipment, materials, and labor have increased at an average rate of over $8 \%$ /year during the past ten years resulting in a doubling of costs every seven to eight years due to inflation alone. ${ }^{39}$ Utility bond yields for financing new construction have increased from 7 to $8 \%$ in 1970 to the 14 to $15 \%$ range today, also reflecting inflation. 37,40

The increases in nuclear power plant construction costs over the past ten years along with projections for the next ten years. can be summarized approximately as follows.

\begin{tabular}{|c|c|}
\hline . & $\begin{array}{c}\text { Cost } \\
(\$ / k W e)\end{array}$ \\
\hline Plant cost in 1970 & 200 \\
\hline Increased" scope 1970-1980 & 150 \\
\hline Increased schedule 1970-1980 & 30 \\
\hline 1980 plant cost in 1970 dollars & 380 \\
\hline Inflation $1970-1980$ & 420 \\
\hline Plant cost in 1980 & 800 \\
\hline Increased scope 1980-1990 & $0-300$ \\
\hline Increased schedule $1980-1990$ & minus $50-100$ \\
\hline 1990 plant cost in 1980 dollars & $.750-1200$ \\
\hline Inflation $1980-1990$ & $825-1800$ \\
\hline Plant cost in 1990 & $1 \mathrm{~b} / \mathrm{b}-3000$ \\
\hline
\end{tabular}

In terms of constant 1970 dollars, costs of plants ready for fue 1 loading in 1980 have increased about $75 \%$ due to increase in scope and about $15 \%$ due to lengthening of the design, licensing, and construction schedule, both resulting from application of stricter environmental and safety regulations, and have more than doubled because of inflation. The overall result is that the costs of plants being readied for fuel loading today are about four times those of plants completed in 1970. If inflations continues at the same rate, $8+\% / y r$, plant costs in 1990 will more than double again to about $\$ 1700 / \mathrm{kWe}$, or 8.5 times typical plant costs in 1970. This assumes no further change in plant scope or schedule resulting 
from stricter reactor safety and environmental regulations and does not take into account the effect of the Three Mile Island accident on construction costs and schedules. Preliminary estimates of the additional construction costs range from $\$ 25$ to $\$ 150 / \mathrm{kWe} .^{41}$ However, it is possible that even the upper value is low since the full impact has not yet been determined. Therefore, to estimate an upper bound it has been assumed that plant costs in 1980 dollars will increase by $\$ 300 / \mathrm{kWe}$ due to increased scope and by $\$ 100 / k$ We due to longer schedules. Along with inflation, the resulting estimate for a plant loading fuel in 1990 is about $\$ 3000 / \mathrm{kWe}$, or 15 times the plant cost of $\$ 200 / \mathrm{kWe}$ in 1970 .

Except for nuclear safety measures, the factors causing nuclear power plant costs to rise, environmental and safety regulations and inflation, are also causing coal-fired power plant costs and other large process plant costs, e.g., synthetic fuel plants, to rise drastically. The environmental regulations regarding air quality, waste water management, and hazardous waste disposal are having a much greater effect on coalfired plants than on nuclear. As a result, coal-fired power plant costs have risen as rapidly as nuclear and are in the same relative position today with respect to nuclear plants as in 1970. However, the design, licensing, and construction lead times for coal-fired plants have increased at a slower rate and are significantly less than for nuclear. It would appear that because of the Three Mile Island accident, nuclear plant costs will increase at a faster rate. in the future than coal.

\subsection{Conctrainte, Uncertainties and Financial Needs of Nuclear Power}

\subsubsection{Introduction}

There are a number of constraints and uncertainties facing nuclear power. Some are technical, some political, and some public relations issues; in composite they are of such overriding importance that they can potentially dictate the viability of nuclear power and the direction it will take. These constraints and uncertainties can be listed in many ways 
and can include many items of varying degrees of importance. For the purpose of this paper they will be categorized as technical or nontechnical constraints. The list has been limited to what we perceive as being the most critical issues.

\subsubsection{Technical constraints}

The technical constraints which seem most critical among the various ones facing nuclear power are:

- uncertainty of uranium resources

- reprocessing/recycle of spent nuclear fuels

- ultimate disposal of high-level radioactive wastes

- nuclear safety.

Each of these issues is the subject of a Major Issues Paper and will not be discussed further in this paper.

\subsubsection{Nontechnical constraints}

The nontechnical constraints which seem paramount at this time are:

- public acceptance

- proliferation

- uncertainties

- manufacturing and construction viability

- capital needs and financial risks.

Again the first two issues are discussed in a Major Issues Paper so only the last three items will be discussed in this paper.

\subsubsection{Uncertaintico}

Uncertainties plague many segments of our governmental, private and corporate lives, but they impose a particularly severe burden on the nuclear power industry. The origin of these uncertainties is sometimes vague, arising from a combination of many events and actions which are often difficult to identify as a causative factor. However, in the nuclear power area, it is possible to clearly pinpoint certain actions or 
lack of actions which have created an atmosphere of indefiniteness on whether nuclear power can be constructed and operated, and if so at what costs in terms of time and money. These uncertainties. frequently but not always arise from regulatory actions, but their resolution usually ends up as being a regulatory or court decision. Following is a listing of the major uncertainties or the causes which lead to them:

- Conflicting (sometimes opposing) requirements and lack of coordination among federal agencies, between state and federal agencies, and among state agencies on the need, siting, construction, and operation of nuclear power plants.

- Lack of clearly identified environmental requirements associated with the siting, construction and operation of nuclear power plants which can be executed and administered with consistency and fairness.

- Conflicting federal, state, and local environmental standards.

- Vacillating government (both state and federa1) policies and actions.

- Fragmentation of regulatory authority andits effect on regulatory policies and decisions.

- Vacillation and lack of clear guidance on the part of state and federal regulatory agencies.

- Uncertainty concerning the effects of pending political and regulatory actions.

- Unpredictable requirements and delays in the licensing of nuclear power plants.

- Retroactive changes and modifications to nuclear power plants.

- Harassment by intervenors through civil disobedience, media exposure, public hearings, appeals to congress, and court actions.

- Delays and inadequacies in rate adjustments and uncertainties on what types of costs can be included in the rate base.

- Rate setting actions (e.g., pass through fuel costs), which discriminate against nuclear power.

- Changing electricity demand patterns and amounts.

- Conflicts between what the utilities perceive as needed capacity to meet their charge for providing reliable service and the state utility commission's desires to curtail capacity in order to hold down rate increases. 
- Escalating prices of fuels and inability to project future costs.

- Inflationary pressures which have escalated capital costs.

- Proliferation of state and federal regulations.

- Inadequate recognition by the public of the role of electric power in our economy .

- Lack of recognition by the public for the need to increase the prices of electricity.

Many of these uncertainties apply to nonnuclear means for generating electricity, but they all apply to nuclear power and act as serious restraints to a national development of nuclear power.

The result of these uncertainties has been to postpone decisions, delay construction, and increase the costs of nuclear power plants to the point where the utilities are not willing to assume the high risks of going through the process. Consequently, they are forced to go nonnuclear where the time and costs are more predictable, even though the long-term costs may be greater.

Uncertainties, in general, are perhaps the most serious constraints on the nuclear power industry and, unless reduced to a manageable level, will eliminate nuclear power as a viable alternative for the utilitics.

\subsubsection{Manufacturing and construction viability}

The curtallment of nuclear power plant construction also has potentially severe consequences for reactor manufacturers and rnnstrurtors. If the utilities do not build nuclear plants, then the manufacturers cannot sell them. Further, there is a mininum level below which the industry cannot maintain its viability. A precise number is not available on how many new orders per year a reactor manufacturer must obtain in order to sustain a viable but economic manufacturing operation, but the consensus seens to be Llial it should be about lour to $1 \times 1000$ MWe units per manufacturer per year. If the present four U.S. reactor manufacturers are to be sustained, this would indicate a need for about 16 to 24 reactors per year (including foreign orders) to keep the preacntly constituted American reactor manufacturing industry in a healthy condition. As a minimum, 
there must be at least two reactor manufacturers in order to maintain competition.

Orders could come from foreign countries as well as American customers, but foreign reactor manufacturers are developing a strong capability and are aggressively competing for the foreign markets. Thus, it is questionable whether American manufacturers and constructors could accept the risk of depending on foreign customers for most of their markets if the American market should shrink to where it would not support all four manufacturers. Recent statistics ${ }^{42}$ on orders placed for reactors outside of the United States indicate that the U.S. manufacturers' share of the market has dropped from $100 \%$ to $5 \%$ in the last ten years.

Meanwhile, the American market for nuclear power-plant awarded contracts has declined from 20 plants in 1966 to 0 plants in 1978. In fact, orders for the past four years would marginally sustain, at most, one reactor manufacturer, not taking into account cancellations which have exceeded new orders. For how long a time the industry can continue on this basis is a critical issue - the outcome of which could affect the country's ability to maintain the nuclear power option as one of its energy alternatives.

A recent report 43 noted that U.S. installed manufacturing capacity is 25 to $30 \mathrm{GW} /$ year but predicts that domestic orders will be only 2 to $6 \mathrm{GW} /$ year if that. The report says that GE will opt out of the nuclear business after the 1980 elections if the political climate for nuclear does not change for the better, that the future of $B \& W$ is in doubt because of TMI, and although CE and Westinghouse have orders to sustain them through the $1990 \mathrm{~s}$, they will face difficulties in the 1980 s maintaining design and engineering teans. Regarding the world situation, the report says that General Electric, Babcock \& Wilcox, Kraftwerk Union, and Asea Atom probably will be forced out of the nuclear business if changes for the better do not occur within five years; and, if changes still have not occurred by 1988, Westinghouse and Combustion Engineering nuclear business could also go under. In their worse case scenario the report predicts that such vendor fallout could threaten the viability of nuclear power worldwide. 


\subsubsection{Capital needs and financial risks}

A recent Engineering Technology Division paper ${ }^{44}$ concluded that capitalization requirements per se need not be a limiting factor to the development of future energy supply systems since energy's capitalization needs are at most a few percent of GNP. However, the studies reviewed conditioned their conclusions with caveats relating to the social and political conditions which must prevail if the needed capital is to be made available at acceptable interest rates. Also it was noted that if any of the energy industries encountered problems in raising capital it would be the electric utilities. Furthermore, looming large among the capitalization problems facing the electric utilities are those of nuclear power plants because of their higher capital costs and the perceived financial risks associated with nuclear power.

The electric utility industry is the most capital intensive industry in the United States, and even under normal circumstances it would have difficulty in meeting. Its financial needs should growth continue at the rate as during the past 20 years. However, in the $1974-75$ period, a series of events changed the capital financing requirements of the utilities from a potential problem to a continuing crisis. For some utilities the problem went to the point of creating serious financial strains, and most utilities took drastic actions to bring their operating and capital costs in line with their ability to raise capital.

Since nuclear power plants are more capital intensive than coal, oil, or gas-fired plants, the major impact of this poor financial condition has been to cause the utilities to delay and cancel the more capital intensive nuclear plants rather than the fossil fuel plants. Also, in many states, the higher costs of the fossil fuels can be passed through to the consumer without further regulatory action which, from the utilities' point of vlew, clrcumvents part of the charge rate problem. l'hus, nuclear plants, even though they may have a lower life cycle cost than fossil fuel plants, are not being built. The situation is one which feeds on itself and, unless permanent actions are taken to correct the current financial imbalance, the trend to delay or postpone the construction of nuclear plants 
could feed on itself with potentially serious impact on the utilities, the reactor manufacturing industry; and the public.

This in itself is a serious problem, but the TMI accident added a new dimension to the perceived financial risks associated with nuclear power plants. This nuclear risk dimension was dramatically illustrated by Merrill Lynch Pierce Fenner \& Smith's, Inc. (MLPF\&S) utility bulletin for May - 1979. The title, "Three Mile Island's Aftermath: A Nuclear Panic," tells the story but the details were that:

- the stock market as a whole moved up,

- electric utility stocks moved down a few percent,

- the stocks of nuclear electric utilities fell more,

- the stocks of companies owning B\&W nuclear plants plummeted.

MLPF\&S speculated on what kind of repairs would be needed for the TMI Unit 2 plant, how much they. would cost, how long the plant would be shut down, and so on. They commented that nuclear plant modification agreements reached between the utilities and NRC might end the stock market's nuclear panic but would not mark the end of opposition to nuclear power. The Merrill Lynch analysis was representative of those made by other financial and investment institutions, the net result being that for utilities owning nuclear power plants the stock prices went down and bond interest rates went up, both acting to make it more difficult and costly to raise equity capital.

For the utility directly concerned (General Public Utilities), the effect was even. more direct and financially traumatic. Estimates are still being made on the costs to clean up, repair, and restore to service the damaged reactor; but a round-number estimate of $\$ 1 / 2$ billion or more does not seem unreasonable. Perhaps the major and most damaging cost is the purchase of makeup power, and this cost is estimated at about $\$ 10 \mathrm{mil}-$ 1 ion/month each for untts $1 \& 2$. This emphasizes the critical importance of getting these plants back on line as quickly as possible. In fact, Milton Levenson (EPRI) 45 used TMI as a case study to analyze the nature of financial consequences that may result from a nuclear power plant accident. Of the three categories of costs - direct property damage, thirdparty liability, and replacement power - he concluded that the latter was 
the dominant financial loss except for the very low probability, highconsequence accidents. These financial obligations have been reflected in the price of the GPU stock now at an all time low and their bonds which are selling to yield nearly 14\%. Aggravating the situation for the Metropolitan Edison Company and its parent, General Public Utilities Corporation, is that TMI-1 closed by regulatory action because of the TMI-2 accident will not restart until well into 1980 at the earliest. This has burdened the utility with tremendous additional costs for the purchase of replacement power, and they are currently seeking a second rate increase in four months in order to restore their financial solvency. Thus, the financial risk for GPU from the TMI nuclear accident might be bankruptcy or its equivalent.

Another nuclear power plant which is in financial difficulties is Seabrook, $50 \%$ owned by Public Service Company of New Hampshire (PSNH). These difficulties are due to several factors, including: contradictory rulings by NRC and EPA, uncertainties related to regulatory decisions, violent protests and demonstrations by antinuclearites aimed at stopping plant construction, and inability to get Public Service Commission approval to include construction work in progress (CWIP) in the rate base. This latter issue is the most serious financial constraint at present since it inhibits certain other utilities from buying a larger share of the project from PSNH. In addition opponents of the plant rallied the public into forcing the Massachusetts Municipal Wholesale Electric Company to reduce from $14 \%$ to $6 \%$ its ownership share of the plant. As a result of these financial difficulties, PSNH is considering a delay in startup of Seabrook Unit 2 and may cancel it altogether.

The foregoing examples illustrate the financial problems stemming from the uncertainties and perceived financial risks associated with nuclear power plants. However, the other side of the issue was presented at the International Conference on Financing Nuclear Power held at Copenhagen, Denmark, during September 1979. The message from the hankers present was, "We cannot preserve world economic stability without a substantial nuclear power program. The financing to support such a program must, and can, be found." A managing director for Merrill Lynch commented that "Nuclear power is not an option but rather a necessity for economic 
growth,... and we at Merrill Lynch believe that capital is and will remain available." There were other statements on the investment community's ability to finance nuclear power, and the financiers and utility executives attending the conference expressed considerable confidence in the ability to provide the future funding for the nuclear power industry. "But," to quote Nucleonics. Week (Sept. 27, 1979, pg. 6), "if there was one major cloud on the horizon, it was the repeatedly mentioned area of uncertainty: the unknown and conceivably lethal effects of pending political and regulatory actions."

\subsection{Proliferation}

\subsubsection{Introduction}

The United States has been concerned with nuclear weapons proliferation from the start of the nuclear era. The initial approach was one of secrecy regarding all nuclear technology. When it became apparent that denial fostered national efforts to develop nuclear expertise, the alternative policy of promoting international cooperation under safeguards was inaugurated by Eisenhower. The relative effectiveness of the international approach was shattered by the Indian nuclear explosion of 1974 . Since that time, a resurgence of denial has occurred led by Canada and the United States. At this time, tensions between proponents of technology denial and proponents of stengthened international institutions for technology transfer have not been resolved. In the interim, tendencies toward national programs have possibly been increased because of perceived instability of international markets in nuclear technology and materials. A historical review of nonproliferation events is given in Table 6 .

\subsubsection{Problem of nuclear weapons proliferation}

Simply stated, the problem of nuclear weapons proliferation may be phrased thus: How can the nuclear power enterprise be managed on a global scale so as to be acceptable from the standpoint of weapons proliferation while, at the same time, making available widespread economic benefits in both the short and long term? 
Table 6. Chronology of events in nonproliferation

1945 U.S. detonated first atomic bomb.

1946 The Baruch Plan for international control of sensitive nuclear activities submitted to the U.N. Proposal not accepted; allowed to expire.

1949 U.S.S.R. detonated its first nuclear device.

1952 U.K. detonated its first nuclear device.

1953 President Eisenhower presented "Atoms for Peace" initiative before the United Nations General Assembly.

1957 'IAEA established under United Nations' auspices.

1960 France detonated its first nuclear device.

1960 IAEA adopted the first international nuclear safeguard system primarily for matcrial accountability and control.

1964 The People's Republic of China detonated its first nuclear device.

1968 NPT negotiated and opened for signatures.

1970 NPT entered into force.

1974 India exploded a nuclear device.

1974 Major nuclear suppliers first met in London to develop guidelines for the export of nuclear material, equipment and technology.

1976 Nuclear Suppliers Group established.

1976 U.S, deferred commercial reprocessing as an example to other nations.

1976 U.S. restricted the transfer of sensitive nuclear farilities (for reprocessing or enrichment) for a three-year period.

1977 U.S. embargoed the transfer of sensitive facilities.

1977 Proposed expansion of U.S. uranium enrichment capacity, and proposed International Nuclear Fuel Cycle Evaluation (INFCE) program.

1977 Inauguration of INFCE.

1978 Nuclear Suppliers Guidelines (NSG) published establishing

criteria for transfer of nuclear materials, facilities, and technologies to be followed by 15 supplier nations.

1978 Nuclear Nonproliferation Act (NNPA) of 1978 was signed. This clarified and stabilized U.S. terms for nuclear cooperation. 
To arrive at a better understanding of the dimensions of this problem we shall consider first some ancillary aspects of the matter to set the issue in perspective. Thus we shall first ask what the motivations are for nations to acquire nuclear weapons, next consider the nature of the coupling between nuclear power and weapons production, examine the world's need for nuclear power; and finally analyze the problem in the light of these considerations.

\section{Motivation of nations to acquire nuclear weapons}

In his penetrating short study of the psychology of proliferation, Betts 46 cites three fundamental motives for nations to acquire nuclear weapons: fear, status, and ambition. Fortunately, many nations currently assumed to possess the technical capability and nuclear materials with which to build nuclear weapons have not yet been motivated to do so. Most of these nations seem to perceive the possession of nuclear weapons to be less desirable from a security viewpoint than alliances or collective security arrangements with neighboring nations or superpowers. The Nonproliferation Treaty is one such multinational arrangement.

Betts cites the following list of countries which currently require very careful consideration from the motivation standpoint:

$\begin{array}{lll}\text { Argentina } & \text { Israel } & \text { South Africa } \\ \text { Brazil } & \text { Libya Korea } & \text { South Korea } \\ \text { Egypt } & \text { North Kaiwan } \\ \text { Iran } & \text { Pakistan } & \text { Yugoslavia }\end{array}$

Often the motivation is a defensive response against the perceived nuclear weapons capacity of a traditional or potential rival. Thus, for example, Pakistan is reacting to India, Argentina might react to Brazil, and Brazil to Argentina. Japan though not currently on Betts's list of problem countries, might react to North Korea, South Korea, or Taiwan.

The elimination of national desires for nuclear weapons based on deeply felt security needs or powerful ambitions appears to be the most difficult element of the nuclear weapons proliferation problem. A onebomb-per-year production capacity would constitute less than $10 \%$ of the military budget of even the poorest powers on the above list, and four times that production rate would cost only twice the money. 
Coupling between nuclear power and weapons production

Nuclear weapons can be manufactured with relatively small amounts of any of the fissile isotopes, especially uranium 235, plutonium 239, and uranium 233. Because of the small amounts needed and the desire for highpurity materials, all nuclear weapons materials to date have been produced in special facilities for isotope enrichment or in special reactors for isotope production. These options will exist with or without commercial nuclear power, and recent developments appear to make centrifuge enrichment of natural uranium the most important proliferation avenue as a direct path for weapons production. At the same time, insutficiently regulated commercial nuclear power offers nonweapons nations the possibility of appearing to abide rigorously by nonproliferation treaties while (1) surreptitiously diverting small amounts of fissile material, (2) surreptitiously diverting neutrons through irradiation of special fertile assemblies to create fissile material over a long time period, or (3) confiscating large amounts of fissile material at the time of an impending crisis. While fissile fuel in the commercial fuel cycle is rarely in weapons-usable form, relatively simple processing of spent reactor fuel can be performed to obtain weapons-usable material.

It is important to consider all paths to proliferation with or without nuclear power. An important, often overlooked, problem is that any intense source of neutrons can be used for production of fissile material. Such sources include high-power research reactors, fuel or blanket positions in power reactors, accelerators, or possible future fusion reactors. High-purity weapons materials can be produced by placing uranium 238 or thorium 232 in these neutron environments and following this irradiation with a fairly straightforward chemical processing step.

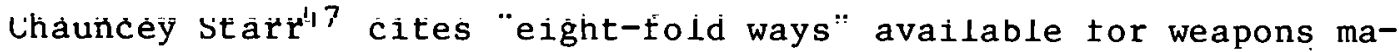
terial production in roughly the following order of increasing cost and difficulty: research reactor, production reactor, centrifuge cascade, accelerator, electromagnetic separation, aerodynamic jet cascade, power reactor. Ihe location of the gas centrifuge cascade in this list is arguable; a study made for the office of Technology Assessment ${ }^{48}$ has placed it first in the list, and we would also be inclined to place it higher than Starr did. Nonetheless, Starr's general logic is valid within his assumed 
framework, and it supports his argument that deferral of plutonium reprocessing and the breeder reactor affects only the more expensive and less plausible routes to proliferation.

While this argument is correct for nations starting from zero, it ignores the sunk costs many nations will already have expended for nuclear facilities at the time their governments might decide to build weapons. A nation having a plutonium reprocessing plant or a centrifuge cascade for reactor feed, for example, could produce the needed fissile material in days or weeks at a low incremental cost. The Arms Control and Disarmament Agency estimates a total elapsed time of one year and a cost of $\$ 0.85$ million to produce an explosive device starting with the suitably enriched output of a reprocessing plant or an enrichment plant. Four to six years and $\$ 50$ million to $\$ 200$ million are needed for routes that require the construction of enrichment plants, small. reactors, and/or reprocessing plants. It is important to note that since these costs are small fractions of the military budgets of virtually all nations, any nation with the resolve to produce weapons can do so given enough time. The time estimates appear rather long considering the times required for the Manhattan Project and the technical advances since then, but these time estimates do not reflect the magnitude of expenditure and the quality of ta1ent available to the United States during World War II.

It is felt that a small clandestine facility for recovering plutonium from long-cooled spent light-water reactor fuel could be built for considerably less than ACDA's estimate and in less time. The plutonium recovery operations would involve much higher personnel radiation exposures than would be experienced in commercial plants, but the radiation exposure level would be nondisabling and could be accepted as a military necessity. Albert Carnesale, a member of the Ford study committee, cites a "political threshold" which a national leadership must cross in deciding to build a weapon. 49 This threshold, he feels, should be maintained as high as possible. The ready availability of plutonium, enriched uranium, or facilities that could easily produce these materials will tend to lower the decision threshold. A decision to build a reprocessing plant for civilian uses had a low political threshold prior to 1977 , but this is no longer the case. Several low-threshold decisions in series over a period 
of years are much easier to make than a single high-threshold decision to build facilities solely for weapons production.

We have concluded that nuclear power and proliferation risk are indeed closely coupled, though not using nuclear power may lead to energy shortfalls which would involve equally serious risks, as will be discussed later. While all nuclear power cycles have some risks, some cycles contain inherently higher risks than others. It is generally beileved that the proliferation risks of the once-through light-water reactor (LWR) fuel cycle are acceptable because there is no direct access to weapons-usable material. We agree that this is currently the case, since there are only a few enrichment plants, the plants are located solely in nuclear weapons states, and no significant reprocessing-recycle operations are under way. The LWRs nevertheless have poteritial risks which include the following:

1. Enrichment. An enrichment plant capable of producing $3 \%$ enriched LWR fuel is intrinsically capable of producing fully enriched, ideal bomb material with minor process rearrangements. A centrifuge plant is particularly attractive for diversion to weapons material production because the equipment is simple and because relatively small plants are feasible in the support of small nuclear power programs. The required change in product enrichment could be carried out in a day or two. Gaseous diffusion plants inherently have more inertia and might require a year or more for the changeover from low-enriched to high-enriched product, and they might be designed so that there would not be enough stages to do the required enrichment on a continuous basis. To give an idea of the relative scales of effort, an enrichment plant capable of making enough low-enrichment fuel for a single standard power plant could be converted to make a dozen bombs a year, and, in the case of the centrifuge plant, the fissionable material for the first bomb could be available two months after the conversion. Several centrifuge pilot plants in this capacity range are being built.

2. Reprocessing. The recovery of plutonium from spent LWR fuel for recycling into power reactors provides a stream of sufficiently pure fissile material to make somewhat inefficient, but still potent, nuclear explosives. Even if special processes are used, such as coprocessing where uranium and plutonium are not separated, the material is in such a form 
that diversion to a clandestine chemical laboratory could lead to recovery of highly fissile plutonium. Alternatively, process changes might surreptitiously be made in the coprocessing plant so that pure plutonium could be isolated.

3. Spent Fuel Storage. The once-through or throwaway fuel cycle leads to spent fuel elements which are stored either temporarily or permanently. While stored material as such cannot be utilized as weapons materials, with the passage of time, as the fission product radioactivity declines, the spent elements become an increasingly tempting source of recoverable plutonium. It would be moderately easy to recover weapons material from the spent fuel in a small reprocessing plant. A one-bomb-ayear effort of this type would be within the financial capability of nearly all countries if stored fuel elements were available.

4. Recycled Mixed-0xide Fuel. Since recycling the reprocessed uranium and plutonium into LWRs can increase the energy derived from the uranium originally mined by about $50 \%$, there is a significant incentive for such recycling. The mixed oxide, $(\mathrm{U}, \mathrm{Pu})_{2}$, fuel resulting from such recycling constitutes a relatively accessible source of weapons material, since the plutonium can be recovered in pure form by a very simple chemical separation, and although the plutonium is not of the isotopic composition most desirable from a weapons point of view, it would nonetheless be adequate for such a purpose.

Fortunately the needs to recycle mixed-oxide fuel into LWRs are not immediate and can be in general deferred until there are adequate institutions and/or technical process improvements to reduce the proliferation risk to acceptable levels. The development of these institutions and/or techniques are particularly important in that they would be needed to support the breeder option which requires fuel recycle. The perceived need of some countries for breeders reinforces the urgency of dealing with proliferation issues in a comprehensive manner.

\section{Problem of subnational nuclear enterprises}

Ted Taylor ${ }^{50}$ has focused attention on the possibility that a highly motivated and knowledgeable individual or small group could produce a nuclear weapon. Without analyzing the magnitude of this claimed danger, it 
is safe to say that this particular risk has been and can continue to be kept at an acceptable level by proper application of IAEA safeguards and physical security. Subnational groups are not likely to command the resources for building fuel reprocessing plants, enrichment plants, or production reactors. The capture of a completed nuclear weapon by a subnational group and its subsequent use for political extortion is probably a greater risk.

World need for nuclear power

The world need for nuclear energy is one of the most fundamental aspects of the proliferation dilemma. Many recent reports have focused on the deteriorating balance between world supply of and demand for gas and oil. Nuclear energy is envisioned by many countries as the only practicable alternative to gas and oil and for the generation of electricity now that the oil and gas are needed for more pressing uses. The United States is fortunate to have abundant coal and other fossil fuel supplies, but few other nations are so situated. Even so, nuclear energy is needed in the short term to bridge the gap between fossil fuel supply and demand. It is also needed as a long-term option until possibly more desirable energy sources are made available. The United States is also fortunate in its uranium resources, and it can afford to defer plutonium recycle in LWRs and the breeder until such a time as less proliferating nuclear fuel cycles are available. Many countries believe they cannot afford to wait. Their need is great and their alternatives are few.

Perceived energy needs without reasonably assured supply options could become an explosive world issue. Shortage of energy could well lead to economic depression in the Western countries and act as a brake on progress in the developing world. While it may be impossible to strike a quantitative balance between the risks of energy shortfall and of nuclear weapons proliferation, we believe that they are of the same order of magnitude. The absence of the nuclear power option would be expected to increase world tensions and therefore to increase the national incentives toward nuclear proliferation.

To summarize, then, we feel that abandoning the nuclear energy option on a global scale does not appear to be a feasible method of eliminating 
proliferation. Although it would eliminate some routes to weapons production (for example, recovery of plutonium from spent reactor fuel or fresh mixed-oxide fuel), it would not eliminate other paths which are quite accessible, both economically and technologically, to even the less affluent nations (for example, centrifuge enrichment, or production reactors). Furthermore, the dangers to world stability posed by energy shortages in much of the world, almost inevitably resulting from nonutilization of nuclear power, could well be as large as or larger than those posed by the proliferation of nuclear power.

\subsubsection{Solution of the problem}

\section{Criteria: musts and wants}

In order to guide us in the formulation of possible solutions to the problems posed by the possible link between utilization of nuclear energy and the proliferation of nuclear weapons, and as a yardstick against which to judge proposed solutions, we shall first try to state the necessary and desirable elements of such a solution. The following three criteria are the musts, i.e., the necessary components of any solution:

- Nuclear power operations should be carried out in a manner that will not substantially increase the risks of nuclear weapons proliferation.

- Nuclear power should be widely available to satisfy short-term needs for energy and should also be developed as a practical energy option for the long term.

- The procedures and institutional framework developed for control of nuclear power operations should be internationally acceptable on as wide a basis as possible.

As a list of desirable, though not indispensable, elements of a solution, we cite the following nonexhaustive compilation of wants:

1. Increase incentives for nonnuclear weapons states not to acquire nuclear weapons.

2. Support the desire of nations for as high as possible a degree of energy self-sufficiency. 
3. Support the desire for relatively cheap power.

4. Support the technology-importing nations' sources of fuel cycle services.

5. Avoid undue dominance by nuclear weapons states over nonnuclear weapons states.

6. Support the desire of the majority of nations that no new weapons states be created.

7. Support the desire of exporting nations to profit from export of nuclear technology.

8. Support the desire of importing nations to obtain technology on an equitable basis.

\section{Elements of a solution}

An ORNL/UCCND committee, convened in 1977, arrived at an approach from which we are borrowing here. The elements of the approach are as follows:

1. The problem can be solved neither by purely political nor purely technical means. The solution must involve a mixture of both.

2. The key step in the solution of the problem is the partitioning of nuclear technology activities into high-risk and Low-risk categories where the proliferation risk factors are relative to the degree of control necessary to assure nonproliferation. The risk characterization is likely to be a continuing judgment, and activities may change from one category to another as new technologies are introduced.

3. In order to control the high-risk activities and simultaneously remove the basic problems of national rivalry and secrecy, one or more multinational or international enterprises must be created to own and operate "energy centers" or "fuel cycle centers" containing the high-risk activities. These enterprises must be owned and staffed by a consortium of nations and should be regulated and inspected by a recognized worldwide organization such as the IAEA. There could be more than one such enterprise, so as to provide stable and competitive import-export markets; the existence of some national enterprises in addition, under suitable conditions, is not precluded. 
4. The low-risk activities will be dispersed under national or private ownership but with sufficient inspection (perhaps by resident inspectors) to assure compliance with the restrictions and agreements determined by international agreement for each nuclear activity.

5. As in the Acheson-Lilienthal plan, the primary safeguards mechanism is the reduction of national rivalries and secrecy in nuclear technology and the clear detection of any violation of the international agreements. Sanctions against violation could be part of the agreements, especially where the sanctions are associated with the supply of fuel and components within the nuclear cooperatives.

\section{Political and technical elements required for a solution}

We conclude that the problem cannot be solved by purely political means, since any political solution that permits the deployment of sensitive technology on the basis of political commitments by a government could be negated by a coup d'etat followed by a repudiation of the commitments.

Neither, we conclude, can the problem be solved by purely technical means. Neither we nor anyone else, to date, has been able to devise a technically proliferation-proof system. The various technical options do differ in the degree of proliferation risk - for example, in the time and cost required for producing weapons material once a decision is made to do so - but none would prevent the ultimate success of a national effort. Therefore we conclude, as the Acheson-Lilienthal report did, that a mutually supportive structure of technical and political steps offers the best hope for a solution.

\section{Low- and high-risk activities}

The Acheson-Lilienthal report ${ }^{51}$ considered the following operations to involve significant proliferation risk: (1) provision of uranium and thorium raw materials, (2) production of plutonium and uranium 2.35 (and by implication uranium 233), and (3) the use of these materials to make weapons. The safe activities were stated to be (1) use of radioactive tracers, (2) operation of research and isotope production reactors fueled 
with denatured fissile material or of very small size, or both, and (3) operation of power reactors fueled with denatured uranium or plutonium under reasonable safeguards and inspection.

The differentiation between these two categories of activities is the key logical step in the Acheson-Lilienthal report. The ability to make this distinction enforceable through international collective action represents the unique procedural solution to the proliferation problem.

Analogous to this list from the Acheson-Lilienthal report, we suggest the following catalog of high-risk and low-risk activities, as of the present year:

lligh-Risk Activities

1. Enrichment, particularly now by the centrifuge process and perhaps eventually by the laser process.

2. Storage of irradiated fuels.

3. Chemical reprocessing of irradiated fuels and fabrication of recycle fuel.

4. Weapons production or research.

5. Operation of power reactors using clean fuel containing weapons-usable uranium 235, uranium 233, or plutonium.

Low-Risk Activities Suitable for National Enterprises (under suitable international safeguards and inspection)

1. Uranium and thorium production.

2. Operation of reactors using low-enriched or denatured fuclo, or of very omall o1zc.

\section{Control of high-risk activities}

The ORNL/UCCND commltee concluded that high-risk activities could best be controlied if they were carried out in internationally-controlled fuel service centers. The plausibility of such regional fuel cycle centers was verified in a recent IAEA study. 52 Shares in the ownership of these facilities should be available to all countries on an equitable 
basis; the siting is a more difficult matter but might be resolved as follows: (1) some sites in nuclear weapons states, (2) sites in advanced nonnuclear weapons states with large nuclear power capacity and obvious indigenous weapons potential, (3) sites on islands or in especially stable or "neutral" countries.

Security forces for the centers should be provided by an international military force containing major power elements. Any legal acquisition of such a fuel cycle center by the host country should require many years' notice and compensation; seizure should be regarded as a hostile action.

The sensitive facilities should be designed in a manner that reasonably maximizes the time to produce weapons in the event of a seizure. For example, centrifuges should be capable of being quickly destroyed; chemical reprocessing should be of the coprocessing type. Minimal inventory of pure fissionable materials, if any, should exist.

The international fuel cycle services should be priced at a sufficiently low level to make national facilities economically unattractive. The fuel cycle centers should provide for waste disposal as part of the service.

Severe penalties should be provided for violations of international agreements governing the use and security of these fuel cycle centers. Depending on the nature of the violation, nuclear materials embargo, other economic sanctions, and even international police action might be provided for.

International fuel service centers were not seriously considered by INFCE because the United States was pushing for deferral of reprocessing, while the proponents of reprocessing generally were protecting their national programs.

Incentives for nations not to acquire nuclear weapons: carrots and sticks

Simple incentives may suffice to induce many nations to join a collective security system endorsed by the superpowers. One incentive is the increased security due to potential rival countries not gaining nuclear 
weapons. Another incentive would be economical and widely available nuclear fuel cycle services. It would be desirable to price these services at a discount for countries that have signed the strengthened nonproliferation treaty.

A very strong incentive that could be offered to cooperating nations and that should be considered by the United States and the U.S.S.R., is for the superpowers to assume the burden of the isolation of high-level radioactive waste. Many. countries using nuclear power do not have geologic formations suited to burying such wastes. The added risks to the populations of the United States and the U.S.S.R. arising from such waste isolation would be minor compared with the greatly reduced risks of nuclear weapons proliferation.

The present Nonproliferation Treaty seems to reward rather then penalize nonsignatories reaching weapons status. The new internationa 1 agreement should have built-in penalties for nonsignatories. These penalties will have to be carefully devised so as not to persuade nonsignatories to build their own "proliferating" fuel cycle facilities.

Political decision-makers will have to determine how much they are willing to pay and how much force they are willing to use to preserve nonproliferation. Betts lists five general policy options:

1. Laissez Faire. Recognize the limits of U.S. power and hope for the best.

2. Carrots. Offer compensating economic, technical, and other nonmilitary advantages in return for good behavior.

3. Military aid. Use U.S. power or military assistance to support the security of a country and make nuclear weapons unnecessary.

4. venial. Embargo nuclear rechnology and materials.

3. Sticks. I'hreaten to withdraw support it good behavior is not maintained.

Policy options must be used carefully and in various combinations. Care must be taken not to create additional problem countries as the result of shifting commitments or withdrawal of power. 
World uranium and thorium resource development

One of the great world uncertainties in the energy field is the projection of future demands for nuclear power and the rate at which uranium and thorium resources can be developed to satisfy these demands. The urgency of plutonium recycling and the deployment of the breeder is closely related to these parameters. One element of the new international system should be an expanded search for nuclear raw materials.

While low-risk activities in themselves, uranium and thorium mining, milling and transport should be under international overview. Uranium sales to countries with no civilian need for nuclear fuels would be a danger signal; so would unexplained inventory shifts.

Control of alternative fuel cycles

As was stated earlier, the proliferation problems cannot be solved by either purely political or purely technical means. The framework for the solution is the structure of international enterprises and controls and the safeguards restrictions on the dispersed reactors. The tools for making these political institutions work must be found in the technical area and are associated primarily with reactor design, fuel cycle, storage and transport, and instrumentation for fissile inventory accounting and for detection of diversion. There are a large number of technical options, and it is important that they be considered within the framework of and be adjunct to the political institutions that are evolved. Similarly, the political institutions must reflect the needs identified in the technical options.

Alternative fuel cycles, centered on advanced reactors or breeders, cannot be implemented for many decades (for technical and economic reasons). By then, the context for proliferation concerns and the world nuclear energy regime- will have changed. After the international nonproliferation framework is set up, one should continue to evaluate the usefulness of alternative fuel cycle technologies. The selection of these cycles will have to balance proliferation risk against world needs for nuclear power. Factors to be considered are the uranium resource supply, the rate of nuclear power growth, the fraction of capacity that can be 
supported in "centers," the physical security arrangements, and the proliferation risks of the alternatives.

Institutional problems in the implementation of a new nonproliferation framework

The recommended actions constitute a major reorganization of international instruments for control of nuclear energy and therefore would require long and difficult negotiations involving many countries. Elements in the plan such as international or multinational fuel cycle centers, the imposition of sanctions, the deployment of international security forces, international monitoring of uranium mining, and a greatly expanded international inspection function represent radical departures from current practices. Fortunately, it might be possible to implement the plan in stages starting with the most urgent topics such as spent fuel storage and enrichment.

The plan is believed to satisfy the musts identified earlier, but it does not fully satisfy the wants. For example, it discourages energy self-sufficiency except within a multinational framework. It reduces the possibilities of profit from the export of nuclear technology, for example from export of enrichment of reprocessing plants. The final plan would have to balance costs and benefits for nuclear weapons states, for industrial nonweapons states, and for developing countries in order to gain acceptance trom a working majority of countries.

\subsubsection{Conclusions and recommendations}

We conclude, as the Acheson-Lilienthal report did in 1946, that there is hope for restricting nuclear weapons proliferation while enjoying the fruits of nuclear power. In effect, we believe that the level of proliferation risk that accompanies nuclear power can be held to the same level of risk that exists without it.

The first step in controlling proliferation must be international agreements setting up an improved framework for the control of nuclear power. Specifically, "high-risk" technologies should be restricted to sites within nuclear weapons states or under international superviston or 
both. High-risk technologies include uranium enrichment, fuel reprocessing, fuel refabrication, spent fuel storage, and use of clean plutonium fuels. The alternative fuel cycle technologies represent tools that can be used to improve the level of control within the international nuclear power framework.

The international system that should be set up to control nuclear power would somewhat restrict, but surely not eliminate, the possibility of producing weapons by non-power-plant routes such as enrichment plants or production reactors. These routes would be more difficult in some cases if there were restrictions on technology transfer in sensitive areas such as uranium enrichment. International monitoring of uranium shipments would be a necessary step in providing information on proliferation intent.

A very key problem is the demotivation of certain nonnuclear weaporis states that are keeping their nuclear weapons options open. This demotivation is likely to be difficult and expensive, and in some limited circumstances.it may not be feasible at a11. In the context given above, the benefits of nuclear power would be one incentive to limit proliferation. We are aware that the process of negotiating the necessary international agreements will be long and difficult. Some countries are likely to initiate national fuel cycle efforts in the "high-risk" class before the international agreements are in place. It is to be hoped that these national facilities can later become elements of the international system.

Decision-makers and the public should also be aware that an effective international system for control of nuclear power would represent only "one small step for mankind" on the road to freedom from nuclear weapons proliferation and nuclear war. A vigorous U.S. nuclear technology and fuel cycle services program within the context of international agreements is a vital element of the ability of the United States to influence other sovereign nations to cooperate in international control ventures for mutual benefit. 
NASAP

NASAP results were generally consistent with the findings of the earlier ORNL/UCCND study. The most important observations of the NASAP proliferation resistance assessments are stated to be:

- All fuel cycles entail some proliferation risks; there is no technical " $f i x$ " that will permit operation of a nuclear-power fuel cycle with material that cannot be diverted to use in nuclear weapons or that will preclude a determined owner-operator from designing a proliferation strategy.

- Substantial differences exist, however, between the fuel cycles if they are deployed in NNWS's. Some of these differences are technical in nature (e.g., no reprocessing in once-through fuel cycles), and some result from institutional arrangements (e.g., existing international enrichment services supplies almost totally by NWS's).

- On the other hand, with the progressive introduction of technical and institutional proliferation resistance measures, these differences may be made much smaller by the time the fuel cycles eventually come into widespread use.

- The vulnerability to threats by subnational groups varies between fuel cycles; whereas the once-through fuel cycles are susceptible to only the most sophisticated thrcats, closed fuel cycles are vulnerable to a wide range of threats.

- The once-through system has relatively high barriers to proliteration at this time, but it does have vulnerabilities:

- The greatest proliferation risk in the once-through LWR cycle arises if the potential prolifcrator has an enrichment plant. In the system as deployed, however, virtually all enrichment services are supplied by NWS's.

- Spent fuel also represents a proliferation risk if the potential proliferator has an out-of-system reprocessing facility to recover weapons-usable plutonium.

- Facilities for closed fuel cycles potentially increase proliferation risk because plutonium would appear in weapons-usable form and in forms that are relatively easy to exploit for weapons purposes. 
Without deployment constraints and suitable institutional arrangements for control in NNWS's, plutonium would appear in substantial and widespread inventories in bulk forms, which are inherently difficult to safeguard.

Five basic norms for a strengthened international regime designed to minimize the worldwide distribution of weapons-usable materials while taking account of energy security needs:

- Use of diversion-resistant forms of materials and technologies.

- Avoidance of unnecessary sensitive materials and facilities and an effective export control system

- Joint or international control of necessary sensitive materials and facilities

- Ful1-scope safeguards and a timely international system of warning and response

- Institutions to ensure the availability of the benefits of nuclear energy.

Opposing view

The U.S. doctrine summarized above has not been accepted by most of the uranium-deficient industrialized countries. Plutonium recycle, after a11, had been part of the nuclear package since 1955 and is regarded as a necessary part of the long-term nuclear program.

It is asserted that

- Growing stockpiles of spent fuel are a greater danger than a closed fuel cycle.

- The safest place to put plutonium is inside a reactor.

- The IAEA safeguards regime is adequate to control proliferation for the present.

We believe these views can be readily rebutted, i.e.,

- Growing stockpiles of spent fuel will occur at many sites and would have to be safeguarded whether or not reprocesssing were available. 
- Pu is safe inside the reactor but less safe in reprocessing plants, fab plants, stockpiles, etc.

- IAEA does not have staff adequate to safeguard many national closed fuel cycles.

\section{Observations regarding INFCE}

The most constructive aspects of the INFCE have been the initiation of discussions tending to strengthen international institutions, for example on control of plutonium storage. Supplier countries (Germany, France) have become more cognizant of the proliferation issue.

INFCE has developed a lot of technical data but has not changed any national goals. Those countries who may wish to proliferate (India, Pakistan, Israel, South Africa, etc.) will not be deterred by a U.S. (or even a European) decision to forego reprocessing. INFCE did not develop any new ideas for generating sanctions against proliferators.

The ambivalent U.S. position on nuclear power has strengthened opponents of nuclear power programs everywhere. While the programs of France, U.S.S.R. and South Korea have maintained momentum, other nations such as West Germany, Japan, Sweden, Spain, and Switzerland have slowed up their programs because of political problems simllar to those of the Unj.ted States.

INFCE has not produced anything relevant to the needs of developing countries, which are the potential proliferators. If INFCE has helped make nuclear power unpopular for small countries, discouraging nuclear manpower training programs, there will be fewer personnel to proliferate in the long run. Such impacts were not the stated intent of INFCE.

The general slowdown of nuclear programs delays substantially the worldwide need to deploy breeders and "the plutonium economy." The Carter policies may have been more effective than opponents will admit. The long-term price may be high, however, if the result is an insufficient supply of energy . 


\subsection{Uranium Resources}

\subsubsection{Introduction}

The subject of uranium resources is important because nuclear power requires a supply of fissionable material, found in nature only as $\mathrm{U}-235$. Nuclear technology is currently based on once-through fuel cycles which are inherently inefficient, since valuable fuel resources reside in the spent fuel.

Much more resource-efficient nuclear technologies (i.e. recycling and breeders) are potentially available but have been deferred because of.proliferation concerns. Uranium resources have been a politically sensitive issue because the need for and timing of fuel reprocessing and recycle are related to the quantities and cost of uranium.

Several assessments of uranium resource availability have been publicized ${ }^{53-55}$ leading to some confusion among decision-makers relating to resource adequacy. In our view, there is less disagreement about the probable extent of the uranium endowment than about the probable rate of discovery and development on the one hand, and the prudent rate of deploying breeder reactors on the other hand.

We shall display the currently accepted resource estimates against a range of predicted requirements, for the U.S. We shall also discuss the world uranium resource estimates.

It should be kept in mind that the quantity of uranium available is not fixed, but rather is a function of price, the health of the mining industry, the rate of growth in demand, the social acceptability of mining specific deposits, etc. The urgency of meeting domestic supply goals is also tempered by the prospects for imports and the substitutability of coal for uranium in new plants.

The uranium resource base may be extended significantly through the use of low-grade ores, * covered in a companion ONEP paper. 56 The ana1ysis presented in this section covers only the "high-grade" ores.

*The amount of uranium potentially recoverable from low-grade ores in the United States is 5 million tons or more of $\mathrm{U}_{3} \mathrm{O}_{8}$. 


\subsubsection{Current estimates of high-grade uranium resources in the United States}

The Department of Energy and its predecessors, working closely with the uranium industry, have published estimates of uranium resources and reserves annually since the 1950s. The latest estimates as of January 1 , 1979, are presented in Table 7 for high-grade reserves and the three categories of potential resources; each category is further divided into categories based on their forward costs. The estimates are for $\mathrm{U}_{3} \mathrm{O}_{8}$ from ore considered to be recoverable through mining. Losses that occur in the milling process have not been deducted. The total of these resources is about 4.1 million tons of $\mathrm{U}_{3} \mathrm{O}_{8}$. However, there is a possibility that these resources will be significantly less than this "best" current estimate; this uncertainty can only be resolved by further exploration and data analysis.

Potential resources, as shown in the table, are largely undiscovered, although some inferred but less certain reserves are included. The potential resouces are subdivided into three categories: probable resources, those estimated from extension of known deposits and new deposits within known geologic provinces; possible resources, those lying in productive geologic provinces that are undeveloped; and speculative resources, those existing in unexploited strata in known productive provinces. Most of the data used to make the reserve estimates were voluntarily provided by the uranium industry.

In estimating potential resources, the Department of Energy uses all the available national data, including data from its own exploration and drilling operations. The Department of Energy is now conducting the National Uranium Resources Evaluation (NURE) Program which is an effort to evaluate resources in all 50 states and to identify areas favorable for exploration by Industry. A comprehensive repurl un the évaluatión of currently known favorable areas believed to contain the majority of U.S. resources is to be completed in late 1980, and the balance of these areas will be evaluated by 1983. Other areas w11l be evaluated from 1983 through 1985. Most past exploration has been in the sandstone deposits in the Rocky Mountain States and in Texas. The NURE program includes these 
Table 7. DOE estimates of recoverable domestic $\mathrm{U}_{3} \mathrm{O}_{8}$ reserves and potential resources as of January 1,1979

(In thousands of tons of $\mathrm{U}_{3} \mathrm{O}_{8}$ )

\begin{tabular}{|c|c|c|c|c|c|c|}
\hline \multirow{2}{*}{$\begin{array}{c}\text { Forward } \\
\text { cost } \\
(\$ / 1 b \text { U308) }\end{array}$} & \multirow{2}{*}{ Reserves } & \multicolumn{4}{|c|}{ Potential Resources } & \multirow{2}{*}{$\begin{array}{l}\text { Total Reserves } \\
\text { and potential } \\
\text { resources }\end{array}$} \\
\hline & & Probable & Possible & Speculative & Total & \\
\hline$\leq 15$ & 290 & 415 & 210 & 75 & 700 & 900 \\
\hline $15-30$ & $\underline{400}$ & 590 & 465 & $\underline{225}$ & 1280 & $\underline{1680}$ \\
\hline$\leq 30$ & $690^{a}$ & 1005 & 675 & 300 & 1980 & 2670 \\
\hline $30-50$ & 230 & 500 & 495 & $\underline{250}$ & $\underline{1245}$ & $\underline{1475}$ \\
\hline$\leq 50$ & $920^{b}$ & 1505 & 1170 & 550 & 3225 & 4145 \\
\hline
\end{tabular}

By-product $\mathrm{U}_{3} \mathrm{O}_{8}$ that could be produced from phosphate and copper leach through the year 2000 is estinated to be 120,000 tons.

$a_{\text {Estimated }} \pm 15 \%$ uncertainty at $90 \%$ confidence level.

$b_{\text {Estimated }} \pm 17 \%$ uncertainty at $90 \%$ confidence leve 1 . 
areas as well as unfamiliar geologic regions without past production history. The program's analyses are to be based on the data available at the time and should not be considered as estimates of the total national uranium endowment, which will tend to increase as more data becomes available and gaps in basic knowledge of uranium deposition and transport are improved.

The Department of Energy estimates have, however, several limitations: (1) only the quantities presently known or surmised to exist, based on judgements from current data, are included; the estimate is not an estimate of the nation's total endownent; (2) the reliability of estimates decreases based on the amount of geological evidence available; and (3) the quantities do not imply any schedule of producibility. Technical and institutional factors will determine whether the resources will be produced at the indicated cost and what the production schedule will be.

There is a wide divergence of upinion on what the future uranium supply capabilities will be. Much of the divergence of opinion arises from misunderstandings of the terms, resources and supplies. An estimate of a resource is a time-dependent variable affected by the amount of prior exploration, the allowable cost for production, and the technology contemplated for production, not an absolute quantity. Reserves are that part of the resource estimate that are known to exist and can be produced economically with current or near-current technology. Reserves are clearly a very conservative measure of resources for long-term supply estimation, and additional potential resources should be considered as a function of higher prices and improved technology.

Potential supply is that portion of the resources that is expected to be discovered and produced at a particular price. Unless exploration and development of mines and mills keeps well ahead of demand, putential resourcc cctimatco are not meaningful indicators of the supply out lonk. for a long period of time, particularly if future uncertainties and constraints are ignored.

The supply process begins with exploration to find the resource; this can take an indeterminate period of time. After discovery, the resource. will be developed by drilling to determine its extent and to estimate the 
cost of production. This usually takes about 2 to 3 years. If the resource is judged to be economic, design and planning for mines and mills would begin. Applications for states and federal licenses would be submitted and licenses would be expected to be issued within 2 to 4 years. The construction of the mine and mill would then begin, and they would be completed within 2 to 5 years. Thus, more than a decade can elapse between the discovery of a new ore body and the start of production from the associated mine and mills. Many uncertainties and constraints can interrupt and extend this period. The scale and continuity of the exploration and development efforts that will be conducted by industry and the yields such exploration will produce are the principal uncertainties in whether the expansion of supply will occur. The exploration yield is regarded by most experts as unknowable. The willingness of industry to make high-risk exploration and mine-mill investments on a schedule needed to meet nuclear industry demands will be affected substantially by the firmness of the market and the institutional framework.

\subsubsection{Interpretation of resource data}

The CONAES resource analysis claims that energy planning should be based primarily on the high-grade uranium "reserve" and "probable" categories. This approach tends to justify early introduction of the breeder.

The Ford/Mitre analysis regards the "possible" and "speculative" categories as likely, and speculates that additional uranium may well be found. This approach tends to defer the need for the breeder.

The NASAP analysis focuses on "producibility" or the rate of production of uranium, considering all high-grade sources and low-grade sources as we11. Their approach leads to conclusions similar to those of the Ford/Mitre study. Table 8 is an indication of uranium price vs time for a variety of supply-demand assumptions.

For the present study, we shall. compare the range of high-grade endowment (Table 7) with NASAP demand projections in F1g. 3. The demand scenarios are bounded by

- $\mathrm{High}=395 \mathrm{GWe}$ in 2000 and 910 GWe in 2025

- Low $=255$ GWe in 2000 and 320 GWe in 2025 
Table 8. U.S. $\mathrm{U}_{3} \mathrm{O}_{8}$ price projection

(A11 prices in 1978 dollars)

\begin{tabular}{|c|c|c|c|c|c|}
\hline \multirow{2}{*}{ Year } & \multirow{2}{*}{$\begin{array}{c}\text { Cumulative } \\
\text { demand } \\
10^{6} \text { ton }\end{array}$} & \multirow{2}{*}{$\begin{array}{l}\mathrm{U}_{3} \mathrm{O}_{8} \\
\text { Low }\end{array}$} & \multicolumn{3}{|c|}{$\begin{array}{l}\text { price for supply } \\
\text { assumptions }\end{array}$} \\
\hline & & & Mid & $\operatorname{Mid}^{b}$ & $\overline{\mathrm{High}}$ \\
\hline
\end{tabular}

High demand

\begin{tabular}{rrrrrr}
1978 & 0.0 & 20 & 20 & 20 & 20 \\
1995 & 0.5 & 65 & 55 & 45 & 50 \\
2003 & 1.0 & 90 & 80 & 55 & 70 \\
2008 & 1.5 & 120 & 95 & 65 & 75 \\
2013 & 2.0 & 160 & 100 & 75 & 80 \\
2017 & 2.5 & 170 & 110 & 85 & 85 \\
2021 & 3.0 & 180 & 125 & 90 & 85 \\
2024 & 3.5 & 190 & 140 & 95 & 90 \\
2027 & 4.0 & 200 & 160 & 100 & 90 \\
2030 & 4.5 & 215 & 170 & 110 & 95 \\
2033 & 5.0 & 230 & 180 & 125 & 100 \\
2036 & 5.5 & 260 & 190 & 140 & 105 \\
2039 & 6.0 & 260 & 200 & 160 & 110 \\
& \multicolumn{7}{c}{ Low demand } & & \\
1978 & 0.0 & 20 & 20 & & 20 \\
1997 & 0.5 & 55 & 50 & & 45 \\
2006 & 1.0 & 60 & 55 & & 50 \\
2015 & 1.5 & 80 & 60 & & 55 \\
2023 & 2.0 & 120 & 60 & & 55 \\
2032 & 2.5 & 160 & 65 & & 55 \\
2040 & 3.0 & 170 & 75 & & 55 \\
\hline
\end{tabular}

$r_{\text {Assumes continuation of the once= }}$ through cycle.

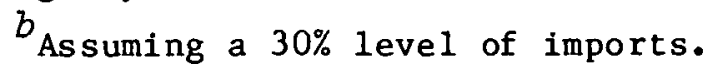


- Standard LWR once-through cycle, $0.2 \%$ enrichment tails

- $15 \%$ Improved LWR once-through cycle, $0.05 \%$ enrichment tails

- LWR with Recycle, $0.2 \%$ enrichment tails

- LWR with Recycle, $0.05 \%$ enrichment tails

Figure 3 shows that, in the event of high demand, the standard LWR-OT cycle with $0.2 \%$ enrichment plant tails will commit the 2.4 million ton $\mathrm{U}_{3} \mathrm{O}_{8}$ endowment by shortly after 2000 , and will use the 4.15 million ton endowment by 2025 . A total of 6.8 million tons would have been committed by 2025 .

The resource picture can be substantially improved by either (a) a 15\%-improved LWR on the once-through cycle combined with enrichment plant tails-stripping, or (b) recycle (preferably combined with tails-stripping). All of these options would be economic if uranium prices rise as expected. The combination of recycle and tails-stripping would reduce $2025 \mathrm{U}_{3} \mathrm{O}_{8}$ consumption below 2.4 million tons and commitment below 4 mil1ion tons.

If demand for nuclear power is "low", then once-through LWR options are adequate through 2025.

\subsubsection{Foreign resource analysis}

World uranium resources have been compiled by INFCE Working Group 1. A summary of the INFCE data appears in the NASAP report. World uranium supply-demand relationships approximate those of the United States; both Communist and non-Communist regions are adequately endowed with uranium. If anything, the world may be better endowed than the United States because it has not been as well explored.

The only major regional shortage of uranium applies to Western Europe and Japan, which must import major quantities. Fuel production in breeders has nhvinus strategic impact for these regions.

\subsubsection{Conclusions and recummendations}

A long as demand for nuclear power is within the range covered by recent DOE projections, orderly development of conventional resources should suffice to supply both world and II.S. needs. This is construed to require the following developmental activities: 


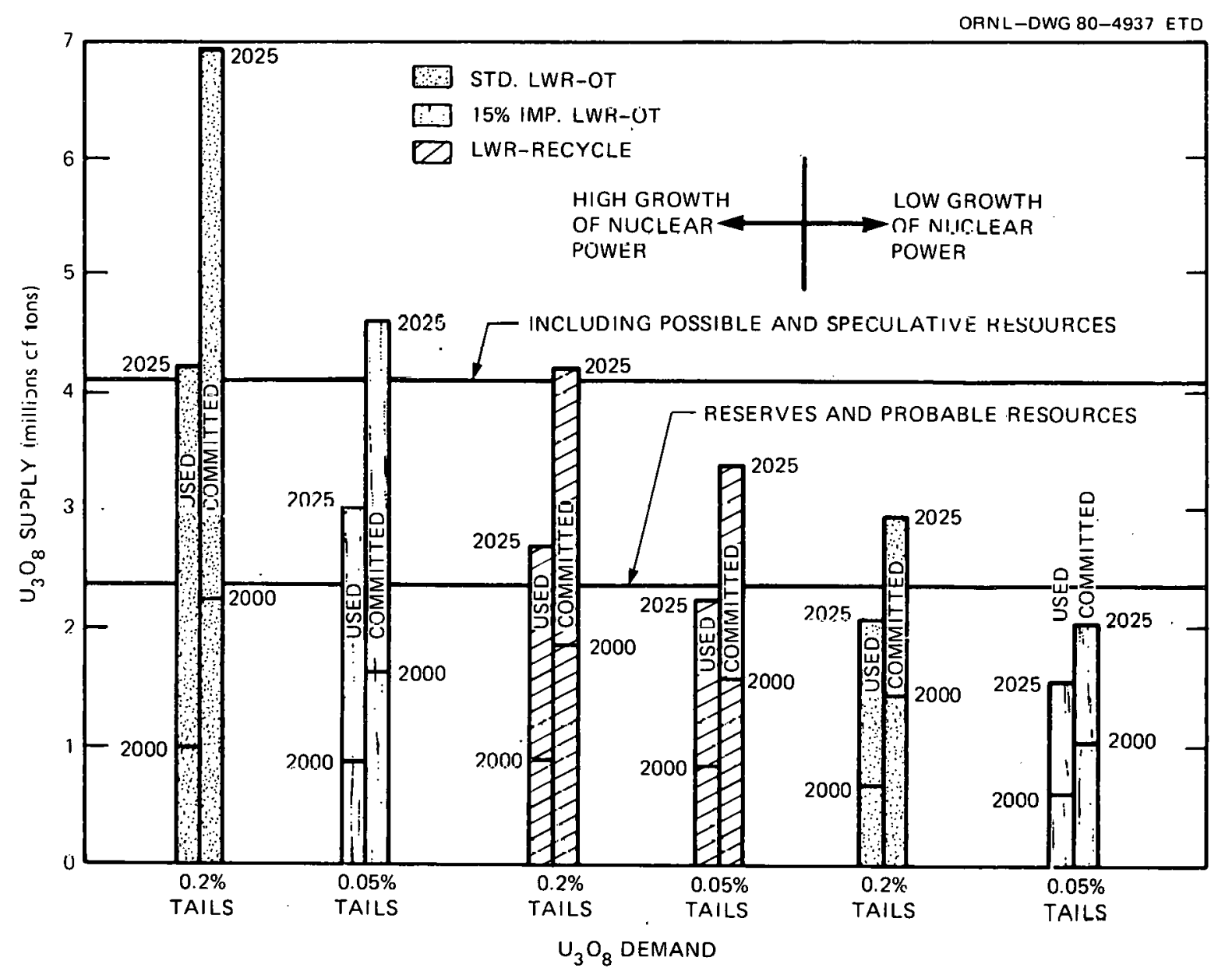

Figure 3. U.S. high-grade uranium resources, supply vs demand 
- Resource assessment programs such as NURE.

- Reșearch on low-grade and by-product sources of uranium.

- Moderately-improved LWRs.

- Advanced isotope separation technology. Improves tails-stripping economics.

- Retain the reprocessing/recycle option.

\subsection{Fuel Recycle}

\subsubsection{Incentives for recycle}

The spent fuel discharged from light water reactors contains substantial amounts of slightly enriched $U-235$ (between $0.7 \%$ and $1.0 \%$ ) and plutonium. If recycled into LWRs, the system energy output would be increased by about $80 \%$ (according to NASAP mass flow data). The $\mathrm{U}_{3} \mathrm{O}_{8}$ requirements for 30 years at 1 GWe ( $70 \%$ capacity factor, $0.2 \% \mathrm{U}-235$ tails) are as follows:

$$
\begin{array}{ll}
\text { Once-through } & 5680 \text { tons } \mathrm{U}_{3} \mathrm{O}_{8} \\
\mathrm{U} \text {-only recycle } & 4340 \text { tons } \mathrm{U}_{3} \mathrm{O}_{8} \\
\mathrm{U}+\mathrm{Pu} \text { recycle } & 3120 \text { tons } \mathrm{U}_{3} \mathrm{O}_{8} \text { * }
\end{array}
$$

The value of the $\mathrm{U}+\mathrm{Pu}$ in the U.S. spent fuel stockpile will increase with time as the quantity of spent fuel increases and as $\mathrm{U}_{3} \mathrm{O}_{8}$ prices escalate. Assuming $\mathrm{U}_{3} \mathrm{O}_{8}$ will have escalated to $\$ 100 / \mathrm{Ib}$ by $2000-2010$, the value of the U+Pu will be about $\$ 35$ to $\$ 50$ billion by 2000 and $\$ 65$ to $\$ 100$ billion by 2010 (using NASAP mass balances and demand projection range).

Assuming that nuclear power is permitted to expand on the oncethrough cycle with spent fuel in interim storage, the recycle option will continue to be open. It will be relatively easy (from a technical and financial point of view) to adopt recycle at any time. The new investments required to support recycle are mainly reprocessing and $\mathrm{Pu}$ fuel

*The data reported here are more favorable to recycle than those usually reported, the main difference being that we are taking credit for plutonium recovered from batches discharged at and near the end of core life. NASAP reports 3420 tons $\mathrm{U}_{3} \mathrm{O}_{8}$ for "self-generated recycle" of U+Pu, over 30 year life. Sufficient $P u$ was available in fuel discharged in years 28,29 and 30 to get about $10 \%$ more energy in a Pu-burner LWR. 
fabrication plants. The fuel cycle investment required to support 1 GWe of reactors fueled solely from the spent fuel stockpile compared to 1 . GWe of standard once-through reactors is compared in Table 9. About half as much fuel cycle investment is required for a recycle increment of capacity as for a once-through increment.

The incentives to recycle are obviously even stronger for countries who import uranium than they are for uranium producers such as the United States. The spent fuel stockpile represents a strategic fuel reserve which can be called upon to counter political and market pressures. Implementation of reprocessing will depress demand for uranium and therefore moderate uranium price rises. In a world where the energy markets are dominated by OPEC, uranium consumers will be sensitized against the possibilities of a uranium cartel.

Fuel reprocessing and recycle not only provides a resource safety valve for light water reactors, but it also opens up the posssibility of much more efficient reactor/fuel cycles. For example, evaluation of tight-pitch Pu-fueled PWRs by reactor vendors and universities suggests that such reactors could achieve conversion ratios (CR) approaching unity instead of the 0.6 achieved in conventional lattices.* The $\mathrm{U}_{3} \mathrm{O}_{8}$ requirements for 30 years at 1 . GWe (70\% capacity factor, $0.2 \%$ U-235 tails) are as follows, for standard LEU-fueled PWRs combined with tight-lattice Pu burners and with fuel recycle:

$$
\begin{array}{ll}
\mathrm{U}+\mathrm{Pu} \text { recycle, standard pitch } & 3120 \text { tons } \mathrm{U}_{3} \mathrm{O}_{8} \\
\mathrm{U} \text { recycle, } \mathrm{Pu} \mathrm{CR}=0.7 & 2880 \text { tons } \mathrm{U}_{3} \mathrm{O}_{8} \\
\mathrm{U} \text { recycle, } \mathrm{Pu} C \mathrm{R}=0.8 & 2520 \text { tons } \mathrm{U}_{3} \mathrm{O}_{8} \\
\mathrm{U} \text { recycle, } \mathrm{Pu} C R=0.9 & 1910 \text { tons } \mathrm{U}_{3} \mathrm{O}_{8}
\end{array}
$$

Reprocessing is a necessary step for high-CR thermal reactors. Reprocessing is a necessary step also for breeder reactors, which increase energy production from $\mathrm{U}_{3} \mathrm{O}_{8}$ mined by orders of magnitude compared to standard once-through LWRs.

Finally, reprocessing would be a decisive preliminary to permanent waste disposal. While disposal of spent fuel appears to be technically

\footnotetext{
*It should be noted that such tight-lattice designs may have safety and economic disadvantages discussed more fully in Sect. 4.3.
} 
Table 9. Investment ${ }^{a}$ in fuel cycle support facilities to support GWe of standard LWR

(\$ millions)

\begin{tabular}{|c|c|c|}
\hline & Once-through & $\operatorname{Recycle}^{b}$ \\
\hline Mining and milling ${ }^{c}$ & 100 & \\
\hline Enrichment & 90 & $40^{d}$ \\
\hline Reprocessing & & 45 \\
\hline Fuel fabrication & 3 & $15^{e}$ \\
\hline \multirow[t]{2}{*}{ Interim storage } & 3 & \\
\hline & 196 & 100 \\
\hline
\end{tabular}

$a_{\text {Based on NASAP data, U.S. conditions. }}$

$b_{\text {Supported by the spent-fuel stockpile }}$ without mining additional $\mathrm{U}_{3} \mathrm{O}_{8}$.

$c^{c}$ Assumed to be a prorated share of a Chat tanooga shale-based facility, equivalent to about $\$ 100 / 1 \mathrm{~b} \mathrm{U}_{3} \mathrm{O}_{8}$.

$d_{\text {Reenrichment of the } U \text { recycled. }}$

${ }^{e}$ Average of $\mathrm{Pu}$ and recycle $\mathrm{U}$ fabrication. 
feasible, such disposal is implausible as long as the potential to recycle exists. Even if a lot of spent fuel were placed into retrievable geologic storage, it would look like only a temporary solution to the waste problem.

Also spent fuel would, after several hundred years, be relatively easy to reprocess, and thus could become an easily obtainable source of material for proliferation or illegal diversion purposes.

\subsubsection{Recycle issues}

The nuclear industry encountered major difficulties in implementing a nuclear fuel reprocessing capability in the United States even before the President indefinitely deferred the fuel-cycle option for nonproliferation reasons. Mechanical head end equipment and liquid effluent problems plagued operation of the first smali-scale commercial reprocessing plant at West Valiey, New York, and start-up problems led to the decision not to begin hot operations at the GE plant at Morris; Illinois. Factors contributing to the problems of the industry were the adverse public reactions to releases of radioactivity, leading to stricter requirements for control of wastes and effluents that came into existence in the 1970s. As a result, there have been major uncertainties in the fuel recycle program in the United States which continue to the present.

Nevertheless, the major issue facing reprocessing is the proliferation issue (see sect. 4.6). It seems unlikely that reprocessing will be authorized in the United States until decision-makers believe that such a step will not contribute significantly to the proliferation problem.

Opponents of reprocessing have argued that plutonium use should be avoided because "plutonium is the most toxic substance known to man." The history of personnel exposed to plutonium indicates this claim is a gross exaggeration. Yet, the Karen Silkwood trial suggests that at least some courts may believe that exposures to plutonium are somehow special.

The economic argument against reprocessing has been invoked by opponents, citing the very high prices quoted by the French for reprocessing at Cogema (over $\$ 500 / \mathrm{kg}$ ). While the GESMO testimony indicated that reprocessing would be economic, U.S. representatives to INFCE presented a 
different view. They indicated reprocessing would not be economic until after $\mathrm{U}_{3} \mathrm{O}_{8}$ prices exceeded $\$ 100 / 1 \mathrm{~b}$. European data indicated reprocessing would be economic if $\mathrm{U}_{3} \mathrm{O}_{8}$ prices exceeded $\$ 40 / 1 \mathrm{~b}$. (The NASAP discussion supported the U.S. inputs to INFCE; the NASAP data base supported the European position equally we11.) In any case, most people in the field believe reprocessing costs are very sensitive to the scale of operation. On the other hand, the Indian input to INFCE claimed their reprocessing plant concept (which is about 100 ton/year) was economic - in apparent rebuttal of the U.S./European claims about the economics of scale (favoring plants of 1500 ton/year). In our view the Indian plant is cheap because it probably has environmental technology no more advanced than that of the U.S. plants 15 years ago. (There has been a fivefold escalation in the capital cost of U.S. plants to satisfy safety and environmental criteria, relative to criteria used in NFS's West Valley plant.)

The U.S. position in INFCE, which was more or less supported by the other industrialized countries, was that the economic advantages of thermal recycle were not likely to be large and that reprocessing should be coupled to the introduction of breeders. While we agree that thermal recycle should be deferred until nonproliferation institutions have been strengthened, we do not agree that thermal recycle lacks merit. On the contrary, the process of licensing mixed oxide fuels for recycle should be resumed at the proper time.

A basic problem in planning recycle facilities is projecting the future growth and direction of the commercial nuclear power industry: "Specifically, it is necessary to predict the growth scenario of speific reactors and the associated fuel-cycle system so that industrial fuel reprocessing can be established at the appropriate time and on the scale needed. This is critical from the standpoint of establishing the scale of the technology to be developed and the principal steps to be included in the development.

In addition, there are difficulties inherent in resolving the technical problems associated with particular reactor/fuel-cycle systems, including: 
1. development of equipment and processes to separate and recover the fertile and fissile material in spent-fuel assemblies in a form (solid)suitable for both storage and shipment,

2. development of the process and equipment to convert highlevel wastes into a solid form suitable for terminal storage in a federal waste repository and to remove and collect gaseous radioactive effluents before release to the atmosphere, and

3. implementation of appropriate safety (seismic, shielding, effluent controls, etc.) and safeguard (securityaccountability) criteria.

\subsubsection{Status of the technology}

Reprocessing. Three commercial fuel reprocessing facilities have been constructed in the United States, but only one of these, the Nuclear Fue1 Services (NFS) plant at West Valley, New York, was actually operated. The NFS plant, as constructed and operated in the late 1960s and early 1970s, would not meet current regulations. The General Electric plant at Morris, Illinois, was not commissioned because of technical problems and the volatile status of licensing and environmental issues, and licensing proceedings on the Barnwell Nuclear Fuel Plant (Allied General Nuclear Services) in South Carolina have been suspended. Licensing proceedings for the construction of a fourth plant (Exxon Nuclear Corporation) were begun but were later suspended. Safety analyses and environmental. reports for the latter two facilities were prepared by the applicants, but final actions have not been taken by the NRC. Generic environmental and safety evaluations of fuel reprocessing have been prepared by the NRC.

Generic problems continue to impede the licensing of any reprocessing facility. These include:

- Establishment of regulations for allowable releases limits for gaseous fission product effluents. $\mathrm{Kr}-85$ release limits have recently been specified by EPA, but the technology to ensure adherence to 
these limits remains to be demonstrated. In the case of $\mathrm{C}-14$ and tritium, permissible release limits have not been established. A1though satisfactory processes have been demonstrated on a laboratory scale, they have not been scaled up.

- Establishment of acceptable high-level waste forms. Waste management technology development has been impeded because the choice of an acceptable final waste form has not been made and, in turn, because it may depend on the selection of final repository.

- Establishment of the appropriate level of safeguards, the required accuracy for accountability for strategic nuclear materials, and the possible need for proliferation countermeasures, such as coprocessing and spiking of plutonium product and inclusion of proliferationresistant engineering features.

Fast-breeder reprocessing plants are expected to handle spent fuel containing relatively more plutonium and short-lived fission products than plants designed for LWR fuel. Licensing breeder fuel reprocessing plants may present additional problems related to spent-fuel characteristics and to unique LMFBR head-end procedures (e.g., sodium handling). The technical data required to assess the safety and environmental aspects of FBR fuel processing will be provided by the planned RD\&D program.

Facilities to reprocess fuel from power reactors exist in Belgium, France, Germany, Great Britain, India, Italy, and Russia. A number of countries are operating small reprocessing facilities in connection with RD\&D programs. Small experimental LMFBR reprocessing facilities have been operating in France and the United Kingdom. Hot cell studies, directed principally toward FBR fuel reprocessing development, have been carried out in the United States over the last decade. The basic technology for reprocessing of uranium and uranium/plutonium oxide pellet fuels with low burnup exists in the PUREX process. However, a commercial reprocessing plant for mixed-oxide power reactor fuels that conforms to current U.S. federal and state requirements has not yet been operated. Specific areas that still require some development work include: 
- operation and maintenance of the mechanical head-end equipment,

- methods for handling highly radioactive residues that remain after the dissolution of high-burnup fuel,

- technology for reducing radioactive off-gas releases (e.g., $\mathrm{Kr}-85$, iodine, and tritium) to conform to anticipated regulations,

- remotely operated and directly maintained conversion processes for plutonium from power reactor fuels,

- high-level waste solidification and vitrification to prepare for terminal storage.

Some variations of the conventional PUREX technology have been suggested as proliferation countermeasures. Coprocessing involves the incomplete separation of uranium from plutonium, so that weapons-usable materials are not accessible. Another approach includes partial decontamination so that the plutonium is always associated with a high level of radiation. These countermeasures are more effective against diversion rather than national proliferation.

Coprocessing solvent extraction has the technical problems of the reference PUREX process and, in addition, would require careful optimization of flow rates and mass balances and very careful process control. Conversion of the coprocessed product to an acceptable form for fabrication also would require some development. Several conversion processes are currently under development in the United States.

Coprocessing with low decontamination introduces additional developmental needs. In reprocessing, expanded remote operation and maintenance of the plant would be required. If decontamination factors of at least 100 are maintained, only modest changes to present technology would probably be required. At a minimum, the chemical processes would be more uncertain. Retention factors for the held-over fission products would have to be established in' hot cell tests, with subsequent demonstration at the production level. In product conversion, existing approaches would have to be modified to accommodate remote operation and maintenance. Coprocessing with partial decontamination is not currently being developed.

The technology for recycle of fast reactor fuels based on the uranium-plutonium cycle is similar to that for LWR fuels on the same cycle; 
there are, however, important differences that make fast reactor fuel recycle technology more difficult than recycle technology for LWRs. Significant differences exist between FBRs and LWRs because of the higher irradiation levels, the higher fission product concentrations, the higher fissile contents of the fuel, and the different fuel element cladding and designs.

Areas requiring more RD\&D emphasis include:

- development and maintenance of shearing equipment for highly irradiated fuels;

- dissolution of fuels with higher plutonium content; feed clarification, and collection of larger quantities of insoluble fission product residues;

- possible increased solvent degradation because of higher radiation levels.

Fuel recycle needs for LMFBRs and GCFRs are quite similar, so the preceding discussion is generally applicable to both fuels. However, for the LMFBR, fuel cleaning for sodium removal is needed.

The technology for reprocessing thorium-based oxide pellet fuels is less advanced than that for uranium-based fuels. The THOREX process has been used to process irradiated thorium oxide fuels of low burnup in government plants and, in limited quantities, in a small-scale industrial plant. The Federal Republic of Germany is undertaking laboratory-scale development of thorium fuel reprocessing for its gas-cooled pebble-bed reactors. Thorium oxide fuels have not been processed in a large-scale plant specifically designed for thorium processing, but highly irradiated thorium fuel containing $U-233$ has been processed by the THOREX process in pilot-plant-scale equipment.

Table 10 (from NASAP Volume IX draft report) summarizes the RD\&D requircments of various reprocessing options.

Thorium fuels are generally more difficult to dissolve than uranium fuels, and if thorium and uranium are reprocessed separately, as in the HTGR, additional processing steps are required. Considering the extensive 
Table 10. Estimated cost range ( $\$$ million) for development and commercialization of a new reprocessing technology $a, b$

\begin{tabular}{|c|c|c|c|c|c|}
\hline . & $\begin{array}{c}\text { LWR } \\
(\mathrm{U} / \mathrm{Pu} \text { cycle })\end{array}$ & $\begin{array}{c}\text { Water } \\
\text { reactor } \\
(T h \text { cycle })\end{array}$ & $\begin{array}{c}\text { HTGR }^{d} \\
(\text { Th cycle) }\end{array}$ & $\begin{array}{c}\text { FBR } \\
\left(U / P_{u} \text { :ycle }\right)\end{array}$ & $\begin{array}{c}\text { FBR } \\
\text { (U/Pu core, } \\
\text { Th blanket) }\end{array}$ \\
\hline Base Technology RD\&D & $100-150$ & $300-450 e$ & $300-500$ & $350-500$ & $450-600$ \\
\hline Hot Pilot Plant & None & $600-900^{e}$ & $700-1000^{e}$ & $600-900^{e}$ & $700-1000^{e}$ \\
\hline $\begin{array}{l}\text { Licensing Support for } \\
\text { Lead Hlant }\end{array}$ & $150=-250$ & $200-300$ & $200-350^{\circ}$ & $250-300$ & $300-400$ \\
\hline Total cose of RDAD & $250-400$ & $1100:-1650$ & $1200-1850$ & $1200-1700$ & $1450-2000$ \\
\hline $\begin{array}{l}\text { Cost of Lead Plant } \\
\text { Lead Plant Capacity }\end{array}$ & $900-1600$ & $1500-2100$ & $1600-2300$ & $1500-2100$ & $2200-3000$ \\
\hline $\begin{array}{c}\text { Tonnes of heavy } \\
\text { metal per year }\end{array}$ & 1500 & 1500 & $400-600$ & 1500 & 1500 \\
\hline GWe supported & $\sim 55$ & 2560 & $40-60$ & $40-50$ & $40-50$ \\
\hline
\end{tabular}

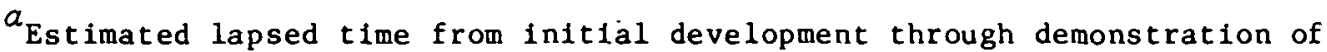
lead plant ranges from 12 years for established technology to 30 years for new technology.

$b_{\text {January }} 1978 \$$.

Includes LWR, HWR, and LWBR.

$a_{P}$. R. Kasten and W. E. Unger state that the expected costs of the HTGR reprocessing RD\&D program have been substantially overstated in the above NASAP table. It is noted that the heavy element throughputs in the case of the HTGR cycles are much less than in the other. cycles for a given energy output. The authors of the present report agree there are considerable uncertainties in the HTGR fuel cycle RD\&D costs which should probably cover a broader range.

$e_{W}$. E. Unger states this estimate does not include $\$ 110$ million for pilot plant operation, which should be added.

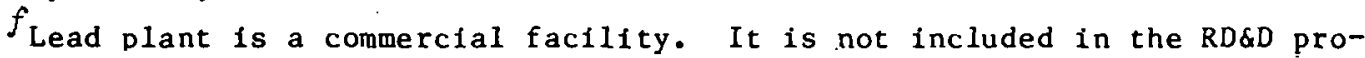
gram, and costs are assumed to be recoverable in fees. The tabulated cost of the plant is direct investment and does not include licensing support. 
amount of effort that was required to establish the technology for processing uranium-plutonium fuels, reaching a similiar stage of development for the thorium cycle would require 20 years or more of effort.

\section{Fabrication}

The present commercial fuel fabrication industry is based on LWR fuel. Several of these licensed fabrication facilities are considering expansion of capacity and process. modifications. No problems are expected in amending the licenses to cover these changes.

To date, there have been no off-site environmental effects from accidents in low-enrichment uranium dioxide fuel fabrication plants. Accidents have been rare in these plants because the technical problems are not challenging and the plant design and operation are safety oriented. Occupational dose commitments and chemical exposures resulting from accidental releases are also estimated to be quite low because the materials are not very hazardous and the plants are licensed and regulated by the government.

The very small quantities of radionuclides now released in the LWR fuel fabrication effluent gases and liquids result in concentrations of radioactive material in these media that are about 0.04 and $10 \%$, respectively, of 10 CFR 20 limits at the site boundary.

Kerr-McGee and B\&W (Lynchburg facility) have licensed development facilities that have been working on plutonium fuel rod production for the Fast-Flux Test Facility (FFTF). The Kerr-McGee plant is now on standby, and Kerr-McGee is considering decommissioning it. Westinghouse has filed an application to construct and operate a commercial plant in South Caro1ina. The suspension of the Generic Environmental Statement for LWR Mixed Oxide Fuel (GESMO) hearings resulted in NRC stopping all case review of the Westinghouse application.

Licensing of plutonium-containing mixed-oxide fuel [10 CFR 70.22(f)] requires plants to be designed, fabricated, constructed, tested, and operated under quality-assurance programs. Quality assurance comprises systematic actions necessary to provide confidence that structures, systems, 
components, and operations will perform satisfactorily in service (10 CFR 50, Appendix B).

All operations at mixed-oxide fuel fabrication plants that involve handling plutonium (except that contained in shipping containers or fuel elements) are carried out inside process enclosures such as cells or gloveboxes. These enclosures provide confinement of plutonium in the event of equipment failure. The process building, essential equipment, and supporting systems are designed to withstand natural phenomena, including tornadoes, earthquakes, and floods. During the life of a mixedoxide fuel fabrication plant, equipment or accessory failures may occur. Monitors are installed to detect any failure or abnormal condition that could cause safety-related damage. Corrective action is automatically provided. The ventilation system is designed to function during and after accidents and to pass all plant-ventilation air through high-efficiency particulate air filters before releasing it to the atmosphere. In summary, a'mixed-oxide fuel fabrication plant is:

1. designed, fabricated, constructed, tested, and operated according to a quality-assurance plan;

2. designed to cope with accidents;

3. designed to minimize the off-site consequences of potentia $\perp$ accidents.

Some incidents, such as glove tears or other glovebox malfunctions, àre expectéd to occur as part of the normal operation. Uthè mònè sèrious accidents, such as glovebox-window breakage, will occur far less often. Although their off-site consequences are judged to be insignificant, such accidents are included in the estimate of airborne effluents resulting from normal operations.

Analysis of the consequences of such an accident and minimization of the impact receive significant treatment in design and licensing actions. An extensive set of regulatory requirements exists to protect the environment from releases from recycle facilities. These are expected to be reviewed and redefined before fuel recycle is permitted. 
In order to be licensed, fabrication plants for plutonium recycle fuel must meet the same regulatory requirements to protect the environment as LWR reprocessing plants. The design of the fuel fabrication plant must adhere to the concept of no releases of radioactive liquids to the environment. Aqueous solutions containing plutonium will be treated for plutonium recovery, concentrated, and solidified. Noncondensables will be filtered and released as gas. Plutonium-containing solids are treated for plutonium recovery, residues are converted to a nonleachable form, transferred to stainless steel containers, and stored in a stable geologic formation. Solids that contain small amounts of beta and gamma activity are buried at licensed sites. Gases containing radioactive and noxious material are filtered and processed before release.

A licensed plant for HTGR U-235 fuel manufacture currently exists at General Atomic in San Diego, California. Future plants must be designed to meet future regulatory requirements; these may increase costs and engender delays if regulations change during plant construction. The various U-235 enrichment fuel-cycle alternatives for the HTGR present no basic differences, from a safety and licensing standpoint, from the previous reference high-enrichment $(\sim 90 \%)$ uranium cycle.

Recycled thorium (together with recycled U-233) has associated significant gamma activity and radon emissions, causing most operations to be remote and highly automated. The current limited experience does not provide assurance that licensing difficulties will be readily overcome. No facilities utilizing remote operation and remotẻ maintenance have been licensed to date.

Estimated costs of RD\&D for recycle fuel fabrication development are given in Table 11.

\subsubsection{Addressing the issues}

The U.S. deferral of fuel reprocessing and recycle and the INFCE study do not appear to have persuaded many other countries to drop their plans for reprocessing and fuel recycle. At some point it will become apparent that the U.S. example is not effectively producing the desired 
Table 11. Estimated cost range for development and commercialization of a new fuel

fabrlcailon rechnology

( $\$$ million)

\begin{tabular}{|c|c|c|c|}
\hline & $\begin{array}{l}\text { Type A } \\
\text { (uranium } \\
\text { fuel) }\end{array}$ & $\begin{array}{c}\text { Type B } \\
\text { (plutonium } \\
\text { fuel) }\end{array}$ & $\begin{array}{l}\text { Type C } \\
\text { (high gamma } \\
\text { fuel) }\end{array}$ \\
\hline Base Technology RD\&D & $5-15$ & $110-140$ & $190-270$ \\
\hline Hot Pilot Plant & None & $120-150$ & $240-300$ \\
\hline $\begin{array}{l}\text { Licensing Support for } \\
\text { Lead Plant }\end{array}$ & None & $75-100$ & $150-250$ \\
\hline Total Cost of RD\&D & $.5-15$ & $305-390$ & $580-820$ \\
\hline Cost of Lead Plant & $a$ & $425-600^{b}$ & $750-1200^{b, c}$ \\
\hline $\begin{array}{l}\text { Lead Plant Capacity } \\
\text { heavy metal } \\
\text { (tonnes/year) }\end{array}$ & 500 & $250-500^{d}$ & $250-500^{d, e}$ \\
\hline GWe supported & $15-20$ & $15-20$ & $15-20$ \\
\hline
\end{tabular}

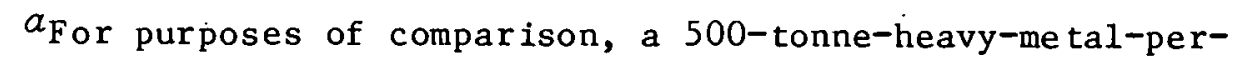
year plant would cost about $\$ 60$ million.

bcusl of lead plant would be supported by sale of fabricátion services and is not considered an RD\&D cost. Lead-plant cost tabulated does not include licensing support, which is part of RD\&D.

$c_{\mathrm{P}}$. R. Kasten states the expected range of costs for HTGR fabrication facilities should be below the range of costs given in the table. The authors of the present report are not in a position to resolve the comment.

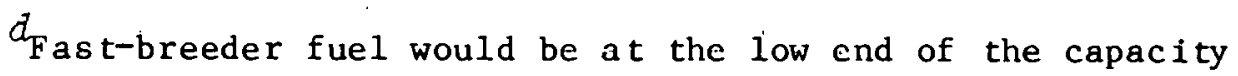
range.

$e_{A}$ facility for supporting 15 to 20 GWe of HTGR capacity using U233 fuel would have a capacity of about 150 to 200 tonne heavy metal per year. The cost of the program would be expected to fall with in the range reported above. 
result. At that time consideration of the licensing of fuel reprocessing and recycle may resume.

Given the current slowdown in the nuclear business, there is truly little to be gained by immediate thrusts into large-scale fuel recycle. However, good arguments can be made for resumption of the AGNS program as an early demonstration of a commercial-scale recycle fuel plant. The purpose of these activities would be to prove the recycle option, its regulation, its costs and environmental impacts. The facilities could also be used to demonstrate safeguards, U.S.-style.

Demonstrating fuel recycle in LWRs would reduce uncertainties about recycle in breeders. Given the present situation, it seems more likely that the timing of the breeder program will dictate the timing of LWR reprocessing, and recycle in LWRs will emerge concurrently with breeder cycles. The recycling of thorium/U-233 fuels is much more difficult, complex, and costly than the recycling of uranium/plutonium fuels and an extensive period of time will be needed to conduct an engineering demonstration of both the reprocessing and refabrication steps.

At this point it appears doubtful that fuel reprocessing and recycle is suited to conventional private enterprise. The needs to maintain safeguards and environmental controls are paramount; until the technology is fully developed and standardized it is subject to ratcheting from the regulatory bodies. The following measures were suggested at a 1976 conference sponsored by the Institute for Energy Analysis: 57

1. Government ownership of fuel, especially plutonium, with fuel being leased to users.

2. Government ownership and control of reprocessing.

3. Colocation of fuel reprocessing and Pu fabrication plants. There was broad support for these positions from participants in the workshops, which included representatives of the utility industry, the nuclear suppliers, universities, and state and Federal Government.

The above steps would facilitate a further step, a greater international presence in fuel recycle, especially in the handling of plutonium. The United States would have to experiment with the implementation of these measures at its lead recycle plant. 


\subsection{Waste Disposal}

\subsubsection{InLruducLlon}

This discussion of nuclear waste disposal will be confined to an overview of the issues. The reader is referred to a companion ONEP paper by Ted Besman entitled Nuclear Waste Management. The sources for the present paper are basically the same as Besman's, except that we have borrowed heavily from the NASAP report (whose waste discussion was authored loca11y).

The nuclear waste issue was largely ignored by the AEC and by the Joint Committee on Atomic Energy during the 1950s and 1960s. I'h is is very unfortunate because the opportunity existed then to demonstrate and implement a workable system. I'he present situation is much more difficult because of the diffusion of responsibility and concern which has occurred, and the vested interest of highly vocal groups in preventing a solution.

Perceived progress toward a solution to the waste problem is a necessary step toward a viable nuclear power program. This is so because the public and government decision-makers no longer have faith in technologists' claims that the waste problem can readily be solved. Construction of nuclear power plants is increasingly being challenged on the basis that the wastes are unmanageable. At the same time it should be noted that regardless of what course nuclear power might take, the nation and the world has a radioactive waste disposal problem which will not vanish but be with us indefinitely.

\subsubsection{Source and nature of radioactive wastes}

In the early years of nuclear energy the bulk of radioactive waste in the United States was generated by the military program - nuclear weapons and naval propulsion. However, commercial nuclear power and medical uses of radioisotopes have now become major sources of radioactive wastes and will continue into the future. Radioactive waste is thus an unavoidable consequence of the nuclear age. In this report attention is directed to the radioactive wastes associated with the generation of nuclear power 
though this category of wastes is volumetrically very small compared to defense generated wastes and will continue to be so for many years. Medical and other users of nuclear energy are small compared to either of the other categories but do generate significant quantities of low-level wastes.

Every step in the nuclear fuel cycle - mining, milling, enrichment, fuel fabrication, reactor operations, and fuel-reprocessing and refabrication - creates radioactive wastes in varying forms and of varying intensities. These include wastes categorized as low level (LL), high-level (HL) and transuranic contaminated low-level (TRU) wastes. This section is primarily concerned with the latter two categories. The wastes from nuclear power which are of primary interest are those generated through irradiation of the nuclear fuel. These in turn are present in the spent fuel or alternatively are released during fuel reprocessing and recycle. These wastes due to their intense and persistent toxicity must be effectively isolated from the biosphere for hundreds, perhaps thousands of years. Effective management of these wastes depends upon a high degree of technological excellence, an awareness of the sociopolitical problems, and a sensitivity to public concerns on this issue.

The wastes produced in the irradiated nuclear fue 1 , the so-called high level wastes (HLW), are most important. They are produced in large amounts and consist of fission products, unburned uranium, generated plutonium, and other activities. The waste nuclei with short half-lives decay quickly and soon constitute no problem. Those with very long halflives decay so gradually that their intensity is relatively low, but the intermediate-lived nuclei (between about 1 and one million years) pose the serious problems. Some idea of how the intensity of radiation changes with time can be obtained by noting that: for each year of reactor operations the spent fuel contains about five billion curies of radiation when it is first removed from the reactor, in 150 days this decays to about $3 \%$ of this amount; and, in 10 years to about 0.3 percent of the original. At this time about 80 percent of the activity comes from the fissionproducts - the largest contributor being cesium-137 and strontium-90 next. In another 600 years the Cs -137 drops to about 3 curies, and its activity 
and that of the other fission products become negligible. At this stage the long-lived actinides become the main source of the HLW disposal problem.

In terms of types of radiation, the main activity of the actinides comes from alpha particles which cannot penetrate a thick sheet of paper; the beta particles, the main activity of the fission products, would be stopped by one-eighth inch of iron; and the gamma rays activity, from both actinides and fission products, can be attenuated by a factor of one million with five feet of concrete. Thus, the wastes pose hazards only when they escape from their containment and are available in forms for inhalation or digestion. These characteristics become the technical basis for developing methods for the safe management and disposal of radioactive wastes.

\section{9 .3 Waste issuess}

Although a great deal of effort has been expended to develop methods of nuclear waste treatment and disposal, the lack of agreement on waste disposal forms and of standards for licensability constitute a major deficiency of the nuclear fuel cycle. It has been assumed that wastes. from any of the major fuel cycle options can be disposed of In an acceptable way. However, major decisions must be made to resolve the outstanding issues. Major economic impacts may result from mandated standards for waste management.

The issues may be classified under waste treatment standards, geologic repository standards, treatment of low-level wastes, and the need for AFR facilities.

The critical issues in waste treatment include the lack of agreement on the ultimate configuration of the fuel cycle, the lack of agreement on the required degrec of immobilization of hazardous materials within the waste medium, the lack of expert agreement on low-level radiation-exposure risks, and the ambiguity of the ALARA emission standard for radioactive

effluents. Depending on the interpretation of these parameters, the technology for waste treatment existing today may be fully adequate to meet societal needs, or it may fall considerably short. Developing accepted 
standards may be a difficult and time-consuming step, and one which slows the progress of the overall waste program.

The standards and regulations for a geologic waste repository will have to deal with many difficult issues, including:

- the extent to which government-owned waste disposal facilities will be licensed and the process for licensing action;

- how to define "permanent" isolation (the degree of assurance required from each of the multiple isolation barriers);

- the extent of potential hazard to future generations from the TRU wastes, principally plutonium after the first 100 to 500 years (conceivably, future standards might limit TRU content of the depository, forcing as high as practicable recycle of TRU into reactors);

- the extent to which stored wastes must be retrievable;

- the extent to which state and local entities will be compensated for the possible undesirable impacts and risks of a repository and the extent to which state and local bodies will be authorized to establish criteria.

The issues for low-level beta-gamma waste disposal facilities para1lel the issues for high-level repositories.

AFR facilities are controversial in that they require spent-fuel transportation in contrast to the alternative of enlarging at-reactor storage pools. Because AFR facilities are temporary, their deployment "postpones" terminal waste disposal; their use may also introduce states' and local rights' issues that may delay licensing.

\subsubsection{Technical considerations}

The predominant form of waste from the once-through fuel cycle is the spent fuel discharged from the reactor. The spent fuel is generally stored underwater at the reactor site for some time. Following a suitable period of cooling, the spent fuel may be moved to an away-from-reactor (AFR) storage site. Ultimately, if fuel reprocessing were not authorized, the spent fuel would be suitably packaged and placed in a geologic repository. Storage of spent fuel in a repository can be conducted in a 
retrievable mode in anticipation of a later decision to allow reprocessing and to confirm the safe performance of the geologic medium.

While much R\&D work has been done on the closed fuel cycle, there remains a shortage of commercial plant operating experience upon which estimates of future performance can be reliably based. This is especially true of those operations that will generate the most radioactive wastes: mixed-oxide fuel fabrication and large-scale commercial reprocessing. A principal source of radioactive waste in the closed nuclear fuel cycle is the reprocessing plant where the integrity of the fuel cladding is breached. Fission gas is released, collected, and packaged; fission products are concentrated into high-level wastes, and irradiated fuel cladding and hardware are disassembled and collected. Reclamation of mixed-oxide fuel fabrication scrap also contributes to the production of transuranium (TRU) wastes.

All waste management systems rely on a multibarrier approach to achieve the desired level of isolation. The first engineered barrier is the chemical form of the waste itself, which should be stable and resist attack from the storage environment. The waste is generally placed into a container, which forms a secondary engineered barrier. .Finally, hazardous wāstès aree to be stored In geologic repositorles that are selected for their highly stable character, thus forming a natural barrier that isolates the waste from a nuclide transport medium path to the biosphere. Most discussion of the waste issue has focused on the role of the Federal Government in providing facilities for ultimate storage of nuclear wates. What has been somewhat overlooked is that each utility has the capability to provide on-site storage for 30 or more years of spent fuel. In addition, facilities for the compaction and engineered storage of low-level wastes can also be provided at the site. The utility can, for a modest cost, become essentially sclf-réliant on waste stóragc pending some future federal policies and actions on wastes. TVA has apparently decided to pursue such a policy.

Storage of high-level liquid wactec from the weapone production program has been practiced for 35 years, and almost $340,000 \mathrm{~m}^{3}$ (90 million gal) of acid and alkaline solutions and sludges have been accumulated in about 200 tanks at DOE reprocesșing sites during this period. Although 
more than 20 carbon steel tanks storing neutralized defense wastes are known to have developed leaks, the released radionuclides have been retained in the soil within the immediate vicinity of the-vessels, and no radiation exposure to personnel or to uncontrolled areas has resulted. The experience gained with such storage has led to the design of new liquid storage systems that justify greater confidence in containment integrity. The substantial advantages to be gained from reduced radiation levels and heat evolution rates during subsequent waste processing will probably make some interim liquid storage desirable. The complexity and cost of acceptable safe systems will tend to limit their capacity to no more than a few years of. plant generation.

Regulations call for high-level liquid wastes from commercial operations to be solidified within 5 years after they are generated and for the resultant stable solids to be shipped to a federal repository within 10 years after the liquids are generated. Methods for solidification of high-level wastes from reprocessing plants range from calcination to incorporation in glass. The actual volumes of waste will depend on many factors that cannot be determined without the benefit of actual operating experience. Although waste management economics will undoubtedly tend to force the final volumes toward smaller values, additional wastes not considered here, arising from maloperation, equipment decontamination, etc。, will tend to increase them. Similarly, possible future requirements for higher-quality waste products (less leachable in water, more radiation resistant) may also result. in higher volumes of waste per metric ton of fuel processed.

The support R\&D for waste treatment covers development of a number of forms for containment of high-level waste, iodine, and other radioactive materials to be stored for long periods of time. It is assumed that parallel R\&D programs would cover spent-fuel encapsulation and high-level waste treatment for permanent storage. The former operation,would provide wastes to be placed into early repository tests (on a retrievable basis) and provide a firm design basis for the commercial-scale encapsulation facility associated with operation of a lead geologic repository.

A high-level waste pilot plant should be associated with the reprocessing hot pilot plant (capacity of 150 metric tons of heavy metal per 
year) and would develop the generic procedures for vitrifying high-level waste. These techniques are required, even in the event that commercial reprocessing were not authorized in the United States, to treat wastes that have been generated in the past, such as those at the NFS plant at West Valley, New York. The general character of high-level waste is not expected to be fuel-cycle dependent; however, the difficulty of pilot plant operations will probably be strongly influenced by the activity level. This is in turn influenced by the fuel burnup and ex-reactor coo1ing time.

$R \& D$ on waste treatment may include work on actinide partitioning and transmutation in fast reactors as well as incineration and other compaction and fixation techniques. This process, if successfully developed, could substantially reduce long-term hazards (greater than 1000 years) from terminal waste storage. The program is necessarily long-term in that $i t$ is coupled to reprocessing and fast-reactor development and deployment. The major RD\&D efforts that must be accomplished to ensure safe disposal of solidified waste are (1) increased knowledge of rock behavior as it applies to thermomechanical and thermohydrologic interactions; (2) development of a data base to identify nuclide leaching rates, groundwater chemistry, nuclide solubility in groundwater, and nuclide transport through rocks; and (3) increased knowledge of the overall impact of radiation on disposal media.

Several different geologies are candidates for the siting of geologic repositories. Salt has been selected as a leading candidate geology, but other geologies are also being evaluated. The R\&D requirements for indepth examination of different geologies differ in kind but not in general content.

The cost and schedule of geologic $R \& D$ efforts leading to a repository are moet uncerta1n. Several media/sites will be investigated, but the depth of each investigation has not been determined. Even after a repository is in full-scale operation, it appears likely that geologic research into alternatives would continue at a significant level.

DOE has estimated a spent-fuel disposal charge of $\$ 117 / \mathrm{kg}$ heavy metal and an AFR storage plus disposal charge of $\$ 232 / \mathrm{kg}$ heavy metal. The latter is equivalent to $1 \mathrm{mill} / \mathrm{kWh}$ or $5 \%$ of generating cost. This charge 
includes cost recovery for the waste management facilities as well as the associated $R \& D$. In. view of the major uncertainties in waste facility standards, such cost estimates must be regarded as highly uncertain.

\subsubsection{Considerations of public concern}

As discussed in Sect. 4.1 - Public Acceptance, one of the chief public concerns with nuclear power is the management and ultimate disposal of the HL radioactive wastes. One aspect of this concern is the perceived large amount of radioactive fission products produced, and another is the toxicity and long half life associated with plutonium and other actintdes: The former is a short-term problem of tens to hundreds of years while the latter is a long-term problem believed to persist for hundreds of thousands of years. The nuclear critics have focused on this problem using as their cudgel Pu-239 with a half-1ife of 24,000 years. Thus, even after one-half million years a millionth of the plutonium activity remains, and it will remain a source of radioactivity as far into the future as one can contemplate. Furthermore, there is no way that anyone can guarantee isolation of all of the plutonium-containing wastes for even a fraction of this period. The antinuclearites have seized upon these circumstances to fan the fears of the public placing great emphasis on the legacy of danger to future generations. This emphasis on the potenial hazards from plutonium ignores that we have long-lived potassium-40 in our bodies, that the earth's crust contains significant amounts of U-238 ( 4.5 billion year half-1ife) and radium-226 (1,600 year half-life). It also conveniently overlooks the fact that some toxic chemicals, e.g. lead and arsenic, are stable and thus have infinite half lives. Thus, the presence of longlived contaminants is not an unprecedented concern, and the shorter halflived isotopes may be the real problem. Nevertheless, as long as the public preceives plutonium as being the chief problem in radioactive waste management, it must be treated as such.

However, there is more to the public concern about radioactive waste than just plutonium. The nuclear critics have used this issue to put the regulatory and other government agencies on the defensive but the general 
public does not differentiate this finely. It sees radioactive waste as a near-term hazard, a potential threat to future generations, and an example of government uncertainity and ineptness. Thus, among the issues to be addressed are how to correct public misimpressions and restore their faith in government's and industry's ability to solve the problems.

Public interest in decommissioning is expected to increase as commercial nuclear facilities approach the end of useful life. Because the mechanically useful life of power reactors is likely to exceed the "paper" life of 30 or 35 years, one can expect decommissioning to be a controversial subject. There may be valid grounds for phasing out reactors sited near urban areas as soon as practicable; there are also valid grounds for extending operating, licenses for some reactors beyond the book life. Decommissioning is considered a subject for $R \& D$, now. Some of the key questions are:

- Societal impacts of decommissioning as opposed to extended life.

- Research into equipment damage as a function of operating life. Evaluation of interim replacement needs.

- Public attitudes toward decommissioning options.

\subsubsection{Action plan for waste disposal}

If we were responsible for the national waste program, we would undertake some immediate, visible, steps.

1. Advertise needs for both 1 ow-level and high-level waste disposal sites, both military and civilian wastes.

2. Work toward a handful of regionally dispersed HLW sites and several times that number of LLW sites. These sites are to be federally owned and operated, with costs to be charged to the users.

3. Use regional grouping of states to participate in site selection.

4. Develop a formula for compensating state and local governments for impacts and risks.

5. Construct demonstration facilities for retrievable disposal of HLW and spent fuel. 
6. Support $R \& D$ on waste treatment and disposa1.

7. Actively develop standards for waste treatment and disposal, involving the NRC and states selected for disposal sites.

8. Encourage utilities to develop on-site storage facilities for spent fuel and low-level wastes.

9. Develop an information and education program to advise the public on the nature and extent of the radioactive waste disposal problem and what is being done to resolve it.

A program concentrating on research and development will not do the job. The public will regard such a program as proof the problems have not been solved; the basic problems are social and political, not technical.

\subsubsection{Decommissioning and decontamination}

Experience in decommissioning and decontamination of nuclear facilities has been limited to uranium milling, several developmental reactors, and fuel-cycle facilities associated with development or defense programs.

Decommissioning requirements were not directly addressed as part of a federal statute until 1978. Congress passed the Uranium Mill Tailings Radiation Control Act of 1978 in November of that year. This act amended the Atomic Energy Act of 1954 to require a decommissioning plan and proof of financial ability to execute it as part of the license application for a uranium mine. As a result, abandoned mill tailings piles are now being stabilized and covered to protect the environment and eventually to restore the land area for other uses.

Firm requirements for decommissioning and decontamination (D\&D) of nuclear facilities do not currently exist. The NRC staff is conducting some studies of its regulatory position with respect to D\&D of facilities. NRC studies are expected to cover the following: pressurized-water reactors, boiling-water reactors, multiple reactor facilities, uranium mills, uranium fabrication, by-product utilization, fuel reprocessing, mixed oxide fabrication, and low-level waste burial grounds. 
Three alternatives for decommissioning nuclear reactors were previously identified in Regulatory Guide 1.86. These alternatives are protective storage, entombment, and dismanting.

Protective storage consists of preparing the facility to be left in place safely for an extended period. Radiation monitoring, environmental surveillance, and security procedures are designed to ensure the health and safety of the public. This mode may be adopted as a permanent solution for facilities not contaminated with long-lived nuclides.

Entombment involves sealing highly radioactive or contaminated components within a high integrity shielding structure. All fuel assemblies, process materials, and other radioactive wastes are removed prior to this entombment. The materials removed would be prepared for ultimate disposal as either high- or low-level waste. Unrestricted access to all uncontrolled parts of the facility is possible after completion of the entombment.

Dismantling involves the removal of all radioactive components and materials that exceed the criteria for unrestricted access. This process may be undertaken shortly after cessation of power production operations.

The volume of radioactive wastes from decommissioning and decontamination is large enough so that there is an economic incentive for reduction of waste volume. This may be accomplished in a variety of ways: evaporation, calcination, incineration, mechanical compaction, or cutting.

The estimated cost for immediate dismantling of a commercial size PWR has been reported to be approximately $\$ 40$ million. This figure represents roughly $5 \%$ of the estimated capital cost of $\$ 800 / \mathrm{kWe}$ for a $1000-$ MWe LWR. The creation of a sinking fund which accumulates $5 \%$ of the initial plant capital investment at the end of plant life has been suggested as a means of funding decommissioning. 'The decommissioning sinking fund allowance can then be included in economic evaluatione as an additional component of the annual fixed charge rate on capital investment.

The alternatives for decommissioning other fuel-cycle facilities are the same as those outlined above for nuclear reactors. Decommissioning costs for highly radioactive fuel-cycle facilities, such as reprocessing plants or plutonium fuel fabrication plants, are expected to be comparable to those of nuclear reactors. 
CHAPTER 5. NUCLEAR FUEL CYCLE OPTIONS

\section{1 Introduction - General Choices Which Are Available}

The world-wide nuclear industry is currently based on the oncethrough fuel cycle based on natural uranium or low-enriched uranium (LEU). This cycle is currently the lowest-cost possibility. However, it is limited in two respects, i.e., it will become uneconomic as we run out of lowcost uranium and it cannot support a long-term nuclear option.

The general choices to follow the once-through cycle are the following:

1. thermal reactor fuel recycle,

2. a recycle system dominated by fast breeders (the plutonium economy),

3. a recycle system dominated by thermal reactors but making use of fast breeders,

4. the advanced once-through cycle, and

5. de-emphasis of nuclear power.

\subsection{Criteria for Ranking Nuclear Options}

Current criteria favor continuation of the LWR once-through cycle until decision-makers perceive the rate of nuclear power generation being limited by fuel availability or cost. To justify supplementation or eventual replacement of this system by a nuclear alternative implies superiority of the replacement system to the LWR in one or more respects.

As discussed in sections of this report, the criteria of public acceptance and utility acceptance have become important elements in the choice of nuclear power systems. Combining these with the conventionally accepted criteria by which nuclear power systems are judged, the following represent a set of criteria against which one can make judgements as to whether a given system is an acceptable substitute for the LWR once-through:

a. public acceptance,

b. ut1lity acceptance, 
c. political acceptance, i.e. proliferation or diversion resistance,

d. safety

- low probability of catastrophic accident

- low probability of routine activity release

- low probability of occupational exposure,

e. effective use of resources,

f. economics,

g. commercial feasibility.

There are other criteria which could be added, but the above list covers what appear to be the most important current issues. Also, there is considerable overlapping of the above criteria, to wit: utility acceptance assumes public acceptance but also may involve technical and economic issues outside the public ken; political acceptance presumes public acceptance but also may involve policy issues, in this case proliferation resistance, to which the public is generally indifferent; public acceptance indirectly includes safety, but this issue is so paramount that it needs to be considered separately; effective use of resources contains both conservation and economic elements, but from the long-term view it transcends current economics and becomes a dominant issue in terms of having a longterm assured and stable energy supply. Commercial feasibility implies that the technology of a system has been demonstrated to the point that large commercial reactors can be built with a high degree of confidence that they will operate reliably and within an accepted cost range, that the industrial capability exists to supply such reactors commercially, and that a potential market exists for the system. Lack of current commercial feasibility does not mean that a system should not be developed if its potential is sufficiently great, but it does imply that further development work must be done to make the system commercially acceptable.

It is neither feasible nor appropriate within the scope of this report to evaluate each nuclear power alternative to the LWR in relation to each of the above criteria. However, the criteria will be used as a check list to determine when and if one or more of them become important elements in evaluating an alternative vis-a-vis the LWR-OT system. Also, the alternatives analyzed will be those that emerge from the NASAP study as important 
contenders for supplementing or replacing the LWRs, since this study is currently an important element in how the Executive Branch of the Federal Government views nuclear power. The criteria as listed above are in rough order of importance, but for convenience a different ordering is used in discussing the various fuel cycle options.

\subsection{Capabilities of the Various Reactor Options}

\subsubsection{PWRs}

of all the reactor types, these are the most widely used, both in the United States and world-wide. Together with the BWR, they provide the lowest cost nuclear base-load power with a once-through cycle, under current U.S. conditions.

At somewhat higher uranium costs, PWRs would be competitive as $\mathrm{Pu}-$ cycle converters, or as Th-cycle converters with $\mathrm{Pu}$ as the starting fissile material. The thorium cycle starting with HEU (highly enriched U235) or MEU (about 20\% U235) is not economically attractive, but some fuel experience of this type may be useful for $R \& D$ steps in deploying the Th cycle.

Until recently, it might have been assumed that PWRs satisfied all the criteria of Sect. 5.2. In view of the uncertainties of public acceptance related to safety questions, there is now doubt whether this will continue to be true.

The fuel utilization of PWRs on the once-through cycle can be improved by $15-30 \%$, according to NASAP studies.

Modifications include:

- Extended burnup

- Wetter lattice

- Blankets

- Modified fuel management

- Preplanned coastdown

- More frequent refueling.

At least some of these modifications appear to be economic and commercially feasible. In the resource analysis (Sect. 4.7) we have assumed a $15 \% \mathrm{im}-$ provement is likely by $1990-2000$. 
of long-term significance are the possibilities of improving the neutron economy of recycle PWRs by increasing the metal/water ratio. Figure 4 shows that whereas the present lattice has a conversion ratio of 0.6 , the conversion ratio of $\mathrm{Pu} / \mathrm{U}$ or $\mathrm{U} 233$ fuels can be increased to 0.8 by removing half the water from the lattice. (Breeding can be achieved with U233/Th by removing additional water, using short fuel exposure, blankets and movable fuel control. Breeding can probably be achieved with $\mathrm{Pu} / \mathrm{U}$, also by going to a very dry lattice, etc.) Figure 5 shows that the fissile loadings of tight-pitch cores must be high; therefore the savings in fuel burnup costs are compensated with higher fuel inventory costs. Also, the fuel utilization of the total system is limited by the U/U235 cycle, which is helped very little by a tight lattice.

It should be noted that little has been published on the safety an-. alysis of tight-pitch PWRs. DOE-Division of Naval Reactors has conducted both analysis and experimental investigation of tight-pitch U233/Th cores, and results justified operation of the LWBR core at Shippingport. The lower water content of these designs is compensated for in part by a lower average specific power. Pumping power would be greater than in a conventional lattice.

The following is quoted from a recent MIT report: ${ }^{58}$

"Many practical questions must be answered before serious consideration can be given to use of tight-pitch cores: thermal-hydraulics, mechanical and economical. While moderator void-reactivity coefficients and steady state DNंBR are not calculated to be limiting, plant and core redesign to accommodate higher core pressure drops appears an inevitable requirement, and transient/accident limits await a definitive assessment. Fuel cycle cost calculations show that system fuel cycle costs (at the indifference value of bred fissile species) are quite insensitive to the fuel-to-moderator ratio - resulting in low impediments or low incentives depending on one's point of view."

\subsubsection{BWRs}

It has been assumed that BWRs will coexist with PWRs. The fuel cycle modes of the two types of LWRs are expected to be comparable. 
ORNL-OWG 80-4938 ETD

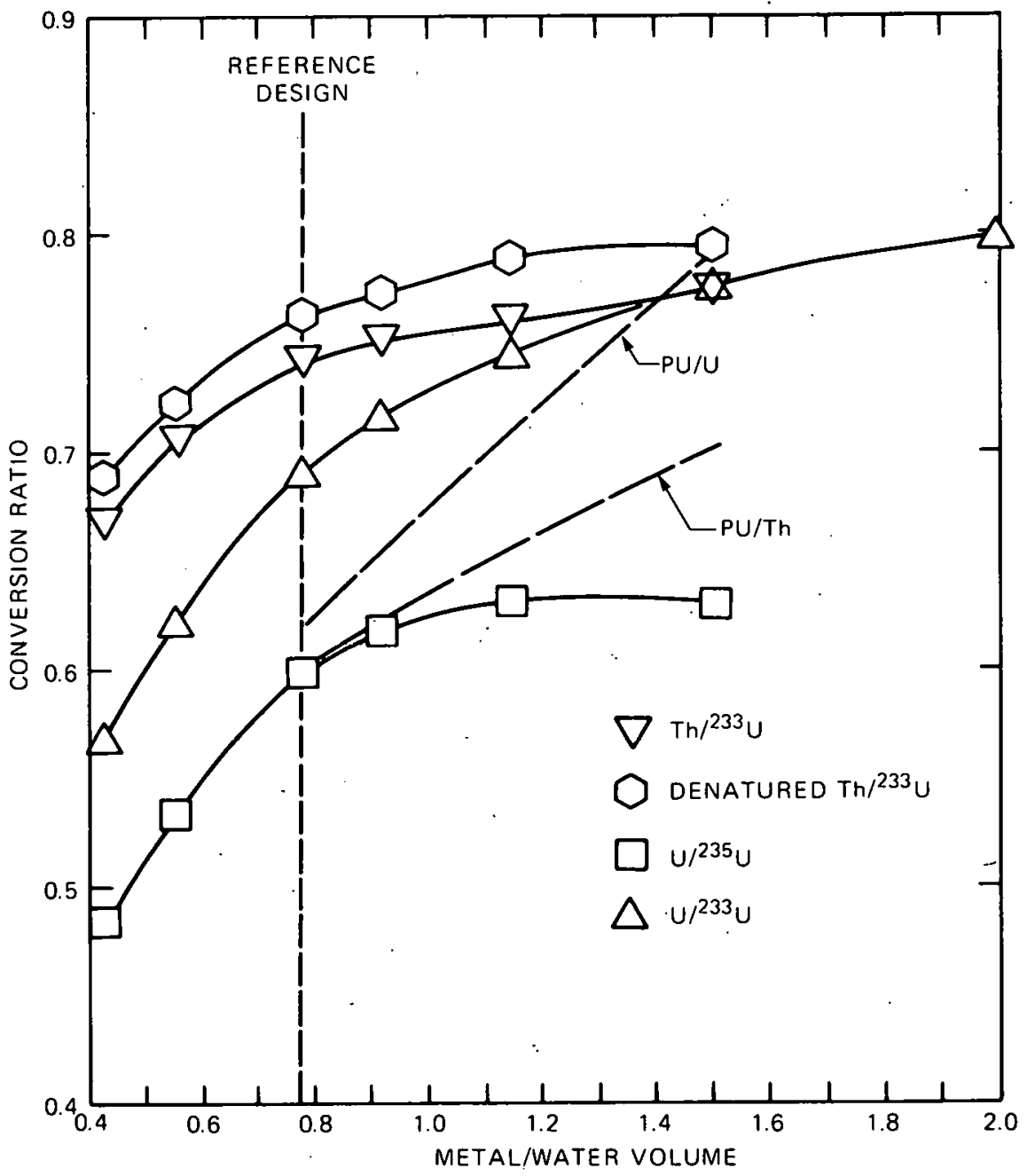

Figure 4. Conversion ratio of various LWR fuel cycles, fuel burnup of $30,000 \mathrm{MWd} / \mathrm{ton}$ 


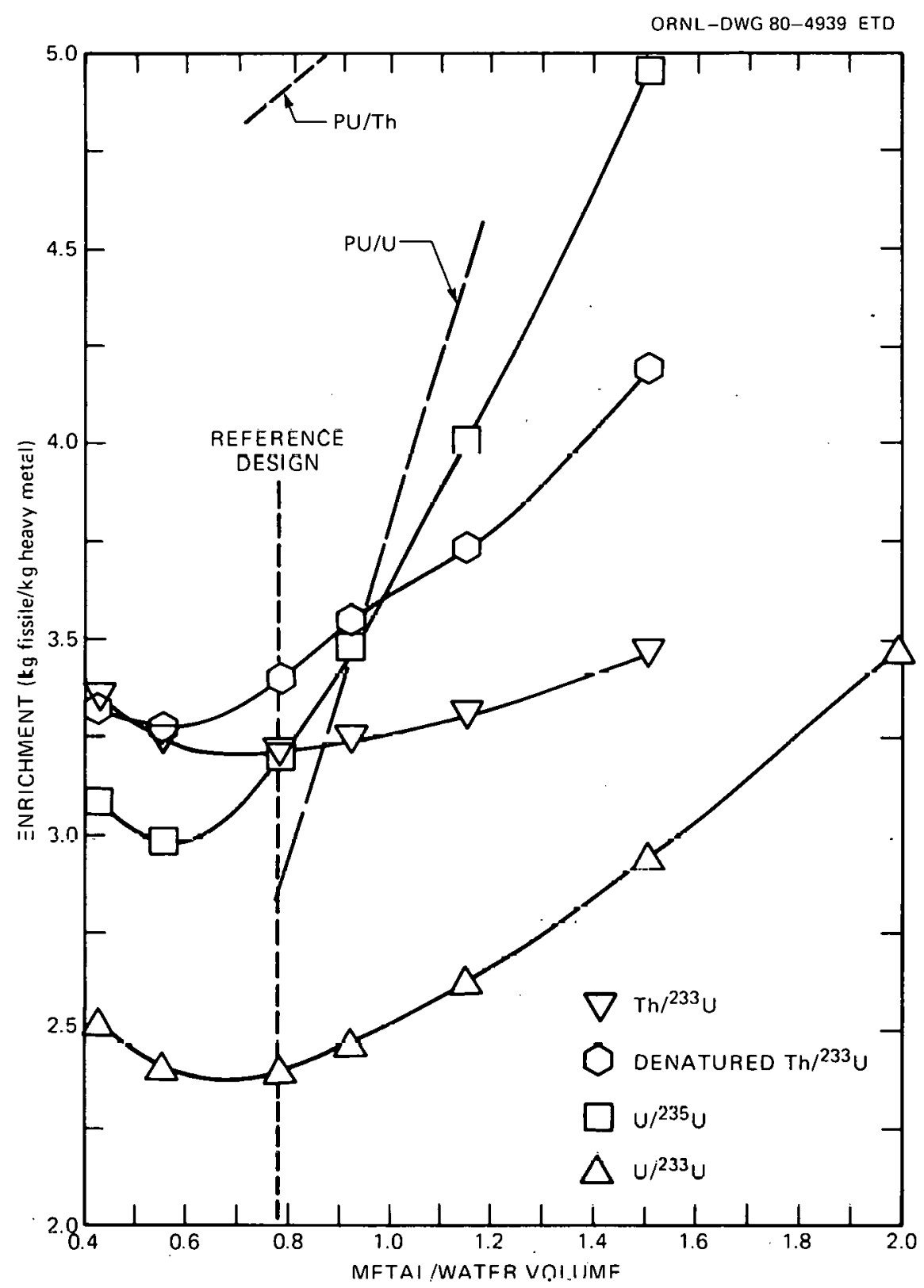

Figure 5. Fissile loading of various LWR fuel cycles, fuel burnup of $30,000 \mathrm{MWd} /$ ton 


\section{$5.3 .3 \mathrm{HWR}$}

This reactor is competitive in Canada and some other countries committed to this type, building the Canadian design. The HWR-LEU could be competitive in the United States if the Canadian design could be licensed; however, studies have indicated that satisfying licensing will increase capital costs to a level where near-term use would not be feasible. EPRI claims that code requirements would increase pressure tube thickness, thereby weakening the neutron economy.

A major advantage of the HWR for some countries is its ability to use natural uranium fuel. However, enriched uranium of 1.0 to $1.2 \%$ U235 is the optimal once-through fuel, on both economic and resource grounds.

The HWR is suited also to Pu recycle or to the (denatured) thorium cycle. The Japanese are developing an HWR dedicated to efficient Pu recycle. The NASAP assessment indicated the HWR to be less proliferation-resistant than the LWR because of on-stream refueling and the possibility of heavy water diversion to a clandestine production reactor. These arguments are not particularly persuasive; on the other hand the operator of an HWR does not have to import enrichment services leading to a greater degree of independence.

On balance, the HWR does not offer much advantage for adoption in the United States. The economics are not likely to be better than LWRs. The resource utilization, while better, cannot have a major impact as long as LWRs dominate the scene. There are simply no commercial advantages to U.S. adoption of the HWR.

\section{$5.3 .4 \quad \underline{A G R}$}

This gas-cooled reactor, thus far restricted to the U.K., has a fuel cycle similar to that of the PWR. It has not been successful in international competition. There do not appear to be any unique benefits available to the future nuclear industry from the AGR.

\section{3 .5 HTGR}

The HTGR occupies a unique place in an ultimate nuclear configuration in that it is the only logical fission source of high-temperature process 
heat. It is also a unique energy source for high-efficiency power cycles such as the direct-cycle gas turbine. In the ultimate fossil fuel-poor society, this energy source could be extremely important.

The HTGR is also attractive in the intermediate-term for electric power production, particularly if $\mathrm{U}_{3} \mathrm{O}_{8}$ becomes more costly. The NASAP analysis indicates HTGRs may be competitive with LWRs at current $\mathrm{U}_{3} \mathrm{O}_{8}$ prices of $\$ 40 / 1 \mathrm{~b}$. The uncertainty is so great, however, that the breakeven price is stated to be perhaps as high as $\$ 180 / 1 \mathrm{~b}$. The licensing process in the United States is well advanced, and if the HTGR finds utility support it may be commercialized.

The HTGR fuel design and fuel cycle is unlike those of water reactors, requiring special R\&D. Fuel is contained in small graphite-coated particles imbedded in a graphite matrix. This configuration tends to favor the uranium-thorium cycle over the low-enriched uranium cycle because one can get little benefit from the fast fission of U238 and one can benefit from the excellent neutronic properties of the bred U233. Fuel burnups tend to be several times those of water reactors, so that initial fuel enrichment is higher and discharge fuel contains relatively small amounts of plutonium (for low-enriched or denatured uranium fuels). The HTGR competes best if HEU is a licensable fuel in the recycle mode. On the other hand, HTGRs on the denatured uranium-thorium cycle may have nonproliferation advantages over other types of reactors because of the difficult fuel cycle and the deficiency as a $\mathrm{Pu}$ producer.

As for the HWR, there are only modest advantages to be gained and high risks in introducing the HTGR at this time. It is questionable whether sufficient interest exists in the reactor manufacturing community or the utilities to finance this development. Therefore as with the HWR, government financing would be required. Commercial deployment could not occur in the United States before the year 2000 which is late to have appreciable effect on cumulative uranium requirements.

HTGRs have certain safety advantages such as very high melting point and high core heat capacity, although they are by no means free of safety problems. HTGRs could be perceived by the public as being safer and therefore more acceptable than LWRs. Additional safety analysis of HTGR seems 
warranted to assess the possibilities of limiting the consequences of catastrophic accidents. The HTGRs seem to be a reasonable backup nuclear system which could be introduced if LWRs are ultimately rejected on safety grounds.

\section{$5.3 .6 \underline{\text { SSCR }}$}

This reactor is a conventional PWR (with conventional lattice and materials) using variable $\mathrm{D}_{2} \mathrm{O}$ concentration as a control mechanism and thereby conserving neutrons. The modest gains in fuel utilization are not likely to be worthwhile until $\mathrm{U}_{3} \mathrm{O}_{8}$ costs increase. At that point, the SSCR would have to be compared to other types of advanced LWRs.

\section{$5.3 .7 \underline{\text { LWBR }}$}

This reactor represents the ultimate in PWR fuel efficiency, based on the Th/U233 cycle. The price is paid several ways:

- Very high U233 inventory and fuel inventory cost.

- Low burnup, high fuel cycle cost.

- Complex fuel cycle requiring both prebreeder and breeder. The resultant is uneconomic, even at high $\mathrm{U}_{3} \mathrm{O}_{8}$ costs. There has been no commercial interest.

The LWBR technology is applicable to tight-lattice LWRs with conversion ratio 0.8 to 0.9 . These are much more likely to be of commercial interest than the LWBR.

\section{$5.3 .8 \quad \mathrm{LMFBR}$}

There is a widespread assumption that breeders are a necessary part of any long-term nuclear option. The LMFBR is the most developed of the breeders. Whereas it had formerly been believed that LMFBR's capital costs were going to be about the same as LWRs, it is now believed that costs are likely to be in the range 1.25 to 1.75 times LWR capital costs. The capital cost is likely to be strongly affected by safety requirements imposed during licensing. It would be desirable to obtain a good rationalization 
of the probable range of LMFBR costs as a function of the safety philosophy. The LMFBR is further handicapped by a very high fuel recycle operating cost (sensitive to the scale of operation), by questionable public acceptance and a vacillating degree of commitment from the government.

The LMFBR is a very flexible reactor with a variety of fuel options (oxide, carbide, metal) and a variety of alternate fuel cycles. Plutonium is the preferred fuel because of its high neutron production in a fast spectrum. The major fuel cycle options are as follows:

a. Pu/U238 core; U238 blanket. This is the classical cycle and provides the highest breeding ratio. Opponents of the Pu-cycle breeder maintain that the continued growth of a $\mathrm{Pu}$ economy will lead to excessive risk of proliferation. The breeding ratio of a reference advanced oxide design would be 1.32 .

b. Pu/U238 core; Th blanket. To a first approximation, this reactor is nearly self-sufficient in Pu production; the net fuel produced is $\mathrm{U} 233$ for symbiotic advanced converters. The breeding ratio is nearly as good as a.

c. Pu/Th core; Th blanket. This reactor is a Pu to U233 transmuter. It can support a much larger number of advanced converters than $b$. However, it does not breed ae well, with a BR about 0.1 below a. and $b_{0} ;$ and the system doubling time is handicapped as well because breeders form a small fraction of the total number of reactors. Therefore this fuel cycle option requires a continuing supply of $\mathrm{U}_{3} \mathrm{O}_{8}$ to converter reactors.

d. U233/U238 core; Th blanket. With a heterogeneous design, the denatured breeder appears to achleve a respectable BR. When combined with b. or c., a strongly positive rate of system growth can be supported. 'l'his system is competitive only at very high $\mathrm{U}_{3} \mathrm{O}_{8}$ costa, howcver.

In addition to the breeder's unique property of producing fuel, the fast spectrum reactor is able to transmute fission actinide wastes as an alternate to geologic waste disposal.

\section{3 .9 GCFR}

The GCFR fuel cycle is very similar to that of the LMFBR. It may have a lower capital cost which could be a decisive advantage. There is no way 
to prove the GCFR is better than the LMFBR overall without constructing both types.

\section{$5.3 .10 \underline{\mathrm{MSR}}$}

The Molten Salt Reactor (MSR) has the advantage of being capable of development in evolutionary stages from a low CR burner reactor to a thermal breeder with a breeding ratio of perhaps 1.04 to 1.05 . Studies per-. formed by ORNL indicate that the MSR makes very effective use of resources and could as a near breeder provide an assured resource base which would last for many hundreds of years. Preliminary studies indicate that the MSR could be economically competitive with other systems and certain inherent features might make it the safest of all the systems.

Another advantage of the MSR is that it of fers a system completely different and independent of all the other systems. Thus, if one wished to have redundancy to our nuclear power development efforts, the MSR would offer the pure alternative in this regard.

The MSR denatured converter is a very proliferation-resistant cycle according to the NASAP analysis. One possibility is a once-through system with discharge of spent fuel only at the end of reactor life, another possibility is a break-even breeder with onsite processing.

The chief disadvantages to the MSR are that it requires a considerable amount of additional $R \& D$ and demonstration work, it lacks a commercial sponsor, and because of its operating characteristics and its requirements for remote maintenance, acceptance by the utilities might be slow.

In summary, the MSR offers a sufficient number of advantages and unique features in relation to other systems that further development work on the concept might be warranted in the event of a nuclear revival, depending on the degree of success of competing reactor types.

\subsubsection{Other advanced systems}

Other cycles investigated by NASAP include the Fast Mixed Spectrum Reactor (FMSR) and various electric breeders.

The FMSR is a metal-fueled breeder concept which is presumed to operate on a once-through cycle with natural uranium fuel at equilibrium. The cycle requires extremely long fuel residence ( 17 years) at unprecedented 
fast neutron fluence. Even if it were feasible, a major disadvantage would be the very high initial loading of U235, which hurts the economics.

Fusion devices or linear accelerators are potential neutron generators. The neutrons can be multiplied and captured in fertile blankets. Either a fuel "refresher" mode or fuel producer mode are possible. The former does not require reprocessing. Linear accelerators appear to be feasible but costly sources. Fusion-fission hybrids may ultimately be promising alternatives to the breeder as fuel producers.

\subsection{General Choices for an U1timate Nuclear Cycle}

\subsubsection{Iransition from the present cycle}

The resource analysis of Sect. 4.7 indicates that the present oncethrough LWR fuel cycle policy cuuld be sustained within the United States for another 30 years or more, depending on the balance between uranium supply and demand. It could be much longer than 30 years if nuclear power growth is limited to the low end of the supply projection. Resource constraints are not the only criteria to be considered in possible future reassessments of the present policy. Future considerations may include:

- The desire to stimulate nuclear capacity growth.

- The economics of reprocessing and Pu recycle may appar attractive.

- There may be international agreements on fuel recycle safeguards that may favor establishment of fuel recycle centers in the United States (instead of in less secure countries).

- Since the world does not appear to be following the U.S. lead in deferring reprocessing, the policy may be reconsidered.

- It may be desirable to undertake reprocessing to supply fuel for breeder reactor deployment.

As was indicated in Sect. 4.8, the transition to reprocessing and plutonium recycle is technically easy at any time that political acceptance is gained. Closing of the fuel cycle substantially increases the resource base (at least temporarily) and provides time for the ultimate cycle configuration to develop. If the growth of demand for nuclear power is no 
greater than projected in Chapter 3 (the 1978 DOE forecasts), then introduction of a new commercial technology (other than possibly reprocessingrecycle) is unnecessary prior to 2010 and can probably be delayed well beyond then.

We are assuming in this analysis that LWRs will remain viabie. If not, there would be a setback of nuclear power for at least several decades. Possibly a new fission enterprise could be developed based on HTGRs or MSRs which may be perceived as substantially different than LWRs.

\subsubsection{Ultimate choices}

In this section, we shall present an analysis comparing several choices for an ultimate nuclear configuration. These choices are:

- thermal reactor recycle;

- the fast breeder-dominated system,

- thermal recycle supported by fast breeders,

- the advanced once-through cycle, and

- de-emphasis of nuclear power.

\section{Thermal reactor recycle}

As was indicated in Sect. 5.3, several reactor alternatives are of potential interest for some ultimate thermal reactor technology. These include the HWR, the HTGR or some type of advanced LWR.

1. The Pu/U cycle. This is the most straightforward in that LEU fuel is used in the first cycle, and then $U$ and $P u$ are recycled.

2. The U233/Th cycle, with U235 starting fue1. This cycle requires full enrichment of uranium, followed by conversion of U235 to U233. Since the initial fuel inventory of most U235/Th cycles is higher than that of LEU cycles, large-scale implementation of this cycle places heavy pressure on uranium mining and enrichment. As the $\mathrm{U} 233$ inventory builds up, this pressure is reduced. The high front-end loading of this cycle leads to higher fuel cust than the Pu/U eycle except in the HTGR.

3. The U233/Th cycle, with Pu starting fuel. This cycle is more complex than the preceding because the initial LEU cycle is followed by a Pu/Th cycle before the ultimate $U 233 / T h$ cycle is reached. While the cycle 
appears to be economic, it is limited (in LWRs and HTGRs) by the relatively low conversion ratio of $\mathrm{Pu} / \mathrm{Th}$ cycles ( 0.6 to 0.7 ).

4. The denatured $\mathrm{U} 233 / \mathrm{Th}$ cycle. These cycles are similar to the U233/Th cycles, except for the complication of U238 and Pu. The economics and resource potentials are comparable to that of other thorium cycles, except that conversion ratios are limited to about 0.9 .

For the present assessment, we shall assume that recycle LWRs in the range of conversion ratio of 0.8 to 0.9 will be deployed, with a continuation of LEU-LWRs for the initial cycle. Comparable (possibly somewhat more favorable) results would be achieved with HWRs or HTGRs.

\section{Fast-breeder-dominated system}

The fast breeder-dominated scenario emphasizes deployment of $\mathrm{Pu} / \mathrm{U} \mathrm{cy}-$ cle breeders during the expansion of nuclear power. Pu is recovered initially from spent LWR fuel but later is generated by the breeders. Surplus fuel may be exported, either as $\mathrm{Pu}$ or as U233 (including denatured U233).

The ultimate configuration may be assumed to be LMFBRs supporting an equal number of Pu-burner LWRs and process-heat HTGRs. Many of the thermal reactors may be outside the United States.

\section{Thermal recycle supported by fast breeders}

'The fast breeder is by tar the best system for $\mathrm{Yu}$ fuels. U233 is generally the best fuel for thermal reactors, although Pu239 is also an excellent fuel for LWRs.

Une can envision an ultimate nuclear system dominated by thermal reactors in a recycle mode but where fast breeders are used as fuel producers and to burn the garbage efficiently - the transuranium isotopes including Pu240 and Pu242. Uranium is mined at a modest rate from low-grade and byproduct sources.

The fuel produced by breeders for LWRs may consist of Pu239/U, U233/ Th (possibly denatured) or U233/U. Figures 4 and 5 illustrate that these fuels can readily achieve conversion ratios of 0.8 .

$\mathrm{U} 233 / \mathrm{U}$ is a fuel which has received essentially no attention, even within NASAP. According to Figs. 4 and 5, it can achieve $C R=0.8$ at about 
a $3 \%$ enrichment which is roughly $1 / 2$ or less the enrichment required with $\mathrm{Pu} / \mathrm{U}$ to achieve $\mathrm{CR}=0.8$. A breeder fuel factory supplying external PWRs can produce considerably more fuel as U233/U than as $\mathrm{Pu} / \mathrm{U}$. (Less $\mathrm{Pu}$ is recovered from the spent $U 233 / \mathrm{U}$ than from the $\mathrm{Pu} / \mathrm{U}$ so that the net fuel consumption of the two fuels is the same at $C R=0.8$.) These alternate cycles deserve additional analysis in the portion of DOE's program devoted to long-term questions.

Figure 6 shows a plot of $\mathrm{U}_{3} \mathrm{O}_{8}$ supply required to support a 1000 GWe nuclear industry depending on the conversion ratio of the recycle LWR and the fraction of capacity as breeders. The $0.8 \mathrm{CR}$ LWR may be assumed to be a conventional tight-pitch $\mathrm{Pu} / \mathrm{U}$ or U233-fueled reactor. The $0.9 \mathrm{CR}$ LWR would be similar to the $0.8 \mathrm{CR}$ reactor except for the use of blankets and movable-fuel control (could be an LWBR-type high-gain converter). Figure 6 shows that if the recycle LWRs have a conversion ratio of 0.9 , then 20,000 tons/year of $\mathrm{U}_{3} \mathrm{O}_{8}$ will support $1000 \mathrm{GWe}$ when the LMFBR/LWR ratio is 0.2 . Mining can be eliminated when the LMFBR/LWR ratio is 0.34 . If the recycle LWR conversion ratio is 0.8 , substantially more fuel supply is needed (50,000 tons/year of $\mathrm{U}_{3} \mathrm{O}_{8}$ at an LMFBR/LWR ratio of 0.2$)$.

For purposes of this analysis, then, the thermal recycle reactor will be assumed to have either $C R=0.8$ or $C R=0.9$, and the ratio of breeders to thermal reactors to be 0.2 .* $^{*}$

The authors agree that the HTGR has good resource/economic potential, but do not concur that this is far superior to the LWRs.

*P. R. Kasten states,

"Consideration should be given to bringing in the HTGR prior to the fast breeder and letting the HTGR work in conjunction with the FBR after the time the FBR comes into use. This kind of analysis will show that the HTGR is far superior to the LWR. Note my discussion of this scenario in ORNL-5515.59 This scenario shows that the HTGR does have a significant role to play in conjunction with the FBR and that it is important to introduce such a thermal reactor system prior to FBRs to have the most impact. Under such a scenario, the HTGR would have a CR of about 0.9 , whereas the LWR would have a CR of about 0.8 when both are fueled with $U-233$ from LWRs. In addition, the LWR would not operate on the thorium cycle prior to the advent of FBRs which has a significant impact on fuel requirements. This scenario was not considered in the NASAP analysis and is a significant shortcoming of the analysis." 


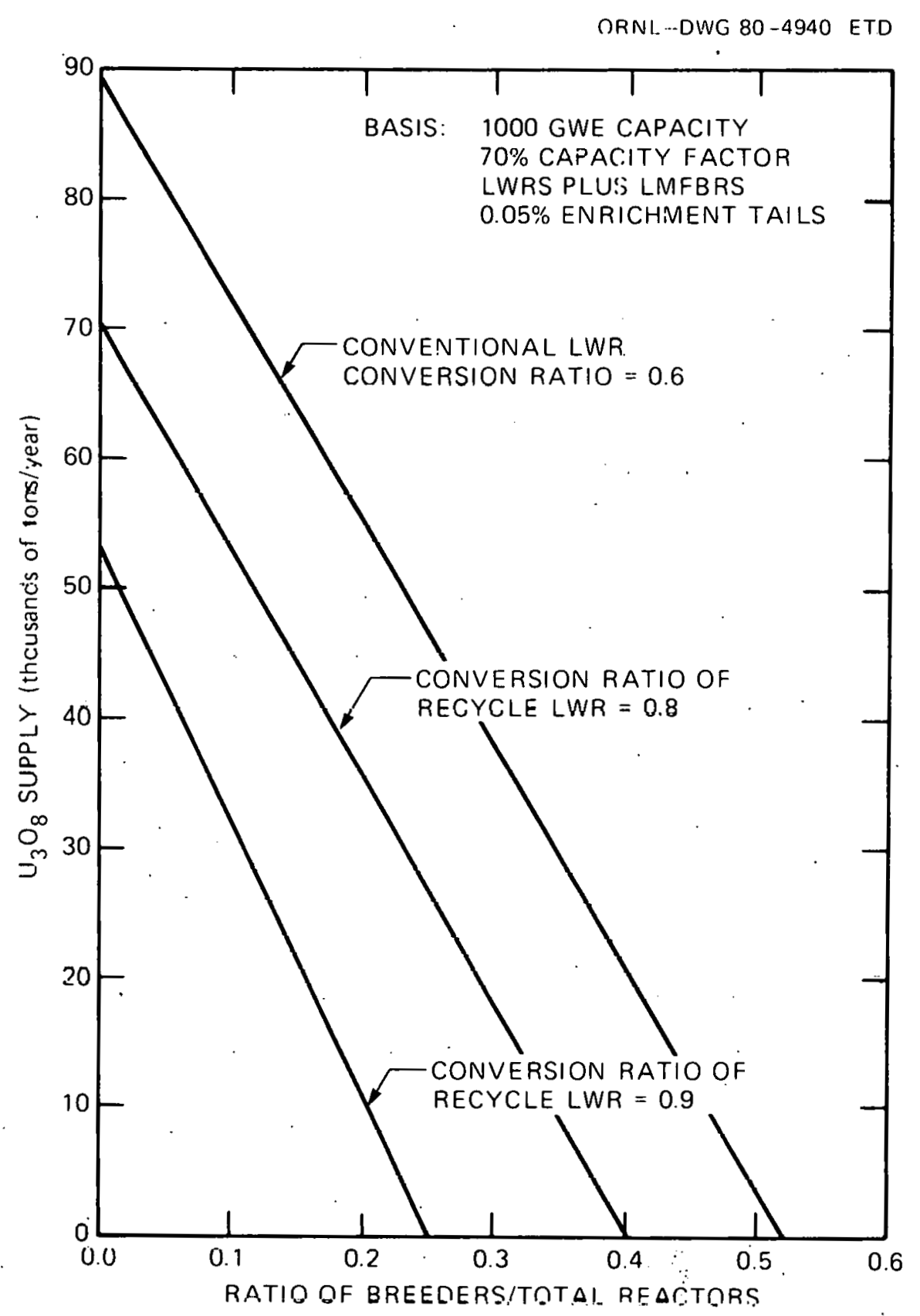

Figure 6. $\mathrm{U}_{3} \mathrm{O}_{8}$ supply requirements for thermal recycle-fast breeder systems 
Advanced once-through cycle

The NASAP analysis amply demonstrates that the once-through HTGR or HWR provides only marginal resource and economic gains over the improved LWRs.

The authors agree that the HTGR has good resource/economic potential, but do not concur that this is far superior to the LWRs. Of the advanced cycles, one has the choice of the molten salt reactor, the gas-core reactor, the fast mixed spectrum reactor and a fuel regenerator based on electric breeding. If Volume VIII of the NASAP report had been presented objectively, it would have been apparent that the MSR is the cream of that crop. The MSR does have commercialization disadvantages, but so do all of the advanced concepts. The GKR probably has insurmountable materials and operational problems. The FMSR probably has insurmountable materials problems but would be uneconomic if they were overcome (unless reprocessing were allowed, in which case it becomes an LMFBR). The electric breederfuel refreshers appear uneconomic and possibly impractical.

Therefore, in this analysis we shall assume the MSR for the advanced once-through cycle.

De-emphasis of nuclear power

This may be assumed for the long-term if suitable fusion or solar sources of electricity are developed. We believe it premature to adopt this approach until an alternative is commercialized.

\subsubsection{Resources comparison}

The $U_{3} O_{8}$ consumption of the various long-term options based on the above assumptions, ${ }^{*}$ and using NASAP data, are as follows:

$$
\underline{\mathrm{U}_{3} \mathrm{O}_{8} \text { (tons/year) }}
$$

$\begin{array}{lr}\text { Thermal recycle } & \\ \quad(C R=0.8) & 70,500 * \\ \quad(C R=0.9) & 53,500^{*} \\ \text { Breeder-dominated (breeding ratio }=1.32) & 2,500 \\ \text { Thermal plus breeders } & 35,000 \\ \quad \text { (Thermal CR }=0.8) & 11,000 \\ \quad \text { (Thermal CR }=0.9) & 53,000 \\ \text { Advanced once-through cycle (MGR) } & 0 \\ \text { Nuclear phase-out } & 160,000 \\ \text { Continuation of present once-through }\end{array}$

$$
\text { cycle }
$$

*1000 GWe capacity, $70 \%$ capacity factor, $0.05 \%$ enrichment plant tails.

**Somewhat better performance can be obtained from HWRs or HTGRs because of a more efficient U235 cycle than that of LWRs. 
U.S. production of 20,000 tons $\mathrm{U}_{3} \mathrm{O}_{8}$ /year indefinitely is probably achievable, even if it is ultimately extracted from seawater.

Production of 50,000 tons $\mathrm{U}_{3} \mathrm{O}_{8}$ may be possible. At $\$ 500 / 1 \mathrm{~b} \mathrm{U} \mathrm{U}_{3} \mathrm{O}_{8}$ this would be equivalent to $8 \mathrm{mills} / \mathrm{kWh}$ for this example.

It should be noted that the transition to the long-term energy mix may occupy several hundred years during which time there would be gradual shifts to more efficient cycles. Th1s would include provision for fuel production for process heat reactors (ignored above). The thermal recyclebreeder option could go to a "zero"-mining (2500 tons/year to supply U238 plus thorium) configuration by increasing the breeder to thermal reactor ratio to about 0.34 (thermal $C R=0.9$ ).

\subsubsection{Economics comparison}

The NASAP analysis ${ }^{60}$ indicates that the range of $\mathrm{U}_{3} \mathrm{O}_{8}$ costs at which the LMFBR becomes an economic choice over the once-through LWR is from about $\$ 130$ to $\$ 190 / 1 \mathrm{~b} \mathrm{U}_{3} \mathrm{O}_{8}$. However, a question regarding a transition to FBRs is whether they should be preceded by recycle in LWRs. The NASAP report notes that self-generated LWR recycle does not appear to of fer a clear economic advantage until $\mathrm{U}_{3} \mathrm{O}_{8}$ costs exceed $\$ 100 / 1 \mathrm{~b}$, and not until $\mathrm{U}_{3} \mathrm{O}_{8}$ reaches $\$ 200 / 1 \mathrm{~b}$ do the savings exceed the assumed range of uncertainties. Uther analyses, including that of the Generlc Euviruimental Statement on Mixed Oxide (GESMO), 61 suggest that fuel recycle in LWRs would be economic at below $\$ 50 / 1 \mathrm{~b} \mathrm{U} \mathrm{U}_{3} \mathrm{O}_{8}$. The evidence indicates that economics would not be a significant barrier if a future government decision. were made to allow recycle in LWRs, whereas economics might be a significant barrier in breeder commercialization. If the national interest were to require breeders, significant government support would be required to early plants.

The power costs (m11ls/kWh) of Llie variuus lung-Leilu uptions based on similar assumptions* and using NASAP data, are estimated as follows:

*70\% capacity factor, constant 1978 \$ cost analysis. 


\begin{tabular}{|c|c|c|c|}
\hline & & $\mathrm{U}_{3} \mathrm{O}_{8} \mathrm{pri}$ & \\
\hline & $\$ 40 / 1 b$ & $\$ 100 / 1 b$ & $\$ 160 / 1 b$ \\
\hline $\begin{array}{l}\text { Advanced once-through cycle } \\
\text { Thermal recycle }\end{array}$ & & $22-28$ & $24-30$ \\
\hline$(C R=0.8)$ & 21 & $24-26$ & $27-29$ \\
\hline$(C R=0.9)$ & & $25-29$ & $28-32$ \\
\hline Breeder-dominated & & $25-28$ & $27-30$ \\
\hline $\begin{array}{l}\text { Thermal plus breeders } \\
\text { (Thermal CR }=0.8 \text { ) } \\
\text { (Thermal CR }=0.9 \text { ) }\end{array}$ & & $\begin{array}{l}24-27 \\
25-29\end{array}$ & $\begin{array}{l}27-30 \\
28-32\end{array}$ \\
\hline Nuclear phase-out & & & \\
\hline $\begin{array}{l}\text { Continuation of present } \\
\text { once-through cycle }\end{array}$ & 21 & $25-26$ & $29-31$ \\
\hline
\end{tabular}

The power costs for the various options are remarkably close together, suggesting that the ultimate cycle would be determined more by resource than by economic considerations. One reason for this is that recycle LWRs form most of the reactor mix. Even the LMFBR-dominated cycle is half thermal reactors at equilibrium. It is recognized that the above costs relate to systems which are at different stages of technology development and hence, the uncertainties associated with these costs vary accordingly. The range of costs for the different options is presumed to cover these uncertanties, but to the extent that they don't, especially on the high cost side, a given system may not become economically acceptable.

The use of breeders in the ultimate mix is balanced of $f$ against purchase of $\mathrm{U}_{3} \mathrm{O}_{8}$, so as to keep $\mathrm{U}_{3} \mathrm{O}_{8}$ prices at an acceptable level. As long as $\mathrm{U}_{3} \mathrm{O}_{8}$ is available, it would tend to be used. Strong upward pressure on $\mathrm{U}_{3} \mathrm{O}_{8}$ prices would require an increase in the relative number of breeder reactors.

The unavalability of breeders (fuel producers) could result in significantly higher power costs than if breeders were available in the asymptotic situation because ultimate uranium prices might be several hundred dollars/1b $\mathrm{U}_{3} \mathrm{O}_{8}$ higher in the former case. The cost of uranium recovery from seawater could be the critical parameter. Such problems appear to be more than a century away, since shales and phosphates contain millions of tons of uranium which are potentially recoverable, especially under favorable government policies. 
If the advanced once-through cycle (MSR) were chosen, at some point (a century or more away) on-site reprocessing would be introduced to reduce the quantity of feed material. The cost of on-site processing would have to be balanced against the savings in fuel.

Another method of comparing the policy options consists of comparing the capitalization required. Table 12 lists the facilities required to support each of the policy options while Table 13 tabulates the total capitalization required. It is assumed that uranium would be recovered from Chattanooga shale to support the industry. Table 13 leads to the conclusion that the most economic asymptotic mix would be dominated by thermal reactors in a recycle mode. There would be no strong economic incentive for breeders while uranium equivalent to that from shales remains available. On the other hand, introducing breeders in a supporting role is not costly on an overall basis and leads to overall advantages from the resource point of view.

Table 13 illustrates that the capital cost of the reactor plants is far greater than the cost of the fuel cycle facilities. It also illustrates the significant favorable impact of advanced isotope separation on those strategies using large amounts of $\mathrm{U}_{3} \mathrm{O}_{8}$.

\subsubsection{Commercial feasibility}

The critical elements of the nuclear strategy are the deployment of improved LWRs, the deployment of fuel recycle, and the deployment of breeders. There are also some backup elements, advanced converters and advanced once-through cycles.

\section{Improved LWR fuels}

The commercial feasibility of improving LWR fuels requires their development and licensing, and the demonstration of economic benefits to users. Thus far, DOE, vendors and utilities have cooperated in this effort. Barring unforeseen technical difficulties, the commercialization of improved once-through fuels should be straightforward.

The recycle strategy calls for commercialization of high-conversion ratio tight-lattice LWRs. Some of the technology is being proven in the 
Table 12. Facilities required to support a 1000 GWe nuclear industry

\begin{tabular}{|c|c|c|c|c|c|c|c|}
\hline \multirow[t]{2}{*}{ Option } & \multirow{2}{*}{$\begin{array}{l}\text { Once- } \\
\text { through } \\
\text { LWR }\end{array}$} & \multirow{2}{*}{$\begin{array}{l}\text { Advanced } \\
\text { once- } \\
\text { through }\end{array}$} & \multicolumn{2}{|c|}{$\begin{array}{l}\text { Thermal recycle } \\
\text { Recycle CR }\end{array}$} & \multicolumn{2}{|c|}{$\begin{array}{c}\text { Recycle with } \\
\text { breeder } \\
\text { Recycle CR }\end{array}$} & \multirow[t]{2}{*}{$\begin{array}{l}\text { Breeder } \\
\text { dominated }\end{array}$} \\
\hline & & & 0.8 & 0.9 & 0.8 & 0.9 & \\
\hline \multicolumn{8}{|l|}{ Nuclear Capacity, GWe } \\
\hline LWR-LEU-Std. & & & 470 & 304 & 238 & 65 & \\
\hline LWR-15\%IMP OT & 1000 & & & & & & \\
\hline LWR-Pu Std. & & & & & & & 490 \\
\hline LWR-PuCR $=0.8$ & & & 530 & & 562 & & \\
\hline LWR-PUCR $=0.9$ & & & & 696 & & 735 & \\
\hline LMFBR-Pu/U & & & & & 200 & 200 & 510 \\
\hline MSR & & 1000 & & & & & \\
\hline $\begin{array}{l}\text { Mining, } 10^{3} \text { ton } \mathrm{U}_{3} \mathrm{O}_{8} / \text { year } \\
\text { Fabrication, } 10^{3} \text { ton }\end{array}$ & $161 / 130$ & $66 / 53$ & $86 / 70$ & $67 / 54$ & $43 / 35$ & $14 / 11$ & 2.5 \\
\hline HM/ year & & & & & & & \\
\hline LWR-LEU & 15.1 & & 12.0 & 7.8 & 6.1 & 1.7 & \\
\hline LWR-Pu/U & & & 13.6 & 17.8 & 14.4 & 18.8 & 12.5 \\
\hline LMFBR-Core & & & & & 2.5 & 2.5 & 6.4 \\
\hline $\begin{array}{l}\text { Reprocessing, } 10^{3} \text { ton } \\
\mathrm{HM} / \text { year }\end{array}$ & & & & & & & \\
\hline LWR & & & 25.6 & 25.6 & 20.1 & 20.1 & 12.5 \\
\hline ' LMFBR & & & & & & & 6.4 \\
\hline $\begin{array}{l}\text { Enrichment, } 10^{6} \mathrm{SWU} / \text { year } \\
\text { Spent Fuel Storage, } \\
\text { ton HM }\end{array}$ & $\begin{array}{c}114 / 205 \\
462\end{array}$ & $47 / 84$ & $50 / 91$ & $33 / 59$ & $26 / 46$ & $7 / 13$ & \\
\hline $\begin{array}{l}\text { Waste Treatment, ton } \\
\text { HM/year }\end{array}$ & 15.4 & $25.6^{c}$ & & & & & \\
\hline $\begin{array}{l}\text { Terminaf, Storage, } 10^{3} \\
\text { ton } \mathrm{HM}^{-}\end{array}$ & $\because 462$ & 768 & .768 & 768 & 768 & 768 & 768 \\
\hline
\end{tabular}

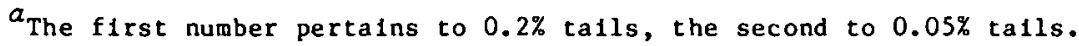

$b_{30}$ years discharge.

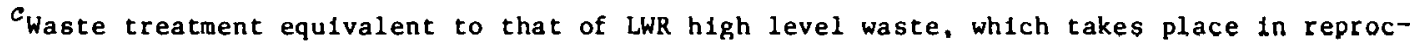
essing plant.

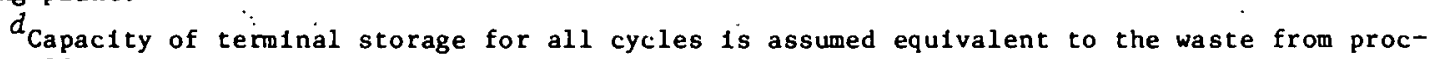
essing 30 years of LWR fuel from the standard cycle, except for long-cooled long-burnup LWR oncethrough cycle. 
Table 13. Capital cost of fazilities supporting a 1000 GWe nuclear indistry (\$ billions)

\begin{tabular}{|c|c|c|c|c|c|c|c|}
\hline \multirow[t]{2}{*}{ Option } & \multirow{2}{*}{$\begin{array}{l}\text { Once- } \\
\text { througi } \\
\text { LWR }\end{array}$} & \multirow{2}{*}{$\begin{array}{l}\text { Ad vanced } \\
\text { once- } \\
\text { through }\end{array}$} & \multicolumn{2}{|c|}{$\begin{array}{l}\text { Thermal recycle } \\
\text { Recycle CR }\end{array}$} & \multicolumn{2}{|c|}{$\begin{array}{c}\text { Recycle with } \\
\text { breeder } \\
\text { Recycle CR }\end{array}$} & \multirow[t]{2}{*}{$\begin{array}{l}\text { Breeder } \\
\text { dominated }\end{array}$} \\
\hline & & & 0.8 & 0.9 & 0.8 & 0.9 & \\
\hline Reactor Plants ${ }^{a}$ & 800 & 1000 & 800 & 800 & 862 & 862 & 960 \\
\hline Uranium Supply $b, c$ & $146 / 113$ & $50 / \angle B$ & $78 / 64$ & $61 / 49$ & $39 / 32$ & $13 / 10$ & 2 \\
\hline Fabrication - LEU & 2 & & 2 & 1 & 1 & 0 & \\
\hline $\mathrm{PWR}-\mathrm{Pu}$ & & & 12 & 15 & 12 & 16 & 11 \\
\hline LMFBR & & & & & 5 & 5 & 12 \\
\hline Reprocessing - LW: & & & 26 & 26 & 20 & 20 & 13 \\
\hline -LMFBF & & & & & 8 & 8 & 20 \\
\hline Enrichment ${ }^{c, d}$ & $88 / 23$ & $36 / 10$ & $39 / 10$ & $26 / 7$ & $20 / 5$ & $5 / 2$ & \\
\hline Spent Fuel Storag & 9 & & & & & & \\
\hline Waste Treatment & 1 & 9. & & & & & \\
\hline Terminal Storage & 10 & 17 & 17 & 17 & 17 & 17 & 17 \\
\hline Fuel cycle Subtotal ${ }^{c, d}$ & $256 / 16.3$ & $122 / 84$ & $174 / 131$ & $146 / 115$ & $122 / 100$ & $84 / 78$ & 75 \\
\hline Total $c, \vec{a}$ & $1056 / 963$ & $-122 / 1084$ & $974 / 931$ & $946 / 915$ & $984 / 962$ & $946 / 940$ & 1035 \\
\hline
\end{tabular}

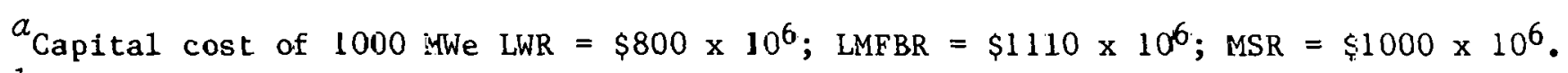

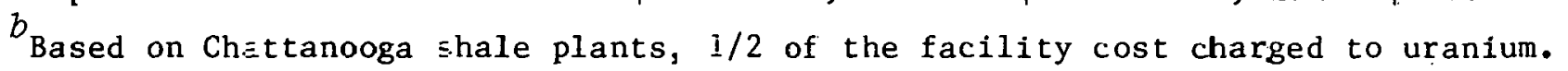

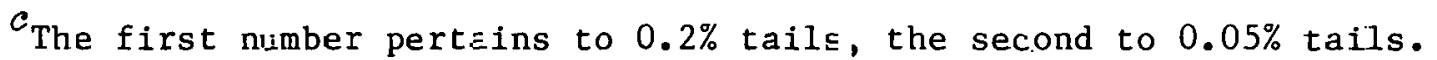

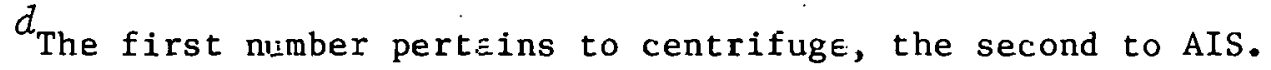


Water-Cooled Breeder Program, but a joint government-industry effort would be required to complete development and licensing of such fuels. Since studies indicate that high-conversion LWR fuels are unlikely to provide short-term economic advantages over standard LWR fuels, the government may have to provide incentives for their use or require them through regulation. The government would also have to carry out research on tightlattice fuel assemblies to prove their safety and reliability.

If thorium-cycle fuels were to have resource/economic advantages, their.introduction would follow the same route as other high-conversion fuels.

\section{Recycle fuels}

Industry has indicated its desire and willingness to produce and use recycle fuels based on their assessment that they would be economic. While considerable development and demonstration of recycle fuels has occurred, additional $R \& D$ will undoubtedly be required to satisfy licensing requirements. When the ban on reprucessing 1s lifted, government and industry must take concerted actions to reduce uncertainties and risks and establish interfaces between government and private responsibilities in the recycle area. Commercial utilization of the recycled fuel should be feasible since it can be used in current LWRs without any change of operating procedure.

\section{Fast breeder}

The commercial feasibility of LMFBRs is primarily dependent upn twn factors: (1) a mature private industry technology capable of supporting the deployment of commercial LMFBRs, and (2) the economic competitiveness of LMFBRs with LWRs (and possibly advanced converter reactors).

The LMFBR is the major nuclear power system alternative to the LWR under development in the industrialized nations of the world. However, the rate of progress among the different nations varies considerably depending upon their technical and economic capabilities and their national policies with respect to nuclear power. Generally, the United States has moved from a leadership position to a laggard position. within the past five years, and the date by which commercial deployment can be supported is more dependent upon governmental policy decisions than it is upon technical capability. 
Under an all-out program LMFBRs could begin to be deployed shortly after the turn of the century, but realistically this date would be hard to achieve.

The date of economic competitiveness for the LMFBR depends upon nuclear power growth and uranium supply and cost conditions. High nuclear growth and high price uranium favor earlier commercialization, while low nuclear growth and plentiful inexpensive uranium could delay commercialization of LMFBRs for many years beyond 2000 .

The decision to deploy breeders implies acceptance of a substantial economic penalty in the early stages, as well as development of a new technological/industrial base. Substantial subsidies would be required over at least two decades.

In summary, it appears that even with a vigorous R\&D program LMFBRs realistically cannot achieve significant commercial deployment before about 2010 with the ultimate date of deployment being dependent upon mally unknowns to which we do not now have the answers. If the French Superphenix demonstration is successful and if the United States obtained a license to use the Superphenix design, then commercial deployment of LMFBRs conceivably could be achieved earlier - perhaps by as much as ten years - but this approach also involves unknowns which could act to eliminate any gain in litue.

As discussed in Chapter 2, The History and Status of Nuclear Fower, the government and private industry in the past worked smoothly and effectively as a team to move rapidly and aggressively in the development of advanced technologies. Currently, however, the government is pronouncedly ambivalent toward the development of new and large. scale technulogies, particularly nuclear power. Consequently, private industry questions the government's will to take on such tasks and has lost confidence in government's ability to establish sound and stable attitudes and policies toward advanced technological developments. This has caused private industry to become suspicious and wary of entering into high risk developments which are dependent upon stable government policies and/or support for success. Such an attitude is slow in its formulation and is equally slow to reverse. Hence, this could be a serious inhibiting factor in moving quickly to the development of a complex, high risk technology such as the LMFBR. 


\section{Advanced converters}

In the absence of any commercial advantages over LWRs, introduction of HWRs or HTGRs for base luad power generation does not appear to be feasible withoug strong government initiatives. No industrial organizations appear willing to assume the risks of supplying these reactors. A major reason for this is that the LWRs have their front-end costs behind them. The system has achieved great momentum and risks associated with modifications to the system are evolutionary and incremental. For any new system, such as the HTGR for example, there are high front-end costs and great uncertainties on the fuel recycle costs. Hence, the risks appear to the utilities to be very high. Therefore, for an entrepreneural private company to be willing to take these risks, they must be able to foresee a significant economic advantage over a well-entrenched competitor, and this is not obviously the case. In fact the uncertainties and consequent risks associated with the fuel recycle may become a major barrier for any of the thorium fuel recycle systems.

Of the two advanced converter types, the HTGR appears to be of greater interest to the U.S. because of its potential for process heat production. The HTGR appears to be a reasonable backup to the LWR in the event the LWR loses public acceptance. Once the HTGRs were built for prociess heat, possibly its vendors could gain utility orders as well.

\section{Advanced once-through cycles}

There is no commercial interest in advanced once-through cycles such as the MSR. Such cycles would require greater technical proficiency on the part of utilities than they require for LWRs or would require for LMFBRs. The government would have to determine that such systems would be needed and would have to support the RD\&D. If other nuclear options were not permitted, the commercial feasibility would depend on utility evaluation of MSRs compared to solar and other long-term options.

\subsubsection{Public acceptability}

Improved LWRs

The public would support LWR Improvements assuming the safcty of the reactors was not compromised. 
Recycle fuels

Publlc acceplatice of LWR fuel recyclc will be ctrongly related to public acceptance of the reprocessing and refabrication steps. If these are accepted, the public probably will be receptive to use of the fuel in LWRs, the reactor concept with which they are most familiar and with which there will be 10 or more years of additional experience by the time of commercial use of recycled fuel. The recycle fuel may be perceived as being less safe because of the greater amounts of $\mathrm{Pu}$ involved, but it is doubtful if this will greatly.influence public acceptability.

\section{Fast breeder}

Although there is a question as to whether the LMFBR is more or less safe than the LWR, unless attitudes undergo a dramatic change the LMFBR will not be accepted as readily by the public as the LWR. This public perception of the LMFBR is due to a number of factors, some of which are: (1) nuclear power opponents view the breeder as the decisive issue in public acceptance of nuclear power; (2) the public has developed a fear of plutonium and, since much attention has been focused on the fact that the breeder systems involve large amounts of plutonium, the public views it with fear and suspicion; (3) the LMFBR will, because of its different characteristics, likely be perceived by the public as posing more health and satety risks than the LWR; (4) there ls less expeslence with LMFDRs than with LWRs.

With respect to the first point, opponents of nuclear power perceive that the fast breeder reactor is the ultimate goal of nuclear power development, and fear that once it is deployed on utility systems and accepted by the public, they will have lost the nuclear power war. Thus, they can be expected to concentrate their efforts on "scopping the breeder." This group will be reinforced by those who see the LMFBK as the most serious of the various proliferation threats, and they will also work against its acceptance. Finally, the no-energy growth groups see the breeder as symbolic of further energy growth and defeating their efforts to severely restrict energy growth and use. Hence they will work hard and diligently to defeat its acceptance. 
Another public category includes many influential members of the public who have developed an inordinate fear and suspicion of plutonium. The opposition of some groups has taken the form of a holy crusade and they oppose the breeder because they consider it as inherently evil - an instrument of the devil so to speak. These people are unlikely to be persuaded to change their views, and they can be expected to oppose the breeder in any way and at every turn. In fact from their perspective, plutonium, and hence the plutonium breedeer, is so insidiously evil that any means are justified in stopping its development and eventual acceptance by the public. Other members of the public fear plutonium chiefly because of what they don't know about. it. Better education and information on the pros and cons of plutonium could change the attitude of many of these people.

Opposition to the breeder which might arise from another public category can be allayed by reducing the uncertainties which surround the safety aspects of the LMFBR and by educating the public on the measures taken to limit the health and safety risks and their magnitude compared to other socially acceptable risks.

On the other side, there will be a segment of the public who favor the LMFBR because: (1) it guarantees our future supply of electrical energy, (2) it greatly increases our degree of national energy independence, (3) it enhances our national security, (4) it restores the United States to a position of technical leadership, and (5) it promises to provide lower cost electricity. As fuel supplies become more scarce, uncertain, and costly this group can be expected to grow and become more influential, and to fight hard and persistently for the breeder.

In summary, the LMFBR public acceptance battle can be expected to be fought harder and on much broader issues than has been the case for the LWR, and there are many uncontrollable elements on both sides of the issue which could be decisive in influencing final judgments.

\section{Advanced systems}

To a first approximation, the public is indifferent to the choice of LWRs as opposed to advanced converters. Introduction of a radically different system such as the MSR might generate public concerns about fuel leaks. On the other hand the MSR may have some inherent safety features that will alleviate public concerns on this score. 
If a convincing case could be made that an advanced system were safer than the LWR, this could generate support from some segments of the attentive public。

\subsubsection{Utility acceptance}

Improved LWRs and recycle fuels

Utility acceptance is dependent primarily on the economics of improved fuels and fuel recycle relative to the economics of the existing cycle. Reduced fuel consumption is inherently attractive. Recycle of fuel values from spent fuel $1 \mathrm{~s}$ especially of interest as a means of improving the ulilities' bargaining position with uranium producers.

\section{Fast breeders}

In principle the utilicles have alteady indicated a willingness to accept the LMFBR as part of their electric power generating systems, and the major nuclear power utilities have been among the staunchest defenders of the breeder. Also an LMFBR system is complementary to the LWR system because the latter will be the source of plutonium needed to initially startup LMFBRs, and as the LMFBKs generate plutonium any excess could be used to fuel LWRs. This flexibility and complementarity of the two systems enhances the attractiveness of LMFBRs for the utilicles.

However, some of the problems being experienced by the utilities in connection with nuclear power, e.g. public acceptance, financial strains, regulatory uncertainties, could be aggravated by the LMFBR. Within the next 20 to 30 years before LMFBRs can be depluyed on utility oyetems, some of these issues might have been resolved. But to the extent that they aren't, they could inhibit utility acceptance of LMFBRs.

An imputant frarure of any electricity generating system is economics. LMFBRs are unlikely to be accepted untll their economic competitiveness seems to be assured, but once this has taken place utillties will find ways to incorporate them as part of their generating systems. 


\section{Molten salt reactor}

As noted in Sect. 5.3.10, utility acceptance of this option may be inhibited by its operating characteristics which may be more akin to those of a chemical plant than to the LWR electricity generating plants. However, this reactor has attractive safety characteristics, a good economic potential, and other favorable features which could make it atcractive to the utilities if they are willing to accept its operating differences.

\subsubsection{Political acceptance}

\section{Fuel recycle}

Political acceptance is primarily related to the proliferation and diversion risks of plutonium fuels and concerns about the health and safety risks of recycle facilities and plutonium. Political acceptance is strongly influenced by public attitudes, which are more likely to focus on the latter concerns.

Reprocessing is currently not politically acceptable in the United States because of proliferation concerns. There are several mitigating circumstances which could lead to a future change of policy:

- Recycle is not needed at present but may be needed at a future time.

- Future developments in international institutions may reduce risks.

- U.S. adoption of fuel recycle at a future time may be percelved as 1rrelevant to proliferation.

\section{Fast breeders}

Political acceptance has a broader connotation for the LMFBR than for any of the other alternatives. This political acceptance relates primarily to three broad issues: (1) proliferation, (2) national security, and (3) energy independence.

Fuel recycle is essential to breeder reactors. The main area in which the LMFBR is especially vulnerable with respect to proliferation resistance is the large amount of plutonium which must be moved through the system. 
The LMFBR is a particularly salient proliferation issue because many nations are aggressively seeking to develop it. Thus, for the United States to slow or abandon development of the LMFBR may represent a moot solution to the proliferation problem if other nations proceed as they have indicated that they will, to develop and adopt the LMFBR. These points will not be lost on the politicians, and they are unlikely to forego development of the breeder on the proliferation issue alone. Also as noted earlier this is a transient issue which might be muted with time.

With respect to the second political acceptance issue, it appears that our political bodies, are becoming more sensitive to the need to improve our energy independence posture, take actions to provide a protected and assured source of fuel to meet national security needs, and develop renewable or an inexhaustible energy resource which will serve the nations needs indefinitely. These are all long-range measures, far longer than the political horizons of our elected representatlves; luwever, it is believed that as the profoundly serious nature of these issues becomes more apparent our political institutions are likely to respond in a positive fashion. Such a response would favor political acceptance of the LMFBR.

Thus, there are political trade-offs involved in acceptance of LMFBRs. However, politicians as a whole are realists and as developing events increasingly dramatize our vulnerability to an inadequacy of domestic energy supplies, it is believed that the political response to LMFBKs will be positive and favorable.

\section{Phase-out of nuclear power}

A phase-out of nuclear power would not resolve all of the 1 ssues surrounding the nuclear controversy. It would reduce the risk to the public of catastrophic releases of radiation. It would exacerbate energy supply

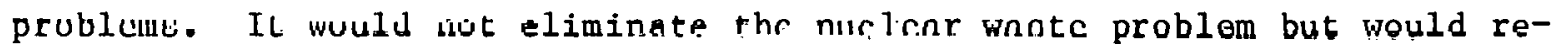
duce the amount of waste.

Finally, the impact of a phase-out of nuclear power on proliferation problems could well be an increase of proliferation risk. For one thing, energy supply shortages could increase international tensions. The international safeguards system and the Nonproliferation Treaty could not survive a phase-out of nuclear power so that new international institutions would be required. 


\subsection{Implications for Nuclear Strategy}

The dynamics of the resources situation and the commercialization analysis leads to an obvious ordering of the options for the United States.

1. There is a need to take steps to increase public acceptance of the nuclear option based on the once-through cycle.

2. There is a need for government planning of steps to be taken by government in the event the nuclear option is to be encouraged once again.

3. The response to uranium availability and rate of production uncertainties is to expand and pursue the NURE program more aggressively:

4. The response to further extending our uranium supplies is to develop methods for economical extraction of more U235 from the enrichment tails.

5. A further response to uranium shortages/price escalation is a thermal recycle strategy.

6. The response to the next generation of uranium shortages/price escalation is the introduction of fast breeders in a supporting role. This may occur concurrently with thermal recycle. The number of breeders in the reactor mix will increase in response to uranium price.

7. The HTGR appears to be a useful backup to the LWR and u1timately a source of process heat and/or an improved converter in the recycle mode.

\subsection{Implications for Nuclear R\&D Policy}

LWR safety. Research on LWR safety has obvious implications for increasing safety margins and hopefully improving public acceptance of nuclear powĕr. Research which improves operability is of particular interest. However, much of LWR safety research is demonstrably not cost-effective. Therefore, social research directed at understanding public concerns appears necessary. Physical research should then be directed at reducing those concerns. 
LWR once-through improvements. Research on improved fuels and reliability for LWRs is cost-effective and improves the competitive position of nuclear power. It also improves public perception of nuclear power.

NURE. Discovery of uranium and better definition of resources extends the usefulness of LWRs both in the once-through and the recycle mode.

Waste treatment and disposal. Both demonstration and research appear to be necessary to resolve public cuncerns. Both spent fuel and high lcvel waste must be considered.

Fuel reprocessing-recycle. This technology should be demonstrated and licensed so that it can be implemented when needed.

Tight-lattice LWRs. The LWBR program should be continued and ultimately similar technology should be demonstrated on the $\mathrm{Pu} / \mathrm{U}$ cycle.

Recovery of uranium from low-grade ores. This is one ultimate backup to the breeder, but will prove useful even if breedels ale depluyed.

Fast breeders. This is a favored element of the long-term strategy. While commercial implementation is not likely to be needed befuse 2010, a long time is required to conduct the necessary intermediate demonstrations. The public distrust of the breeder may favor its remote siting at energy centers with on-site fuel cycle facilities.

HTGRs. This technology is useful in the long-term for process heat, possibly as an improved converter in the recycle mode, and as a backup to the LWK. 


\section{A RATIONAL NUCLEAR POWER STRATEGY}

\subsection{Introduction}

The previous chapters were devoted to: giving a brief history of nuclear power, developing a thesis on what its role should be in the U.S. energy future, discussing some of the major issues confronting nuclear power, and analyzing the major nuclear fuel cycle options and the role that each might have. Thus, these chapters contain in an abbreviated form many of the pros and cons of nuclear power, the problems it faces in being fully accepted, the technical aspects of following different courses of action in establishing nuclear power as an essential element in the nation's energy supply strategy, and the critical role played by the government in all of these. These chapters also summarize some of the international aspects of nuclear power and how they could, and possibly will, influence the directions taken by the United States.

It was found that nuclear power can play an important role in the United States, and an essential role world-wide, as supplies of more convenient fossil fuels dwindle. For the long-term, nuclear power is the only proven "inexhaustible" source of energy. Nevertheless, further deployment of nuclear power faces significant barriers in the face of public concerns about nuclear safety and wastes, the financial weakness of the electric utility industry, an overly complex regulatory environment, and a lack of clear direction from the Federal Government. The societal barriers are far more important than the technological or resource barriers, since there appear to be sufficient resources and technology to carry nuclear power well into the twenty-first century (with the fast breeder a desirable, but not necessary, option).

In this chapter an attempt will be made to step back and take a broad perspective of all these issues in order to derive a strategical approach to the myriad of conflicting issues. The success of such an approach depends on how well one can surmount the subordinate issues (even though important) and concentrate on those items which critically determine the fate of nuclear power. This demands that we resist getting involved in the details of issues which do not significantly contribute to this approach. These are, or should be, addressed in the preceding chapters. 
Under this philosophy this chapter will address the following issues:

1. Developing a basis for the acceptance of nuclear power.

2. Analyzing the government's key role in this strategy.

3. Discussing the considerations involved in developing a rational nuclear power strategy

4. Listing the steps in the development of a rational nuclear power strategy.

If this list appears deficient, remember that each of these has subordinate components, and note the dictum that we are trying to divorce this chapter's discussion from the details.

\subsection{Development of a Basis for Acceptance of Nuclear Power}

Nuclear power is in the forefront of a public skepticism concerning: our cultural values; the trade-offs involved in substituting one value for another; a seeking of social, economic, and political security; a longing for a simplier way of life; and the promises and conflicts of the technological inputs needed to achieve these goals. Many of these desires are conflicting and some mutually exclusive, and thus they pose a dilemma which leads to uncertainty, confusion, and frustration. The manifestation of these conflicts appears in many segments and aspects of our social structure, but nuclear power is in many respects a natural target on which the angers and frustrations of the more active segments of the public can be vented. Thus, the problem of public acceptance is more critical for nuclear power than for any other technological aspect of our society, though the problem is by no means limited to nuclear power.

This topic, developing a basio for acceptance of nuclcar power, ie almost, but not quite, synonymous with public acceptance of nuclear power. One reason, which people are reluctant to voice but nevertheless has been shown by the history of human experiences to be true, is that some segments of the public are more influential and hence more important than 
other segments of the public. Also there are two ways to treat public acceptance - to follow or to lead. Many of our most renowned and successful national leaders have followed the latter course though appearing to follow the former. Franklin Roosevelt was a prime example of this approach. We believe that nuclear power, due to its breadth and complexity, is one of those issues on which the proponents, and particularly the government, if convinced that it is in our best national interests, needs to take the lead. An essential part of this lead role is to advise, educate, and convince the general public that such actions are in their best interest.

In attaining public acceptance of nuclear power, there needs to be an assessment of what constitutes public acceptance. Certain special interest groups, particularly the nuclear power opponents, advocate a consensus on whatever approach is taken on the development of nuclear power. However, a consensus position provides them with essentially a veto power and is tantamount to the rejection of. nuclear power so long as anyone opposes any aspect of it. Thus, consensus agreements cannot be sound basis for determining the public acceptability of nuclear power.

Other groups, most likely to include the government bureaucrats and politicians, are seeking an overwhelming vote of confidence from the public before they act. This gives them security in their position and reduces the risk and responsibility of their decisions and actions. This also is not a sound position for assessing public acceptance as a basis for aggressive action.

Politicians consider election to public office to be a landslide - a public mandate - if they are favored by a few percent over half of the popular vote. So why should they look for much stronger support before taking a policy position on an issue which might have a profound effect on the general welfare of the country?. They should give guidance and convince the public of the soundness and wiseness of their position. Therefore, it is neither rational nor necessary to seek as much as $60 / 40$, or $75 / 25$ ratio vote of the public in favor of nuclear power before moving ahead with a positive nuclear power policy. For example, should $55 \%$ of the public favor nuclear power this is already strong support, since not all of the remaining $45 \%$ would represent opposition to nuclear power - a high percentage of the minority would be uncertain or indifferent. 
In line with the observation that certain segments of the public, including some special interest groups, are more important than others, consideration needs to be given to the views of these groups, pro and con alike. However, it is important to assess the rationality, objectivity, and relevance of these various positions. An irrational objector to nuclear power does not deserve the same credibility as a rational proponent and vice versa. Also, those who are using nuclear power as a means to other goals should be suspect regardless of which side of the issue they are on. Extreme positions on either side of the issue also should be suspect because fulfillment of the projections on which the position is based are usually of lower probab1lity than more moderate positions. Important$1 y$, there is a large segment of the public composed of various diverse groups who are indifferent to what our sources of energy might be, but have a concern as to the well-being of our country and how it can best be achieved. This segment of the public is otten sophisticated in their fields of speciality but may not be strongly informed on the technical or economic aspects of the energy issues. Their strength lies in their ability to assess other areas of expertise and determine from these assessments what actions are likely to be in their best interests as well as the best interests of the country. Bankers, economists, investment brokers and businessmen are examples of a few of the categories comprising this segment of the public. Politicians should fall into this category but generally do not because their interests are too frequently of a shorterrange nature. It is important that such public groups be brought in on, and advised of what role nuclear power is believed to have and the alternative options if nuclear power is not available.

Two different but closely related segments of the public. who exert a strong influence on general public attitudes are the academic and religious leaders. Some of these are in the category of those speking to use the nuclear power issue to attain other goals, usually social or political. However, there are others of them who have a genuine concern on the ethical or moral issues associated with nuclear power. Many of these people are poorly informed on the technical aspects of nuclear energy, but they have a deep understanding of human nature and are cognizant of the multifaceted nature of ethical and moral issues confronted in everyday 
life. They are thus uniquely qualified to make ethical and moral judgements if they are adequately informed on the issues. Also by training and experience they should be receptive to well reasoned and logical arguments which take account of these ethical and moral questions. Thus these groups are key elements in any attempts to achieve better public understanding and exercise of sound judgements on nuclear power within this f ramework.

However, the above does not imply that the general public does not have an important role in the acceptance of nuclear power. Their role is ultimate, and the above discussions relate primarily on how the public can be convinced or led into carrying out this role in a way that is to their overall benefit. In this context there are some widespread public concerns about nuclear power (see Sect.4.1). Our analysis indicates that fundamentally these concerns can be reduced to one primary concern and two dominant derivative concerns. The primary concern is exposure to radiation and the subsidiary concerns - reactor safety and radioactive waste disposal. There are many sources of these two derivative concerns; but, as noted earlier in the interest of avoiding the details, these will not be discussed in this chapter.

Nuclear radiation presents a number of contradictory faces to the public. It has been a dominant and continuing feature of the earth since the beginning of time, but accurate human knowledge of the sources, characteristics and effects are of relatively recent origin; the various types of radiation manifest themselves in a clear and unambiguous manner, but detection techniques are relatively new and sophisticated; there is general fear of nuclear radiation because it is unseen, unheard, and generally unfelt, yet it can be detected, identified, and characterized with positiveness and precision exceeding that of any other technology; the public is concerned about the unknown health and safety effects of radiation but the knowledge of these and how to protect against them is greater than for almost any other areas of public health and safety. The public sees one set of nuclear radiation faces and the scientists and technologists see another set. The public is skeptical of acceptance of nuclear energy on the basis of what it sees but the scientists and technolnqists are receptive to nuclear energy on the basis of what they see. 
Thus, it seems apparent that a fundamental step in achieving the acceptance of nuclear power by the public is to help and enable them to see the other set of faces, in other words "to demythologize radiation."

Nuclear safety is clearly one of the primary subsidiary concerns which the public has for nuclear power. However, many if not all of the analyses on what constitutes the basis for this concern indicate that it is the radiation aspects of nuclear energy. Therefore, in developing a better public understanding of the nature of radiation, it is necessary to recognize that radiation poses potential hazards and the public must be protected against these hazards to a degree that is deemed acceptable by them. This in essence is the safety problem of nuclear power. However, the issue is more complicated than this simplistic statement of the problem. There are varying degrees of satety as exemplified by the frequentiy voiced question, "how safe is safe enough?" New and more safety features can be incorporated into any particular system, such as nuclear power, ad infinitum but this does not guarantee that each new or different feature will increase the overall safety of the system. This is because there is an interrelationship among the various systemal features and, while the addition of one particular feature may improve the safety of the system, it might change another feature (such as increased complexity) in the direction of decreasing system safety. Thus, there are safety trade-offs and one might expect that a given system has a design inherent maximum safety level and by doing more or less to the system one decreases the level of safety. Unfortunately it is not possible to know when this maximum safety level has been achieved, and furthermore the system involves a number of continually changing variables (people for example) such that the conditions which define the maximum level of safety are constantly changing and the so-called maximum level of safety becomes a transient. There are also safety interrelationships and trade-offs involving features of the system and factors which are external to the system. For example, the safety of a nuclear power plant might be incrementally increased by adding steel and concrete but, when the reduced risks of the nuclear system attained by such an action is offset by the increased risks attributed to producing the needed steel and concrete then for the public at large, one is not justified in further increasing the safety of the nuclear plant through this means. 
These questions though philosophical in nature are quite germane to the nuclear power issue since there are those $e^{62}$ who are inclined to view the safety of nuclear power system as an end in itself without critically analyzing how changes affect other parts of the system or what their effects might be, external to the system. The NRC considers the questions of, "How much public protection are we to require? How much risk is tolerable?" to be fundamental issues of top priority with which they must grapple. Clearly, answers to these types of questions must be put into some reference framework in order to effectively deal with the total issue of nuclear power plant safety. However, different perspectives are obtained depending on whether one asks, "How safe is safe enough?" or "How safe can we afford to be?"

Superimposed upon these basic philosophical questions of nuclear safety is the predominantly economical question of the "risks versus benefit" issue which could be more accurately phrased as "harm versus benefit" since risk contains a probability component and alludes to what might happen, while harm and benefit are in counter position to one another.

History is replete with examples where societies have had to decide whether the risk of harm from a certain situation is justified by the potential benefits likely to be received. Daily we as individuals or as the public at large are confronted with these situations, and in most cases the decision is unpremeditated and taken almost instinctively. There is no basic reason why nuclear energy couldn't be put in the same perspective by the public but frequently it isn't. For example, an individual, if made aware that the chances are quite high that there will be bU,000 deaths from automobile accidents, reacts by mentally estimating his or her chances of being one of the 50,000 and usually concludes that they are small enough to justify whatever use they are making of their automobile. However, if given the same statistics with respect to a potential nuclear accident, the reaction is not "what are my individual chances of survivIng," but rather to plcture this as a horritying accident which society will not accept. Thus, the two frameworks are completely different. There are many reasons for this latter point of view, but there is much that can be done to educate the public in the proper methods of analyzing 
these risks and putting them in a more balanced perspective. There probably is unanimity of opinion that all benefits justify risks to varying degrees. If applied to acceptance of nuclear power, this suggests that the public must be informed as clearly and accurately as possible what the benefits are likely to be and what risks they as individuals must take if they are to enjoy these benefits.

Management and disposal of radioactive wastes is a central public concern with respect to nuclear power and until resolved will be a continuing focus of opposition. Here again the public's concern revolves around their fear of radiation and in this situation its impact on future generations. Since there is no assured answer to this question, opponents of nuclear power have seized this issue as one which they can embellish to fan the fears and distrusts of the publ1c. However nuclear wastes if classified as toxic elements with certain charactericing features fall into the same category as other toxic elements in our environment which we have learned to handle at an acceptable level of risk to health and safety. Certain characteristics of nuclear waste make it moredifficult to handle than other toxic elements and others make it less difficult to manage. However, this type of a problem is neither unique nor unprecedented to our society. Margaret Maxey, the ethicist, points out that, "If unacceptable risks to our environmental quality were to be measured in terms of the half-life or rate of decay of toxic elements or their potential for lethal dose commitments to a population, then we would have long since undertaken geologic burial of mercury, lead, àrsènlc, chromium, and chlu rine, whose half-life is infinite. ${ }^{63}$ And she goes on to say that the radioactive waste problem stems not from scientific or technological considerations but "from public misperception of the risks involved and the ease with which those misperceptions have been exploited by those who have chnsen to politicize the nuclear energy option of the nation."

However, nuclear waste management is a critical element in the public and political acceptance of nuclear power and it is essential that the country get along with the job. There are four important elements to the nuclear waste management and disposal problem:

1. Develop a planned and aggressive campaign to inform the public on the nature and scope of the nuclear waste 
disposal problem, what can be done about it, and the risks in relation to other socially accepted risks.

2. Exhort the government on the urgency of taking positive actions toward the resolution of the radioactive waste disposal problems.

3. Advise the government and the public that the technology is available for establishing acceptable waste disposal methods though these methods are not necessarily optimal; explain that the chief problem is public distrust and lack of confidence in the government and other responsible institutions.

4. Proceed rapidly to establish several. demonstration waste disposal programs: use the experience from these demonstrations with a strongly supporting $R \& D$ program to move toward the optimal method for waste. disposal.

These issues - radiation, nuclear power safety, and management and disposal of radioactive wastes - are fundamental concerns held by the public in relation to nuclear power and actions directed to resolving them will provide a sound rational basis for the general acceptance of nuclear power.

\subsection{Government's Key Role}

As noted in Sects. 2 and 3 the Federal Government played a critical role in the early development of nuclear power. During the 1960 s nuclear power, primarily in the form of LWRs, blossomed as a result of an unprecedented government-industry collaboration. Some of the important elements in the success of this joint venture were:

- Promotion of nuclear power by the Atomic Energy Commission the dominant executive agency.

- Promotion of nuclear power by the Joint Committee of Atomic Energy, the dominant congressional committee on nuclear energy.

- Industry gambles in the form of turnkey contracts, sizeable capital commitments, and large R\&D programs.

- Promotion and regulation resting in the same agency, Lhe AEC. 
- No effective opposition within or outside government.

- Overly optimistic cost projections ("electricity too cheap to meter").

- Externalities not effectively provided for (radioactive waste disposal, radiation protection, inadequately informed public).

- A national desire to turn the "swords" of war into the "plow-shares" of peace.

- An exuberant national attitude and belief in the invincibility of technology.

This elphoria was followed by the inevitable letdown and many factors combined in the 1970 s to bring nuclear power to a stalemate in the United States. Among these are:

- National Environmental Policy Act (1970)

- Disbandment of AEC

- Creation of NRC and ERDA (1974)

- Demise of JCAE (1977)

- Large reductions in projected energy growth

- Perception that nuclear power was not cheap

- Growth of state/local role in licensing

- New proliferation-related barriers to exports

- Crowth of an organized opposition plus a licensing process which encourages opposition

- Semireligious issues on the morality of nuclear power

- Three-Mile Island accident (1979)

- A growing lack of confidence in NRC.

The combined effect of these factors has: accentuated philosophical differences which already existed among the present five NRC commissioners resulting in a virtual cessation of nuclear power plant licensing, caused the utilities to stop nuclear plant orders because of the uncertainties primarily with respect to licensing and cost, and discouraged nuclear vendors and engineer-constructors who are feeling the pinch of the de facto moratorium with some of them.dropping out of the business and others expected to do so if business does not revive. This stalemate situation cannot continue indefinitely and a move one way or the other must take 
place within the next few years. Otherwise it is likely that private enterprise will abandon the industry and and make no additional commitments to nuclear power.

The present situation actually constitutes a de facto moratorium on nuclear power since there will be few new orders for nuclear power plants until there is a change in the trends towards more regulation, longer licensing times, and growing uncertainties on the actual requirements for constructing and operating a nuclear power plant - leading to drawn-out construction times and higher costs to which there are no apparent limits. The utilities cannot operate in such an environment; and when accentuated as it is by growing inflation, high interest rates, and a decreasing growth in demand for electricity, the problems become completely unmanageable. Consequently, the utilities have ceased placing orders for new nuclear power plants, are cancelling those plants not well along in construction, and show no indications of changing this position in the future. If it survives, it may revert to a wholly government-owned operation reminiscent of the situation prior to 1954. If the situation for nuclear power does improve, then we may be entering into a new era of realism which could be an essential step in progressing to a mature and healthy industry.

Since the existing situation results primarily from governmental actions, the changes must come about through governmental actions as there are no other mechanisms which can be effective at this point. However, in order for the government to provide sound and effective leadership, a number of changes must take place in the customary ways of doing business. These needed changes are generally related to our modern techno-industrial society and are not unique to nuclear power. Hence there will be. many other forces acting to bring them about. However, they are particularly important to nuclear power because it has become the focus of many dissident forces attacking various segments of our political system. Among several of the more important changes which we see as being needed are:

- Congress and the Executive Branch must think and plan in a time frame much longer than the political time frame in which they are accustomed to thinking and planning. 
- Congress and the Executive Branch must rise above the tendency to respond to single constituency groups without first carefully analyzing the effect of such actions upon the general welfare of the nation.

- When a particular course of action seems to be in the best interests of the country as a whole, Congress and the Executive Branch must be willing to support such an action even though it is vigorously opposed by vocal activists with a more limited goal.

- When Congress and the Executive Branch, thrmgh careful analysis and deliberations, deem an action to be in the best interests of the country as a whole, they must be wllling to take clie lead in carrying this to the people in an effort to obtain their understanding and support.

- The energy issues, and specifically nuclear power, cannot be resolved without statesmanship on the part of our elected leaders in Washington.

- Congress and the Executive Branch must recognize and take into account the fact that energy, including nuclear power, is a worldwide issue which must be treated in that context.

- Congress and the Executive Branch must understand that invescments in new energy technology (including $R \& D$ ) of even hundreds of billions of dollars are not a high price relative to the price of oil imports. In adđifion, there are sume speclfle uplluns whlch we see ds beling available to the government which will improve the situation, among which are the following:

1. Congress and the Excutive Branch of the government must adopt a more realistic attitude toward nuclear power, recognizing it as an essential element in the country's energy strategy, and assume the leadership for gaining public support for a pronuclear position. Government plans and policies must then be formulated and executed which are compatible with, and supportive of, this new attitude.

2. Fundamental reforms in the regulation of nuclear power are needed. Some of the objectives of such reforms are to provide:

(a) strengthened management within, and more decisive actions by, the NRC; 
(b) development of an institutional attitude by the NRC which will enhance their prestige and develop public confidence and trust in their decisions;

(c) stability and consistency in regulatory actions aimed at reducing the uncertainties faced by the utilities in assessing the costs and benefits of nuclear power;

(d) increased focus on significant safety items in contrast to measures which are marginal contributors to safety and are adopted for political reasons, have cosmetic appeal, or have not received a critical cost/benefit analysis;

(e) a more equitable balance between concerns for environmental protection and the needs for energy;

(f) a streamlined process which drastically reduces the time now required for the licensing of nuclear power plants.

3. Financial incentives for utilities to build nuclear power plants can take the form of:

(a) arranging for low interest rate capital funding,

(b) supporting the inclusion of construction costs and interest in the rate base,

(c) eliminating the double-taxation (corporate and individual) of electric utility dividends, and

(d) provide tax incentives for utilities to build nuclear power plants. 4. Support strong R\&D programs designed to resolve what are percieved to be the major problems blocking the public acceptance of nuclear power, such as radioactive waste management and reactor safety.

5. Recognize and act upon the unresolved government/private industry interfaces involving responsibilities for:

- nuclear power plant safety

- nuclear fuel cycle facilities

- RD\&D.

6. As a last resort, reversion of nuclear power to a wholly government-owned operation reminiscent of the situation prior to 1954.

By far the most important of these options is number one. The reasons are that a receptive attitude by the Executive Branch and Congress is essential if nuclear power is to have a future in this country, and without it the other options will neither be meaningful nor effective. 
These are weightly issues, and it is not the intent of this paper to suggest that the Oak Ridge National Laboratory can set national policy or determine political attitudes. However, it is important to recognize that any strategy for nuclear power is dominated by these issues and they must be taken into account in trying to develop a rational strategy for nuclear power.

\subsection{Considerations in a Rational Nuclear Power Strategy}

The analysis of Sect. 3 indicated that the near term role of nuclear power is to assist coal in meeting the electricity generating needs of the country. Should nuclear power undergo a de facto moratorium, the country's electricity needs for the next 15 to 20 years will be met with a continuing but declining use of oil and gas, a small but steady assist from hydro power, a growing dependence upon coal, and stringent conservation measures. Should oil and gas imports be drastically reduced for any reason, electric growth would stagnate and electricity might even decline in use.

Beyond about 1995 to 2000 the probabilities are high that oil and gas will be scarcer and more costly, and higher priority uses will make these fuels generally unavailable for the generation of electricity. The advanced technologies, i.e., solar and geothermal, seem unlikely to be available in significant amounts and the burden of generating electricity will fall upon coal and nuclear power. Even modest rates of electricity growth are likely to strain the system, and nuclear power will be needed in significant amounts to avoid a declining use of electricity.

In the still longer term, particularly beyond about 2025, coal will be increasingly called upon as a replacement fuel for the natural gaseous and liquid fuels, and corrcopondingly lese able to meet the electricity generation needs. Thus dependence upon one of the four long-term sustainable energy sources (nuclear fission, solar, geothermal and fusion) will increase. With respect to these four, fusion is technically so uncertain that it has a low probability of being available in time; geothermal is faced with such formidable engineering and environmental problems as to make questionable its practicability on a large scale; thus, leaving 
nuclear fission power and solar energy as the most likely primary contenders for the role of being a large and long-term sustainable energy source. Since the technical uncertainties of developing solar energy as a major source of power for the generation of electricity are greater than those associated with nuclear power, the arguments for developing the latter are strong and logical.

The above analysis tacitly assumes a stable world political situation in which: the United States continues to import its greater than proportionate share of oil; there is an absence of cut-throat competition for dwindling supplies of the highly valuable fossil fuels; there is no major threat to world peace; and, international confidence is restored in the soundness of the U.S. dollar. However, it is almost certain that all of these conditions will not prevail in the future and any perturbation of the existing world system is likely to be amplified manyfold in its effect upon our domestic energy capability. The Iranian situation has dramatically demonstrated the fragility of U.S. relations with supposedly friendly countries; our vulnerability to interrupted imported energy supplies; and our inability to control international events. This stems from only a small perturbation to the world's political structure. Should a larger perturbation occur, such as a military confrontation, the impact upon our wel1-being and national security would be difficult to predict, but would likely have catastrophic dimensions. In this context, nuclear power assumes a new and critical dimension as an important element in a geopolitical strategy for national security and energy self-sufficiency. The reasous for this are that: (1) Avallability of nuclear power in ample amounts will assuredly contribute to a higher degree of energy self-sufficiency, and (2) No other alterative energy source can with assurance provide this same capability nor compensate for the lack of nuclear capability. However, complementary elements which would contribute to this strategy are conversion to coal, production of synthetic fuels from coal and shale, gas production from unconventional sources, development of solar and geothermal energy sources, and strong conservation measures. Some of the more important considerations on why it is desirable to achleve a greater degree of energy self-sufficiency than we now have are: 
- A major power cannot retain its security if secondary powers can cut off food, energy, strategic materials, etc.

- Knowing that our nation's security and viability is not tied to foreign energy supplies would give added force and direction to our foreign policy.

- Energy self-sufficiency would stop one of the main driving forces for rapid inflation, arbitrary oil price increases.

- Reduced imports of energy would improve our balance-of-trade position and strengthen the dollar.

- Energy self-sufficiency would release foreign supplies of fossil energy for use by developing countries, and thus relieve world tensions.

As a result of the 1973-74 oil embargo, Presidents Nixon and Ford tried to implement a policy of energy self-sufficiency (Project Independence), but Congress and the public were not ready to make the sacrifices necessary to its success. Today the country may be in a more receptive mood. Other countries such as the U.S.S.R., France, and Japan are pursuing nuclear self-sufficiency strategy with great vigor.

An important consideration for the future viability of nuclear power is the need to maintain the viability of the electric utilities. Section 2.4 contains a brief discussion of the altered financial condition of the utilities which has occurred over the past ten years. Today many utilities are in desperate financial straits due to the following combination of circumstances:

- high power plant capital costs which have escalated by a factor of four in the past ten years and seem likely to increase by another factor of two to four over the next ten years (see Sect. 4.4);

- historically high cost of money which makes it difficult, if not impossible, for utilities to float long-term bond issues at acceptable interest rates;

- low utility stock prices which have fallen significantly below book value making it impossible for the utilities to raise equity capital without further dilution of stock values and consequent lower stock prices; 
- utility accounting practices which depreciate capital facilities at the low actual cost rather than much higher replacement costs, reducing the internal generation of capital for future additions to a grossly inadequate figure;

- inadequacy of rate increases which has helped to create the above problems and aggravates them further by causing lower bond ratings (thus, even higher interest rates) and lower dividends (and even lower stock prices). Thus, the spiral to financial instability is accelerated.

The situation is sufficiently serious that the electric utilities are cancelling capital projects of all types (particularly nuclear), and deferring future commitments. However, as their financial condition deteriorates further, it will be even more difficult for them to undertake capital additions in the future for either coal or nuclear plants.

If this situation is not corrected, the result will be that the utility systems will deteriorate, operating costs will rise, reliability will decrease, and electricity will not contribute as it should to national energy supply. The situation is very reminiscent of what the nation's railroads have gone through and the lesson is fresh enough that it mustn't go unheeded. A more optimistic contrasting situation is that of the nation's oil producers and distributions. Here the increased costs are passed through to the consumer, providing the oil companies with adeqnate capital for further exploration and development.

In view of the foregoing considerations and the uncertainties involved 1 in the possible energy demands and the tuel supplies to meet these demands, an essential element of realistic strategy is to provide for flexibility to meet unforeseen and rapidly changing situations. In meeting energy needs this flexibility must be achieved at two levels: flexibility to choose among the alternative fuels; and flexibility within the various nuclear fuel cycles. Providing this flexibility from among the nuclear fuel options is discussed in sect. 5 with the conclusion that multiple, overlapping fuel options must be developed. The ultimate option is to provide a long-term inexhaustible source of energy. The two primary contenders for this goal are possibly solar energy, and more assuredly nuclear fission energy. The flexibility for nuclear energy to respond to this need is obtained via fuel reprocessing and recycle as an intermediate 
term goal, and via breeder reactors as the long-term goal. Introducing reprocessing/breeders is the simplest way to rapidly expand nuclear fuel supplies in the near term/far term, respectively.

\subsection{Steps in the Development of a Rational Nuclear Power Strategy}

Achieving the strategic goals discussed in the previous section depends upon maintaining the nuclear option in its present form as a shortterm contributor to our electrical energy needs but eventually expanding and shaping the short-term developments into a form compatible with the long-term goal. The following are some of the major steps which need to be taken in the development of such a strategy:

1. Since the public, acting through government, will ultimately decide how much nuclear power will be used, they must be convinced of the need for nuclear power. Actions which can be taken that will promote accomplishment of this goal are:

- Take steps to demythologize nuclear radiation and put it in perspective with other real and potential hazards.

- Establish trade-offs between the needs for energy to support soclety and the risks of generating this energy.

- Enhance the public's confidence in nuclear power by - Assuring a government/industry structure that places safety above profles, while keepling the two lil a balallied perspeclive.

- Take steps to develop confidence and trust in the regulatory institutions.

- Demonstrate the safe management of nuclear wastes.

- Provide evidence of the true economic status of nuclear power. - Accept that some of the nuclear opposition will never be convinced.

2. Conduct research and development as a means for strengthening the nuclear option to include:

- Developing safer reactors/improving design margins.

- Demonstrating nuclear waste disposal

- Military wastes

- (Pilot-scale) wastes from nuclear power

- Improving LWR reliability/economics. 
For the last 15 years, AEC/ERDA/DOE has concentrated on advanced nuclear technology and put little effective effort into the above.

3. Provide for mitigation of resource constraints (nuclear power in the United States may hit uranium resource constraints sometime between 2000 and 2025) to include:

- Development of more resource-efficient LWRs on the once-through cycle.

- Increased uranium exploration.

- Improved processes for recovery of uranium from low-grade ores.

- Advanced isotope separation processes which can more economically strip U235 from enrichment tails.

- Demonstration of reprocessing and recycle technology.

- Development of technology for optimal recycle in LWRs (higher conversion ratios).

- Demonstration of fast breeder reactor and its fuel cycle.

According to the NASAP analysis, the first four of these improvements should be sufficient to support growth to 600 GWe through 2025 . Considering 5 and 6 as well, we conclude that LWRs might do the nuclear job through 2050, if nuclear capacity were limited to 600 GWe. The breeder is required as a hedge against rising uranium prices and in the event more nuclear power is required.

4. Develop and demonstrate the reprocessing/recycle technology as the key to greatly expanding the potential of nuclear power.

- A great deal of energy stored in the spent fuel from LWRs, can be made rapidly available.

- Recycle in LWRs increases energy production per unit of $\mathrm{U}_{3} \mathrm{O}_{8}$ produced by about $80 \%$ in present systems. Fuels optimized for oncethrough cycles would yield somewhat less.

- From a resource point of view, fast breeders are much preferred to thermal reactors for utilizing $\mathrm{Pu}$ in spent LWR fuels. Fast breeders increase energy production per $\mathrm{U}_{3} \mathrm{O}_{8}$ by orders of magnitude.

- Reprocessing/recycle technology requires much greater attention to nonproliferation institutions and safeguards than the present oncethrough cycle. 
- Implementation of reprocessing will tend toward buyer's market in uranium, at least temporarily.

5. Develop as a long-term strategy for the U.S. fission technology mix to consist of one or more of the following:

- A high-gain thermal recycle system with sustained mining of low-grade ores.

$-25,000$ tons $\mathrm{U}_{3} \mathrm{O}_{8}$ /year might support about $500 \mathrm{GWe}$.

- The high gain converters can be supported in part by fuel production in breeders or electric hybrids. One LMFBR can support about four timco ac many high gain converters.

- A fast-breeder dominated system (The Plutonium Economy)

- LiLtle mining of uranium

- Allows export of (denatured?) fuel

- The choice of ultimate technology will be based on economic/political criteria.

6. Move rapidly to a long-term fission RD\&D program to cover the following major options:

- Demonstrate reprocessing/recycle on a large enough scale to develop meaningful licensing criteria, sateguards, cost experience. There is no doubt other nations $\bar{w} 111$ also do the same.

- Develop high-gain LWR technology to be implemented when recycle is commercialized.

- Develop the HTGR

- Long-term use for process heat

- Likely to be competitive with LWRs in the long-term

- Intermediate-term possibility for commercialization in the event of an LWR construction moratorium.

- Demonstrate the fast breeder on a meaningful scale so that the option would be available when needed (probably not needed for a long time). - Requires significant reduction in capital cost

- Neede better image relative to catastrophic accidents.

- Introducing a new fission system will be very expensive and time consuming ( $\$$ billions and decades). Foreign developments may help reduce the time and the costs. 
7. Take governmental actions to strengthen the nation's electric utilities including the following:

- Encourage state utility commissions to give rate increases commensurate with the need.

- Provide tax incentives for raising capital funds.

- Consider government-backed loans to reduce interest rates.

- Provide "fast-track" 1icensing for generating plants.

8. Above all, the government (particularly Congress and the Executive Branch) must adopt and demonstrate a receptive attitude toward nuclear power; exert strong leadership in gaining its acceptance; and develop and follow-through on plans and actions necessary to assure its rightful role in our nation's and the world's energy strategy.

It should be noted that the above steps constitute the elements of a strategy which will: educate the public on the need for nuclear power, provide a climate in which utilities can continue to make a vigorous contribution to the nation's energy supply, retain and enhance the nuclear option in its present form; provide for fuel recycle as a hedge against uranium resource inadequacy, and eventually provide for development of a breeder reactor system as the ultimate in the achievement of an inexhaustible nuclear power fuel supply which will meet a large portion of the country's energy needs for an indefinite period.

\subsection{International Aspects}

The special needs of findustrildzed and of developing countries should be recognized. Some of the industrialized countries perceive a very large need for nuclear power relative to the uranium available to them. The only system perceived to have the resource potential to satisfy these constraints is the Pu cycle breeder. It is quite possible for the breeder to be the optimum choice of reactor in some countries while convcrters are the optimum clivice (for the majority of reactors) in resourcerich countries such as the United States.

The developing countries have a different (not always clear) set of priorities. These may include: 
1. Desire to minimize foreign exchange component of reactor cost. Some countries perceive HWRs to have advantages here.

2. Need for small units. If the United States wishes to make an impact here, completing development of a small integral reactor. such as $B \& W^{\prime}$ s Consolidated Nuclear Steam System would be welcomed by several countries, assuming the price would be competitive. (Such a system would be attractive to U.S. utilities, as we11, in the current low-growth situation.)

3. Assurances that they will not be discriminated against for access to the most economic technology. The key. is to insure that the most economic technology is designed in a nonproliferating way, and that economic fuel cycle services are readily available in the intcrnational market.

The history of nuclear power development thus far has been characterized by technology transfer, mainly of LWRs and HWRs from North America. Future reactor technology may well be țransferred from the country of initial commercialization to the United States. Advanced reactor programs in the United States should be conducted accordingly. 


\section{REFERENCES}

1. J. E. Kenton, "The Birth and Early History of Nuclear Power," EPRI Joumal, July/August 1978.

2. American Nuclear Society, LaGrange Park, Illinois, Nuclear News (February 1979).

3. Massachusetts Institute of Technology Press, Workshop on Altemative Energy Strategies, Vol. 3 (1977).

4. D. F. Cope, Oak Ridge National Laboratory, internal document (Aug. 2, 1979).

5. E. G. Silver, Oak Ridge National Laboratory, internal document (Feb. $28,1980)$.

6. Edison Electric Institute, New York, N. Y., Statistical Yearbooks 1974 and 1977.

7. Massachusetts Institute of Technology Press, Workshop on Altemative Energy Strategies, Vo1. 2 (1978).

8. The National Research Council, National Academy of Sciences, Problems of U.S. Uranium Resources and Supply - The Year 2010 (1978).

9. National Academy of Sciences, Washington,. D. C., Energy in Transition 1985-2010, Final Report of the Committee on Nuclear and Alternative Energy Systems, National Research Council (1979).

10. T. D. Anderson et al., An Assessment of Industrial Energy Options Based on Coal and Nuclear Systems, ORNL-4495 (July 1975).

11. H. F. Bauman, Oak Ridge National Laboratory, internal, document (Nov. $2,1979)$.

12. T. D. Anderson, Oak Ridge National Laboratory, internal document (Nov, 8, 1979).

13. B. D. Melber, S. M. Nealey, J. Hammersia and W. L. Rankin, Battelle Human Affairs Research Center, Nuclear Power and the Public: Analysis of Collected Survey Research, PNL-2430. (November 1977).

14. B. D. Melber, "Understanding Public Perspectives on Nuclear Power and Alternative Options," 86th Annual Convention of the American. Psychological Association, Toronto, Canada (August 1978).

15. A. M. Weinberg, "Nuclear Energy: Salvaging the Atomic Age," The WiZson Quarterly, Summer 1979. 
16. The White House - Fact Sheet - The President's Response to the Recommendations of the President's Commission on the Accident at Three Mile Island, Dec. 7, 1979.

17. W. B. Cottrel1, Oak Ridge National Laboratory, internal document (Oct. 31, 1979).

18. Gilbert Associates, Inc., Nuclear Energy Center Licensing Study for the Southern States Energy Board by Gilbert/Commonwealth, GAI Report No. 2006 (May 1979).

19. National Research Council of the Academy of Science, U.S. Energy Supply Prospects to 2010, Report of the Supply/Delivery Panel of the Committee on Alternative Nuclear Energy Systems (1979).

20. Factors Affecting the Electric Power Supply 198085 , Special Study by the Bureau of Power, Federal Power Commission (Dec. 1, 1976).

21. National Electric Reliability Council, Research Park, Princeton, N.J., 9th Annual Review (August 1979).

22. Political, Legal, Regulatory, Institutional and Financial Considerations - Supply/Delivery Systems for Energy Resources, Prepared for the National Academy of Science for the CONAES Study by National Economic Research Associates (March 1977), Draft.

23. U.S. Department of Energy, Washington, D.C., Nuclear Proliferation and Civilian Nuclear Power, Report of the Nonproliferation Alternative Systems Assessment Program, Vol. V1 - Safety, tinvironment and Licensing Considerations (December 1979), Draft.

24. William and Mary, The Nuclear Power Plant Licensing Process, No. 15, Rev. 1974.

23. Keport of the President's Lommission on The Accillenl ul Three Mize Island - The Need for Change: The Legacy of TMI, Washington, D.C. (October 1979).

26. J. M. Hendrie, Remarks at the Amer1can Embassy Seminar, London, England, U.S. Nuclear Regulatory Commission News Releáse dacéd OCr. 31, 1979 .

27. V. Gilinaly, The Effect of Thros Mi.l.e Isl.and on Amemire's Nuri.enr Policy, Remarks before the New York Chapter of the American Jewish Committee, U.S. Nuclear Regulatory Commission News Release dated Oct. 31,1979 .

20. P. A. Biadford, Thes Nuclerir Oplion: Did it Jump on Was it Fus7sad, Remarks before the NARUC Annual Regulatory Studies Program, U.S. Nuclear Regulatory Commission News Release dated Aug. 15, 1979. 
29. V. Gilinsky, Nuclear Energy and Three Mile Island, Remarks before the Government Affairs Committee, American Newspaper Publishers Association, U.S. Nuclear Regulatory Commission News Release dated Oct. 2, 1979 .

30. V. Gilinsky, Statement before the Senate Committee on Environment and Public Works, U.S. Nuclear Regulatory Commission News Release dated July 20, 1979.

31. "White House Ponders Whether to Ask for NRC Resignations, Nucleonics Week, Nov. 22, 1979.

32. A. W. Murphy (Ed.), "Nuclear Power Plant Regulation," Chapter 4, The Nuclear Power Controversy, The American Assembly, Columbia University, Prentice-Ha11, 1976.

33. R. C. Sears, Bechtel Power Corporation, personal communication (July 20, 1979).

34. J. P. M. Maidment, Nuclear Power Plants-Cost, Schedule, and Productivity, An Overview of the Industry and Implications for the Future, Washington Public Power Supply System (April 1979).

35. J. H. Crowley, "Power Plant Cost Estimates Put to the Test," Nuclear Engineering Intemational, July 1978, pp. 39-43.

36. L. F. C. Reichle, "The Economics of Nuclear versus Coal," Presented before the Richmond Society of Financial Analysts, Richmond, Virginia, Oct. 30, 1979.

37. H. I. Bowers, "Capital Investment Cost Estimates for Large Nuclear and Coa1-Fired Power Plants," Presented at a Seminar on Coal versus Nuclear Electric Utility Generating Costs in the 1980s, Washington, D. C., June 29-30, 1977.

38. United Engineers and Constructors, Inc., Final Report and Initial Update of the Energy Economic Data Base (EEDB) Program - Phase I, CON4954-1 (December 1979).

39. Whitman, Requardt and Associates, Hardy-Whitman Index of Public Uti1ity Construction Costs, Bulletin No.110, to July 1, 1979.

40. "Prices of Recent Issues," The Wall Street Joumal, Monday, March 31, 1980 , p. 25.

41. Byron Lee, Jr., Chairman, AIF Policy Committee to Follow-up to the Three Mile Island Accident, personal communication (Jan. 17, 1980).

42. Kidder Peabody and Company, Inc., The Research Department, Worldwide Nuclear Reactors as of Dec. 31, 1976, April 19, 1977.

43. M. Lonroth and $W$. Walker, "The Viability of the Civil Nuclear Industry," Nucleonics Week, Vol. 20, No. 39, Sept. 27, 1979. 
44. D. F. Cope, Oak Ridge National Laboratory, internal document (June $26,1979)$.

45. M. Levenson, Electric Power Research Institute, Päpër Prepared for the Atomic Industrial Forum (U.S.) and Donatom in Copenhagen International Conference on Financing Nuclear Power, Sept. 23 26, 1979.

46. Richard K. Betts, "Paranoids, Pygmies, Pariahs, and Nonproliferation," Foreign Policy No. 26, Spring 1977, pp. 157-183.

47. C. Starr, "Nuclear Power and Weapons Proliferation The Thin Link," Presented at the American Power Conference, Chicago, I11inois, April $19,1977$.

48. United States Congress, Office of Technology Assessment, Nuclear Proliferation and Safeguards (1977).

49. A. Carnesale, Harvard University, private communication.

50. J. McPhee, "Profiles: T. B. Taylor," New Yorker, Vol. 49, Dec. 3, 1973, p. 54; Dec. 10, 1973, p. 50; Dec. 17, 1973, p. 60.

51. A Report on the Intermational Control of Atomic Energy, Prepared for the Secretary of State's Committee on Atomic Energy by a Board of Consultants: C. I. Barnard, J. R. Oppenheimer, C. A. Thomas, H. A. Winne and D. E. Lilienthal, Chairman, Washington, D.C., March 16, 1946.

52. International Atomic Energy Agency, Vienna, Austria, Regional. Nuclear Fue7. Cyole Centera, Vol. I, 1977.

53. National Academy of Sciences, Problems of U.S. Uranium Resources crul Supply to the Year 2010, Report of Uranium Resources Subpane1, L, CONAES Committee (1978).

54. Ford Foundation/The Mitre Corporation, Nuclear Power Issues and Choices, Ballinger Publishing Company, 1977.

55. U. S. Department of Energy, Wash1ngtun, D.C., Nuclear Proliferation and Civilian Nuclear Power, Report of the Nonproliferation Alternative Systems Assessment Program, Volume III - Resources and Fuel Cyc1.e Frritititi.es (December 1979), Draft.

56. J. E. Vath, Oak Ridge Nationa1 Laboracory, Internal ducumeint (December 1979).

57. M. J. Ohanian, Editor, An Acceptable Future Nuclear Energy System, Condensed Workshop Proceedings, ORAU/IEA(R) 77-261 (December 1977).

58. F. Correa, M. J. Driscoll and D. D. Lanning, An Evaluation of TightPitch PWR Cores, Massachusetts Institute of Technology Nuclear Engineering Report No. MITNE-227 (August 1979). 
59. P. R. Kasten, Gas-Cooled Reactors - The Importance of Their Development, ORNL-5515 (January 1979).

60. U.S. Department of Energy, Washington, D'.C., Nuclear Proliferation and Civilian Nuclear Power Report of the Nonproliferation Alternative Systems Assessment Program, Vol. V-Economics and Systems Analysis (December 1979), Draft.

61. Office of Nuclear Material Safety and Safeguards, Final Generic Environmental Statement on the Use of Recycle Plutonium in Mixed Oxide Fuel in Light-Water Cooled Reactors, U.S. Nuclear Regulatory Commission Report NUREG-002 (August 1976).

62. V. Gilinsky, Nuclear Reactor Regulation After Three Mile Island: What is Happening and What Does It Mean? U.S. Nuclear Regulatory Commission News Release dated Nov. 15, 1979.

63. Margaret Maxey, "The Ethical Eye," EPRI Joumal (November 1978). 
THIS PAGE

WAS INTENTIONALLY

LEFT BLANK 
ORNL/TM-7425

\section{Internal Distribution}

1. T. D. Anderson

2. H. F. Bauman

3. T. Besman

4. H. I. Bowers

5. R. H. Bryan

6. W. D. Burch

7. T. F. Burns

8. J. C. Cleveland

9. T. E. Cole

10-14. D. F. Cope

15. W. B. Cottrell

16. J. G. Delene

17. M. H. Fontana

18. U. Gat

19. W. O. Harms

20. H. W. Hof fman

21. C. R. Hudson

22. S. R. Hurre11

23. J. E. Jones

24-25. P. R. Kasten

26. R. K. Kibbe

27. T. S. Kress

28. L. F. Lischer

29. R. S. Livingston

30. A. L. Lotts

31. R. S. Lowrie
32. F. C. Maienschein

33. S. R. McNeany

34. M. O1szewski

35. A. M. Perry

36. R. L. Rudman

37. J. P. Sanders

38. E. G. Silver

39-63. I. Spiewak

64. H. E. Trammell

65. D. B. Trauger

66. W. E. Unger

67. J. E. Vath

68. J. R. Weir

69. ORNL Patent Office

70. Engineering Physics Info. Center

71. Central Research Library

72. Y-12 Document Reference Section

73-74. Laboratory Records

75. Laboratory Records-RC

\section{External Distribution}

76. Office of Assistant Manager for Energy Research and Development, Department of Energy, ORO, Oak Ridge, TN 37830

77-103. Technical Information Center, Department of Energy, ORO, Oak Ridge, TN 37830

104. H. G. MacPherson, Institute for Energy Analysis, Oak Ridge, TN 37830 